\title{
Surge Protection in Low-Voltage AC Power Circuits - An Anthology Part 2 - Development of Standards Reality Checks
}

François D. Martzloff U.S. DEPARTMENT OF COMMERCE Technology Administration

Electronics and Electrical

Engineering Laboratory

Electricity Division

National Institute of Standards and Technology

Gaithersburg, MD 20899

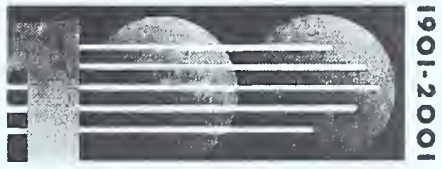

N IST CENTEN N I A L

QC

100

U56

\#6714-2

2002

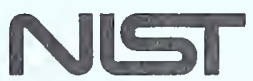

Mational Instritule of Standards and Technology

Technology Administration

U.S. Department of Commerce 



\section{Surge Protection in Low-Voltage AC Power Circuits - An Anthology Part 2 - Development of Standards Reality Checks}

François D. Martzloff

U.S. DEPARTMENT OF COMMERCE Technology Administration Electronics and Electrical Engineering Laboratory Electricity Division

National Institute of Standards and Technology

Gaithersburg, MD 20899

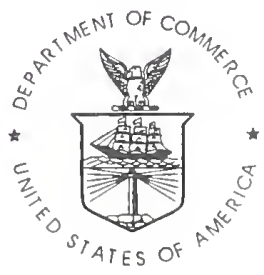

U.S. DEPARTMENT OF COMMERCE Donald L. Evans, Secretary

TECHNOLOGY ADMINISTRATION

Phillip J. Bond, Under Secretary for Technology

NATIONAL INSTITUTE OF STANDARDS

AND TECHNOLOGY

Arden L. Bement, Jr., Director 



\section{FOREWORD}

The papers included in this part of the Anthology were presented over the years as contributions to the development of standards on surge protection and are listed in chronological order. The purposes of these papers were either to support a proposal for developing a new standard, or to suggest that a proposed standard might not be justified. Several of these were joint ventures with geographically close or distant IEEE or IEC colleagues, but all sharing the same interest. Their participation in this effort should be recognized and is acknowledged by the co-author identifications shown in the listing of the table of contents. Furthermore, in recognition of the many contributions known to the author that were made by other researchers, Annex A provides the annotated list of their papers. For obvious copyright limitations, these papers from other researchers cannot be reprinted here. Several of the pre-1985 papers included in this Part 2 were copyrighted by the publishers, who graciously gave permission for reprinting. The post-1985 papers, published while on the staff of a Federal agency, are not subject to U.S. copyright.

The Annotated Bibliography was initially compiled by the author as a contribution to the IEEE "SPD Trilogy" of the Surge-Protective Devices Committee (a set of three standards on the surge environment). This initial compilation is now complemented with additional relevant papers and reports written by the author. Undertaking a listing of "relevant papers" entails the risk of offending researchers whose papers might have been overlooked in the compilation. However, in addition to this printed format (available from the U.S. Superintendent of Documents), this Part 2 is also available on the Web, thus opening the door for suggestions of additional entries for periodic updates of the listing. The Web version includes an html file of the complete collection of the Part 2 papers, which is searchable for any word, with built-in links allowing display of the paper itself in pdf format. The site URL for the complete Anthology, in its several Parts, is: http://www.eeel.nist.gov/811/spd-anthology/

François Martzloff March 2002 
Q 


\section{Contents}

Transient Control Levels: A Proposal for Insulation Coordination in Low-Voltage Systems . . . . . . . . . . . . 1 IEEE Transactions PAS-95, No.1, Jan/Feb 1976- Co-author: Fisher

Transient Control Level Philosophy and Implementation Part 1: The Reasoning Behind the Philosophy . . . . . . . 13 Proceedings, $2^{\text {nd }}$ International Symposium on EMC, Montreux EMC Symposium, 1977 - Co-author: Fisher

A Guideline on Surge Voltages in AC Power circuits rated up to $600 \mathrm{~V} \ldots \ldots \ldots \ldots \ldots \ldots \ldots \ldots \ldots$

Proceedings, $3^{\text {rd }}$ International Zürich Symposium on Electromagnetic Compatibility, Rotterdam, 1979

The Development of a Guideline on Surge Voltages in Low-Voltage AC Power Circuits . . . . . . . . . . . . . . . . 29

IEEE Paper A 79 428-4, PES Summer Meeting, Vancouver, 1979

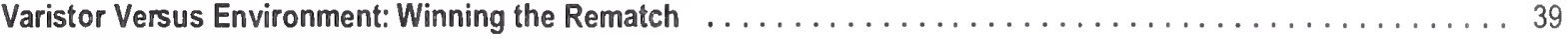

IEEE Transactions PWRD-1, No. 2, April 1986

Real, Realistic Ring Waves for Surge Testing . . . . . . . . . . . . . . . . . . . . . . 49

Zürich EMC Symposium, 1991 - Co-author: Pellegrini

Incompatibility Between the $100 / 1300$ Surge Test and Varistor Failure Rates $\ldots \ldots \ldots \ldots \ldots \ldots \ldots \ldots$

Zürich EMC Symposium 1991 - Co-author: Fenimore

Testing Varistors Against the VDE 0160 Standard . . . . . . . . . . . . . . . . . . . . 65

Open Forum on Surge Protection Application, NISTIR-4654, August 1991.

Validating Surge Test Standards by Field Experience: High-Energy Tests and Varistor Performance . . . . . . . . 75 IEEE Transactions IA-28 No.6, December 1992 - Co-author: Fenimore

Applying Reality Checks to Standards on the Surge Environment $\ldots \ldots \ldots \ldots \ldots \ldots \ldots \ldots$ International Conference on Lightning Protection, 1996 - Co-authors: Mansoor and Nastasi

Using Incandescent Lamp Failure Levels for Assessment of the Surge Environment . . . . . . . . . . . . 93 Zürich EMC Symposium 1997 - Co-authors: Bachl and Nastasi

Developing a Consumer-Oriented Guide on Surge Protection . . . . . . . . . . . . . . . . . . . . . . . . 101 PQA'97 North America, 1997 - Co-authors: Black, Key, May, and Witt

Driving High Surge Currents into Long Cables: More Begets Less . . . . . . . . . . . . . . . . . . . 113 IEEE Transactions PWRD-12, No.3, July 1997 - Co-author: Mansoor

The Effect of Neutral Earthing Practices on Lightning Current Dispersion in a Low-Voltage Installation . . . . . . . 123 IEEE Transactions PWRD-13, July 1998 - Co-author: Mansoor.

The Dilemma of Surge Protection vs. Overvoltage Scenarios:

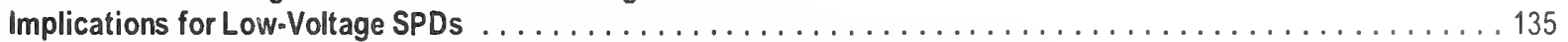

Intemational Conference on Hamonics and Power Quality, 1998 - Co-author: Mansoor

The Fallacy of Monitoring Surge Voltages: SPDs and PCs Galore! . . . . . . . . . . . . . . . . . . . . 143

EPRI PQA'99 Conference, May 1999 - Co-authors: Mansoor and Phipps

On the Dispersion of Lightning Current after a Direct Flash to a Building ..................... 157 International Conference on Lightning Protection 2000.

Annex A - Contributions by other researchers to the development of surge-related standards ......... 165 (Listing and annotations of Part 2 from the complete Annotated Bibliography, Part 1) 



\section{Transient Control Levels: A Proposal for Insulation Coordination in Low-Voltage Systems}

\author{
F.A. Fisher \\ General Electric Company \\ Pittsfield MA \\ fafisher@lightningtech.cpm
}

\author{
François Martzloff \\ General Electric Company \\ Schenectady NY \\ f.martzloff@ieee.org
}

(C) 1976 IEEE

Reprinted, with permission, from

IEEE Transactions on Power Apparatus and Systems, Vol. PAS-95, No.1, Jan/Feb 1976

\section{Significance: \\ Part 2 Development of standards - Reality checks \\ Part 6 Textbooks and tutorial reviews}

One of the first papers addressing the issues of surge protection in low-voltage AC power circuits, making a proposal for a departure from the traditional unidirectional and separate 1.2/50 and 8/20 waveforms, on the basis of the results of monitoring the occurrence of surges in these circuits. Nevertheless, the concept is emphasized that surge test waveforms should not attempt to duplicate the environment, but only to apply "representative" waveforms and levels that will demonstrate the equipment withstand capability.

The proposal also included the concept of establishing first a level of surges that will not be exceeded, thanks to the application of appropriate SPDs, and only then designing equipment that will withstand level higher than the allowable level of surges. This was nothing new, having been applied successfully in the high-voltage utility environment. However, the proposal was new for the low-voltage community.

Unfortunately, the fait accompli of equipment being designed and placed on the market without such coordination prevented application of that proposal. Thus, industry is left with the situation where equipment failures under surge conditions can occur, after which remedies must be found as retrofits.

In 1975, the following statement appeared in the paper and should be kept in mind when questions arise on the selection of "representative waveforms" in IEEE Std C62.41.2:

These BIL amplitudes, while assigned somewhat arbitranily, were (and are) kept in touch with reality by the fact that equipment designed in accordance with standards do not fail when exposed to surges produced by lightning, in contrast to equipment designed prior to the development of the philosophy of insulation coordination and the establishment of standard BILs. 

IEEE Transactions on Power Apparatus and Systems, Vol. PAS-95, no. 1, January/February 1976

TRANSIENT CONTROL LEVELS

A Proposal for Insulation Coordination in Low-Voltage Systems

\author{
F. A. Fisher \\ General Electric Company \\ Pittsfield, Mass.
}

\author{
F. D. Martzloff \\ General Electric Company \\ Schenectady, N.Y.
}

\begin{abstract}
Failure and circuit upset of electronic equipment due to transients is a problem now and is one which has promise of becoming more of a problem in the future as trends continue toward miniaturization and circuit complexity. Protection methods are used more or less extensively and often haphazardly.
\end{abstract}

At present, there does not appear to be a clear approach toward achieving compatibility between the transient withstand capability of devices and the transients to which such devices are exposed. A more scientific approach is needed to guide manufacturers and users of equipment.

The purpose of this paper is to promote a concept of transient coordination for electronic and other lowvoltage equipment through the establishment of a system of Transient Control Levels, similar to the concept of Basic Insulation Levels so successfully used for many.years in the electric power industry. Specific suggestions for possible Transient Control Levels and standard test wave shapes are made, in order to promote wide discussion as to whether these waveforms and levels are the best that can be developed toward good transient coordination for the electronic industry.

\section{INTRODUCTION}

Failure and circuit upset of electronic equipment due to transients is a problem now and is one which has promise of becoming more of a problem in the future as trends continue toward miniaturization and circuit complexity. At present, there does not appear to be a clear approach toward achieving compatibility between the transient withstand capability of devices and the transients to which such devices are exposed. This situation appears somewhat as illustrated on Figure 1. A similar situation prevailed many years ago in the electric power industry. Transients produced by lightning frequently caused failure of such vital and expensive power equipment as transformers and generators. Those transient problems were solved by engineering design guided by the concept of insulation coordination and the establishment of a series of Basic Insulation Levels (BIL's).

Paper F 75 466-3, recommended and approved by the IEEE Surge Protective Devices Committee of the IEEE Power Engineering Society for presentation at IEEE PES Summer Meeting, San Francisco, Calif., July 20-25, 1975. Manuscript submitted February 3, 1975; made available for printing April 28, 1975.
The purpose of this paper is to promote a concept of transient coordination for electronic and other low-voltage equipment through the establishment of a system of Transient Control Levels (TCL's), similar to the concept of BIL's so successfully used for many years in the electric power industry. In the following sections, specific suggestions for possible standard Transient Control Levels and standard test wave shapes will be made. While the waveforms here suggested are chosen somewhat arbitrarily, they are well grounded in physical reality. The purpose of making such suggestions is to promote wide discussion as to whether these waveforms and levels are the best that can be developed, or if indeed the establishment of such standards is the best way to promote good transient coordination for the electronics industry. The ultimate purpose of any system of transient coordination would be to achieve greater product reliability at minimum cost to the user.

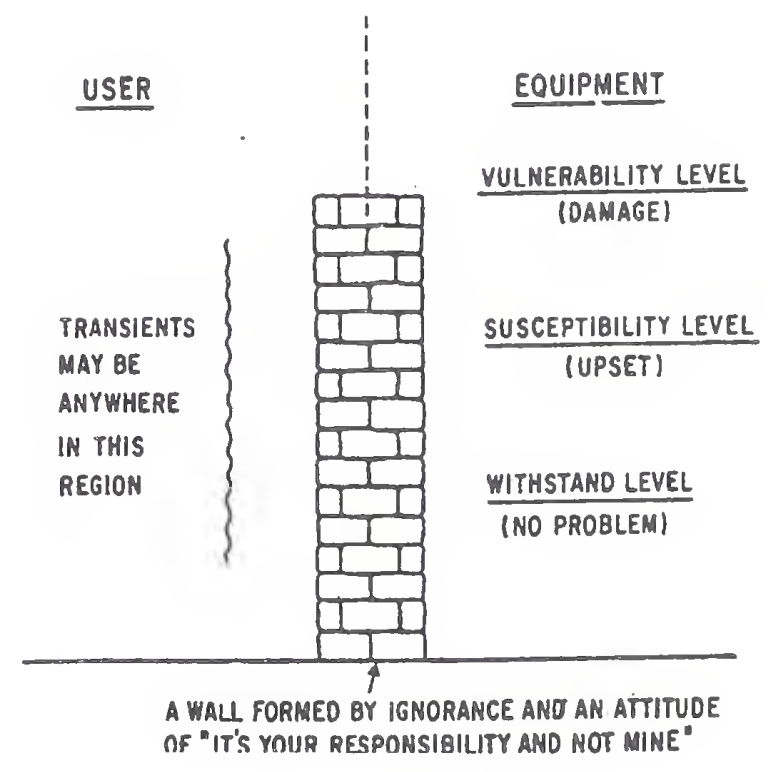

Fig. 1. The present situation.

\section{AN EXAMPLE OF THE PROBLEM}

TCL concepts would be of benefit to all users of electronic and other low voltage equipment, such as railroad, telephone, power, oil industry, aircraft, and high frequency communications. The source of transients to which equipment is exposed may be cither external (lightning and power system switching) or internal (switching of inductive loads, contactor restrikes or cross talk from adjacent circuits). While the concept of TCL's is intended to apply to the full spectrum of frequencies and voltages (DC, $120 \mathrm{~V}, 60 \mathrm{~Hz}$ $\mathrm{AC}, 400 \mathrm{~Hz}$ ) the problcm of transient coordination will 
here be illustrated by discussion of 120 volt $\mathrm{AC}$ systems intended for consumer and residential use. During the introduction of electronic equipment into consumer appliances and other residential use, the importance of transient coordination was not always sufficiently recognized. In some cases, excessive failure rates occurred as a result of transients having amplitudes greater than the withstand level of the equipment.

In residential circuits, transients can occur from two main sources: internally, from the switching of appliances, and externally, most typically from the effects of lightning. One study of internally generated transients ${ }^{1}$ has indicated that in about three percent of U.S. households transients greater than 1200 volts occur one or more times per week. Several studies have been made of externally generated transients. One such study ${ }^{2}$ indicates two percent of recorded transients exceed 1500 volts. The data also indicate that at the location studied, approximately two surges per year would exceed 1000 volts. Field experience ${ }^{1}$ indicated that a 100:1 drop occurred in the failure rate of clock motors when the withstand level was increased from 2000 to 6000 volts. These data indicate that the exposure rate to surges of 2000-volt amplitude was sufficient to be of concern, but that surges exceeding 6000 volts were quite rare, at least on a national basis. Another study ${ }^{3}$ showed that during two weeks of monitoring in a lightning-prone area, several surges exceeding 2000 volts were recorded, with the maximum recorded being 5600 volts. Experience with field trials of Ground Fault Circuit Interrupters sponsored by NEMA and the Underwriters' Laboratory ${ }^{4}$, when correlated with the known nuisance trip level of the devices and the observed number of trips ${ }^{5}$, would indicate an occurrence frequency of perhaps one surge per 7 years above 2000 volts per household.

Most residential wiring systems are constructed in such a manner that the various wiring boxes will flash over if they are exposed to surges greater than 5 to $10 \mathrm{kV}$. This means that the amplitude distribution will be chopped at 5 to $10 \mathrm{kV}$.

Based on these admittedly scattered and tentative numbers, it appears that the typical residential circuit will be exposed to surges of magnitude and frequency of occurrence as illustrated in Figure 2.

The magnitude of the transients produced on 120 volt power lines, however, is not of importance except as it relates to the vulnerability level of the equipment connected to such lines. "Vulnerability" is defined here as the level that causes an irreversible and undesirable change (usually failure) in a device. A corollary term is susceptibility, or that level which causes temporary malfunction of the device. The susceptibility level cannot, by definition, be higher than the vulnerability level. Rectifier diodes and similar semiconductors do not have any particular susceptibility level; they either fail or do not fail when exposed to transients. Active semiconductor devices or a control system operated by a mini-computer system might be a different story. It is quite possible

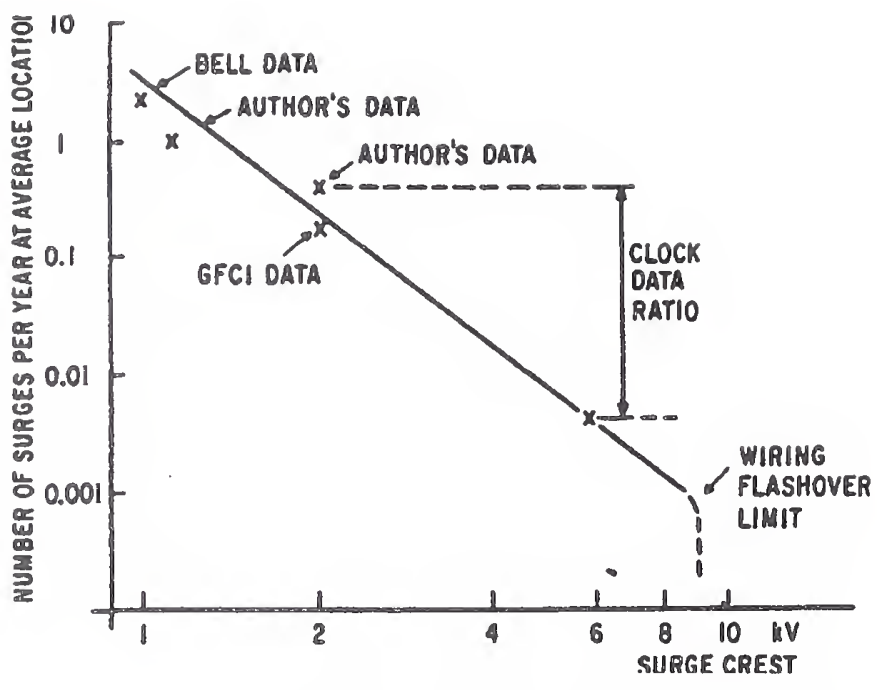

Fig. 2. Exposure of residential circuits to surge (Number of surges vs highest surge at any one location)

that transients of a low level interfere with the operation of the mini-computer, causing it to give incorrect results without causing permanent physical damage. The vulnerability level of such a mini-computer will be higher than the susceptibility level. Both levels must be higher than the normal operating level of the computer logic elements or input/output terminals.

The transient breakdown level or vulnerability of semiconductors is not presently a part of any industry accepted rating system. The vulnerability level is furthermore not inherently related to the normal operating voltage or peak inverse voltage (PIV) level. As examples, consider the data of Table $\mathbb{I}$. During this investigation, power diodes were subjected to unidirectional transient voltages cresting in a few microseconds. The voltages at which failure occurred are seen to have little correlation to the nominal PIV rating.

Similar data have been accumulated for many semiconductors, particularly when semiconductors are exposed to very short transients, characteristic of those produced by nuclear weapons (NEMP). Such information has not been widely reported.

TABLE I

Transient Vulnerability Levels

Typical 1A Silicon Diodes

$\begin{array}{ccc}\begin{array}{c}\text { Diode } \\ \text { Number }\end{array} & \begin{array}{c}\text { PIV } \\ \text { Rating } \\ \text { Volts }\end{array} & \begin{array}{c}\text { Failure Level Under } \\ \text { Reverse Impulse* } \\ \text { Volts }\end{array} \\ 1 & 200 & 1100-1500 \\ 2 & 400 & 1400-1500 \\ 3 & 600 & 1400-1600\end{array}$

*Breakdown observed when exposed to a unidirectional surge rising at 1000 volts per microsecond. 
Clearly, surges occur with amplitudes greater than the vulnerability of the indicated semiconductors. The frequency of occurrence of such damaging surges, while small on an individual basis, may be unacceptably high on a product line. The transient amplitudes, of course, could be reduced by the use of suitable protective devices. Likewise, the vulnerability levels of the diodes to transients could be raised. Some questions now present themselves, all having to do with the question of who should assume what part of the job of providing transient coordination.

a) Should it be the responsibility of the user to control transients to levels that do not damage equipment supplied by vendors?

b) Should it be the responsibility of the manufacturer to provide equipment that will not be damaged by the naturally occurring transients?

c) If it is the responsibility of the user to control transients, to what level should he control them - the published operating levels (in this case the published PIV levels) or some other level higher than the operating level but below the vulnerability level?

d) If it is the responsibility of the vendor to provide surge-proof equipment, what level of transient voltage and transient energy must he anticipate?

Similar questions can be asked for all product lines: consumer, industrial, and military, and at all levels of operating voltage.

\section{INSULATION COORDINATION IN THE ELECTRIC POWER INDUSIRY}

Similar questions occurred many years ago during the development of the electric power industry at a time when the art of designing equipment to withstand the effects of lightning was in its infancy. The nature of the transients, the level of insulation to be used, or what should be expected of the designers of transmission lines and lightning arresters was not clear.

Those transient problems have largely been eliminated today by proper engineering design on a system-wide basis. The evolution of insulation coordination in the electric power industry, while it can be only very briefly described here, may be of benefit to the electronic industry.

First, the type of transients produced by lightning on transmission lines, their magnitude and wave shape were measured. This was not easy in the days of cold-cathode oscilloscopes employing $50 \mathrm{kV}$ accelerating voltages. Even today with vastly improved instrumentation, such investigations are expensive and time-consuming to make. ${ }^{6}$ Yet, on the basis of very limited testdata, a standard voltage test wave was derived, the familiar $1.5 \times 40 \mu$ s wave. Similar investigations in other countries led to the establishment in Europe of the $1 \times 50 \mu$ s impulse wave. International standardizing activities have now produced the $1.2 \times 50 \mu \mathrm{s}$ impulse wave, a test wave used throughout the world for coordination of insulation protection. It was never pretended, however, that naturally occurring surges were of this type, only that the rise and fall times of the natural surges were in the vicinity of the above values.

The next stage in the process of insulation coordination was the establishment of a series of standard test and design levels, BIL's. For example, equipment designed for operation on $115-\mathrm{kV}$ systems was assigned a BIL of $550 \mathrm{kV}$. The designer of equipment to be used on $115 \mathrm{kV}$ systems then was required to provide an insulation structure that would withstand $550 \mathrm{kV}$. The level of $550 \mathrm{kV}$ was derived on the premise that existing lightning arresters could be used to control the transients applied to that apparatus to less than $550 \mathrm{kV}$. The proper design of the insulation system was next demonstrated by subjecting the apparatus in the laboratory to a surge of $1.5 \times 40 \mu \mathrm{s}$ wave shape and a peak amplitude of $550 \mathrm{kV}$. Frequently it was part of the purchase agreement that the equipment had to successfully pass the laboratory test. If the equipment failed, it had to be rebuilt or redesigned. Conversely, it became the responsibility of the user to insure that no surge greater than $550 \mathrm{kV}$ was ever applied to the apparatus.

As a result, power equipment achieves its resistance to lightning-induced transients not so much by being designed to the threat that might be posed by lightning, but by the threat that will be posed by an acceptance test. This acceptance test does not subject the equipment to transients having the complex wave shapes produced by lightning, but instead to transients having elementary wave shapes that can be produced by basically simple test apparatus. Neither does the acceptance test subject the equipment to transients of the amplitude produced by lightning. However, it subjects the equipment to transients of amplitude consistent with the capabilities of existing surge-protective devices.

These amplitudes, the BIL's while assigned somewhat arbitrarily, were (and are) kept in touch with reality by the fact that equipment designed in accordance with standards does not fail when exposed to surges produced by lightning, in contrast to equipment designed prior to the development of the philosophy of insulation coordination and the establishment of standard BIL's.

The test and design levels, the BIL's, are not necessarily fixed. As better protective devices are developed, the levels may be lowered so that reliable equipment can be built at lower cost.

Electronic and control equipment, on the other hand, is all too often designed, built, and delivered before the existence of a transient threat is recognized. If transients turn out to endanger the equipment, there may be no adequate surge protective devices. There may, in fact, not be any satisfactory answer to the problem posed by transients.

\section{THE TRANSIENT CONTROL LEVEL CONCEPT}

One way in which transient compatibility might be achieved in the electronics industry is to establish a transient coordination system similar in concept to the BIL 
system, but of a nature more adapted to the requirements of electronic and control equipment.

In this paper, such a concept is called the Transient Control Level (TCL)* concept. Specifically, it is hereby proposed:

a) That there be defined for electronic equipment (and other low-voltage equipment) a standard transient voltage similar in concept to, but different in wave shape from the $1.2 \times 50 \mu$ s wave used in coordination of insulation in high-voltage power apparatus.

b) That there be defined for electronic (and other lowvoltage) equipment a series of TCL's similar in concept to the BL's.

c) That a start be made on assigning one of these standard levels to individual electronic components and electronic devices.

d) That individual protective devices be rated in terms of their ability to control transients to levels no greater than, and preferably lower than, one of the above levels.

e) That equipment and procedures be developed by which equipment may be tested by vendors to determine which TCL is appropriate to assign to individual components and equipment.

f) That TCL's begin to be used in purchase specifications.

g) That such equipment and procedures be used by purchasers to evaluate vendor-supplied equipment to determine its compliance with such purchase specifications.

h) That such TCL's begin to appear in regulatory specifications for consumer apparatus in which the consumers cannot make the appropriate tests or prepare appropriate specifications.

\section{Suggested TCL Voltage Wave Shape}

The wave shape suggested for the TCL concept (with the understanding that discussion and presentation of alternatives is actively encouraged) is shown on Figure 3. Shown are both proposed open-circuit voltage and short-circuit current waveforms, since the question of the impedance of the source from which voltage surges derive must ultimately be considered. These shapes are different from the longestablished $1.2 \times 50 \mu$ s wave employed in the $B \Pi$ rating system for electric power apparatus because none of the recorded transients exhibited this type of wave shape on 120 -volt AC circuits. The type of transient most frequently recorded appeared of an oscillatory nature, very strongly damped, and in a frequency range between 100 and $500 \mathrm{kHz}$.

Independent work on the resonant frequency of power systems previously indicated a range of 150 to $500 \mathrm{kHz}$ as being the natural frequency of typical residenial sytems. ${ }^{7}$ Other investigations indicate that a lower limit of $5 \mathrm{kHz}$ might be more typical. ${ }^{8}$ Thus, it appears that the observed transients are not at all typical of lightning surges propagated directly into the system but are rather the response of the power system to an initial excitation caused by a nearby lightning stroke. The internally generated transients due to switching operations typically are of the same basic type as those produced by the indirect effects of lightning. The observed transients are in each case more nearly the result of the natural oscillatory response of the local wiring system, in this case the wiring system of typical residences. Similar surge wave shapes have been encountered in a wide variety of other systems, ranging from airplanes to space booster rockets.9.10 Typical examples of recorded transient wave shapes are given in the Appendix. The great bulk of the recorded transients exhibit a faster front time and shorter decay time than do the transients produced by lightning on high-voltage power lines, the $1.2 \times 50 \mu$ s type of wave.

Switching transients in air break contacts (internally generated transients) can produce rise times in the order of 10 to $100 \mathrm{~ns}$. Although this steepness attenuates rapidly with distance, the typical front time is still less than $1.2 \mu \mathrm{s}$. For some types of devices (rectifier diodes) the wave shape is of secondary importance, with only the peak magnitude being important. For other types of apparatus (inductive devices such as motors), the front time, or more correctly the rate of change, is of importance equal to that of the peak magnitude. In still other types of devices (surge protective devices), the total energy content of the surge is of most importance.

\section{Current Wave Shapes and Source Impedances}

The characteristics of short-circuit current wave shapes are less well known than those of open-circuit voltage. The short-circuit current is of importance both for evaluation of surge protective devices and for equipment of low input impedance such as lower voltage semiconductor devices. In any discussion of test wave shapes and test levels, it is important to recognize the natural response of the device in the test. It is inappropriate to prepare a specification that implies that a specified voltage must be developed across a device of low input impedance, such as a spark gap after it has broken down, or to seemingly require that a specified short-circuit current be produced through a high input impedance, such as the line-to-ground insulation of a relay coil. The characteristics of short-circuit currents are poorly defined because the impedance of the circuits from which transients are produced is poorly defined or unknown.

For purposes of discussion, it is suggested that two different types of impedance be considered, one independent of frequency (resistive source impedance or classical surge impedance, $Z=\sqrt{\mathrm{L} / \mathrm{C}}$ ), and one of simple inductive source impedance. The waveform shown on Figure $3 \mathrm{~b}$ assumes a source impedance of

\footnotetext{
* The TCL concept was first proposed by one of the authors (F. A. Fisher) in regard to electronic equipment on the Space Shuttle. ${ }^{12}$
} 


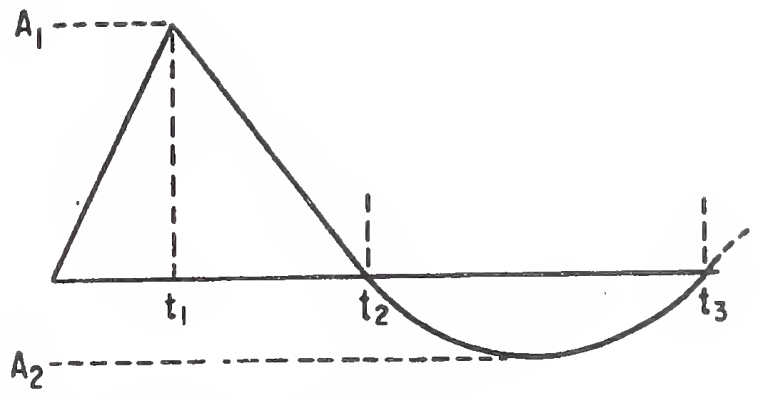

0) Open-circuit voltage $t_{1}=0.25 \mu \mathrm{s} \quad A_{2} \leqslant 50 \% A_{1}$ $t_{2} \geqslant 5 \mu \mathrm{s}$

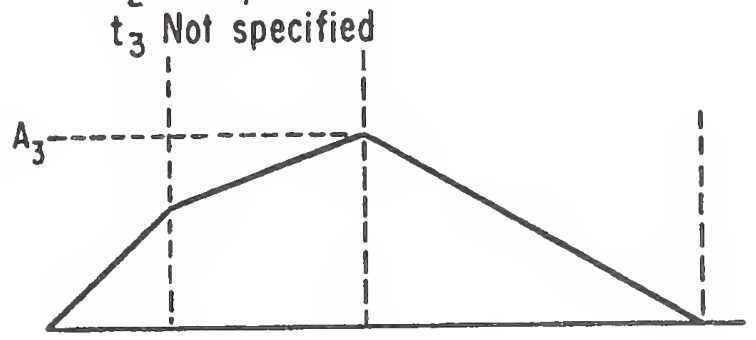

b) Short-circuit current

$\mathrm{A}_{3}$ computed from source impedance See Toble II

Fig. 3. Proposed TCL wave shapes.

$10 \mu \mathrm{H}$. Again, for purposes of discussion, it is proposed that a resistive source have an impedance of $50 \mathrm{ohms}$, and an inductive source have an impedance of $10 \mathrm{mH}$.

\section{Voltage and Current Levels}

Central to the success of the BIL system of insulation coordination is the fact that only a limited number of BIL's were established, arranged in a generally geometric order of progression. For purposes of discussion, we therefore propose that there be established a series of TCL's progressing in the approximate ratio of $\sqrt[3]{10}$ or 3 values per decade. Such possible TCL's, as rounded to convenient voltages, then appear as shown on Table II.

The subject of source impedance and short-circuit current needs to be further discussed since the concept of constant surge impedance, and particularly constant inductive surge impedance, may not be valid. Transients of high voltage and large energy content tend to be produced by physically large systems, whose inductance tends to be larger than that of the systems producing lower voltage or lower energy transients.

\section{Proof Test Techniques}

The generation of surge voltages in the laboratory is well known to manufacturers and users of high power equipment. However, producing a test wave of the shape and levels proposed here may present some difftculty for the small equipment manufacturer. To answer this need, a previously developed circuit ${ }^{11}$, as shown in Figure 4, may be applicable.
TABLE II

Possible Transients Control Levels

\begin{tabular}{cccc} 
Open & \multicolumn{2}{c}{$\begin{array}{c}\text { Circuit } \\
\text { Level }\end{array}$} & \multicolumn{2}{c}{$\begin{array}{c}\text { Short Circuit } \\
\text { Voltage } \\
\text { (volts) }\end{array}$} & \multicolumn{2}{c}{ Current (amperes) } \\
No. $=50 \Omega$ & $\mathrm{Z}=10 \mathrm{H} H$ \\
1 & 10 & 0.2 & 2.63 \\
2 & 25 & 0.5 & 6.56 \\
3 & 50 & 1 & 13.1 \\
4 & 100 & 2 & 26.3 \\
5 & 250 & 5 & 65.6 \\
6 & 500 & 10 & 131 \\
7 & 1000 & 20 & 263 \\
8 & 2500 & 50 & 656 \\
9 & 5000 & 100 & 1310 \\
10 & 10000 & 200 & 2630
\end{tabular}

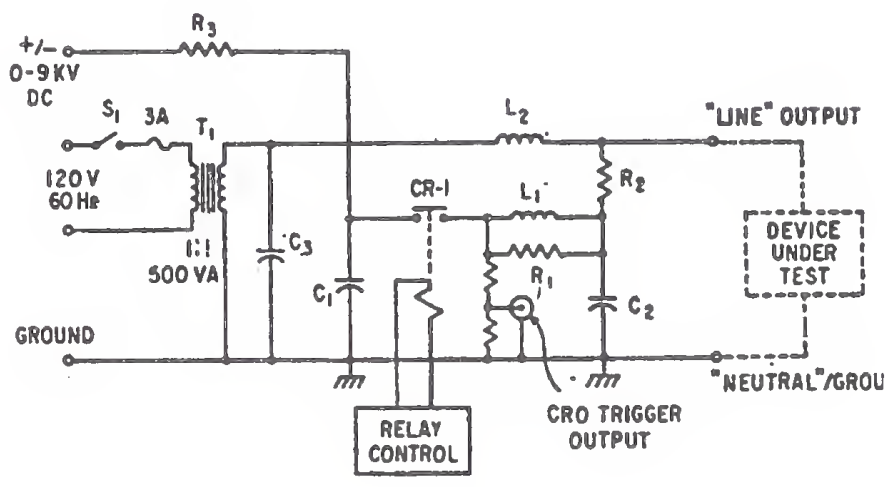

Fig. 4. Test circuit for applying spikes on 120-volt. AC lines.

The objective of this design was to super-impose on a $120-$ volt, $60-\mathrm{Hz}$ power line a transient having a rise time to first peak of 0.5 uus, followed by a damped ringing at $100 \mathrm{kHz}$ in which each successive peak is $60 \%$ of the preceding peak amplitude. The amplitude of the first peak is adjustable f r o $\mathrm{m} 0$ to 8000 volts. The source impedance for the high-voltage transient is $50 \mathrm{ohms}$.

The $0.5 \mu$ s rise characteristic is obtained by the series resonance of $\mathrm{L} 1$ and the capacitance of $\mathrm{Cl}$ and $\mathrm{C} 2$ in series. Component values were selected to make $\sqrt{\mathrm{L} / \mathrm{C}}$ approximately $50 \mathrm{ohms}$, and Rl was selected to provide heavy damping for a smooth transition to the following wave.

The $100 \mathrm{kHz}$ damped ring results from the parallel resonance of $\mathrm{L} 2$ with the parallel capacitance of $\mathrm{C} 1$ plus $\mathrm{C} 2$. Again, $\sqrt{\mathrm{L} / \mathrm{C}}$ is about $50 \mathrm{ohms}$. The series damping resistor $\mathrm{R} 2$ was selected to produce the decay to $60 \%$ amplitude between successive peaks.

\section{CONCLUSIONS}

1. The present lack of transient coordination methods in low-voltage systems does not allow the user of electronic equipment to obtain the best reliability at lowest cost.

2. Manufacturers, vendors, and users could benefit from a systematic approach to transient coordina- 
tion similar in concept to the $\mathrm{BIL}$ used for many years in high-voltage systems. This is illustrated in Figure 5.

3. A concept of Transient Control Level (TCL) is proposed by the authors. This involves discrete steps of withstand level and proof tests based on the capability of available $s$ urge protective devices and reflecting the occurrence of surges in the real world.

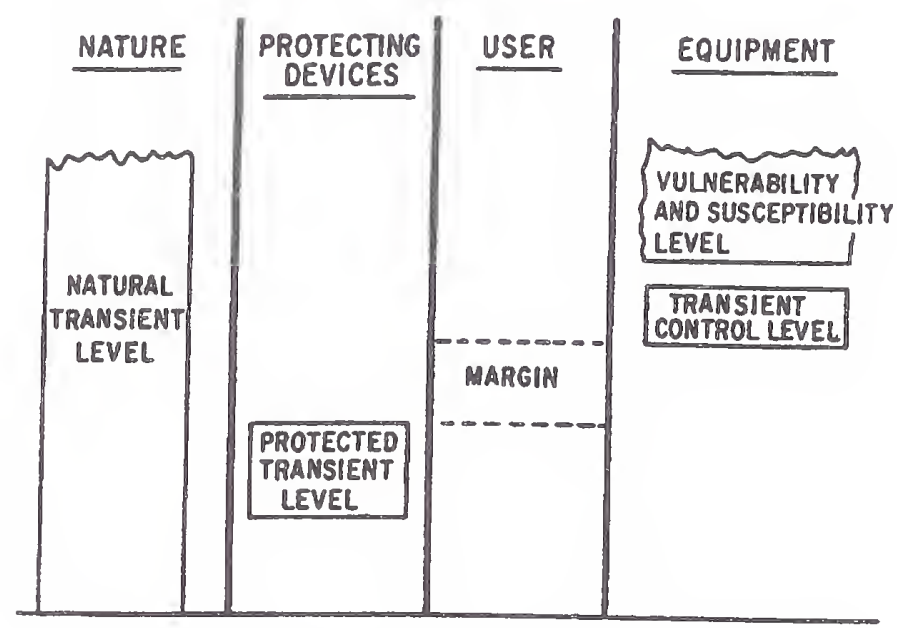

Fig. 5. Well-coordinated low voltage system.

4. Discussion is earnestly invited on the parameters to be considered in defining TCL's such as:

- voltage waveform of the transients

- source impedance of the transients

- current waveform of the transients

- levels to be assigned - current and voltage

- proof-test techniques.

Successful application of the TCL concept will require careful stud yof these factors, so as to develop a valid consensus among all interested parties.

\section{REFERENCES}

(1) F. D. Martzloff and G. J. Hahn, "Surge Voltages in Residential and Industrial Power Circuit, "IEEE Trans. Power Apparatus Systems PAS-89, No. 6, 1049-1056 (July-Aug. 1970).
(2) P. M. Speranza (Bell Laboratories); Oral Communication to IEEE-SPD WG \#3. 4. 4 (Oct. 1974).

(3) J. E. Lenz, "Basic Impulse Insulation Levels in Mercury Lamp Ballast for Outdoor Appreciation, Illum. Eng. 133-140 (Feb. 1964).

(4) A. Martin and A. W. Smoot, "Fact Finding Report on Ground Fault Circuit Interrupters," Underwriters Laboratories File E45269 (March 1972).

D. W. Nestor (Rucker Electronics), private communication (1972).

IEEE Committee Report, "Bibliography on Surge Voltages in AC Power Circuits Rated 600 Volts or Less," IEEE; Trans. Power Apparatus Systems PAS-89, No. 6, 1056-1061 (July-Aug. 1970).

(7) H. A. Gauper Jr., General Electric Co.; oral communication to NEMA, Ground Fault Protection Section (Aug. 1973).

P. M. Speranza and L. H. Sessler (Bell Laboratories); oral communication to NEMA, Ground Fault Protection Section (Aug. 1973).

(9) J. A. Plumer, F. A. Fisher, and L. C. Walko, "Lightning Effects on the NASA F-8 Digital-Fly-byWire Airplane," Contract NAS 4-2090, NASA Scientific and Technical Information Facility, College Park, Md. 20740.

(10) J. A. Plumer, "Lightning Effects on General Aviation Aircraft," Report No. FAA-RD-73-99, National Technical Information Service, Springfield, VA. 22151.

(11) E. K. Howell and F.D. Martzloff, "High Voltage Impulse Testers," Report 75CRD039, General Electric Company, Corporate Research and Development Center, Schenectady, N. Y.

(12) "Space Shuttle Lightning Protection Criteria Document," NASA, Lyndon B. Johnson Space Center, JSC-07636, September 1973. 


\section{APPENDIX}

\section{TYPICAL WAVE SHAPESS}

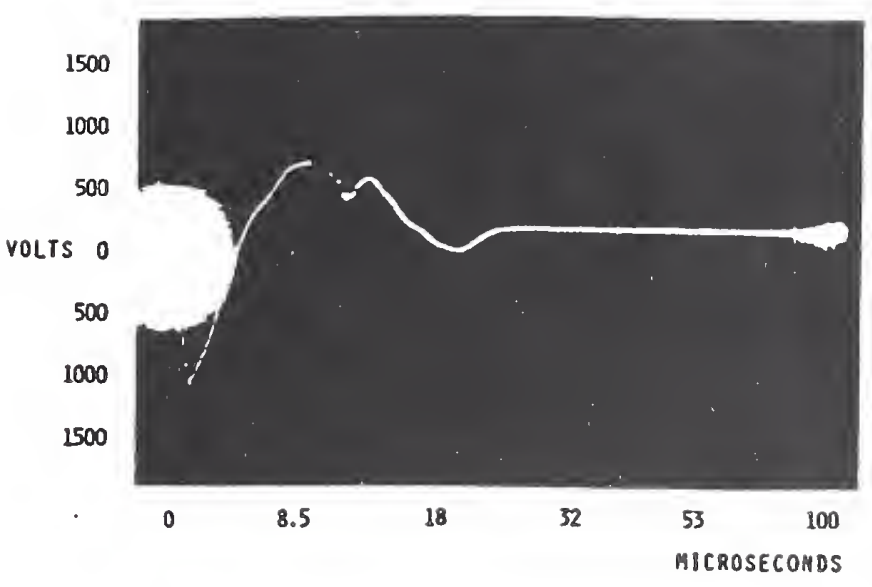

Fig. A1. Transient recorded during starting of a furnaceblower at service box.

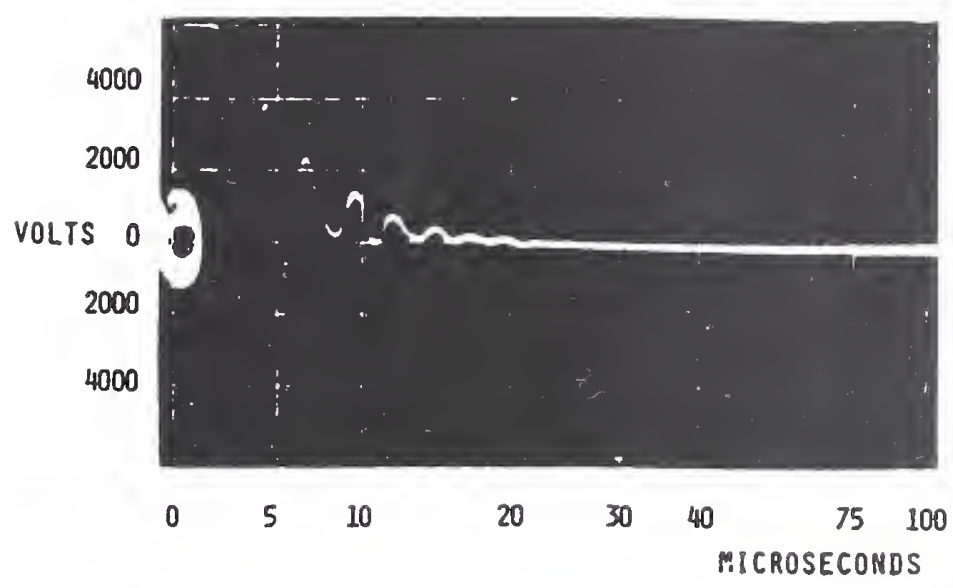

Fig. A2. Transient recorded during lightning storm on street pole.
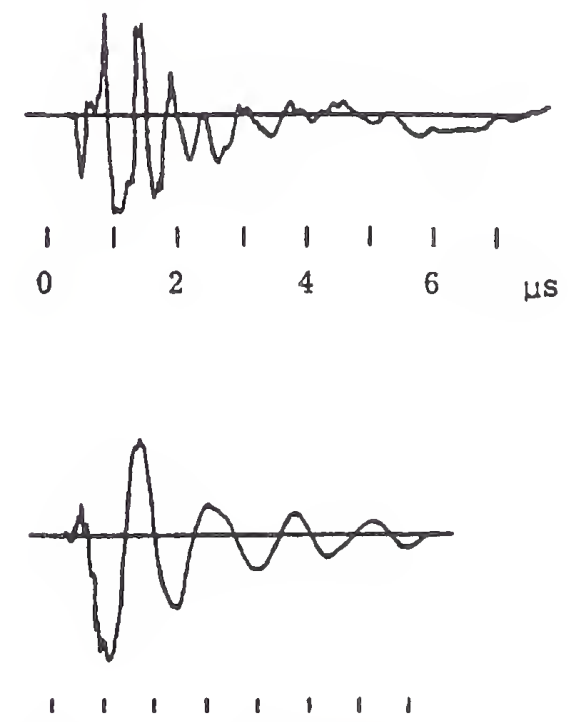

Fig. A5. Typical transients recorded during lightning injection tests on fighter-type aircraft (amplitudes are relative).

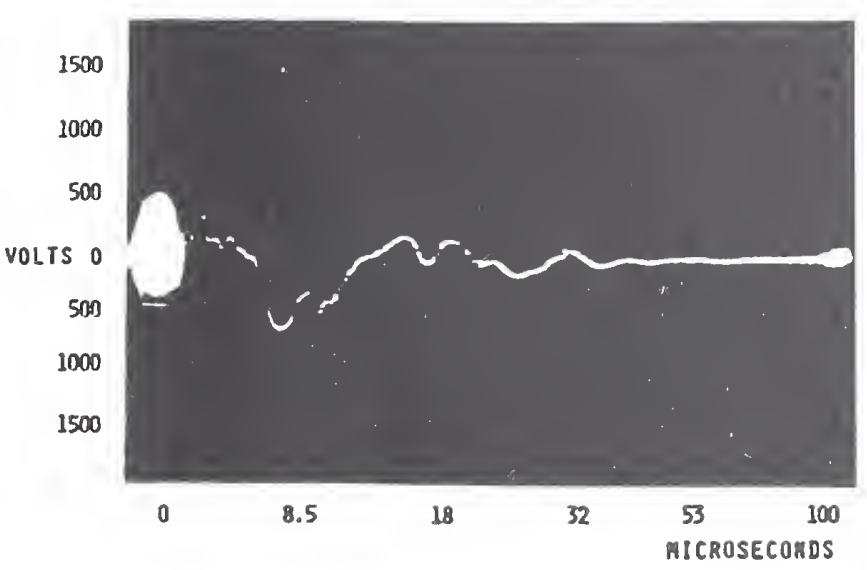

Fig. A3. Transient recorded during unidentified disturbance at service box.

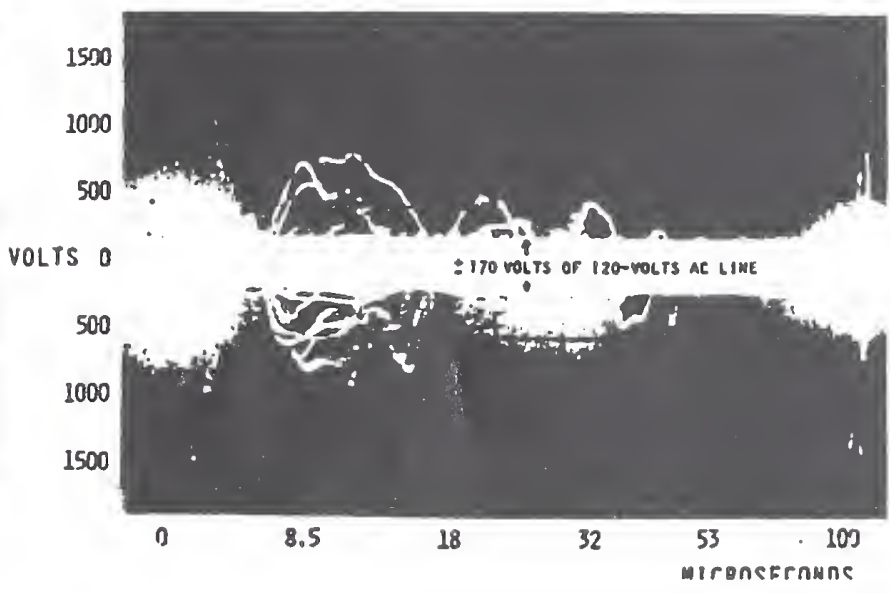

Fig. A4. Composite recording of furnace ignition transformer transients over 24 hours at service box.

anslormer transients over 24 nours at servic
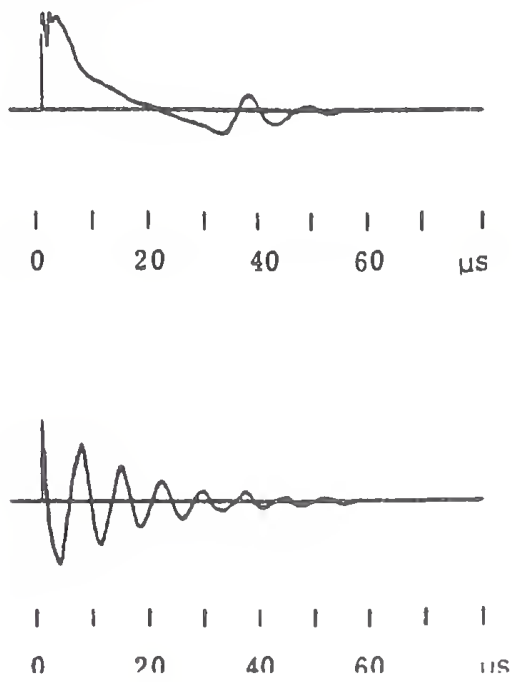

Fig. A6. Typical transients recorded during lightning injection tests on small general aviation aircraft (amplitudes are relative). 
Discussion

S.M. Harvey (Ontario Hydro Research Division, Toronto, Canada): This paper provides a clear presentation of the case for a transient interference immunity standard applicable to residential and, presumably, light commercial electronic equipment. Designing transient or surge withstand compatibility into low-voltage equipment is not, of course, a new concept. The telephone companies have been doing it for years. However, the authors have commendably proposed their Transient Control Level concept in the context of a general and down to earth philosophy of testing that should encourage informed discussion.

Following the establishment of Basic Insulation Levels, the electric power industry has not been idle in the area of overvoltage testing of low-voltage equipment. A number of committees, including the Power System Relaying Committee of the IEEE Power Engineering Society and Technical Committee No 41 of the International Electrotechnical Commission have been working for years on the surge testing of static relays used for transmission line protection. The Swedish Electrical Commission has prepared a draft proposal for interference withstand capability testing of apparatus used in power stations and industrial installations. These committees have proposed a range of test waveforms including the familiar 1.2/50 impulse at peak voltages of 1,3 , and $5 \mathrm{kV}$, a moderately damped $1 \mathrm{MHz}$ oscillatory wave at peak voltages of $0.5,1$, and 2.5-3.0 kV, and a high-frequency spark test at $2-4$ and $4-8 \mathrm{kV}$.

In 1974, Ontario Hydro introduced a uniform transient immunity test specification for relays and other equipment intended for substation relay or control buildings. The test waveform is a moderately damped oscillatory transient whose frequency 'can be specified in the range of $100 \mathrm{kHz}$ to $2 \mathrm{MHz}$. One of four test levels, specified in Table I, can be called for. The test is supervised by our Supply Division and manufacturers are encouraged to supply their own test equipment. However, it is still frequently necessary for Ontario Hydro to make its own test generators available.

Table I

Transient Test Levels

\begin{tabular}{ccc} 
Test & Peak Amplitude (Volts) & Source Impedance (ohms) \\
\cline { 2 - 3 } A & 5000 & $100-500$ \\
B & 2500 & $100-150$ \\
C & 1000 & $30-50$ \\
D & 500 & $30-50$
\end{tabular}

Note that these levels when specified at I $00 \mathrm{kHz}$ are very similar to tests 6 and 9 in Table II of the present paper. Level B, incidentally, when specified at I $\mathrm{MHz}$ is equivalent to the IEEE Relay Test [1].

Our experience with the tests, although limited, suggests that minor circuit deficiencies leading to operational upsets are common but that damage is relatively rare. Probably the marginally greatest value of the tests at this time lies in their potential for creating an awareness of the transient problem.

A number of questions being considered at this stage of our transient test program can be rephrased to apply also to the proposals in this paper. Perhaps the authors could comment on the following:

1. What is the advisability of introducing a new test waveform or test procedure in addition to those already in circulation?

2. Would it be necessary to shield the test circuit of Fig. 4 or to locate it, say, 4-6 meters from the equipment under test? In the latter case, should the voltage and current waveforms be measured at the near end or the far end of the connecting cable?

3. Can the test circuit of Fig. 4 correctly simulate transient disturbances that occur when the white wire neutral and the green wire ground are connected together a quarter wavelength from the device under test?

4. Can a reliable certification procedure, particularly in terms of energy deliverable to a load, be established for test generators differing in design from the one shown?

5. Finally, what is the incidence of damage or significant upset to equipment now used in resident at or light commercial environments and does it justify the introduction of transient testing to this class o apparatus? If applied, in view of the data contained in Fig. 2 of the paper, what criterion would be used to select a test level of less than, say 500 volts?

\section{REFERENCES}

[1] ANSIC37.90a-1974(IEEE Std 472-1974)

Guide for Surge Withstand Capability (SWC) Tests.
E.J. Cohen (U.S. Dept. of Agriculture, Washington, D.C.): We feel the concept expressed in this paper is long overdue in the field of electrical protection of electronic equipment. Experience within the telephone industry has already demonstrated that, with present trends to ever smaller equipment, protection problems can be severely aggravated. The over voltage and current tolerance of microelectric circuits has decreased to the point where protection should be major consideration in circuit design.

Added to this increased equipment vulnerability, we have found a .,communications gap" between the manufacturers of electronic equipment, and the producers of protection devices. When a protection defect is uncovered, we frequently encounter disagreements between the equipment and arrester manufacturers. By establishing "Transient Control Levels," as proposed by this paper, much of this "finger pointing" could be eliminated. As both equipment and arrester manufacturers -should know precisely what the other adequate protection should be minimized.

It is felt that while the concept expressed here is valid, further consideration should be given to the levels and waveshapes involved in the tests. As these parameters may be critical to the workability of this proposal, every effort should be made to generate realistic values.

Manuscript received August 13, 1975

Richard F. Hess (Sperry Flight Systems, Phoenix, Arizona): I agree that some form of action is needed to properly assess and overcome the adverse effects of power transients on military and commercial equipment. Assuming a consensus is reached concerning the need for transient control and the adoption of Transient Control Levels (TCL), the following comments are intended to complement the proposal for transient control in low voltage systems.

The voltage specification is based upon measurements which are appropriate to present and past equipment designs. For the most part these designs use devices which present a relatively high impedance to a source of transient energy.

Damage occurs during a power transient when the device breaks down and high to medium voltages are developed across the device while large to medium currents are flowing through it. Standard components are not normally tested under transient conditions, therefore it may be difficult to determine whether they would break down or to assign a confidence level that they would survive such a transient. When a device breaks down, either a voltage or a current viewpoint could be assumed when describing the threat of the power transient to the device.

If in order to conform to a specified TCL a device has been designed to withstand a specified voltage level, then the voltage specification is appropriate. However, a manufacturer designing equipment to meet a specific TCL could adopt an approach which calls for the use of transient power supprcssion devices (tranzorbs, metal oxide varistors, etc). In this case, transient power surges are manifested as large current surges into equipment (through the protection device) rather than a large voltage transient across the equipment. Even when passing large currents, the network impedances (suppression devices, etc.) will probably be significant enough to produce a natural mode current response within the total network. Thus, current measurement of such a network would contain a significant oscillatory component similar to that present in the voltage measurements.

Two types of TCL specifications should be provided:

1. Voltage

2. Current

Like the voltage specification, the waveform and magnitude of the current specification at each TCL would be based upon the measurement of the current response modes of networks containing power suppression devices and excited by a power transient.

With the two types of specifications, equipment could be designed and tested to withstand a power transient by safely withstanding specified voltage levels or by safely passing specified currents levels. The test equipment for, the voltage specification would be calibrated under open circuit conditions and would be designed to deliver current (in the event of device breakdown) at a level at least as large as that specified in the current specification. The test equipment for the current specification would be calibrated under short circuit conditions and would be designed to provide voltage (in the event of a high impedance) at a level at least as large as that specified in the voltage specification.

Manuscript received August 14, 1975. 
Tests for semiconductor vulnerability (damage) levels using square pulse waveform are common practice with the military. The damage level of many discrete components has been determined ari recorded. However, the damped sinusoid pulse is more appropriate to susceptibility testing (transient upset). Depending upon the type of equipment being tested and the frequency content of expected transients, it may be desirable to test using more than one waveform. lower frequency, high amplitude sinusoid $(100 \mathrm{KHz})$ would be used to vulnerability testing and a higher frequency sinusoid $(500 \mathrm{KHz}, 1 \mathrm{MHz}$ or $10 \mathrm{MHz}$ depending upon the bandwidth of the equipment) would be used for susceptibility testing. At each frequency the equipment shoul be subjected to at least two pulses:

1. Maximum pulse is positive

2. Maximum pulse is negative

As a final observation, testing and test equipment should be kept a simple as possible to avoid adding inordinate costs to the equipment ideally, the degree of confidence obtained by such testing should result in a net reduction in equipment costs (manufacture plus maintenance).

F.A. Fisher and F. D. Martzloff: We appreciate the response of the discussors and will attempt to both respond to their questions and expan somewhat on the protection philosophy we propose. First of all, it should be pointed out that while this paper was written using household appliances as an example and presented before a group largely concerned with utility relaying, the problems of transients pervade the entire field of low voltage electrical and electronic apparatus, including the communication (telephone) industry. One of the areas where th authors have seen a great need for better transient compatibility is i the Aerospace field. Much of the background upon which the TCL concept is based comes from consideration of the transients induced in aerospace vehicles by lightning and other energetic discharges. Designers in the Aerospace community tend not to have had thc problem of transients brought as forcibly to their attention as have the designers of relay devices intended to work in the harsh electrical environment of a utility substation. With reference to $\mathrm{Mr}$. Harvey's first question, we feel that it is advisable to introduce new test procedures because th specialized test procedures adapted in the electric utility field may no meet the needs of users in other fields.

Each of the discussors mentions the subject of levels and waveshapes. We suggested the voltage waveshape of Figure 3 of the pape because measurements have indicated that most transients to which electronic equipment is exposed are oscillatory in nature and generally of faster front and tail times than the $1.2 \times 50$ microsecond test wave common in the electric power industry. Several other factors influence our choice. One was that the proposed wave is of long enough duratio that breakdown of semiconductor junctions would not be greatly influenced by deviations from the specified waveshape. With much shorter waveshapes, the resistance of semiconductor junctions to burn out becomes strongly influenced by waveshape. Another is that transients of this nature can be injected into wires by rather simple transformer-coupled pulse-injection generators, whereas transformer injection of higher frequency oscillatory voltages and currents is more difficult. Transformer injection of transients has not been discussed in this paper but is sometimes an appropriate means of evaluating the resistance of a device to circuit upset. Mr. Hess mentions the need for two types of TCL specifications: voltage and current. We agree. We have seen instances of groups worrying wastefully about specifications that call for a specific voltage transient to be developed at the terminals of a device when that device had properly been fitted with a low-pass filter, a low impedance suppressor, or transient suppression spark gap Specifications that do not recognize that one can neither develop a voltage across a short circuit nor circulate a current through an open circuit are not only incomplete but mischievous and counterproductive.

With reference to more of Mr. Harveys questions, we feel that any test circuit should be built in a sufficiently well-shielded cabinet so that there is no need to physically separate the test circuit from any device under test. If a test circuit must be located away from the device under test and an interconnecting cable be used, we would think that the generator open-circuit voltage and shortcircuit current should be measured at end of the cable nearest the device under test.

We do not really know what would be the interaction between a white wire neutral and a green wire ground if the two were connected together a quarter wavelength away from the generator. We take refuge in the observation that transient coordination is more likely to be

Manuscript received October 101975. achieved through the successful passing of even an imperfect test than it is in the avoidance of all but perfect tests.

We hold no special faith in the virtues of the test circuit shown on Figure 4 of the paper and show it only as one example of various test circuits that might be produced. We feel that a reliable certification procedure not only can be, but must be, based on specifications that are not unique to any one test circuit. It is for this reason that we propose specifications be written in terms of open-circuit voltage and short-circuit currents; a concept that implies a fixed generator impedance. Care must be taken that the voltage and current specifications not be incompatible with the generator impedance. Since the writing of this paper another paper discussing the impedance of $\mathrm{AC}$ wiring circuits has been published [1]. Based on this paper, we would now propose that the internal impedance of a transient generator be $50 \mathrm{ohms}$ paralleled by 50 microhenries. Figure 1, reproduced from the referenced paper with the permission of the author, shows how the impedance of the line ("the mains") can be closely approximated by the parallel combination of $50 \mathrm{ohms}$ and 50 microhenries. Levels and waveshapes appropriate to such an impedance might then appear as shown in Figure 2 and Table 1.

As Messrs. Cohen, Harvey and Hess emphasize, the choice of appropriate levels is crucial to the successful implementation of a TCL philosophy. While a TCL of 5000 or 6000 volts might be appropriate to high reliability utility relays or a safety-oriented consumer product such as the Ground Fault Circuit Interrupter, it might impose an unnecessary economic hardship on a high volume item intended for routine household use. Likewise, while a TCL of 500 volts might be too low for residential purposes, it might be appropriate for the power inputs of electronic equipment used in aircraft, and excessively high for the signal inputs of data processing equipment intercommunicating through well-shielded signal wires.

Since of the major purposes of this paper is to promote discussion, it is appropriate to list some of the questions the authors have posed to themselves during the formulation of this proposal:

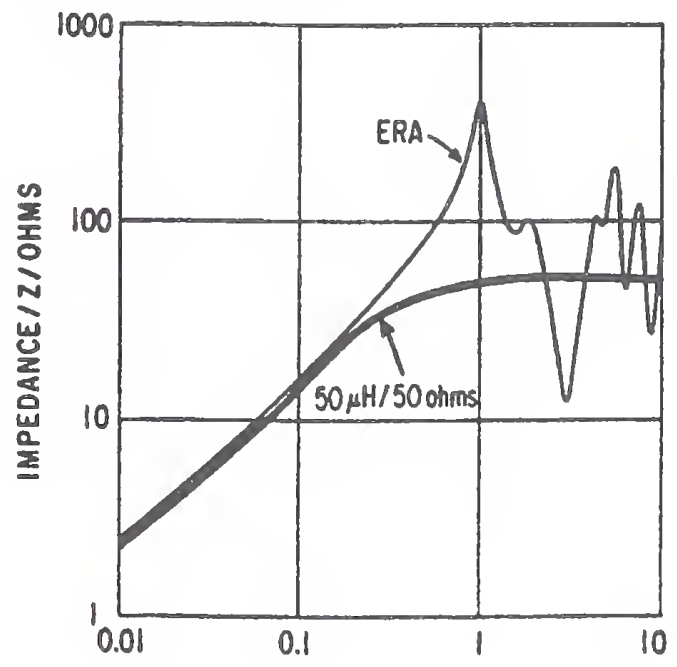

Fig. 1. Comparison of impedance measurements made by the Electrical Research Association (ERA) on the impedance of power systems with a network of $50 \mathrm{ohm} \& 50 \mu \mathrm{H}$ in parallel

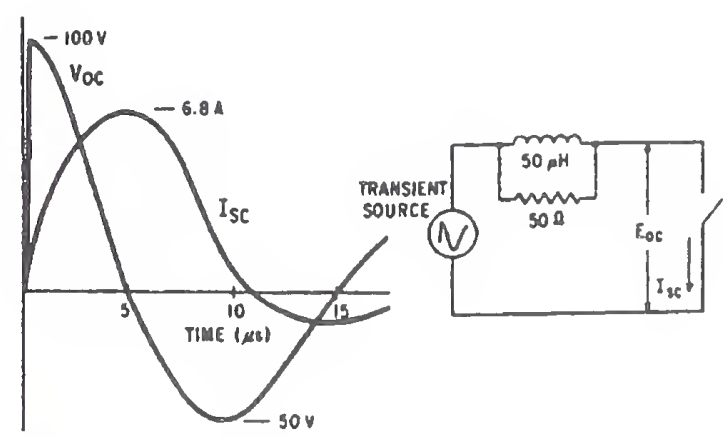

Fig. 2. Short-circuit current ( $I_{S C}$ ) resulting from a transient source with $V_{O C}$ open-circuit voltage and $50 \Omega / / 50 \mu \mathrm{H}$ source impedance. 
TABLE 1

Proposed Transient Control Level Number

1

2

3

4

5

6

7

8

9

Open-Circuit Voltage Level (volts)

Short-Circuit

Current Level (amperes)

0.68

25

1000

2500

5000

340

- Are there sufficient problems relating to transient coordination to warrant an effort, likely to be major and long term, to achieve better coordination between the transients to which equipment is exposed, and the ability of equipment to withstand such transients?
- Would transient control level (or some other) specifications and standards help achieve successful transient coordination between equipment manufacturers, utilities and equipment users?

- Should there be a limited number of fixed levels? The authors feel that it is essential that the number of levels be limited, perhaps to 9-15 levels distributed in a geometric progression over the range 10-5000 volts. The assignment of the levels may have -to be done arbitrarily. This need not be cause for alarm. The electronic industry for years has worked successfully with resistor and capacitor values produced according to an arbitrarily selected geometric progression.

- Should these levels reflect the system voltage, the expected reliability of the equipment function, the environment?

- What kind of source impedance is appropriate? As mentioned above, an impedance of $50 \mathrm{ohms}$ paralleled by 50 microhenries may be appropriate.

- Should open-circuit voltage and impedance be stated or, alternatively, should open-circuit voltage and short-circuit current be specified?

- Is one impedance value suitable for the majority of the systems?

- What waveshape is appropriate, for voltage as well as current? For damage, we are mostly concerned with energy and front-of wave but if upset (interference) is to be included in TCL, then do we need to specify a frequency spectrum?

\section{REFERENCE}

[1] "Impedance of the Supply Mains at Radio Frequencies", J. H. Bull, Proceeding of 1st Symposium on EMC, Montreux, May 1975. 


\section{Transient Control Levels Philosophy and Implementation Part 1: The Reasoning behind the philosophy}

\author{
François Martzloff \\ General Electric Company \\ Schenectady NY \\ f.martzloff@ieee.org
}

\author{
F.A. Fisher \\ General Electric Company \\ Pittsfield MA \\ fafisher@lightningtech.com
}

Reprinted, with permission, from

Proceedings, $2^{\text {nd }}$ International Symposium on Electromagnetic Compatibility, Montreux, 1977

\section{Significance:}

Part 2 Development of standards - Reality checks

Part 5 Monitoring instruments, laboratory measurements and test methods

Part 6 Textbooks and tutorial reviews

Presentation to the EMC community in a European forum of the Transient Control Level concept being proposed in the US via the IEEE Power Engineering Society (See Fisher and Martzloff in IEEE Transactions PAS 95, 1976). A companion paper on implementation is reprinted in Parts 5 and 6 (See Fisher and Martzloff in the same forum).

The proposal also included the concept of establishing first a level of surges that will not be exceeded, thanks to the application of appropriate SPDs, and only then designing equipment that will withstand level higher than the allowable level of surges. This was nothing new, having been applied successfully in the high-voltage utility environment. However, the proposal was new for the low-voltage community.

Unfortunately, the fait accompli of equipment being designed and placed on the market without such coordination prevented application of that proposal. Thus, industry is left with the situation where equipment failures under surge conditions can occur, after which remedies must be found as retrofits

In 1975, the following statement appeared in the paper and should be kept in mind when questions arise on the selection of "representative waveforms" in IEEE Std C62.41.2:

These BIL amplitudes, while assigned somewhat arbitrarily, were (and are) kept in touch with reality by the fact that equipment designed in accordance with standards do not fail when exposed to surges produced by lightning, in contrast to equipment designed prior to the development of the philosophy of insulation coordination and the establishment of standard B/LS. 
$\varnothing$ 
TRANSIENT CONTROL LEVEL PHILOSOPHY AND IMPLEMENTATION

I. The Reasoning Behind the Philosophy

F.D. Martzloff and F.A. Fisher

General Electric Company, Corporate Research and Development, Schenectady, New York, and Pittsfield, Massachusetts

\section{Abstract}

This is the first of a pair of papers describing how better transient protection might be achieved through the use of a Transient Control Level (TCL) philosophy. The authors have developed and are proposing this TCL philosophy because damage to and upset of electronic and other low-voltage equipment by transients seems to be a never-ending problem, and one that is likely to get worse in the future as electronic controls permeate even more of the products which affect our lives. A number of proposals have been made - some already incorporated into standards - on various test wave shapes and specifjcations. The authors propose an approach integrating many of these proposals while focusing attention on significant parameters.

\section{Introduction}

An area where present standards do not seem to offer sufficient guidance to designers and manufacturers of electronic equipment is in what types of transients to consider and how to prove that equipment works in the presence of transients. This situation is perhaps under better control in the electric power field than it is in the fields of aerosapce, general industry, housewares, and the military. For instance, the insulation of high-voltage apparatus is coordinated to the threats that nature provides to that insulation through the philosophy of insulation coordination as expressed in the Basic Insulation Level (BIL) system. The BIL system provides for a standardized series of levels being coordinated with the protective abilities of existing protective devices. On the other hand, electronic and control equipment is all too often designed, built, and delivered before the existence of a transient threat is recognized. If transients turn out to endanger the equipment, there may be no adequate surge protective devices. In fact, there may not be any satisfactory answer to the problem posed by transients.

The authors" TCL philosophy is aimed at achieving better coordination than now exists between the transients to which equipment is exposed and the abilities of equipment to withstand the transients. It is patterned after the BIL approach to insulation coordination so successfully used in the electric power field.
The purposes of this first paper are to explain the reasoning behind the different elements of the BIL system of insulation coordination, and to explain how similar reasoning has led to the formulation of the TCL philosophy. Some observations on how to perform TCL tests are given in a companion paper [1].

\section{Proposal for $\mathrm{TCL}$}

This proposal can be summarized by saying that we want to:

1. Establish the concept that equipment shall be rated in terms of its ability to withstand a limited set of transient proof tests, rather than in terms of its ablility to withstand unknown "actual" transients.

2. Establish the concept that transient specifications apply to power and signal lines. In the past, only power tines have been considered.

3. Establish a set of levels (1imited in number) to which equipment is designed and tested.

4. Establish a set of standard test waves (1imited in number) to which low-voltage equipment will be subjected.

5. Establish standardized relationships between voltage and current (source impedance).

6. Differentiate between the task of establishing the family of test levels and wave shapes, and the task of actually selecting a specific level. This means that:

- We will propose to you a family of levels and wave shapes

- You will select the specific level and shape, based on your reliability goals, your costs, and your experience.

This proposal is made with awareness that it may be one more of an already confused array of standards. However, if accepted by a large section of industry and users, it could become a unifying link and make the applications more successful. 
In the following paragraphs, we will attempt to present the background justifying our proposal, for each of the points listed above.

\section{Basis for rating equipment}

The concept that equipment be rated in terms of its ability to withstand a standard test rather than "actual" service conditions is not new. This is at the very heart of the systern of BIL, which has been so successful in the field of electric utility equipment.

Fortunately for the utilities, few parties were involved in making the decisions, and thus it was possible at an early stage to establish the BIL system and to enforce it because of the near total control of the engineering department of a utility over the system design. In the field of low-voltage systems, however, the selection and purchase of a multiplicity of components and equipment by a multiplicity of buyers from a multiplicity of vendors on behalf of a multiplicity of users have made it very difficult to maintain the organized systems approach which succeeded in the case of the electric utilities.

A basic concept, which needs to be mutually accepted by users and manufacturers of equipment, is that it is impossible to simulate all possible transient overvoltages (and over-currents) that a product line might experience in service. However, by designing the equipment to a certain standard and controlling the level of transients by suitabTe protection, a much greater chance of successful operation in the cruel real world will be obtained.

The task is then to establish a set of standard tests, acceptable to the vast majority of applications, reflecting the real world but not pretending to duplicate it, simple enough to be practical, conservative enough to ensure reliability, but realistic in terms of economics.

Obtaining complete agreement from all is most unlikely an impossible goal, and thus the unsatisfactory situation endures. This stalemate can be broken by accepting a proposal which might nc: be perfect, but is better than many isolated sisindards or no standard at all.

\section{Al1 lines subject to transient tests}

The existence of transients on power lines is by now a recognized and accepted fact, so that most applications will involve a certain amount of precautions in specifying transient withstand capability. However, in the case of signal lines, this recognition is Jess frequent, and there have been examples where a total lack of appreciation of the problem has led to the design and deployment of equipment that cannot be protected from transients.

Transients can be introduced into a piece of equipment by the power lines from many sources, such as lightning, switching transients, fault clearing, and coupling from adjacent circuits. Signal lines, especially in the case of extensive systems covering a vast area, can also be subjected to induced transients by ightning, adjacent circuits, ground currents, etc. Since quite often the signal circuits tend to be at a lower voltage than the power circuits, the discrepancy between the rated level in the circuit and the actual level of transients makes the signal circults more susceptible to transient problems.

A question related to which 1 ines are to be subjected to transients is that of "common mode" versus "transverse mode." This is not always clear and must be addressed in a comprehensive specification.

\section{Test Leve1s}

An important feature of the BIL systern was that it involved a linfted number of test levels graded to the operating voltage of the system for which apparatus was being designed. A successfu 1 TCL system should also be designed around a relatively small number of levels. One who tries to establish levels is pulled in two directions; one to avoid complexity by establishing a minimum number of levels, and in another to provide levels that accommodate existing practices with minimum disruption.

One way to achieve this is through the use of major and minor intervals in the levels. Figure 1 shows several possible level series. The scales show the range 30 to 3000 yolts divided into intervals based on $10^{1 / 3}, 10^{1 / 5}$, and $10^{1 / 6}$. The physical positioning of the numbers on the figure shows how those numbers match the proportionate interval scales. In the past, we have proposed that there be three levels per decade with the spacing between levels being approximately $10^{1 / 3}$. The factors $1.5,3$, and 6 seem appropriate, particularly since such a set could include the voltage levels 600, 1500, and 3000 volts in some existing specifications. The widely used specification MIL-704 includes the 600-volt level for transients, and it would appear that this number, at least, should appear in any set of TCL levels. Levels based on the above progression appear in the left-hand column.

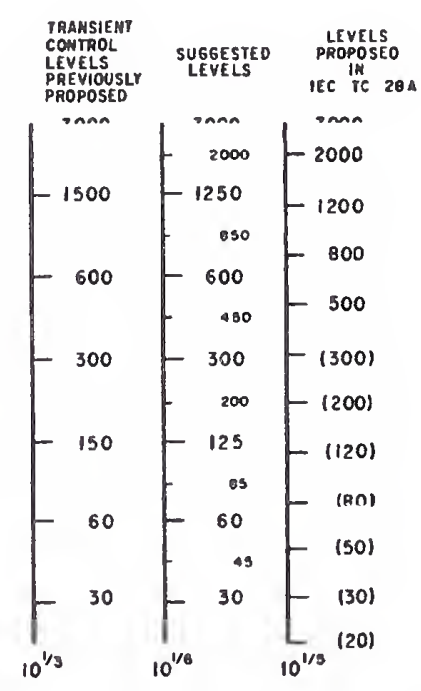

Fig. 1: Proposed levels for TCL voltages compared to existing level systems 
A progression proposed in IEC TC 28A, Low Voltage Insualtion Coordination, is shown in the right-hand column. The levels that have been proposed range from 500 to 12000 volts. On Fig. 1 , the levels in parentheses are inserted only to indicate the sequence. This progression, which seems to be based on the factor $10^{1 / 5}$, does not include the 600-volt level.

Levels as arranged in the center column might appear to provide an appropriate compromise. We propose that the levels in boldface print be the recommended levels while those in lighter print be used, preferably sparingly, when intermediate levels are needed. Associated with each of these levels would be a short-circuit current level, the magnitude of which is related to the voltage levels through defined source impedances. Source impedance will be discussed further below.

Some of the levels will seem very low, particularly to those accustomed to dealing with transients on power lines. They may not be unrealistic for some low-voltage signal circuits. A more important point, however, is that the establishment of a series of levels, from which a choice may be made, is a task separate and distinct from that of deciding to what level a piece of equipment should be designed. This latter point is discussed in more detail later.

\section{Wave shape}

Many test waves have been proposed in the posed.

These wave shapes range from the very fast rise, short duration, to the slow-rise, long duration, with oscillatory or unidirectional voltages. Each of these is based on practical considerations for specific applications; but the total picture is then one of confusion and discouraging attempts at standardization.

Observations of oscilloscope recordings and independent work on the resonant frequency of power systems [2] have shown that most transient voltages in low-voltage systems have an oscillatory wave shape, in contrast to the well-known and generally accepted unidirectional wave used in high-voltage insulations standards. Frequencies are typically in the range of $5 \mathrm{kHz}$ to $500 \mathrm{kHz}$, with the majority of the transients having frequencies above $100 \mathrm{kHz}$ [3].

On the basis of these observations, the authors have proposed the voltage wave shape of Fig. 2, as being most representative of transients in low-voltage systems.

This wave is a composite. One component is aimed at producing the effects associated witn fast rise times. Coupled interference and the response of inductive devices are examples. Another component is aimed at producing the ef fects associated with the more slowly changing, and oscillatory, tail. Voltage summation in capacitive circuits coupled by rectifiers is an example. Energy handing capability of surge protective devices is another.

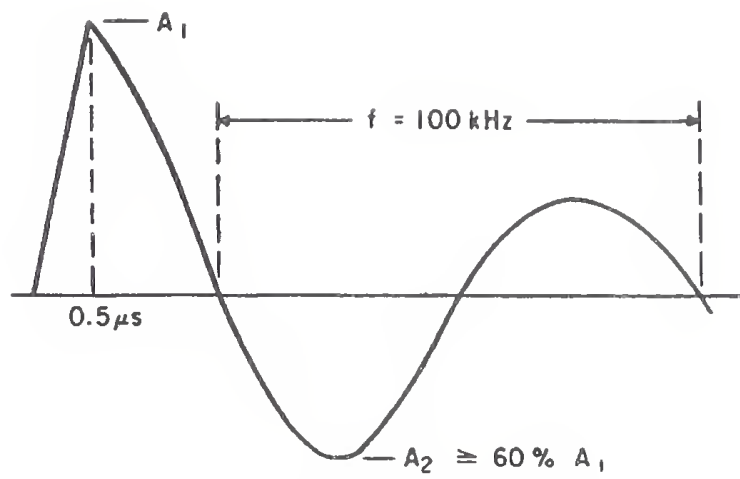

Fig. 2: Proposed TCL voltage wave

While this wave may then appear artificially contrived, it will subject test samples to the two most significant effects of voltage, circuit upset, and circuit damage. Since the wave may be produced by simple laboratory circuits, comparison tests may be easily done by different organizations. [4].

This wave shape was first defined by a consensus at a meeting of the Ground Fault Protection Section of NEMA, in August 1973, and has since received increasing acceptance, notably at the Underwriter's Laboratories. Recently, independent considerations [5] have given further support to a $0.5 \mathrm{\mu s}$ rise time and $5 \mu \mathrm{s}$ duration impulse.

However, in all probability this one oscillatory TCL wave will not meet the needs of all users. Therefore, we propose that the wave of Fig. 2 be supplemented by two unidirectional voltage waves: the classic ANSI $1.2 \times 50 \mathrm{\mu s}$ impulse wave and a $10 \times 1000 \mu$ s wave $[6,7]$.

We believe that most applications can be treated by one of these three wave shapes, once the concept is accepted that a perfect match of "actual" wave shape and "test" wave shape is not essential. The first wave, fast rise and $100 \mathrm{kHz}$ ring, would be more applicable for circuits exposed to "lightning remnants" (the natural oscillation of a power system excited by a lightning discharge or switching transient at some remote point) as well as control circuitry exposed to induced transients. The second wave shape, the familiar $1.2 \times 50$ unidirectional, would be applicable to circuits where direct exposure to lightning. strokes is likely; while the third (long tail) would be applicable to situations involving lightning current discharge on long cables. The second and third wave shapes are also representative of transients produced by the switching of inductive circuits.

Special applications, such as NEMP (Nuclear Electromagnctic Pulse) hardening, or high-vultage substation supervisory equipment, would rather retain their own well-documented standards.

\section{Source impedance and energy}

In some types of tests, the object is to determine what level of voltage will cause failure (permanent or temporary) of insulation. The 


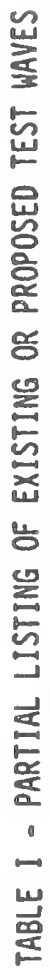

홓

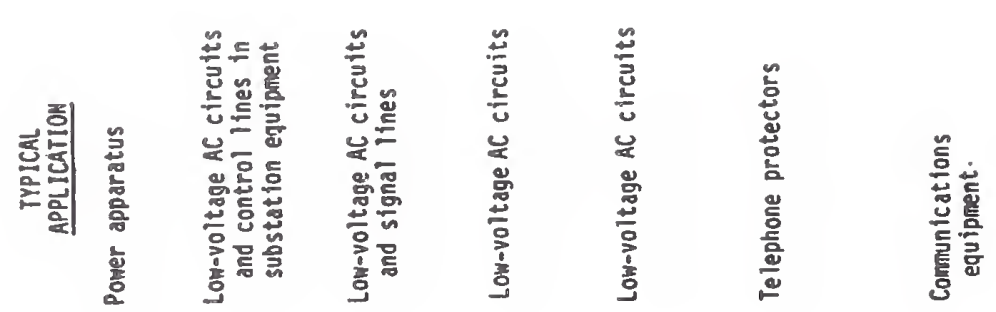
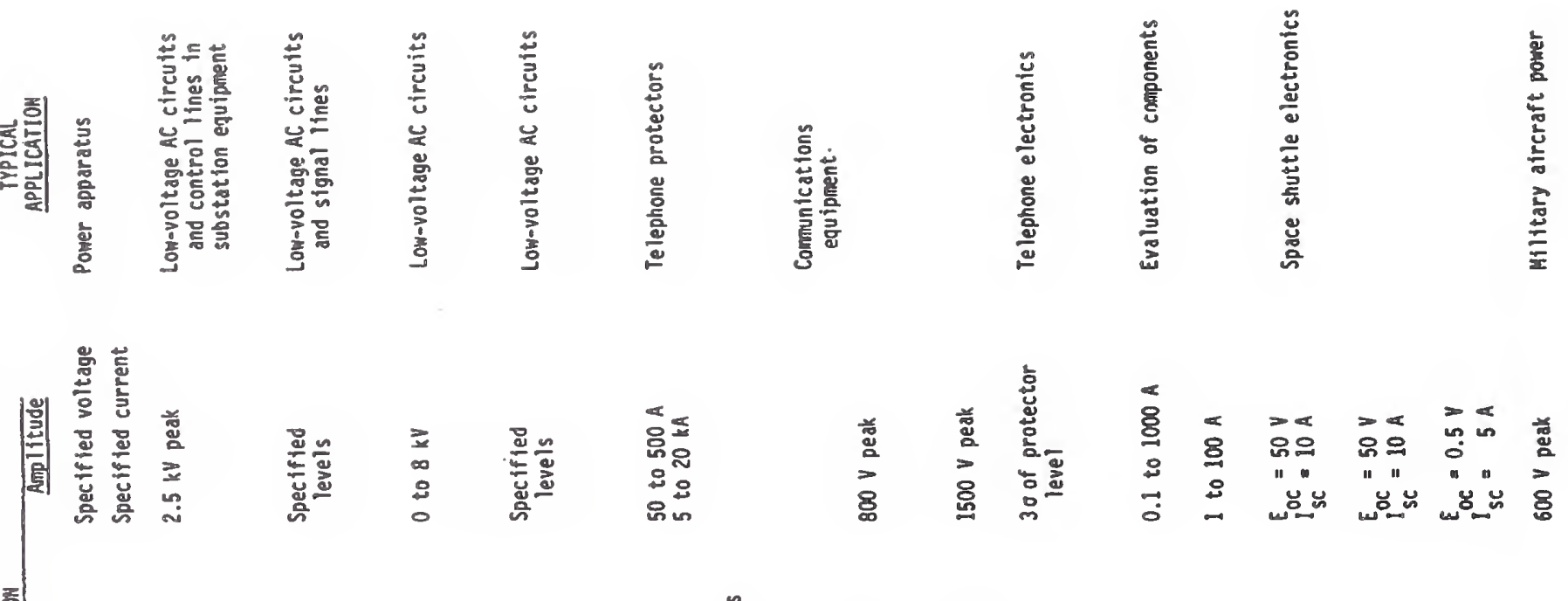

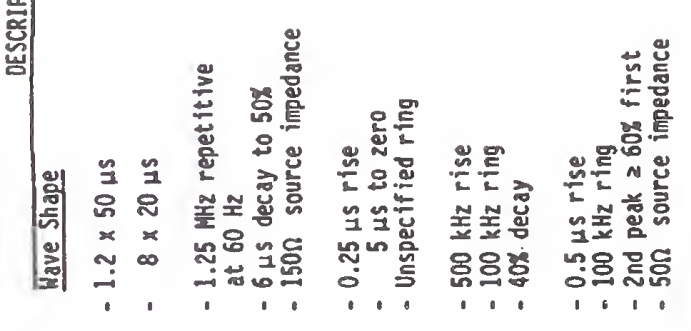

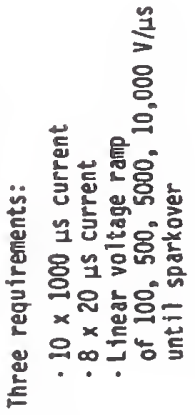

䓂䓂

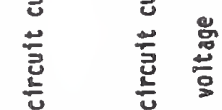

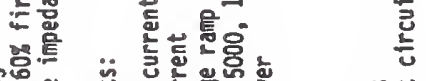

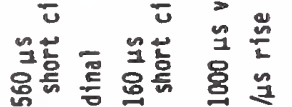

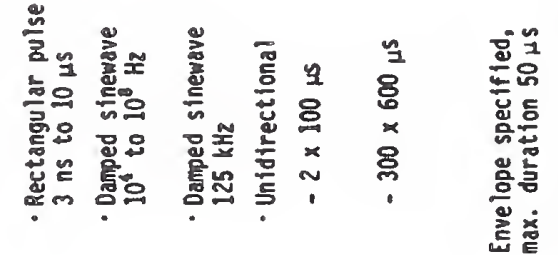

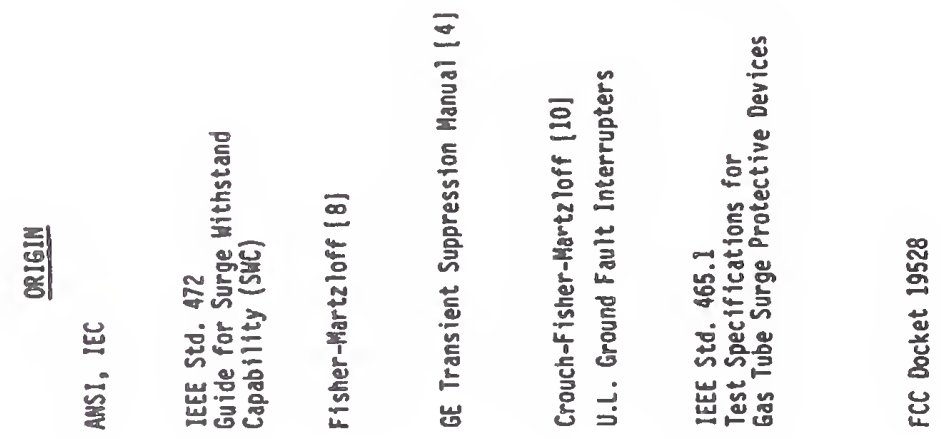

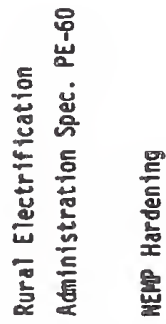

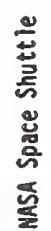


nature of the transient following breakdown is not of much concern. The typical test piece is of high impedance (except after breakdown), and thus does not load the generator. People have tended to over look the source impedance of the generator, even in applications where that impedance is important.

However, with the development of voltage suppression devices, the source impedance becomes an integral part of the suppression scheme. Some types of devices (spark gaps) function by switching into a low impedance state and reflecting the energy associated with the transient back from whence it came. Other devices (varistors, selenium, and Zener type diodes) clamp the voltage across their terminals while conducting the surge current and thus dissipate the surge energy in the protective device. The ability of the device to handle that energy becomes of importance. In either case, the test generators must be capable of supplying an appropriate amount of current, but should not supply too much current.

Test specifications should reflect the fact that, in some cases, voltage is the appropriate measure of the transient, and in other cases current is the appropriate measure. Above all, they must avoid wording that leads the inexperienced to struggle valiantly, with everlarger surge generators, to develop a specified voltage across a correctly functioning spark gap or varistor. This has occurred.

In the original formulation of the TCL concept, the authors proposed, and still do propose, that the generator impedance associated with the $100 \mathrm{kHz}$ oscillatory test wave be an impedance representative of that measured on $a-c$ supply mains. Such an impedance can be represented as 50 ohms in parallel with 50 micro-

The ANSI specifications dealing with the long-established $1.2 \times 50$ us unidirectional wave do not treat source impedance directly, but recognize its existence by providing a separate current test wave for surge arresters or other surge protective devices. In the TCL concept as we now visualize it, this same approach would be followed: separate voltage and current levels.

One of the applications where the $10 \times$ 1000 us unidirectional test wave might be appropriate would be those involving switching of inductive circuits. The impedance associated with such transients can vary over wide limits and may be quite low. We do not feel there is yet a sufficient engineering consensus as to what a suitable standard source impedance might be. Accordingly, we made no recommendations for such impedance, feeling that the evaluation of such impedance must be done on an individual basis for the specific application at hand.

\section{Selection of specific levels}

The task of selecting the transient control level appropriate for any one piece of equipment, or any one application, is one of engineering and cannot be fully dealt with in this paper. However, some discussion of the task is necessary to show how that task fits into the overall TCL philosophy. The BIL system provides some guidance. A fundamental tenet of the BIL system is that the insulation structure of apparatus is not designed until after the required insulation level is agreed upon, and that this insulation level is not chosen until one is sure that there are voltage-limiting devices (surge arresters) that can control natural transients to levels lower than those to which the factory proof test will subject the apparatus under design.

On the other hand, low-voltage and electronic equipment is all too often designed without consideration of transients or whether protective devices might even be available if needed. One guideline is then that equipment should not be designed until an appropriate design level has been chosen. This choice should be made after consideration of the distribution of naturally occurring transients.

The occurrence of transients is a statistical process, both in voltage levels and energy content. Low levels are common while high levels occur rarely. Figure 3 shows the relationship between voltage level and frequency of occurrence on 120-volt residential circuits, from observations made in the United States [9]. While this type of information cannot serve to predict the occurrences at individual locations, it is of interest if one is concerned with the overall statistics of transients. For instance, a manufacturer can select a withstand level (or conversely, a fallure level) by trading off the tangible and intangible cost of failures for the cost of the added protection required to achieve that level. From the graph of Fig. 3, we can see that decreasing the withstand level from, say, 4 $\mathrm{kV}$ to $2 \mathrm{kV}$ is likely to increase the failure rate of a product by a factor of 10 .

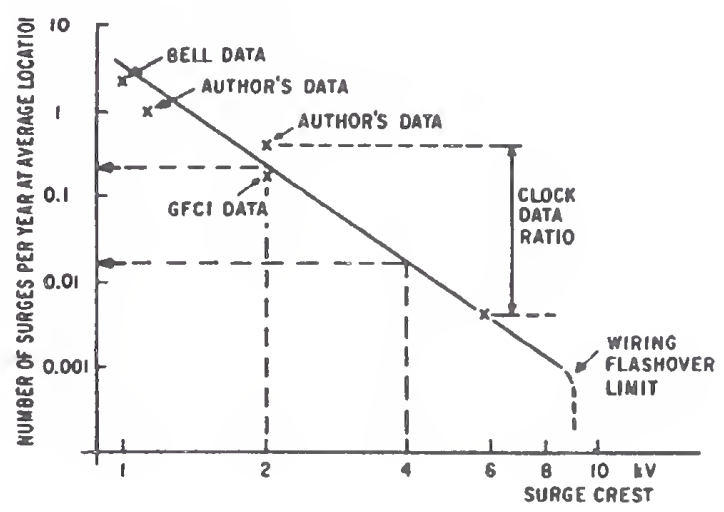

Fig. 3: Exposure of residential circuits to surges (number of surges vs highest surge at any one location)

Selection of the most appropriate level for a specific application should remain the prerogative of the parties directly interested. This choice will be based on a number of factors such as the circuit rated voltage, the exposure of the circuit to induced transients, the presence or absence of a mandatory suppressor in the circuit, the risk analysis (probability of failure, consequence of a fallure, cost-trade off), etc. 
TABLE II - PROPOSED IMPULSE LEVELS BY IEC-TC 28A

\begin{tabular}{|c|c|c|c|c|c|c|c|c|}
\hline \multicolumn{4}{|c|}{ Rated Volrages } & \multicolumn{5}{|c|}{$\begin{array}{l}\text { Preferred Serles of Impulse } \\
\text { Withstand Voltages in Volts }\end{array}$} \\
\hline \multirow{2}{*}{$\begin{array}{l}\text { Line-to- } \\
\text { Earth } \\
\text { Up to } \\
\text { Volts }\end{array}$} & \multirow{2}{*}{$\begin{array}{l}\text { 1-phase } \\
\text { or d.c. } \\
L \text { ine-to- } I \text { ine } \\
L-M \text { or } L-L \\
\text { Up to } \\
\text { Volts }\end{array}$} & \multirow{2}{*}{$\begin{array}{l}\text { 3-Phase } \\
L-N \text { or } L-L \\
\text { Up to } \\
\text { Volts }\end{array}$} & \multirow{2}{*}{$\begin{array}{l}\text { System Voltages } \\
\text { According to } \\
\text { IEC-Pub1. } 38 \\
\text { Volts }\end{array}$} & \multicolumn{5}{|c|}{ Category } \\
\hline & & & & I & II & III & IV & $v$ \\
\hline 80 & $75-150$ & & & 500 & 800 & 1200 & 2000 & 3000 \\
\hline 150 & $150-300$ & $150 / 250$ & $\begin{array}{l}120 / 220 / 240 \\
1-\text { phase d.c. } \\
110 / 220 \text { d.c. }\end{array}$ & 800 & 1200 & 2000 & 3000 & 5000 \\
\hline 300 & $300-600$ & $300 / 500$ & $\left.\begin{array}{l}220 / 380 \\
240 / 415 \\
277 / 480\end{array}\right\}$ phase & 3200 & 2000 & 3000 & 5000 & 8000 \\
\hline 600 & $600-1200$ & $600 / 1000$ & $\begin{array}{r}660 \text { ' } 3- \\
1000\end{array}$ & 2000 & 3000 & 5000 & 8000 & 12000 \\
\hline
\end{tabular}

Note: The values of impulse withstand voltage given in columns I through $V$ are a preferred series of values to be used by the Technical Committees for the purpose of insulation coordination. Products subjected in the field to the same conditions of overvoltages or rated to withstand the same overvoltages are to be assigned values from the same column. While it might be useful to describe products and specify a preferred column for such products, SC $28 \mathrm{~A}$ has refrained from doing so.

An example of such a selection process is found in current proposals of IEC $28 \mathrm{~A}$ for lowvoltage insulation coordination. This proposal includes a matrix of voltage levels depending on one hand on the system voltage and on the other hand on a level category, which is left to the users to choose but implies some recognition of exposure factors. This proposed table is reproduced here as Table II with the permission of the IEC TC 28A Chairman.

\section{Conclusion and Recommendation}

Acceptance of the TCL concept by manufacturers and users of equipment, as well as standardizing and regulatory agencies, would be a great step toward simplification of specifications and toward more reliable system performance.

This paper has incorporated the feedback received after several proposals made at IEEE meetings, and at this point represents the position of the authors, supported and amended by the comments received. Further feedback from the EMC community is earnestiy invited and welcome.

To summarize our proposal, we recommend consideration and eventual acceptance of the following:

1. Major voltage levels of 300,600 , and 1250 volts, with intermediate levels of 450,850 , and 2000 volts used if necessary; the levels to be scaled upwards or downwards by the appropriate powers of ten.

2. A voltage wave shape of $0.5 \mu \mathrm{s}$ rise $\times 100 \mathrm{kHz}$ ring with current related to voltage by a source impedance of $50 \Omega$ and $50 \mu \mathrm{H}$. This wave shape would be supplemented by $1.2 \times 50 \mu \mathrm{s}$ and $10 \times 1000$ us unidirectional waves.

3. All terminals, power and signal, are to be subjected to TCL tests.

4. For any particular piece of equipment, an appropriate level would be chosen from the above series, by mutual agreement between supplier and user.

\section{References}

1. Fisher, F.A. and Martzloff, F.D., "Transient Control Level Philosophy and Implementation; Part II. Techniques and Equipment for Making TCL Tests," Proceedings, 2nd EMC Symposium, June 1977.

2. Speranza, P.D. and Sessler, L.H. (Bell Telephone Laboratories), Oral Communication to NEMA, Ground Fault Protection Section, Aug. 1973.

3. Martzloff, F.D. and Hahn, G.J., "Surge Voltages in Residential and Industrial Power Circuits."

4. Transient Voltage Suppression Manual, General Electric Company, Electronics Park, Syracuse, N.Y., 1976.

5. Lerstrup, K., "Atmospheric Overvoltages on Low-voltage Installations," Document EIC28A/WG1 02/76.

6. IEEE Standard 465.1, "Test Specifications for Gas Tube Surge Protective Devices," 1977.

7. Rural Electrification Administration (REA) Specification PE-60, Washington, DC, 20250.

8. Bul1, J.H., "Impedance of the Supply Mains at Radio Frequencies, "Proceeding 1st EMC Symposium, 1975.

9. Fisher, F.A. and Martzloff, F.D., "Transient Control Levels, a Proposal for Insulation Condination in Low-voltage Systems," IFEF Trans. Power Apparatus System PAS-95 No. 1, 120-129 (Jan.-Feb. 1976).

10. Crouch, K.E., Fisher, F.A. and Martzloff, F.D. "Transfent Control Levels, A Better Way to Voltage Ratings in Power Converter App lications, Proceedings of 1976 Annual Meeting of the IEEE Industry Application Society. 


\title{
A Guideline on Surge Voltages in AC Power Circuits Rated up to $600 \mathrm{~V}$
}

\author{
François Martzloff \\ General Electric Company \\ Schenectady NY \\ f.martzloff@ieee.org
}

Reprinted, with permission, from

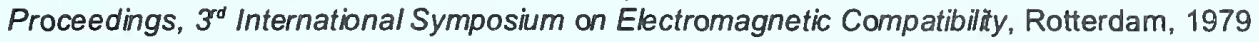

\section{Significance:}

Part 2 Development of standards - Reality checks

Progress report to the European EMC community on the development of what became IEEE Std 587-1980.

Explains the proposition that a Ring Wave should be added to the traditional unidirectional impulses

NOTE: A parallel paper was presented to the 1979 IEEE PES community at the Summer Power Meeting under the title "The Development of a Guideline on Surge Voltages in Low-Voltage AC Power Circuits". 
$\varnothing$ 


\title{
A GUIDELINE ON SURGE VOLTAGES IN AC POWER CIRCUITS RATED UP TO $600 \mathrm{~V}$
}

\author{
F.D. Martzloff \\ General Electric Company \\ Corporate Research and Development \\ Schenectady, New York 12345, U.S.A.
}

\section{Summary}

Surge voltages occurring in ac power circults can be the cause of misoperation or product failure for residentia as well as industrial systems. The problem has received increased attention in recent years because miniaturized solid state devices are more sensitive to voltage surges (spikes and translents) than were their predecessors.

Although surge voltage amplitudes and their frequency of occurrence on unprotected circuits are wel known, their waveshapes and energy content are less well known. On the basis of measurements, statistics, and theoretical considerations, a practical guldeline for outllning the environment for use in predicting extreme waveshapes and energy content can nevertheless be established. The Surge Protective Device Cornmittee of the Institute of Electrical and Electronics Englneers has been developing such a guldeline, the essential elements of which are presented in this paper.

Surge voltages [1] occurring in ac power circuits rated up to $600 \mathrm{~V}$ can be represented by various waveshapes in an attempt to duplicate actual surge voltages. Two major types of surges reflecting differences in the environment are described to represent the situation realistically.

Systems located Inside a building and separated from the overhead lines by some line impedance experience surge voltages of waveshapes and energy levels that differ from those of the outdoor environment. Outside systems. exposed to direct lighening strlkes or lightning-induced surges-typically overhead lines-experience levels implied by IEEE standards for secondary arresters. This guideline addresses particularly the hazards to these two types of systems [2].

\section{Scope}

The guideline presented here primarily addresses ac power circuits with rated voltages up to $600 \mathrm{~V}$, although some of the conclusions offered could apply to higher voltages and also to some dc power systems. Other standards have been established, such as IEEE 472, Gutde for Surge Withstand Capability (SWC) Tests, intended for the special case of high-voltage substation environments, and IEEE 28, Standard for Surge Arresters for ac Power Circults, covering primarily the utilities environment. The guideline presented here intends to complement, not conflict with, existing standards, and to present a practical proposal for the selection of vol tage and current tests to be applied in evaluating the surge withstand capability of equipment connected to these power circuits, primarlly in residential and light industrlal applications.

Some guidance is also presented on how to proceed from the environment description to the selection of "standard" test waves.

The surge voltages [1] considered in this guideline aré those exceeding two per unit (or iwlce the peak operating voltage) and having durations panging from a fraction of a microsecond to a millisecond. Overvoltages of less than two per unit are not covered here, nor are transients of longer duration resulting from power equipment operation and failure modes. Because these lowamplitude and long-duration surges are generally not amenable to suppression by conventional surge protective devices, they require different protection techniques.

\section{The Origin of Surge Voltages}

Surge voltages occurring in low-voltage ac power circuits originate from two major sources: load switching transients and direct or indirect llghtning effects on the power system. Load switching transients can be further dlvided into transients associated with (1) major power system switching disturbances, such as capacitor bank switching: (2) minor swltching near the point of interest, such as an appllance turnoff in a household or the turnoff of other loads in an individual system; (3) resonating circuirs associated with switching devices, such as thyristors; and (4) various system faults, such as short circuits and arcing faults. Measurements and calculations of lightning effects have been made to yield data on what levels can be produced, even if the exact mechanism of any partlcular surge is unknown. The major mechanisms by which lightning produces surge voltages are the foilowing:

(a) A direct lightning strike to a primary circuit injects high currents into the primary circuit, producing voltages by either flowing through ground resistance or flowing through the surge impedance of the primary conductors.

(b) A lightning strike that misses the line but hits a nearby object sets up electromagnetic fields which can induce voltages on the conductors of the primary circuit.

(c) The rapid collapse of voltage that occurs when a primary arrester operates to limit the primary voltage couples effectively through the capacitance of the transformer and produces surge voltages in addition to those coupled into the secondary circuit by normal transformer action.

(d) Lightning strikes the secondary circuits directly. very high currents can be involved, exceeding the capability of conventional devices.

(e) Lightning ground current flow resulting from nearby direct-to-ground discharges couples onto the common ground impedance paths of the grounding network.

Fast-acting protection devices, such as currentlimilng fuses and clrcuit breakers capable of clearing or beginning to part contacts in less than $2 \mathrm{~ms}$, leave trapped inductive energy in the circuit upstream: upon rollapse of the field, very high voltages are generated.

Transient overvoltages [1] associated with the switching of power factor correction capacitors have lower frequencles than the high-frequency spikes with which this document is concerned. Their levels, at least in the case of 
restrike-free switching operations, are generally less than twice normal voltage and are therefore not of substantial concern here, but should not be overlooked.

On the other hand, switching operations involving restrikes, such as those produced by air contactors or mercury switches, can produce, through escalation, surge voltages of complex waveshapes and of amplitudes several times greater than the normal system voltage. The severest case is generally found on the load side of the switch and involves only the device that is being switched. While this situation should certainly not be ignored, in such a case the prime responsibility for protection rests with the local user of the device in question. However, switching transients can also appear on the line side across devices connected to the line. The presence and source of transients may be unknown to the users of those devices. This potentially harmful situation occurs often enough to command attention.

\section{Occurrence and Voltage Levels in Unprotected Circuits}

\subsection{Rate of Occurrence Versus Voltage Level}

The rate ol occurrence of surges varies over wide limits, depending on the particular system. Prediction of the rate for a particular system is always difficult and frequently impossible. Rate is related to the level of the surges; low-level surges are more prevalent than high-level surges [ 3]. Data collected from many sources (Appendix I) have led to the plot shown in Figure 1. This prediction shows with certainty only a relative frequency of occurrence, while the absolute number of occurrences can be described only for an "average location." The "high exposure" and "low exposure" limits of the band are shown as a guide, not as absolute limits [2], to reflect both the location exposure (lightning activity in the area and the nature of the system) and the exposure to switching surges created by other loads. Such data are useful in that they describe the maximum levels likely to be encountered and give some estimate of the rate of occurrence of such surges. Of equal importance is the observation that surges in the range of 1 to $2 \mathrm{kV}$ are fairly common in residential circuits.

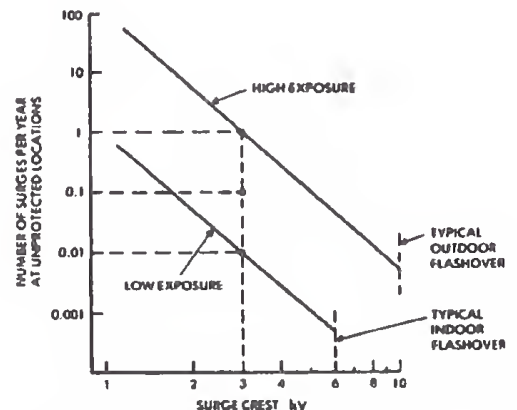

Figure 1. Rate of Surge Occurrence vs Voltage Level

From the relative values of Figure 1, two typical levels can be cited for practical applications. First, the expectation of a $3 \mathrm{kV}$ transient occurrence on a $120 \mathrm{~V}$ circuit ranges from 0.01 to 1 per year at a given location a number sufficiently high to justify the recommendation of a minimum $3 \mathrm{kV}$ withstand capability. Second, the wiring flashover limits indicate that a $6 \mathrm{kV}$ withstand capability may be sufficient to ensure device survival indoors, but a $10 \mathrm{kV}$ withstand capability may be required outdoors.

\subsection{Timing of Occurrence}

Surges occur at random times with respect to the power frequency, and the failure mode of equipment may be affected by the power frequency follow current. Furthermore, the timing of the surge with respect to the power frequency may affect the level at which failure occurs [4]. Consequently, surge testing must be done with the line voltage applied to the test piece.

\section{Waveshape of Representative Surge Voltages}

\subsection{Waveshapes in Actual Occurrences}

Indoor - Measurements in the field, measurements in the laboratory, and theoretica! calculations indicate that most surge voltages in indoor low-voltage systems have oscillatory waveshapes, unlike the wellknown and generally accepted unidirectional waves specified in high-voltage insulation standards. A surge impinging on the system excites the natural resonant frequencies of the conductor system. As a result, not only are the surges typically oscillatory, but surges may have different amplitudes and waveshapes at different places in the system. These oscillatory frequencies of surges range from $5 \mathrm{kHz}$ to more than $500 \mathrm{kHz}$. A 30 to $100 \mathrm{kHz}$ frequency is a realistic measure of a "typical" surge for most residential and light industrial ac line networks.

Outdoor-Surges encountered in outdoor locations have also been recorded, some being oscillatory [5], others. being unidirectional. Because the overriding concern here is the energy associated with these surges, a conservative but realistic description of the surges can be derived from the long-established specified duty of a secondary arrester, as detailed in Paragraph 3.2. While this specification is arbitrary, it has the strength of experience and successful usage.

\subsection{Selection of Representative Waveshapes}

The definition of a waveshape to be used as representative of the environment is important for the design of candidate protective devices, since unrealistic requirements, such as excessive duration of the voltage or very low source impedance, place a high energy requirement on the suppressor, with a resulting cost penalty to the end user. The two requirements defined below reflect this trade-of1.

Indoor - Based on measurements conducted by several independent organizations in 120 and $240 \mathrm{~V}$ systems (Appendix 1), the waveshape shown in Figure 2 is reasonably representative of surge voltage in these power circuits. Under the proposed description of a "0.5 us $\times 100 \mathrm{kHz}$ ring wave," this waveshape rises in $0.5 \mathrm{us}$, then decays while oscillating at $100 \mathrm{kHz}$, each peak being about $60 \%$ of the preceding peak.

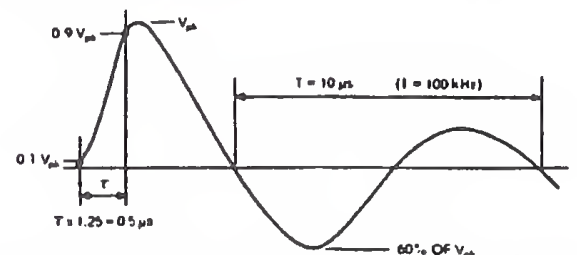

Figure 2. The Proposed 0.5 us $\times 100 \mathrm{kHz}$ Ring Wave (Open-circuit Voltage)

The fast rise can produce the effects associated with nonlinear voltage distribution in windings and the dv/dt effects on semiconductors. Shorter rise times are found in many transients, but, as those transients propagate into the wiring or are reflected from discontinuities in the wiring, the rise time becomes longer.

The oscillating and decaying tail produces the effects of voltage polarity reversals in surge suppressors or other devices that may be sensitive to polarity changes. Some semiconductors are particularly sensitive to damage when being forced into or out of a conducting state, or when the transient is applied during a particular portion of the $6 \cap \mathrm{Hz}$ supply eycle (Appendix II). The response of a surge suppressor can also be affected by reversals in the polarity, as in the case of $\mathrm{RC}$ attenuation before a rectifier circuit in a dc power supply. 
The pulse withstand capability of many semiconductors tends to improve if the surge duration is much shorter than one microsecond. For this reason, the first half-cycle of the test wave must have a sufficient duration.

Outdoor - In the outdoor and service entrance environment, as well as in locations close to the service entrance, substantial energy, or current, is still available. For these locations, the unidirectional impulses long established for secondary arresters are more appropriate than the oscillatory wave.

Accordingly, the recommended waveshape is $1.2 \times$ 50 us for open-circuit voltage and $8 \times 20 \mu \mathrm{s}$ for short-circuit current or current in a low-impedance device. The numbers used to describe the impulse, $1.2 \times 50$ and $8 \times 20$, are as defined in IEEE Standard 28 - ANSI Standard C62.1; Figure 3 presents the waveshape and a graphic description of the numbers.
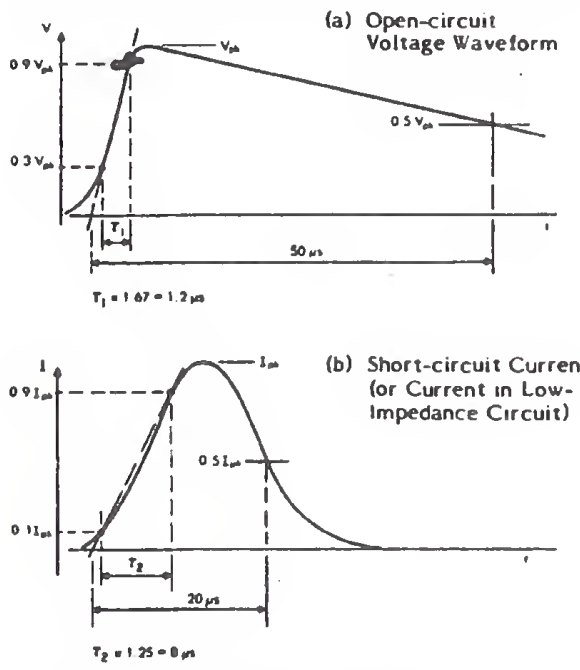

Figure 3. Waveshapes for Outdoor Locations

\section{Energy and Source Impedance}

\subsection{General}

The energy involved in the interaction of a power system with a surge source and a surge suppressor will divide between the source and the suppressor in accordance with the characteristics of the two impedances. In a gaptype suppressor, the low impedance of the arc after sparkover forces most of the energy to be dissipated elsewhere: for instance, in a power-follow current-limiting resistor that has been added in series with the gap. In an energy-absorber suppressor, by its very nature, a substantial share of the surge energy is dissipated in the suppressor, but its clamping action does not involve the power-follow energy resulting from the short-circuit action of a gap. It is therefore essential to the ef fective use of suppression devices that a realistic assumption be made about the source impedance of the surge whose effects are to be duplicated.

The voltage wave shown in Figure 2 is intended to represent the waveshape a surge source would produce across an open circuit. The waveshape will be different when the source is connected to a load having a lower impedance, and the degree to which it is lower is a function of the impedance of the source [6].

The degree to which source impedance is important depends largely on the type of surge suppressors that are current passed through them by the surge source. A test generat or of too high an impedance may not subject the device under test to sufficient stresses, while a generator of too low an impedance may subject protective devices to unrealistically severe stresses. A test voltage wave specified without reference to source impedance could imply zero source impedance - one capable of producing that voltage across any impedance, even a short circuit. That would imply an infinite surge current, clearly an unrealistic situation.

\subsection{Proposed Approach}

Because of the wide range of possible source impedances and the difficulty of selecting a specific value, three broad categories of building locations are proposed to represent the vast majority of locations $[7,8 \mathrm{~h}$ from those near the service entrance to those remote from it. The source impedance of the surge increases from the outside to locations well within the building. Open-circuit voltages, on the other hand, show little variation within a building because the wiring provides little artenuation [9]. Table 1 outlines the three categories of building wiring.

Table 2 shows open-circuit vol tages and short-circuit currents for each of the three categories. The energy deposited in a $500 \mathrm{~V}$ suppressor has been computed and is shown for each of the categories.

\section{TABLE I}

Location Categories

A. Oulside and Service Enirance

Service drop from pole to building entitance Run between meter and distribution paney Overhead line to detached bulldings

Underground lines to well pumps

B. Major Feeders and Short Branch Circuits Distribution panel devices

Bus and feeder systems in industrial planis Heavy appliance ourlets with "shor q" $^{\text {connections }}$ to the service enirance

Lighting systems in commercial buildings

C. Outlets and Long Branch Circuirs

All outlets at more than $10 \mathrm{~m}(30 \mathrm{ft})$ from Category B with wires $14-10$

All oullets at more than $20 \mathrm{~m}(60 \mathrm{ft})$ from Category A with wires 14.10

\section{TABLE 2}

Ranges of Voltage and Currents

\begin{tabular}{|c|c|c|c|}
\hline & Location & $\begin{array}{c}\text { Maximum } \\
\text { impulse }\end{array}$ & $\begin{array}{c}\text { Energy Depos- } \\
\text { ited in a s00 V } \\
\text { Suppressor }\end{array}$ \\
\hline A. & $\begin{array}{l}\text { Outdoor and } \\
\text { Service } \\
\text { Entrance }\end{array}$ & $\begin{array}{l}\text { - } 10 \mathrm{kV} 1.2 \times 50 \text { us for } \\
\text { high-1mpedance circuits } \\
\text { - } 10 \mathrm{kA} 8 \times 20 \text { us for } \\
\text { low-impedance circuits }\end{array}$ & 150 \\
\hline B. & $\begin{array}{l}\text { Major Feeders } \\
\text { and Short } \\
\text { Branch } \\
\text { Circults }\end{array}$ & $\begin{array}{l}\text { - } 6 \mathrm{kV} 1.2 \times 50 \text { us for } \\
\text { high-impedance carcuits } \\
\text { - } 3 \mathrm{kA} 8 \times 20 \mathrm{Hs} \text { for } \\
\text { Impedance circuits }\end{array}$ & 40 \\
\hline & 、 & $\begin{array}{l}\text { - } 6 \mathrm{kV} 0.5 \mu \mathrm{s} \times 100 \mathrm{kHz} \\
\text { for high-impedance curcuits } \\
\text { - } 500 \text { A short circuit for } \\
\text { low-impedance circuits }\end{array}$ & s \\
\hline c. & $\begin{array}{l}\text { Long Branch } \\
\text { Circuits and } \\
\text { Outlets }\end{array}$ & $\begin{array}{l}\text { - } 6 \mathrm{kV} 0.5 \text { us } \times 100 \mathrm{kHz} \text { for } \\
\text { high-impedance circuits } \\
\text { - } 200 \text { A short circuit for } \\
\text { low-impedance circuits }\end{array}$ & 0.8 \\
\hline
\end{tabular}

Tie values slruwil ill the table represeit the midxlutun range, corresponding to the "High Expusure" situation of Figure 1. For less exposed systems, or when the prospect of a failure is not highly objectionable, one could specify lower values of open-circuit voltages with corresponding reductions in the currents. 


\section{Conclusion}

The broad range of surge voltages occurring in lowvoltage ac power circuits can be simulated by a limited set of test waves, for the purpose of evaluating their effects on equipment.

Field measurements, laboratory experiments, and calculations indicate that two basic waves, at various opencircuit voltages and short-circuit current values, can represent the majority of surges occurring in residential, commercial, and light industrial power systems rated up to $600 \mathrm{~V}$ rms.

Exceptions will be found to the simplification of a broad guideline; however, these should not detract from the benefits that can be expected from a reasonably valid uniformity in defining the environment. Other test waves of different shapes may be appropriate for other purposes, and the present guideline should not be imposed where it is not applicable.

\section{Acknowledgments}

The members of the IEEE Working Group contributed the data, shown in Appendix $\mathrm{I}$, that shaped this guideline. Helpful comments, discussions, and reviews by all members of the Surge Protective Devices Committee are also acknowledged. The author is particularly indebted to the contributions of Catharine Fisher and Peter Richman for the presentation and discussion of the concepts and recommendations made in this guideline.

\section{Appendix 1 - Data Base}

Recordings and surge counter data have been contributed from several sources, in addition to the surge counter data obtained by members of the working group. Representative oscillograms and summary statistics are reproduced in this appendix, in support of the voltage levels and oscillatory wave proposals.

\section{Recordings by Bell Telephone Laboratories}

(Data contributed by $P$. Speranza, internal report, unpublished to date)

1.1 Typical Surge Counter Statistics

$120 \mathrm{~V}$ line at BTL facility in Chester, New Jersey, during 42 months of monitoring:

146 counts at 300 to $500 \mathrm{~V}$

14 counts at 500 to $1000 \mathrm{~V}$

3 counts at 1000 to $1500 \mathrm{~V}$

3 counts above $1500 \mathrm{~V}$

\subsection{Typical Automatic Recording Oscilloscopes}

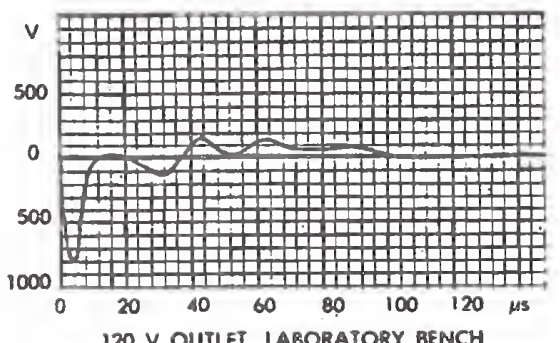

$120 \mathrm{~V}$ OUTLET. LABORATORY BENCH

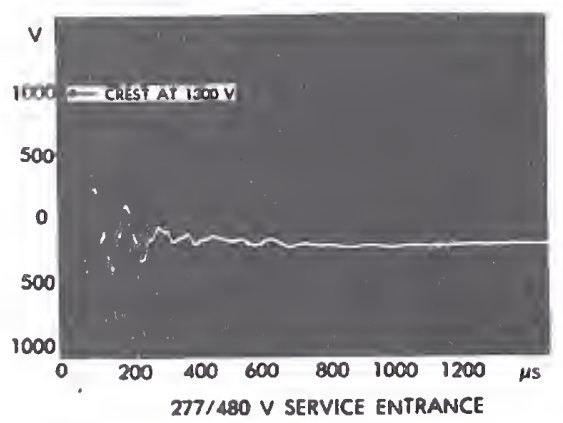

\section{Recordings by General Electric Company}

(Data contributed by F.D. Martzloff (2))

2.1 Surge Counter Statistics

a) Three percent of all U.S. residences experience frequent occurrences (one per week or more) above $1200 \mathrm{~V}$

b) There is a 100:1 reduction in the rate of device failure when the withstand level is raised from $2 \mathrm{kV}$ to $6 \mathrm{kV}$.

2.2 Typical Automatic Recording Oscilloscopes

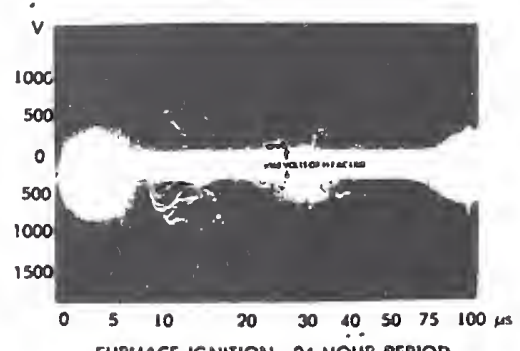

FURUACE IGNHION 24 MOUR PERIOD

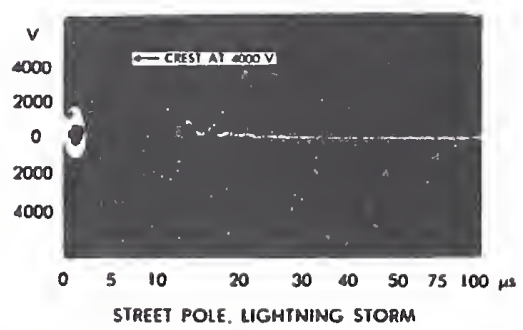

2.3 Simulated Lightning Strokes on a Residential Power Circuit (Laboratory Model of System) T?

$1.5 \mathrm{kA}$ current impulse $(8 \times 20 \mu \mathrm{s}$ approx.) is injected in ground wire
only of service drop. (Higher currents produce flashover of wiring)

$$
500 \mathrm{~A} / \mathrm{div}
$$

5 us/div

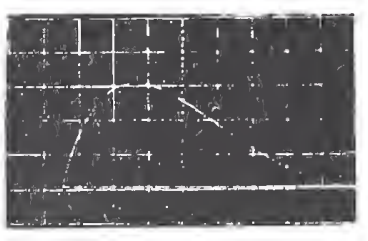

Recording of open-circuit voltage at a branch circuit outlet: $2200 \mathrm{~V}$ peak $500 \mathrm{kHz}$ oscillations

$500 \mathrm{~V} / \mathrm{div}$

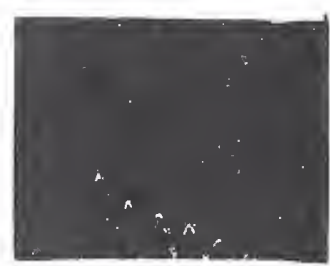

By connecting a $130 \Omega$ load at the same outlet (1 A load) the voltage is reduced to $1400 \mathrm{~V}$ peak, with more damping.

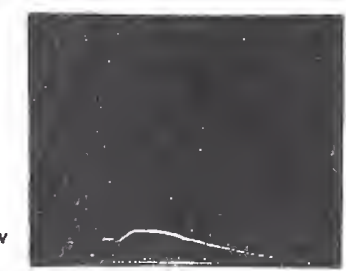

Conclusions From This Test Series

1. A current of $1.5 \mathrm{kA}$ (moderate for a lightning discharge injected in the ground system) raises the wiring system or the nouse $2.2 \mathrm{KV}$ adove ground. Four kiloamperes (still a moderate value) will bring this voltage to $6 \mathrm{kV}$, the typical flashover value of the wiring.

2. A natural frequency of $500 \mathrm{kHz}$ is excited by a unidirectional impulse. 
3. In this example, the source of the transient (from the loading effect of $130 \Omega$ ) appears as $Z=130 \Omega\left[\frac{2200}{1400}\right]-1=75 \Omega$

3. Statistics By Landis and Gyr Company

Surge counter data on various locations in Swiss $220 \mathrm{~V}$ systems (Data contributed by L. Regez - unpublished to date)

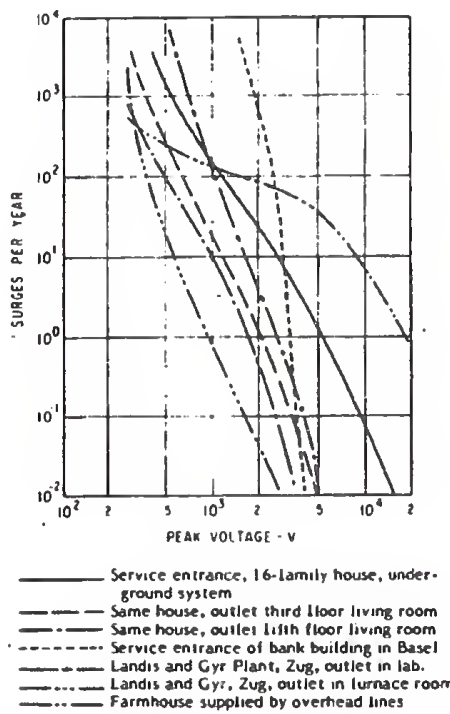

4. Working Group Surge Counter Statistics

Surge counters with four threshold levels $(350,500$, 1000 , and $1500 \mathrm{~V}$ ) were used to record surge occurrences at various locations. Members of the Working Group installed these on 120 and $240 \mathrm{~V}$ systems of various types, including the following: outlets in urbari, suburban, and rural residences; outlets in a hospital; secondary circuits on distribution system poles (recloser controls); secondary of pad-mounted distribution transformers; lighting circuits in an industrial plant; life test racks at an appliance manufacturer; bench power supply in a laboratory.

Summary Statistics of these measurements are as follows:

1. Data base from 18 locations with a total recording time of 12 years spread over 4 calendar years, using 6 counters.

2. Number of occurrences per year (weighted averages) at "average location."

- 350 V: 22

- $500 \mathrm{~V}: 11$

- $1000 \mathrm{~V}: 7$

- $1500 \mathrm{~V}: 3$

3. Significant extremes

- One home with large number of surges caused by washer operation.

- Four locations out of 18 never experienced a surge.

- One home experienced several occurrences above $1500 \mathrm{~V}$, with none below that value.

- One industrial location (switching of a test rack) produced thousands of surges in the 350-500 V range, and several surges in excess of $1500 \mathrm{~V}$. This location was left out of the average computation, but it exemplifies a significant extreme.

From the data base cited in the preceding pages, one can draw the chart below, including the following information on voltage vs frequency (rate) of occurrence:

1. The Bell Laboratories data yield a point of $1000 \mathrm{~V}$ at about 2 occurrences per year $(\cdot)$.
2. The General Electric counter statistics yield a point of $1200 \mathrm{~V}$ at about 1 occur rence per year $(x)$.

3. The General Electric clock data indicate a slope of 100:I from $2 \mathrm{kV}$ to $6 \mathrm{kV}(-\ldots-)$.

4. The Regez data provide a band for the majority of locations (shown cross-hatched), with the exception of the rural location with long overhead line, which has more occurrences.

5. Working Group statistics (. .. . .-) indicate a less steep slope, perhaps because of the influence of outdoor locations included in the sample (similar to the rural data of Regez).

The proposed curve, which is the center of the \pm 10 range of Figure 1 , is shown in bold dashed lines (- - - ) It has been drawn at the 100:1 slope, passing near the Bell and General Electric points and located within the band of the Regez data.

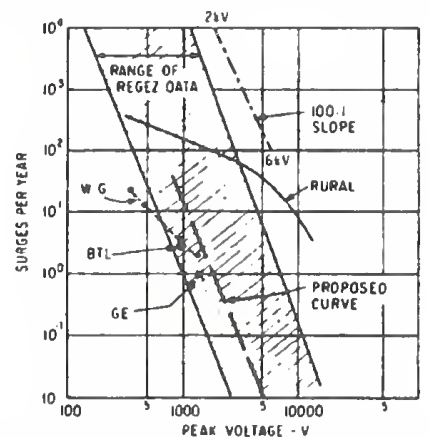

Appendix II - Effect of Transient Polarity Reversals on Semiconductors

Breakdown of semiconductors under various conditions of load and transient overvoltage applications has been investigated.t Evidence is presented in the two investigations cited that a reverse voltage applied during the conduction period of the power frequency produces lower breakdown voltages than the application of the same transient with no load or during blocking. Examples are given below, taken from these two investigations, showing statistically significant differences in the vol tage levels.

\begin{tabular}{|c|c|c|}
\hline & & $\begin{array}{l}\text { verage } \\
\text { kdown (V) }\end{array}$ \\
\hline IN1190 Diode* & $\begin{array}{l}\text { Transient at no load } \\
\text { Fast wave under load } \\
\text { Slow wave under load }\end{array}$ & $\begin{array}{r}1973 \\
830 \\
1097\end{array}$ \\
\hline IN2160 Diode" & $\begin{array}{l}\text { Transient at no load } \\
\text { Fast wave under load } \\
\text { Slow wave under load }\end{array}$ & $\begin{array}{r}2056 \\
894 \\
1106\end{array}$ \\
\hline IN679Diodet & $\begin{array}{l}\text { Transient applied at: } \\
- \text { peak of reverse voltage } \\
-25^{\circ} \text { after start of conduction } \\
-90^{\circ} \text { after start of conduction } \\
-155^{\circ} \text { after start of conduction }\end{array}$ & $\begin{array}{r}1766 \\
1181 \\
906 \\
1115\end{array}$ \\
\hline
\end{tabular}

This effect is one of the reasons for selecting an oscillatory waveform to represent the environment: it will be more likely to induce semiconductor failures than a - unidirectional wave. Also, it shows the significance of the timing of the transient application with respect to the power frequency cycle.

\section{Appendix 111 - Notes and References}

\section{Surge Voltage}

Definitions of terms used in this guideline are consistent with IEEE Standard 100-1977, Dictionary of Electrical and Electronic Terms, 2nd ed.; however, some differences exist. For instance, IEEE Std 100-1977 defines a surge as a "transient wave of current, potential or power in the electric circuit"--a definition broader than that used "Chowdhuri, P., "Transient-Vol tage Char acteristics of Silicon Power Rectifiers," IEEE IA-9, 5, September/ October 1973, p. 582.

+F.D. Martzloff, internal report, unpublished. 
here. Transient overvoltage is defined as "the peak voltage during the transient condition resulting from the operation of a switching device"-a definition more restricted than that of the present guideline.

\section{Amplitudes of Strikes, Worst Case}

The surge voltages described in this guideline include lightning effects on power systerns, mostly strikes in the vicinity of a power line, or at a remote point of the power system. The literature describes the frequency of occurrence vs amplitude of lightnIng strikes, from the low levels of a few kiloamperes, through the median values of about $20 \mathrm{kA}$, to the exceptional values in excess of $100 \mathrm{kA}$ Clearly, a secondary arrester rated for $10 \mathrm{kA}$ can protect adequately in case of a mild direct strike, or of a more severe strike divided among several paths to ground. However, a very high and direct strike will exceed the capability of an ANSI-rated secondary arrester.

\section{References:}

Cianos, N. and E.T.Pierce, A Ground-Lightning Environment for Engineering Usage, Stanford Research Institute Menlo Park, CA 94205. August 1972.

Bodle, D.W., A.J. Ghazi, M. Syed, and R.L. Woodsıde, Char acterizaiton of the Electrical Emvironment. Toronto and Buffalo, N.Y.: University of Toronto Press, 1976.

Martzloff, F.D. and G.J. Hahn, "Surge Voltage in Residential and Industrial Power Circuits," IEEE PAS-89, 6, July/ August 1970, 1049-1056.

\section{Level vs Rate of Occurrence}

The relationship between the level and the rate of occurrence of surges is partly caused by the attenuation of the surges as they propagate away from the source of the surge and divide among paths beyond branching points. Equipment at a given point will be subjected to a relatively small number of high-level surges from nearby sources, but to a larger number of surges from more remote sources.

\section{Timing of Surges with Respect to Power Frequency}

Lightning surges are completely randorn in their timing with respect to the power frequency. Switching surges are likely to occur near or after current zero, but variable load power factors will produce a quasi-random distribution. Some semiconductors, as shown in Appendix 11 , exhibit failure levels that depend on the timing of the surge with respect to the conduction of power frequency current. Gaps or other devices involving a power-follow current may withstand this power follow with success, depending upon the fraction of the half-cycle remaining after the surge before current zero. Therefore, it is important to consider the timing of the surge with respect to the power frequency. In performing tests, either complete randomization of the timing or controlled timing should be specified, with a sufficient number of timing conditions to reveal the most critical timing.

\section{Oscillatory Surges During Lightning}

The "classical lightning surge" has been established as $1.2 \times 50 \mu s$ for a voltage wave and $8 \times 20 \mu s$ for a current wave. Evidence has been collected, however, to show that oscillations can also occur. Lenz reports 50 lightning surges recorded in two locations, the highest at $5.6 \mathrm{kV}$, with frequencies ranging from 100 to $500 \mathrm{kHz}$. Martzlof 1 reports oscillatory lightning surges in a house during a multiple-stroke flash.

References:

Lenz, J.E., "Basic Impulse Insulation Levels of Mercury Lamp Ballast for Outdoor Applications," Iluminating Engrg., February 1964, Pp. 133-140.

Martzloff, F.D. and G.J. Hahn, "Surge Voltage in Residential and Industrial Power Circuit," IEEE PAS-89, 6, July/ August $1970,1049-1056$.

\section{Surge Impedance and Source Impedance}

To prevent misunderstanding a distinction between source impedance and aunge impedance needs to be made. Surge impedance, also called characteristic impedance, Is concept relating the parameters of a long line to the propagation of traveling waves. For the wiring practices of the ac power circuits discussed here, this characteristic impedance would be in the range of 150 to $300 \Omega$, but because the durations of the waves being discussed ( 50 to
$20 \mu s)$ are much longer than the travel times in the wiring systems being considered, traveling wave analyses are not useful here.

Source impedance, defined as "the impedance presented by a source of energy to the input terminals of a device, or network" (IEEE Standard 100), is a more useful concept here.

\section{Power System Source Impedance}

The measurements from which Figure I was derived were of voltage only. Little was known about the impedance of the circuits upon which the measurements were made. Since then, measurements have been reported on the impedance of power systems. Bull reports that the impedance of a power system, seen from the outlets, exhibits the characteristics of a $50 \Omega$ resistor with $50 \mu \mathrm{H}$ in parallel. Attempts were made to combine the observed $6 \mathrm{kV}$ open-circuit voltage with the assumption of a $50 \Omega 50 \mu \mathrm{H}$ impedance. This combination resulted in low energy deposition capability, which was contradicted by field experience of suppressor performance. The problem led to the proposed definition of oscillatory waves as well as high-energy unidirectional waves, in order to provide both the effects of an oscillatory wave and the high-energy deposition capability.

Reference:

Bull, J.H., "Impedance of the Supply Mains at Radio Frequencies," Proceedings of 1st Symposium on EMC. 75CH1012-4 Mont., Montreux, May 1975.

\section{Installation Categories}

Subcommittee $28 \mathrm{~A}$ of the International Electrotechnical Commission has prepared a report, referenced below, in which installation categories are defined. These installation categories divide the power systems according to the location in the building, in a manner similar to the location categories defined in this guideline. However, there are some significant differences between the two concepts. First, the IEC categories are defined for "Controlled Voltage Situation," a phrase that implies the presence of some surge suppression device or surge attenuation mechanlsm to reduce the voltage levels from one category to the next. Second, the IEC report is more concerned with insulation coordination than with the application of surge protective devices; therefore it does not address the question of the coordination of the protectors, but rather the coordination of insulation levels - that is, voltages. Source impedances, in contrast to this guldeline, have not been defined. Further discussion and work toward the application guidelines of both documents should eventually produce a consistent set of recommendations.

Reference:

Insulation Coordination Within Low-Voltage Systems including Clearances and Creepage Distances for Equipment, International Electrotechnical Commission, Report SC28A (Central Office) 5, to be published in 1979.

\section{Open-Circuit Voltages and Wiring Flashover}

Surges propagate with very little attenuation in a power system with no substantial connected loads. Measurements made in an actual residential system as well as in a laboratory simulation have shown that the mosi significant limitation is produced by wiring flashover, not be attenuation along the wires. Ironically, a carefully insulated installation is likely to experience higher surge voltages than an installation where wiring flashover occurs at low levels. Therefore, the open-circuit voltage specified at the origin of a power system must be assumed to propagate unattenuated far into the system, which is the reason for maintaining the $6 \mathrm{kV}$ surge specification when going from the "B" location to the "C" location.

References:

Martzloff, F.D. and K.E. Crouch "Coordination de la protection contre les surtensions dans les réseaux basse tension résidentiels," Proceedings, 1978 IEEE Canadian Conference on Communications and Power, 78CHI373-O, Pp. $431-4>4$.

Martzloff, F.D. Surge Voltage Suppression in Residential Power Circuits, Report 76CRD092, Corporate Research and Development, General Electric Company, Schenectady, N.Y., 1976. 


\title{
The Development of a Guideline on Surge Voltages in Low-Voltage AC Power Circuits
}

\author{
François Martzloff \\ National Institute of Standards and Technology \\ Gaithersburg MD 20899 USA \\ f.martzloff@ieee.org
}

Reprinted, with permission, from IEEE Paper A 79 428-4, PES Summer Meeting, Vancouver, 1979

\section{Significance:}

Part 2 Development of standards - Reality checks

Progress report to the IEEE PES community on the development of what became IEEE Std 587-1980.

Explains the proposition that a Ring $W$ ave should be added to the traditional unidirectional impulses

NOTE Parallel presentation of the subject made to the European EMC community under the title "A Guideline on Surge Voltages in AC Power circuits rated up to $600 \mathrm{~V}$ " 
(2) 
F.D. Martzloff, Member, IEEE

General Electric Company

Schenectady, N.Y. 12345

Abstract - Surge voltages in ac power circuits become more significant with the increased application of miniaturized electronics in consumer and industrial products. A Working Group of IEEE is preparing a Guideline describing the nature of these surges in ac power circuits up to $600 \mathrm{~V}$.

The paper describes the data base and approach used by the Working Group and the recommendations proposed to represent typical surges, in order to obtain feedback before the final writing of the Gujdeline.

Two waveforms are proposed, one oscillatory, the other unidirectional, depending on the location within the power system. Recommendations for source impedance or short-circuit current are also included.

\section{INTRODUCTION}

Surge voltages occurring in ac power circuits can be the cause of misoperation or product failure for residential as well as industrja systems. The problem has received increased attention in recent years because miniaturized solid state devices are more sensitive to voltage surges (spikes and transients) than were their predecessors.

Although surge voltage amplitudes and their frequency of occurrence on unprotected circuits are well known, their waveshapes and energy content are less well known. On the basis of measurements, statistics, and theoretical considerations, a practical guideline for outlining the environment for use in predicting extreme waveshapes and energy content can nevertheless be established. A Working Group of the Surge Protective Devices Committee is currently developing such a guideline; this paper reports the status of the Guideline, presents the considerations which led to the approach chosen, and provides a possible vehicle for discussion before the final writing and publication of the Guideline.

\section{$\underline{\mathrm{SCOPE}}$}

The Guideline primarily addresses ac power circuits with rated voltages up to $600 \mathrm{v}$, although some of the conclusions of fered could apply to higher voltages and also to some dc power systems. Other standards have been established, such as IEEE 472, Guide for Surge Withstand Capability (SWC) Tests, intended for the special case of high-vol tage substation envir onments, and IEEE 28, Standard for Surge Arresters for ac Power Circuits, covering primarily the utilities environment. The Guideline intends to complement, not conflict with, existıng standards.

The surge voltages considered in the Guideline are those exceeding two per unit (or twice the peak operating voltage) and having durations ranging from a fraction of a microsecond to a millisecond. Overvoltages of less than two per unit are not covered, nor are transients of longer duration resulting from power equipment operation and failure modes. Because these low-amplitude and long: duration surges are generally not amenable to suppression by conventional surge protective devices, they require different protection techniques.

Definitions of terms used in the Guideline are consistent with IEEE Standard 100-1977, Dictionary of Electrical and Electronic Terms, 2nc ed.; however, some differences exist. For instance, IEEE Std 100-1977 defines a surge as a "transient wave of current, potential or power in the electric circuit"-a definition broader than that used here. Transient overvoltage is defined as "the peak voltage during the transient condition resulting from the operation of a switching device"-a definition more restricted than that of the Guideline.

While the major purpose of the Guideline is to describe the environment, a secondary purpose is to lead toward standard tests,

\footnotetext{
A $79426-4$ A paper recorunended and approved by the IEEE Sunge Protective Devices Comrittee of the IEEE Power Engineering Society for presentation at the IFEE PES Sumer lleeting, Vancouver, British Columbia, Canada, July 15-20, 1379. Manuscript submitted February 6 1979: made available for printing April 3, 1979.
}

through an application guide that will be prepared in the future. These standard tests will provide a realistic evaluation of the surge withstand capability of equipment connected to these power circuits. Of necessity, the complex real situation must be simplified to produce a manageable set of standards. One must recognize the unavoidably arbitrary character of any standard and be prepared to accept an imper fect approach which can simplify matters, rather than demand a perfect but unattainable match between the actual situation and the standard.

\section{THE ORIGIN OF SURGE VOLTAGES}

Surge voltages occurring in low-voltage ac power carcuits originate from two major sources: load switching transients and direct or indirect lightning effects on the power system. Load switching transients can be further divided into transients associated with (i) major power system switching disturbances, such as capacitor bank switching; (2) minor switching near the point of interest, such as an appliance turnoff in a household or the turnoff of other loads in an individual system; (3) resonatıng circuits associated with switching devices, such as thyristors; and (4) various system faults, such as short circuits and arcing faults. Measurements and calculations of lightning effects have been made to yield data on what levels can be produced, even if the exact mechanism of any particular surge is unknown. The major mechanisms by which lightning produces surge vol tages are the following:

(a) A direct lightning strike to a primary circuit injects high currents into the primary circuit, producing voltages by either flowing through ground resistance or flowing through the surge impedance of the primary conductors.

(b) A lightning strike that misses the line but hits a nearby object sets up electromagnetic fields which can induce voltages on the conductors of the primary circuit.

(c) The rapid collapse of voltage that occurs when a primary arrester operates to limit the primary voltage couples effectively through the capacitance of the transformer and produces surge voltages in addition to those coupled into the secondary circuit by normal transformer action.

(d) Lightning strikes the secondary circuits direcily. Very high currents can be involved, exceeding the capability of conventional devices.

(e) Lightning ground current flow resulting from nearby direct-to-ground discharges couples onto the common ground impedance paths of the grounding network.

Fast-acting protection devices, such as current-limutıng fuses and circuit breakers capable of clearing or beginning to part contacts in less than $2 \mathrm{~ms}$, leave trapped inductive energy in the circuit upstream; upon collapse of the field, very high voltages are generated.

Transient overvoltages associated with the switching of power factor correction capacitors [1] have lower frequencies than the highfrequency spikes with which this document is concerned. Their levels, at least in the case of restrike-free switching operations, are generally less than twice normal voltage and therefore are not of substantial concern here, but should not be overlooked.

On the other hand, switching operations involving restrikes, such as those produced by air contactors or mercury switches, can produce, through escalation, surge voltages of complex waveshapes and of amplitudes several times greater than the normal system voltage. The severest case is generally found on the load side of the switch and involves only the device that is being switched. While this situation should certainly not be ignored, in such a case the prime responsibility for protection rests with the local user of the device in question. However, switching transients can also appear on the line side across devices connected to the line. The presence and source of transients may be unknown to the users of those devices. This potentially harmful situation occurs often enough to command at tention.

While the data have been recorded primarily on $120,220 / 380$, or $277 / 480 \mathrm{~V}$ systems, the general conclusions should be valid for $600 \mathrm{~V}$ systems. To the extent that si'rge voltages are produced by a discrete amount of energy being dumped into a power system, low-impedance, heavy industrial systems can be expected to experience lower peaks from surge voltages than $120 \mathrm{~V}$ residentıal systems, but comparable, or greater, amounts of energy potentially available for deposition in a surge suppressor. 


\section{Rate of Occurrence Versus Vol tage Level}

The rate of occurrence of surges varies over wide limits, depending on the particular system. Prediction of the rate for a particular system is always difficult and frequently impossible. Rate is related to the level of the surges; low-level surges are more prevalent than high-level surges. The relationship between the level and the rate of occurrence of surges is partly caused by the attenuation of the surges as they propagate away from the source of the surge and divide among paths beyond branching points. Equipment at a given point will be subjected to a relatively small number of highlevel surges from nearby sources, but to a larger number of surges from more remote sources.

Data collected from many sources have led to the plot shown in Fig. 1. This prediction shows with certainty only a relative frequency of occurrence, while the absolute number of occurrences can be described only for an "average location." The "high exposure" and "low exposure" limits of the band are shown as a guide, not as absolute limits, to reflect both the location exposure (lightning activity in the area and the nature of the system) and the exposure to switching surges created by other loads.

The literature describes the frequency of occurrence vs amplitude of lightning strikes, from the low levels of a few kiloamperes, through the median values of about $20 \mathrm{kA}$, to the exceptiona! values in excess of $100 \mathrm{kA}[2]$. Clearly, a secondary arrester rated for $10 \mathrm{kA}$ can protect adequately in case of a mild direct strike, or of a more severe strike divided among several paths to ground. However, a very high and direct strike will exceed the capability of an ANSI-rated secondary arrester [3].

The voltage and current amplitudes presented in the Guideline attempt to provide for the vast majority of lightning strikes but should not be considered as "worst case," since this concept cannot be determined realistically. One should think in terms of the statistical distribution of strikes, accepting a reasonable upper limit for most cases. Where the consequences of a failure are not catastrophic but merely represent an annoying economic loss, it is appropriate to make a trade-off of the cost of protection against the likelihood of a failure caused by a high but rare surge. For instance, a manufacturer may be concerned with nation-wide failure rates, those at the upper limits of the distribution curve, while the user of a specific system may be concerned with a single failure occurring at a specific location under "worst-case conditions." Rates can be estimated for average systems, however, and even if imprecise, they provide manufacturers and users with guidance. Of equal importance is the observation that surges in the range of 1 to $2 \mathrm{kV}$ are fairly common in residential circuits.

From the relative values of Fig. 1, two typical levels can be cited for practical applications. First, the expectation of a $3 \mathrm{kV}$ transient occurrence on a $120 \mathrm{~V}$ circuit ranges from 0.01 to 1 per year at a given location - a number sufficiently high to justify the recommendation of a minimum $3 \mathrm{kV}$ withstand capability. Second, the wir ing flashover limits indicate that a $6 \mathrm{kV}$ withstand capability may be sufficient to ensure device survival indoors, but a $10 \mathrm{kV}$ withstand capability may be required out doors.

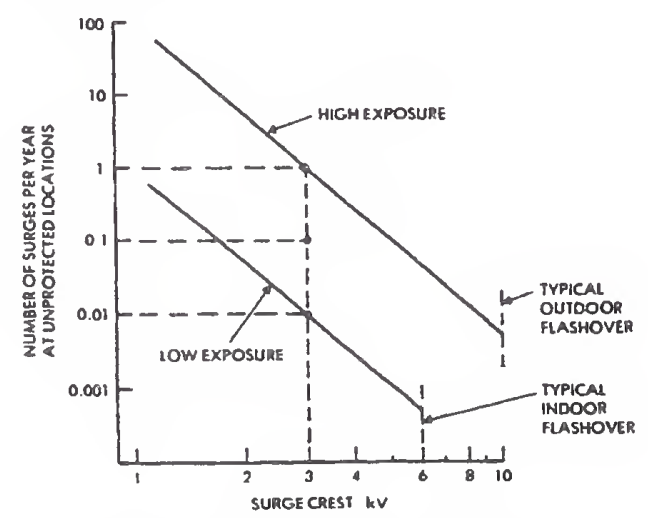

Fig. 1. Rate of surge occurrence vs voltage level.

\section{Timing of Occurrence}

Surges occur at random times with respect to the power frequency, and the failure mode of equipment may be affected by the power frequency follow current or by the timing. Consequently, surge testing must be done with the ac voltage applied to the test piece.

Lightning surges are completely random in their timing with respect to the power frequency. Switching surges are likely to occur near or after current zero, but variable load power factors will produce a quasi-random distribution. Some semiconductors, as shown in Appendix II, exhibit failure levels that depend on the timing of the surge with respect to the conduction of power frequency current. Gaps or other devices involving a power-follow current may withstand this power follow with success, depending upon the fraction of the half-cycle remaining after the surge before current zero. Therefore, it is important to consider the timing of the surge with respect to the power frequency. In performing tests, either complete randomization of the timing or controlled timing should be specified, with a sufficient number of timing conditions to reveal the most critical timing.

\section{WAVESHAPE OF REPRESENTATIVE SURGE VOLTAGES}

\section{Waveshapes in Actual Occurrences}

Indoor - Measurements in the field, measurements in the laboratory, and theoretical calculations indicate that most surge voltages in indoor low-voltage systems have oscillatory waveshapes, unlike the wellknown and generally accepted unidirectional waves specified in highvoltage insulation standards. A surge impinging on the system excites the natural resonant frequencies of the conductor system. As a result, not only are the surges typically oscillatory, but surges may have different amplitudes and waveshapes at different places in the system. These oscillatory frequencies of surges range from $5 \mathrm{kHz}$ to more than $500 \mathrm{kHz}$. A 30 to $100 \mathrm{kHz}$ frequency is a realistic measure of a "typical" surge for most residential and light industrial ac line networks.

Outdoor-Surges encountered in outdoor locations have also been recorded, some being oscillatory, others being unidirectional. The "classical lightning surge" has been established as $1.2 \times 50 \mu \mathrm{s}$ for a voltage wave and $8 \times 20 \mu$ for a current wave. Evidence has been collected, however, to show that oscillations can also occur. Lenz [4] reports 50 lightning surges recorded in two locations, the highest at $5.6 \mathrm{kV}$, with frequencies ranging from 100 to $500 \mathrm{kHz}$. Martzloff [5] reports oscillatory lightning surges in a house during a multiple-stroke flash.

Because the overriding concern here is the energy associated with these surges, a conservative but realistic description of the surges can be derived from the long-established specified duty of a secondary arrester, as detailed below. While this specification is arbitrary, it has the strength of experience and successful usage.

\section{Selection of Representative Waveshapes}

The definition of a waveshape to be used as representative of the environment is important for the design of candidate protective devices, since unrealistic requirements, such as excessive duration of the vol tage or very low source impedance, place a high energy requirement on the suppressor, with a resulting cost penalty to the end user. The two requirements defined below reflect this trade-off.

Indoor - Based on measurements conducted by several independent organizations in 120 and $240 \mathrm{~V}$ systems (Appendix 1), the waveshape shown in Fig. 2 is reasonably representative of surge voltages in these power circuits. Under the proposed description of a $10.5 \mu \mathrm{s}-100 \mathrm{kHz}$ ring wave," this waveshape rises in $0.5 \mu \mathrm{s}$, then decays while oscillating at $100 \mathrm{kHz}$, each peak being about $60 \%$ of the preceding peak.

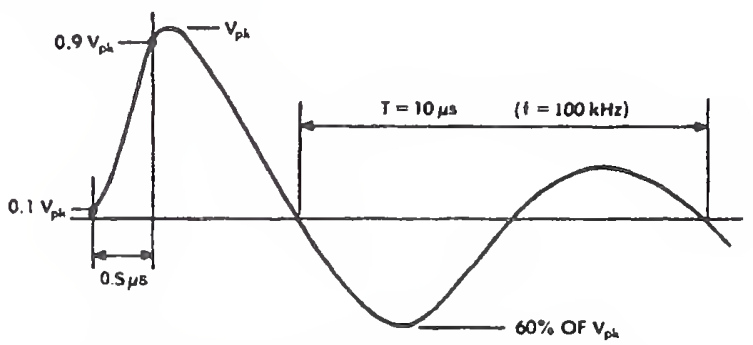

Fig. 2. The proposed $0.5 \mu \mathrm{s}-100 \mathrm{~Hz}$ ring wave (open-circuit voltage).

The fast rise can produce the effects associated with nonlinear vultage Uisulibulivi, il windings and the dr/dt effects on ecmiconduc tors. Shorter rise times are found in many transients, but, as those transients propagate into the wiring or are reflected from discontinuities in the wiring, the rise time becomes longer.

The oscillating and decaying tail produces the effects of voltage polarity reversals in surge suppressors or other devices that may be sensitive to polarity changes. Some semiconductors are particularly sensitive to damage when being forced into or out of a conducting state, or when the transient is applied during a particular portion of the $60 \mathrm{~Hz}$ supply cycle (Appendix II). The response of a surge 
suppressor can also be affected by reversals in the polarity, as in the case of RC attenuation before a rectifier circuit in a dc power supply. The pulse withstand capability of many semiconductors tends to improve if the surge duration is much shorter than one microsecond. For this reason, the first half-cycle of the test wave must have a sufficient duration.

Outdoor - In the outdoor and service entrance environment, as well as in locations close to the service entrance, substantial energy, or current, is still available. For these locations, the unidirectional impulses long established for secondary arresters are more appropriate than the oscillatory wave.

Accordingly, the recommended waveshape is $1.2 \times 50 \mu \mathrm{s}$ for open-circuit voltages and $8 \times 20 \mu \mathrm{s}$ for short-circult current (impulse discharge current) or current in a low-impedance device. The numbers used to describe the impulse, $1.2 \times 50$ and $8 \times 20$, are as defined in IEEE Standard 28 - ANSI Standard C62.1; Fig. 3 presents the waveshape and a graphic description of the numbers.

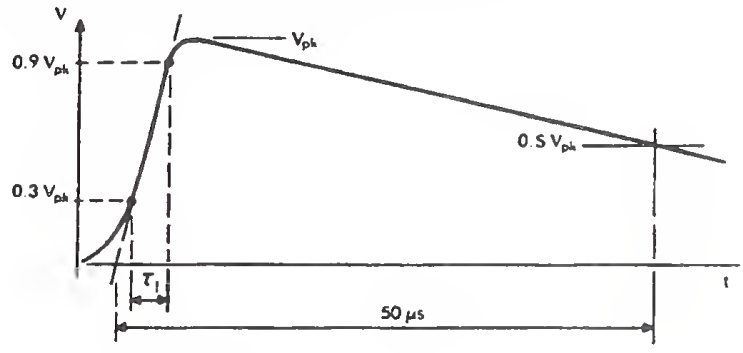

$\tau_{1} \times 1.67=1.2 \mu \mathrm{s}$

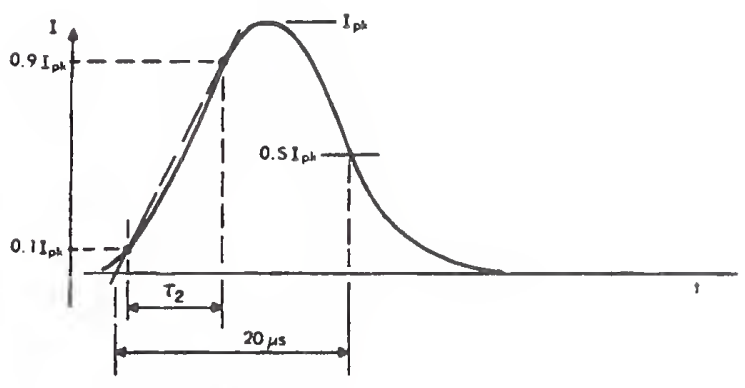

$\tau_{2} \times 1.25=8 \mu \mathrm{s}$

Fig. 3. Waveshapes for outdoor locations.

ENERGY AND SOURCE IMPEDANCE

\section{General}

The energy involved in the interaction of a power system with a surge source and a surge suppressor will divide between the source and the suppressor in accordance with the characteristics of the two impedances. In a gap-type suppressor, the low impedance of the are after sparkover forces most of the energy to be dissipated elsewhere: for instance, in a resistor added in series with the gap for limiting the power-follow current. In an energy-absorber suppressor, by its very nature, a substantial share of the surge energy is dissipated in the suppressor, but its clamping action does not involve the power-follow energy resulting from the short-circuit action of a gap. It is therefore essential to the effective use of suppression devices that a realistic assumption be made about the source impedance of the surge whose effects are to be duplicated.

The voltage wave shown in Fig. 2 is intended to represent the waveshape a surge source would produce across an open circuit. The waveshape will be different when the source is connected to a load having a lower impedance, and the degree to which it is lower is a function of the impedance of the source.

To prevent misunderstanding, a distinction between source impedance and surge impedance needs to be made. Surge impedance, aloo colled character isciv inupelurue, ls a cuncepi relating the parameters of a long line to the propagation of traveling waves. For the wiring practices of the ac power circuits discussed here, this characteristic impedance would be in the range of 150 to $300 \Omega$, but because the durations of the waves being discussed ( 50 to $20 \mu \mathrm{s})$ are much longer than the travel times in the wiring systems being considered, traveling wave analyses are not useful here.

Source impedance, defined as "the impedance presented by a source of energy to the input terminals of a device, or network" (IEEE Standard (00), is a more useful concept here. In the conventional
Thevenin's description, the open-circuit voltage (at the terminals of the neiwork or test generator) and the source impedance (of the surge source or test generator) are sufficient to calculate the short-circuit current, as well as any current for a specified suppressor impedance.

The measurements from which Fig. I was derived were of voltage only. Little was known about the impedance of the circuits upon which the measurements were made. Since then, measurements have been reported on the impedance of power systems. Bull [6] reports that the impedance of a power system, seen from the outleis, exhibits the characteristics of a $50 \Omega$ resistor with $50 \mu \mathrm{H}$ in parallel. Attempts were made to combine the observed $6 \mathrm{kV}$ open-circuit voltage with the assumption of a $50 \Omega / 50 \mu \mathrm{H}$ impedance [?]. This combination resulted in low energy deposition capability, which was contradicted by field experience of suppressor performance. The problem led to the proposed definition of oscillatory waves as well as high-energy unidirectional waves, in order to provide both the effects of an oscillatory wave and the high-energy depositıon capability.

The degree to which source impedance is important depends largely on the type of surge suppressors that are used. The surge suppressors must be able to withstand the current passed through them by the surge source. A test generator of too high an impedance may not subject the device under test to sufficient stresses, while a generator of too low an impedance may subject protective devices to unrealistically severe stresses. A test voltage wave specıfied without reference to source impedance could imply zero source impedance one capable of producing that voltage across any impedance, even a short circuit. That would imply an infinite surge current, clearly an unrealistic situation.

Because of the wide range of possible source impedances and the difficulty of selecting a specific value, three broad categories of building locations are proposed to represent the vast majority of locations, from those near the service entrance to those remote from it. The source impedance of the surge increases from the outside to locations well within the building. Open-circuit voltages, on the other hand, show little variation within a building because the wiring provides little attenuation. Figure 4 illustrates the application of the three categories to the wiring of a building.

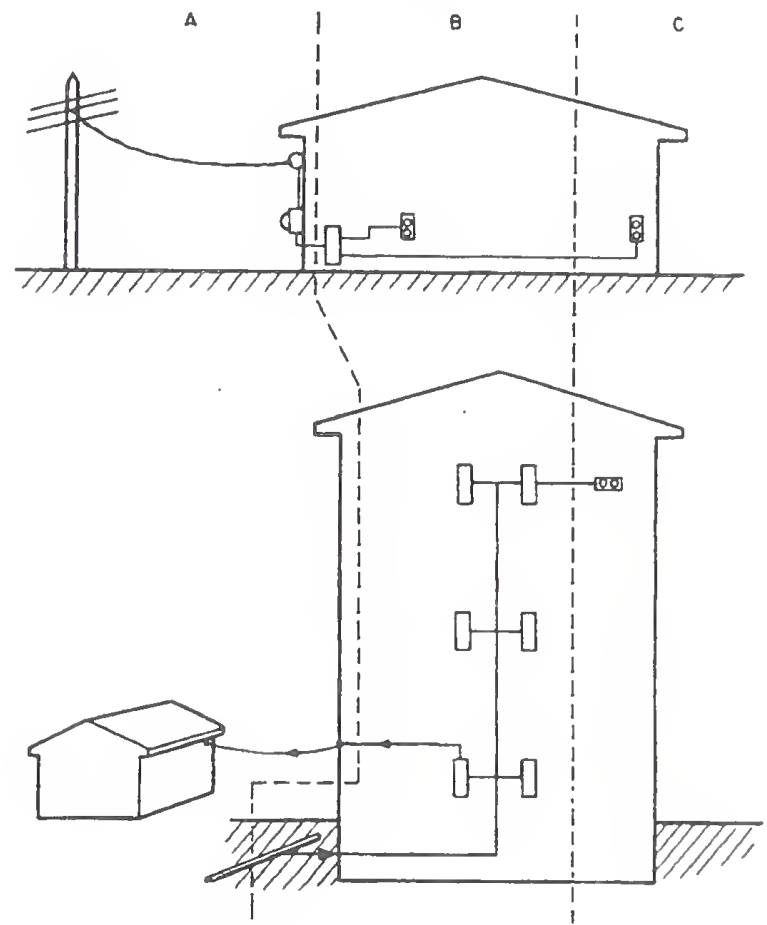

Fig. 4. Location categories.
A. Outside and Service Entrance entranco

Run between meter and distribution panel

Overhead line to detached bulldings Underground tines to well pumps Service drop from pole to building
B. Major Feeders and Short Branch Cirruits Disiriburion panel devices Bus and teeder systems in indusirial plants

Heavy appliance outless with "shor " connections to the service entrance

Lighting systems in commercial buildings
C. Outlets and Long Branch Circuits

Alt oulets at more than $10 \mathrm{~m}(3014)$ trom Category $B$ with wires $\$ 14$ - 10 
Subcommittee 28A of the International Electrotechnical Commission has prepared a Report $[8$ ], in which installation categories are defined. These installation categories divide the power systems according to the location in the building, in a manner similar to the location categorjes defined in the Guideline. However, there are some significant differences between the two concepts. First, the IEC categories are defined for a "controlled voltage situation," a phrase that implies the presence of some surge suppression device or surge attenuation mechanism to reduce the voltage levels from one category to the next. Second, the IEC report is more concerned with insulation coordination than with the application of surge protective devices; therefore it does not address the question of the coordination of the protectors but, rather, the coordination of insulation levels - that is, voltages.

Surges propagate with very little attenuation in a power system with no substantial connected loads. Measurements made in an actual residential system as well as in a laboratory simulation have shown that the most significant limitation is produced by wiring flashover not by attenuation along the wires. Ironically, a carefully insulated installation is likely to experience higher surge voltages than an installation where wiring flashover occurs at low levels. Therefore, the open-circuit voltage specified at the origin of a power system must be assumed to propagate unattenuated far into the system, which is the reason for maintaining the $6 \mathrm{kV}$ surge specification when going from one category to an adjacent category farther into the building.

Furthermore, source impedances are not defined in the IEC report. The Guideline attempts to fill this need by specifying severa levels of source impedance, or of short-circuit current, for the various categories.

\section{PROPOSED REPRESENTATION OF THE ENVIRONMENT}

On the basis of the preceding discussions, the Guideline proposes to reduce the infinite variety of actual conditions to three categories, from the outside service drops to the long branch circuits and outlets.

For each category the most appropriate waveshape is indicated, an open-circuit voltage for high-impedance loads, or a short-circuit current for low-impedance loads. The tabulation that follows shows open-circuit voltages and short-circuit currents for each of the three categories. The energy deposited in a $500 \mathrm{~V}$ suppressor has been computed and is shown for each of the categories.

The values shown in the table represent the maximum range, corresponding to the "High Exposure" situation of Fig. 1. For less exposed systems, or when the prospect of a failure is not highly objectionable, one could specify lower values of open-circuit voltages with corresponding reductions in the currents. IEC Category 1, not represented in the Guideline, would correspond to line cord-connected devices in this context.

\section{CONCLUSIONS}

The broad range of surge voltages occurring in low-voltage ac power circuits can be simulated by a limited set of test waves, for the purpose of evaluating their effects on equipment.

Field measurements, laboratory experiments, and calculations indicate that two basic waves, at various open-circuit voltages and short-circuit current values, can represent the majority of surges occurring in residential, commercial, and light industrial power systems rated up to $600 \mathrm{~V}$ rms.
Exceptions will be found to the simplification of a broad guideline; however, these should not detract from the benefits that can be expected from a reasonably valid uniformity in defining the environment. Other test waves of different shapes may be appropriate for other purposes, and the present guideline should not be imposed where it is not applicable.

The Working Group is approaching the final phases of preparation of the Guideline document; comments are solicited from the engineering and user communities. However, readers must recognize the unavoidably arbitrary character of any standard and be prepared to accept an imperfect approach, which can simplify matters and clarify the issues as well as provide uniform evaluations of performances, rather than demand a perfect but unattainable match between the actual situation and the standard.

\section{ACKNOWLEDGMENTS}

The concepts presented in this paper have greatly benefited from the informed questions and discussions by members of the Working Group on Surge Voltage in AC Power Circuits Rated $600 \mathrm{~V}$ or Less, and from interested reviewers; particular appreciation for effective critiques from Catharine Fisher and Peter Richman is acknowledged. The data base presented in Appendix I has been broadened by the contributions of the Bell Telephone Laboratories and Landis \& Gyr, Inc.

\section{REFERENCES}

1. "Switching Surges Due to De-Energization of Capacitive Circuits," AIEE Committee Report, AIEE Transactions, August I 1957, pp. 562-564.

2. Cianos, N. and E.T. Pierce, A Ground-Lightning Environment for Engineering Usage, Stanford Research Institute, Menlo Park, CA 94205, August 1972.

3. Surge Arresters for Alternating-Current Power Circuits. IEEE Standard 28-1974; ANSI Standard C62.1-1975; IEC Standard 99-2.

4. Lenz, J.E., "Basic Impulse Insulation Levels of Mercury Lamp Ballast for Outdoor Applications," Rluminating Engrg.. February 1964, Pp. 133-140.

5. Martzloff, F.D. and G.J. Hahn, "Surge Voltage in Residential and Industrial Power Cir cuits," IEEE PAS-89, 6. July/August 1970, 1049-1056.

6. Bull, J.H., "Impedance on the Supply Mains at Radio Frequencies," Proceedings of 1st Symposium on EMC, 75CHI01 2-4 Mont. Montreux, May 1975.

7. Martzloff, F.D. and F.A. Fisher, "Transient Control Level Philosophy and Implementation: The Reasoning Behind the Philosophy," Proceedings 2nd Symposium on EMC, $77 \mathrm{CHI} 224-$ SEMC, Montreux, June 1977.

8. Insulation Coordination Within Low-Voltage Systems Including Clearances and Creepage Distances for Equipment, International Electrotechnical Commission Repori SC28A (Central Office) 5 , to be published in 1979 .

Recommended Surge Voltages and Currents Deemed to Represent the Environment

\begin{tabular}{|c|c|c|c|c|c|c|}
\hline & $\begin{array}{l}\text { Location } \\
\text { Category }\end{array}$ & $\begin{array}{l}\text { Comparable to } \\
\text { IEC SC28A } \\
\text { Category }\end{array}$ & Waveform Impulse & $\begin{array}{l}\text { Maximum* } \\
\text { Amplitude }\end{array}$ & $\begin{array}{l}\text { Type } \\
\text { of Specimen } \\
\text { or Load } \\
\text { Circuit }\end{array}$ & $\begin{array}{c}\text { Energy } \\
\text { Deposited in } \\
\text { a } 500 \vee \text { Suppressor } \\
\text { (joules) }\end{array}$ \\
\hline A. & $\begin{array}{l}\text { Outdoor and } \\
\text { Service Entrance }\end{array}$ & IV & $\begin{array}{l}1.2 \times 50 \mu \mathrm{s} \\
8 \times 20 \mu \mathrm{s} \\
\end{array}$ & $\begin{array}{l}10 \mathrm{kV} \text { o.c. } \\
10 \mathrm{kA} \text { s.c. }\end{array}$ & $\begin{array}{l}\text { High Impedance } \\
\text { Low Impedance }\end{array}$ & $\begin{array}{c}-- \\
150 \\
\end{array}$ \\
\hline B. & $\begin{array}{l}\text { Major Feeders } \\
\text { and Short } \\
\text { Aranch Circuite }\end{array}$ & 111 & $\begin{array}{c}1.2 \times 50 \mu \mathrm{s} \\
8 \times 20 \mu \mathrm{s} \\
0.2 \mu \mathrm{s}-100 \mathrm{krz}\end{array}$ & $\begin{array}{l}6 \mathrm{kV} \text { o.c. } \\
3 \mathrm{kA} \mathrm{s.c} . \\
\left\{\begin{array}{c}6 \mathrm{kV} \text { n.r. } \\
500 \mathrm{~A} \text { s.c. }\end{array}\right.\end{array}$ & $\begin{array}{l}\text { High Impedance } \\
\text { Low Impedance } \\
\text { High Impodanco } \\
\text { Low Impedance }\end{array}$ & $\begin{array}{c}\cdots \\
40 \\
-- \\
2\end{array}$ \\
\hline c. & $\begin{array}{l}\text { Long } \\
\text { Branch Circuits } \\
\text { and Outlets }\end{array}$ & II & $0.5 \mu \mathrm{s}-100 \mathrm{kHz}$ & $\left\{\begin{array}{l}6 \mathrm{kV} \text { o.c. } \\
200 \mathrm{~A} \text { s.c. }\end{array}\right.$ & $\begin{array}{l}\text { High Impedance } \\
\text { Low Impedance }\end{array}$ & -- \\
\hline
\end{tabular}




\section{APPENDIX 1 - DATA BASE}

Recordings and surge counter data have been contributed from several sources, in addition to the surge counter data obtained by members of the Working Group. Representative oscillograms and summary statistics are reproduced in this appendix, in support of the voltage levels and oscillatory wave proposals.

1. Recordings by Bell Telephone Laboratories to date)

(Data contributed by P. Speranza, internal report, unpublished

\subsection{Typical Surge Counter Statistics}

$120 \mathrm{~V}$ line at BTL facility in Chester, New Jersey, during 42 months of monitoring:
146 counts at 300 to $500 \mathrm{~V}$
14 counts at 500 to $1000 \mathrm{~V}$
3 counts at 100 to $1500 \mathrm{~V}$
3 counts above $1500 \mathrm{~V}$

1.2 Typical Automatic Recording Oscilloscopes

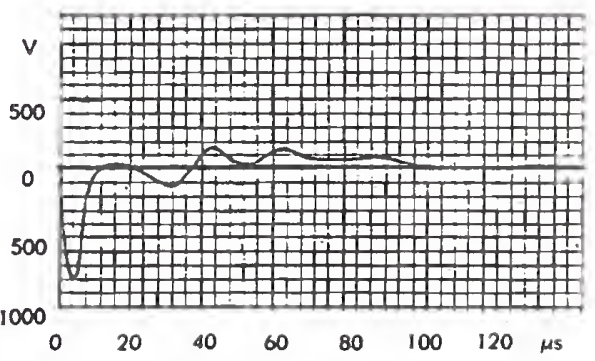

$120 \vee$ OUTLET, LABORATORY BENCH
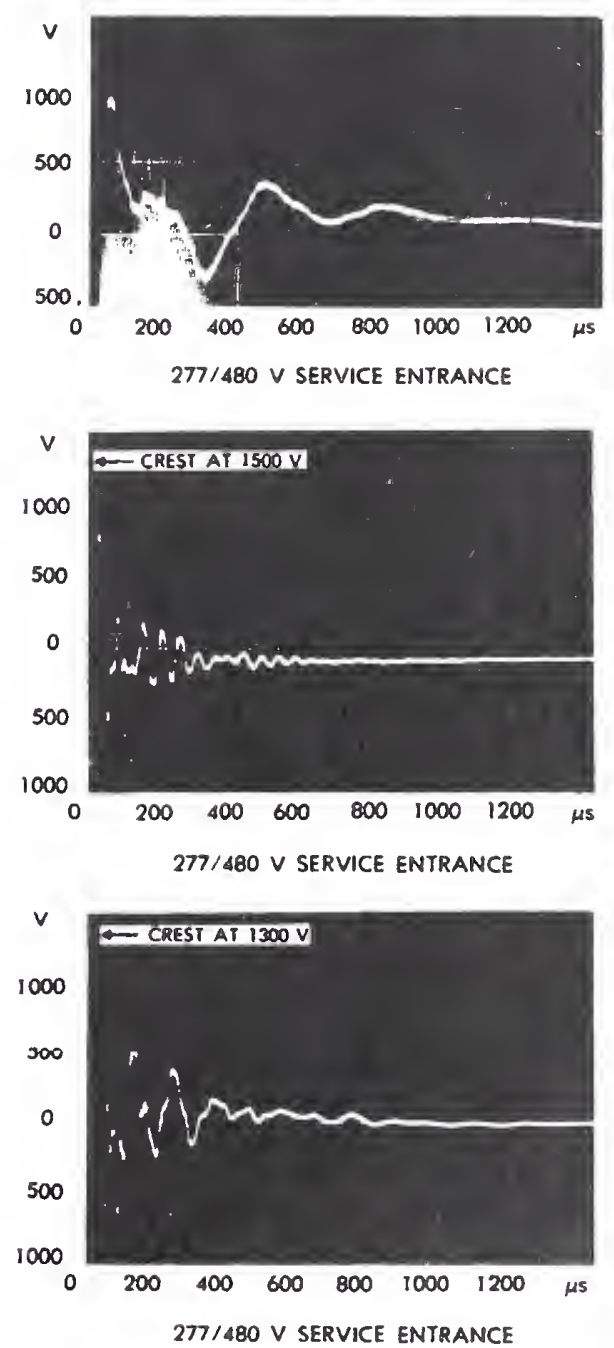

2. Recordings by General Electric Company

2.1 Surge Counter Statistics - Martzloff, F.D. and G.J. Hahn, "Surge Voltage in Residential and Industrial Power Circuits, IEEE Pas-89, 6 , July/August $1970,1049-1056$.

a) Three percent of all U.S. residences experience frequent occurrences (one per week or more) above $1200 \mathrm{~V}$.

b) There is a 100:1 reduction in the rate of device failure when the withstand level is raised from $2 \mathrm{kV}$ to $6 \mathrm{kV}$.

\begin{tabular}{|c|c|c|c|}
\hline Lockton & $\begin{array}{l}\text { Number } \\
\text { of of } \\
\text { Ilomes } \\
\text { Surveyed }\end{array}$ & $\begin{array}{l}\text { Jeecordung } \\
\text { Perictd } \\
\text { (weeks) }\end{array}$ & $\begin{array}{l}\text { Hiskex } \\
\text { winh } \\
\text { Icpetuve } \\
\text { Surkes. }\end{array}$ \\
\hline 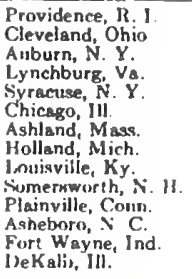 & 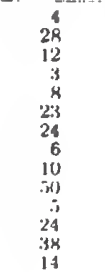 & $\begin{array}{l}2-6 \\
2-4 \\
2-4 \\
2-3 \\
2-3 \\
1-2 \\
1-6 \\
1-2 \\
2-111 \\
2-6 \\
12 \\
111 \\
12 \\
124 \\
3-12\end{array}$ & 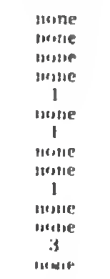 \\
\hline
\end{tabular}

Surge Counter Recordings Above 1200 Volts (Spring, Summer, and Fall)

\begin{tabular}{|c|c|c|c|}
\hline Ieration & $\begin{array}{l}\text { Nirmber } \\
\text { of } \\
\text { llormer }\end{array}$ & $\begin{array}{l}\text { Tuilat } \\
\text { Jlomen } \\
\times \text { Wirek- }\end{array}$ & $\begin{array}{l}\text { Simulxer } \\
\text { ind } \\
\text { Surgex }\end{array}$ \\
\hline Providenre, 11 i. & 6 & (i)! & 1 \\
\hline Ashborn $\mathrm{A}$ C. & $1: 3$ & $x_{i}$ & mile \\
\hline I reKalb, III & 11 & (n) & 2 \\
\hline Somerswurih, N. Il. & 3 & $4 x$ & 1 \\
\hline Chicagn, III. & 12 & ix & mone \\
\hline Clevefand, Ohio & $x$ & 1116 & 1 \\
\hline Decatur, Iil. & 12 & 72 & 2 \\
\hline Holland, Mich. & $i$ & $\therefore 6$ & Holle: \\
\hline Auburn, $x . y$. & 3 & 70 & Inome \\
\hline Springfield, $\mathrm{P}_{0}$ & $i$ & $\because 24$ & meste \\
\hline Ashlend, Mase. & 6 & 72 & molue \\
\hline Pittafield, Masw. & 3 & (i) & 1 \\
\hline Plainville, Conn. & 3 & 6i) & twitie \\
\hline Lynchburg, $V_{\mathrm{a}}$. & is & 1.7 & IIUHF \\
\hline Total & 41 & 446 & $\begin{array}{c}x \text { in } \\
\text { r hivene }\end{array}$ \\
\hline
\end{tabular}

2.2 Typical Automatic Recording Oscilloscopes
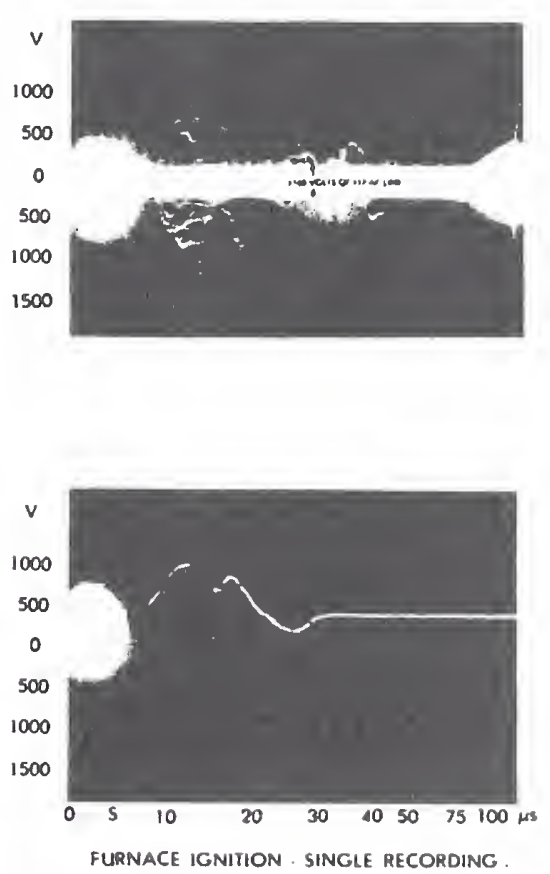


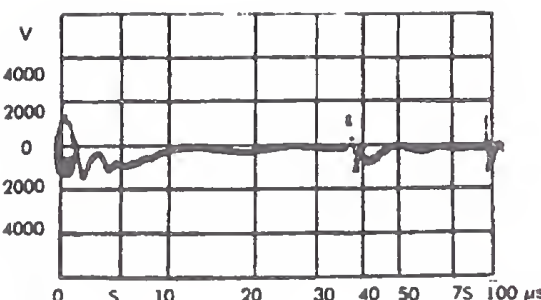

SERVICE ENTRANCE, LIGHTNING STORM

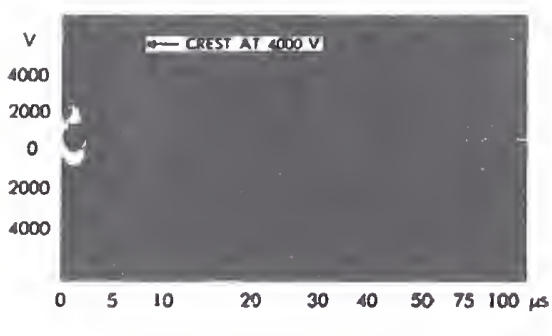

STREET POLE. IJGHINING STORM

2.3 Simulated Lightning Strokes on a Residential Power Circuit (Laboratory Model of System)-Martzloff, F.D. and K.E. Crouch, "Coordination De La Protection Contre Less Surtensions Dans Les Réseaux Basse Tension Résidentiels," Proceedings, 1978 IEEE Canadiun Conference on Communications and Power. $78 \mathrm{CH} 1373-0$, Pp. $451-454$.

$1.5 \mathrm{kA}$ current impulse $(8 \times 20 \mu \mathrm{s}$ approx.) is injected in ground wire only of service drop. (Higher curents produce flashover of wiring.)

$500 \mathrm{~A} / \mathrm{div}$

$5 \mu \mathrm{s} / \mathrm{div}$

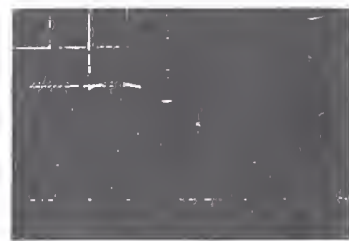

Recording of open-cir cuit voltage at a branch circuit outlet: $2200 \mathrm{~V}$ peak $500 \mathrm{kHz}$ oscillations

$500 \mathrm{~V} / \mathrm{div}$

$2 \mu \mathrm{s} / \mathrm{div}$

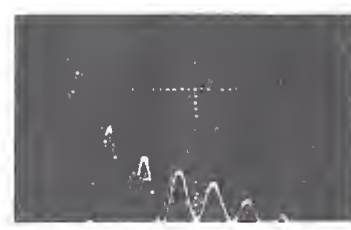

By connecting a $130 \Omega$ load at the same outlet (I $\mathrm{A}$ load) the voltage is reduced to $1400 \mathrm{~V}$ peak, with more damping.

$500 \mathrm{~V} / \mathrm{div}$

$2 \mu \mathrm{s} / \mathrm{div}$

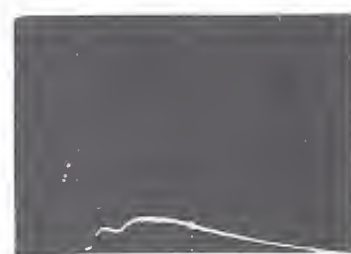

\section{Conclusions from this test series}

1. A current of $1.5 \mathrm{kA}$ (moderate for a lightning discharge injected in the ground system) raises the wiring system of the house $2.2 \mathrm{kV}$ above ground. Four kiloamperes (still a moderate value) will bring this voltage to $6 \mathrm{kV}$, the typical flashover value of the wiring.

3. A natural frequeney of $500 \mathrm{l} / \mathrm{H}=$ is exeited by a unidirectional impulse.

3. In this example, the source of the transient (from the loading effect of $(30 \Omega$ ) appears as

$$
\begin{aligned}
Z & =130 \Omega\left[\frac{2200}{1400}-1\right] \\
& =75 \Omega
\end{aligned}
$$

3. Statistics by Landis \& Gyr, Inc.

Surge counter data on various locations in Swiss $220 \mathrm{~V}$ systems (Data contributed by L. Regez - unpublished to date)
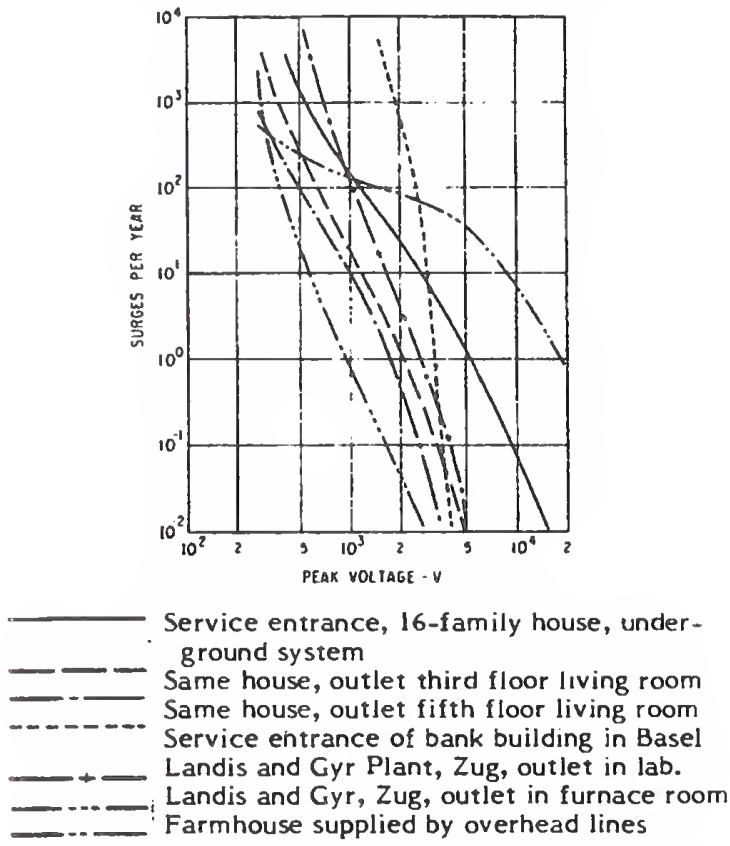

Frequency of Voltage Transients per Year as a Function of the Peak Value of the Voltage Transient for a $220 \mathrm{~V}, 50 \mathrm{~Hz}$ Distribution System with Grounded Neutral

\section{Working Group Surge Counter Statistics}

Surge counters with four threshold levels $(350,500,1000$, and $1500 \mathrm{~V}$ ) were made available to the Working Group by Joslyn Electronic Systems, for recording surge occurrences at various locations. Members of the Working Group installed these on 120 and $240 \mathrm{~V}$ systems of various types, including the following: outlets in urban, suburban, and rural residences; outlets in a hospital; secondary circuits on distribution system poles (recloser controls); secondary of pad-mounted distribution transformers; lighting circuits in an industrial plant; life test racks at an appliance manufacturer; bench power supply in a laboratory.

Limitations on the availability of personnel and communications made this sampling less than optimum from a statistical point of view. However, by computing weighted averages for each location, one can quote an acceptable overall average; this average has been included in the graph drawn to establish the low and high exposure limits.

Summary Statistics of these measurements are as follows:

1. Data base from 18 locations with a total recording time of 12 years spread over 4 calendar years, using 6 counters.

2. Number of occurrences per year (weighted averages) at "a verage location."

- $350 \mathrm{~V}: 22$
- $\quad 500 \mathrm{~V}: 11$
- $1000 \mathrm{~V}: 7$
- $1500 \mathrm{~V}: 3$

3. Significant extremes

- One home with large number of surges caused by washer operation

- Four locations out of 18 never experienced a surge.

- One home experienced several occurrences above $1500 \mathrm{~V}$, with none below that value.

- One industrial location (switching of a test rack) produced thousands of surges in the 350-500 V range, and several surges in excess of $1500 \mathrm{~V}$. This location was left out of the average computation, but it exemplifies a significant extreme. 
From the data base cited in the preceding pages, one can draw the chart below, including the following information on voltage vs frequency (rate) of occurrence:

1. The Bell Laboratories data yield a point of $1000 \mathrm{~V}$ at about 2 occurrences per year ( 1$)$.

2. The General Electric counter statistics yıeld a point of $1200 \mathrm{~V}$ at about 1 occurrence per year $(\mathrm{x})$.

3. The General Electric clock data indicate a slope of 100:1 from $2 \mathrm{kV}$ to $6 \mathrm{kV}(-.-\ldots)$.

4. The Regez data provide a band for the majority of locations (shown cross-hatched), with the exception of the rural Jocation with long overhead line, which has more occurrences.

5. Working Group statistics (-- - ) indicate a less steep slope, perhaps because of the influence of outdoor locations included in the sample (similar to the rural data of Regez).

The proposed curve, which is the center of the \pm 10 range of Fig. 1 in the Guideline, is shown in bold dashed lines $(--)$. It has been drawn at the 100:1 slope, passing near the Bell and Genera! Electric points and located within the band of the Regez data.

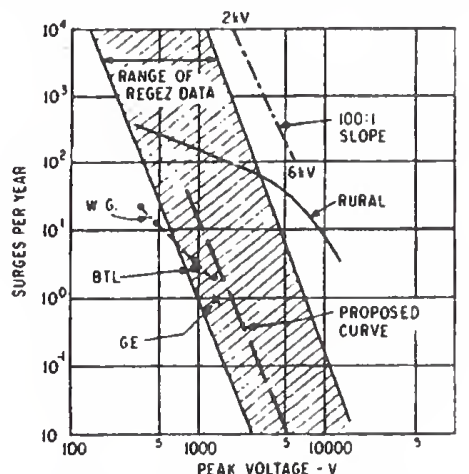

\section{APPENDIX II - EFFECT OF TRANSIENT POLARITY REVERSALS ON SEMICONDUCTORS}

Breakdown of semiconductors under various conditions of load and transient overvoltage applications has been investigated.* Evidence is presented in the two investigations cited that a reverse voltage apolied during the conduction period of the power frequency produces lower breakdown voltage than the application of the same transient with no load or during blocking. Examples are given below, taken from these two investigations, showing statistically significant differences in the voltage levels.

$\begin{array}{llr}\text { IN1190 Diode* } & \text { Transient at no load } & 1973 \\ & \text { Fast wave under load } & 830 \\ & \text { Slow wave under load } & 1097 \\ \text { IN2160 Diode* } & \text { Transient at no load } & 2056 \\ & \text { Fast wave under load } & 894 \\ & \text { Slow wave under load } & 1106 \\ \text { IN679 Diode + } & \text { Transient applied at: } & 1766 \\ & - \text { peak of reverse voltage } & 1181 \\ & -25^{\circ} \text { after start of conduction } & 906 \\ & -90^{\circ} \text { after start of conduction } & 1115 \\ & -155^{\circ} \text { after start of conduction }\end{array}$

This effect is one of the reasons for selectung an oscillatory waveform to represent the environment: it will be more likely to induce semiconductor failures than a unidirectional wave. Also, it shows the significance of the timing of the transient application with respect to the power frequency cycle.

"Chowduri, P., "Transient-Voltage Characteristics of Silicon Power Rectifiers." IEEE IA-9, 5, September/October 1973, p. 582.

†F.D. Martzloff, internal report, unpublished.

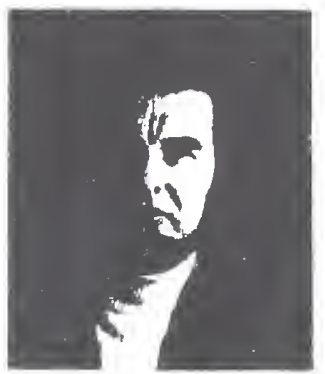

Francoss D. Martzloff (M, 1956) was born in France and received his undergraduate degree at the Ecole Spériale De Mécanique et d'Electricité in 195!; he received the MSEE degree from Georgia Tech in 1952 and the MSIA degree from Union College in 1971.

Since 1956 he has been with the General Electric Company, where he first gained experience in the Transformer and Switchgear Divisions. Upon joining General Electric Corporate Research and Development in 1961 he became involved in power semiconductor circuits and overvoltage protection. He has participated in the introduction and application of metal oxide varistors since 1971 .

In IEEE Mr. Martzloff has been active on the Surge Protective Devices Committee and chairman of the Working Group on Surge Voltages in AC Power Circuits Rated $600 \mathrm{~V}$ or Less. He is also a member of the Ad Hoc Advisory Subcommittee of the USA Advisory Committee on JEC S/C 28A. He has been awarded 10 U.S. patents. primarily in the field of varistors and transıent protection. 


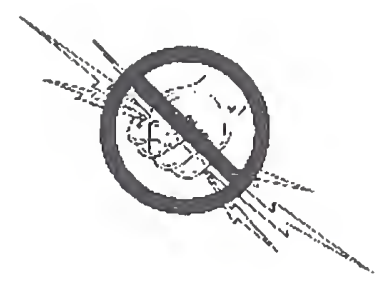




\title{
Varistor versus Environment: Winning the Rematch
}

\author{
François Martzloff, Life Fellow, IEEE \\ National Institute of Standards and Technology \\ Gaithersburg MD 20899 USA \\ f.martzloff@ieee.org
}

\author{
(C) 1986 IEEE \\ Reprinted, with permission, from IEEE Transactions on Power Systems, Vol.PWRD No.3, April 1986
}

\section{Significance:}

This paper is listed under four categories of the Annotated Bibliography as it bears on the corresponding topics. The multiple listing reflects the sections in which this paper is cited as supporting material for IEEE Std C62.41.1 and C62.41.2. Therefore, it can be found in the following four parts of the Anthology:

Part 2 Development of standard - Reality checks

Provides an example of the need to recognize capacitor switching transients when characterizing the surge environment

Part 3 Recorded occurrences, surveys and staged tests

Provides an example of monitoring and staged tests motivated by field failure, leading to a better understanding of the environment in which SPDs were expected to perform.

Part 4 Propagation and coupling of surges

Provides an example of how far (3000 meters) the low-frequency transients generated by capacitor switching can propagate, unabated, in a path involving two step-down transformers.

Part 7 Mitigation techniques

Provides an example of improved mitigation design based on field experience 
$\varnothing$ 


\title{
VARISTOR VERSUS ENVIRONMENT: WINNING THE REMATCH
}

\author{
Françols D. Martzlofi, Fellow IEEE \\ Corporate Research and Development \\ General Electric Company \\ Schenectady, New York 12345
}

\begin{abstract}
An unusual case of difficult application of surge protective devices was solved by field measurements with retrofit of protective devices suitable for the particular environment. Onsite measurements indicated that capacitor switching transients were causing excessive current surges in the varistors and fuses protecting the input to a thyristor motor drive. Knowledge of the environment gained by the measurements allowed understanding of the problem and specification of matching surge protective devices.
\end{abstract}

\section{SUMMARY}

During the initial startup of a solid-state motor drive in a chemical processing plant, difficulties arose with the varistor and its protective fuse at the input of the thyristor circuits. Frequent blowing of the fuse was observed, with occasional failure of the varistor. On-site measurements of the voltages and currents at the input to the drive indicated that switching transients associated with the operation of a remote substation capacitor bank and the relatively low clamping level of the varistor were producing current above the fuse and varistor ratings; hence the short lives of these two components. When the actual conditions at that site were determined by measurements, it became possible to specify surge protective devices capable of withstanding that environment. Immediate relief was secured by the installation of a larger varistor at the same point of the circuit; long-term protection was obtained by the addition of a gapless metal-oxide varistor arrester on the primary side of the step-down transformer feeding the drive. The situation has been changed from failures occurring every few days to no further problems in the 3 years since the larger varistor was installed.

\section{INTRODUCTION}

This paper presents a case history illustrating how surge protective devices that are successfully applied for the majority of cases can occasionally suffer failure when exposed to exceptionally severe surge environments. This paper also shows how little attenuation occurs, at the frequencies produced by switching surges, between the distribution level $(23 \mathrm{kV})$ and the utilization level $(460 \mathrm{~V})$, even though a long line and two step-down transformers exist between the source of the transient and the point of measurement.

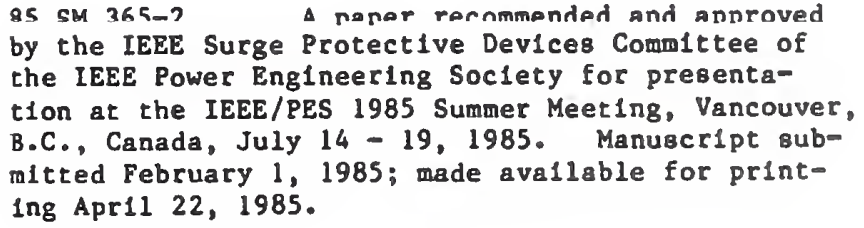

The problem involved a $460 \mathrm{~V}$ power supply to a thyristor drive circuit in a chemical processing plant extending over several square miles. During the initial startup, difficulties arose with the varistor and its protective fuse at the input of the thyristor circuits. Frequent blowing of the fuse was ohserved, with occasional failure of the varistor. The plant substation, fed at $23 \mathrm{kV}$ from the local utility, included a large capacitor bank with one-third of the bank switched on and off to provide power factor and system voltage regulation. These frequent switching operations were suspected of generating high-energy transients that might be the cause of the failure of the fuses and varistors, beceuse literally thousands of similar drive systems have been installed in other locations without this difficulty. On-site measurements performed after repeated blowing of fuses and occasional failure of varistors connected at the input to the thyristor drive indicated that indeed the devices were not matched to their environment. From this point on, specifying larger sizes, sizes appropriate to the environment [1], solved the problem.

\section{POWER SYSTEM AND SWITCHING TRANSIENTS}

Figure 1 is a simplified one-line diagram of the significant elements of the power system causing the varistor failures. The incoming $115 \mathrm{kV}$ power is stepped down to $23 \mathrm{kV}$. Three banks of $5400 \mathrm{kVAR}$ capacitors are connected to the $23 \mathrm{kV}$ bus. Typical operating conditions involve two banks connected at all times, with the third bank switched on or off automatically to provide voltage regulation. Power distribution throughout the site is done at the $23 \mathrm{kV}$ level.

The various drive systems which experienced the difficulty are supplied at $460 \mathrm{~V}$ by $2300 / 460 \mathrm{~V}$ transformer in their control house. A substation close to the control house supplies the $2300 \mathrm{~V}$ power from the $23 \mathrm{kV}$ distribution system.

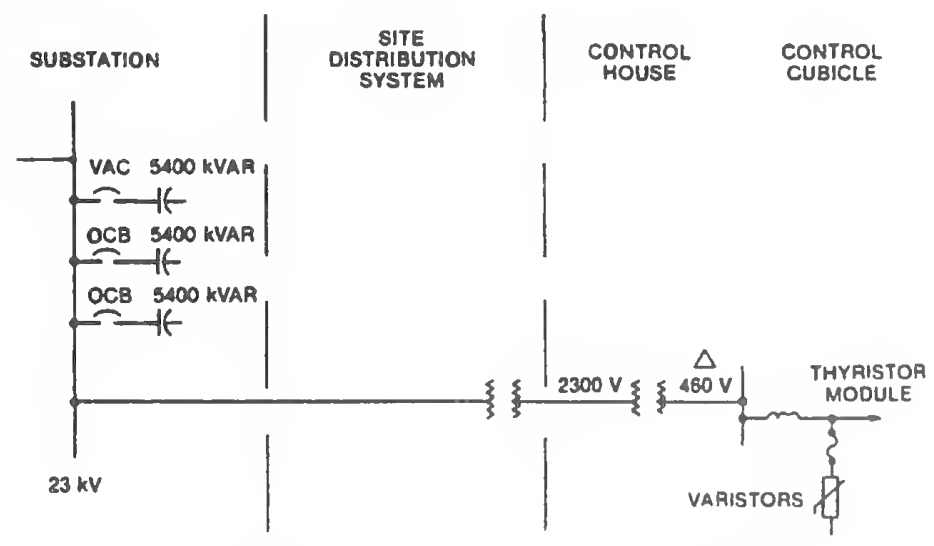

Figure 1. Simplified one-line diagram 
Figure 2 is a simplified three-phase schematic of the power input. In the original circuit, the thyristor modules were protected by varistors at the power input of the $1250 \mathrm{hp}$ drive, where the measurements were made. A $6 \mu \mathrm{H}$ line inductance, L1, was inserted between the bus and the thyristor modules; $20 \mathrm{~mm}$ varistors rated $510 \mathrm{~V}$ were connected in a delta configuration, in series with a current-limiting fuse in each line. The varistor connection was about $80 \mathrm{~cm}$ long, introducing an estimated $1 \mu \mathrm{H}$ inductance into each lead.

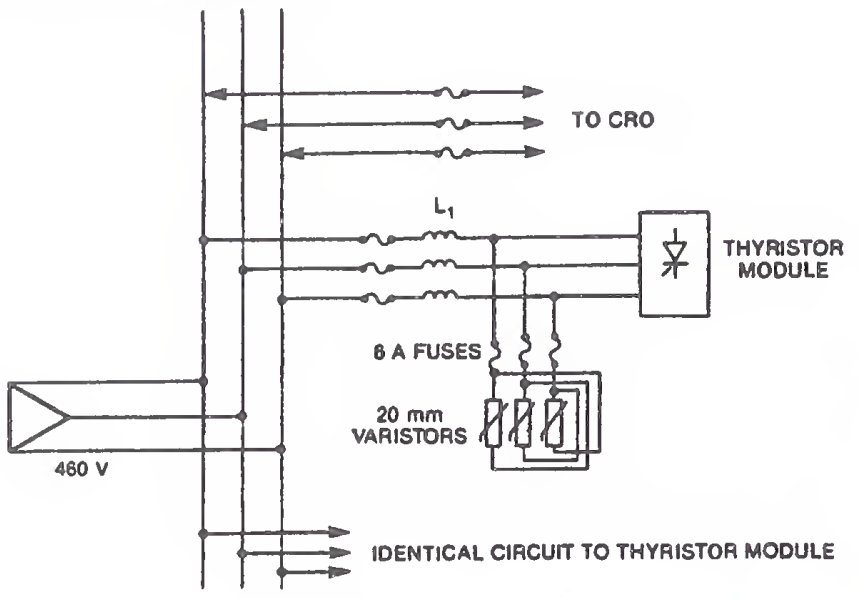

Figure 2. Simplifted three-phase schematic

\section{Instrumentation and Measurements}

Oscilloscopes were used to measure voltage across one varistor and its connection and currents through all varistors. Voltage measurements were made phase-to-phase on the Doating delta $460 \mathrm{~V}$ bus bars with Tektronix P6015 1000:1 probes, connected to a Tektronix 7633 storage oscilloscope in differential mode. Current measurements were made with a Tektronix CT5 20:1 current transformer coupled with a P6021 current probe and connected to a second Tektronix 7633 storage oscilloscope.

The trigger modes used during a two-hour monitoring period included positive or negative slopes for both slow ac and highfrequency modes. For the various modes, the level was adjusted to produce a trigger for a voltage exceeding the normal line voltage crest by about $20 \%$, or a varistor current in excess of $2 \mathrm{~A}$. No trigger occurred during the monitoring period. A low-frequency voltage recorder installed by plant personnel produced a recording characterized as representative of an unusually quiet day in the power system operations.

Manual off-on switching of the $5400 \mathrm{kVAR}$ capacitor bank at the $23 \mathrm{kV}$ utility substation was the next step in the measurement procedures because the switching of a capacitor bank is always a prime suspect for producing transients. Measurements were performed with one oscilloscope monitoring the line voltage upstream of the line inductors (Figure 2) and another oscilloscope monitoring the sum of the currents in the three varistors (Figure 3 ).

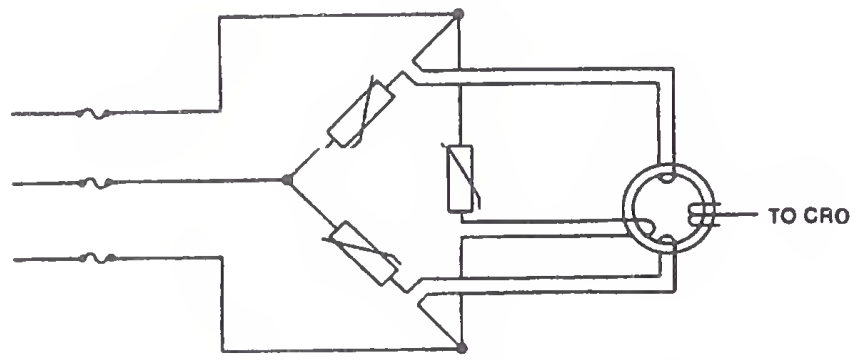

Figure 3. CT connection for recording all three varistor currents

\section{Results}

The oscillograms of Figure 4 show typical voltage recordings made during this sequence. The voltages are not open-circuit transient voltages. They are instances of the voltage appearing at the bus entrance point. This voltage is the sum of the varistor clamping voltage, the voltage drop in the varistor connections, and the voltage across two $\mathrm{Ll}$ inductances.

A typical total event recorded on one of the phases during a capacitor bank closing is shown in Figure 4A. A low-frequency oscillation with a period of $3 \mathrm{~ms}(330 \mathrm{~Hz})$ and initial peak-to-peak amplitude of $450 \mathrm{~V}$ decayed in about $10 \mathrm{~ms}$. The high-frequency oscillations are resolved in the recording of Figure 4B (recorded during a similar switching sequence). This high frequency has an initial peak-to-peak amplitude of $2000 \mathrm{~V}$, decaying in about $5 \mathrm{~ms}$. The period is $180 \mu \mathrm{s}(5.5 \mathrm{kHz})$. A similar, third event is shown in Figure $4 \mathrm{C}$. For scaling the amplitudes, the steady-state voltage is shown in Figure 4D.

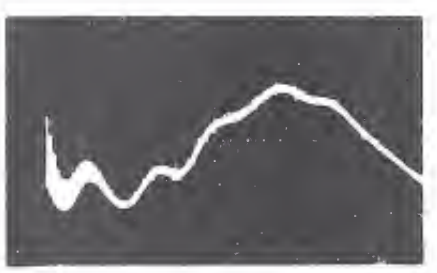

A Sresp: $2 \mathrm{ma} / \mathrm{div}$ Vorteal: $300 \mathrm{~V} / \mathrm{d} / \mathrm{V}$

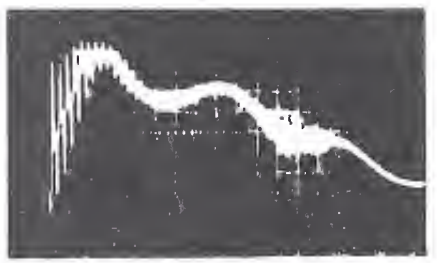

C Sweep: I ma/div Vertical: $500 \mathrm{~V} / \mathrm{d}$.

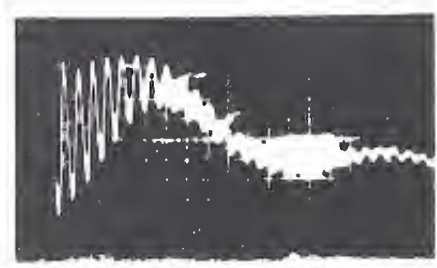

B Soenp: $0.5 \mathrm{~ms} / \mathrm{dly}$ Vertlcal: $\sin \mathrm{V} / \mathrm{dlv}$

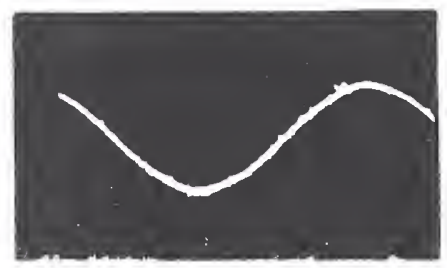

D Smeep: 2 ตร/ด1 Vertleal: $500 \mathrm{~V} / \mathrm{d} 1 \mathrm{v}$
Figure 4. Capacitor switching transients and steady-state voltage

Observe that, depending on the time of closing with respect to the $60 \mathrm{~Hz}$ voltage, the $5.5 \mathrm{kHz}$ oscillation varies in amplitude; furthermore, the modulation by the $330 \mathrm{~Hz}$ oscillation pushes crests of the $5.5 \mathrm{kHz}$ oscillation above the $1000 \mathrm{~V}$ level some time after the beginning of the trace, at a time when the $5.5 \mathrm{kHz}$ amplitude is already lower, producing a burst of pulses above the $1000 \mathrm{~V}$ level.

The significance of this finding will be discussed next, with reference to Figure 5, which shows recordings of transient currents in all of the three varistors. The $510 \mathrm{~V}$ varistor has a nominal voltage at $1 \mathrm{~mA} \mathrm{[2]} \mathrm{in} \mathrm{the} \mathrm{range} \mathrm{of} 735 \mathrm{~V}$ to $970 \mathrm{~V}$. For a varistor with a nominal voltage in the middle of this range, a current in the order of tens to hundreds of amperes will flow if a voltage of $1000 \mathrm{~V}$ is applied to the varistor. Figure 5A shows a train of current pulses in the range of 10 to $40 \mathrm{~A}$. In the burst of Figure SB, the recorded current pulses range from $5 \mathrm{~A}$ to $200 \mathrm{~A}$. The current and voltage traces are not simultaneous events because each of the two oscilloscopes was triggered by its internal circuit. The nearly symmetrical appearance of this burst can be compared to the symmetry of the voltage peaks exceeding the $1000 \mathrm{~V}$ level in Figure 4, the one correlating with the other.

The oscillograms of Figures 4 and 5 were selected as most severe from a series of 20 capacitor switching sequences. Some sequences could not even produce a current or voltage trigger; four sequences produced bursts with the central peak exceeding $120 \mathrm{~A}$, two of these reaching $200 \mathrm{~A}$ peaks. 


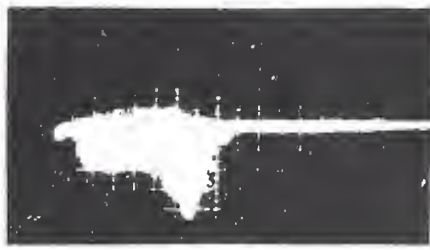

A. Sweep: $0.2 \mathrm{~ms} / \mathrm{div}$ Vertlesl: $29 \mathrm{~A} / \mathrm{dl}$

Flgure 5. Current surge bursts during capacitor switching

These recordings establish the nature of the current surges that are conducted by the varistors, with an estimate of $10 \%$ reaching $200 \mathrm{~A}$ maximum crests and another $10 \%$ reaching $120 \mathrm{~A}$ crests, for all capacitor bank switching.

In Figures 4 and 5 , we note that the characteristic appearance of the voltage and current usually observed during $a$ switch restrike is absent [3], indicating a clean switching action of the vacuum interrupters used for switching the capacitor bank. Restrikes are most likely to occur during de-energizing. In all the offon switching sequences of this test series, no significant transient was observed during de-energizing; all occurred during energizing.

The oscillograms of Figures 4 and 5 establish and explain the pattern of current pulses. The voltages of Figure 4 are not the open-circuit voltages impinging the drive input but, rather, the voltages resulting from the clamping action of the varistors. To better evaluate the magnitude of the switching transients, opencircuit voltages were recorded in a next sequence, with all fuses to the drive open, thus disconnecting both the varistors and all sensitive loads. Figure 6 shows two typical recordings of open-circuit voltages and two of voltages resulting from varistor clamping, recorded during a series of 10 switching sequences for each condition. Table 1 shows the recorded crests of the five highest voltages in each condition; the difference between the two groups, with due allowance for the imperfect statistical basis of the observations, indicates that the $510 \mathrm{~V}$ varistors reduced the peaks from a typical high of $1450 \mathrm{~V}$ to a typical high of $1100 \mathrm{~V}$.
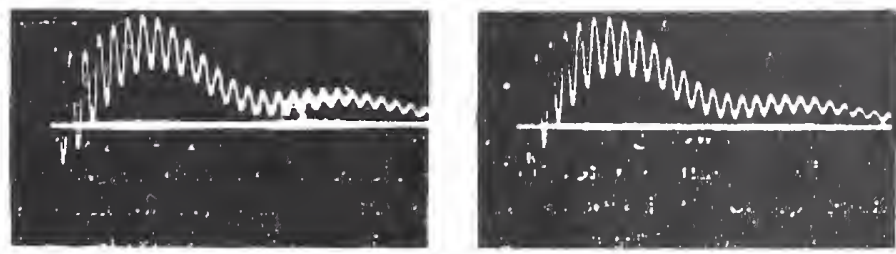

Open-CIrcull Voliages
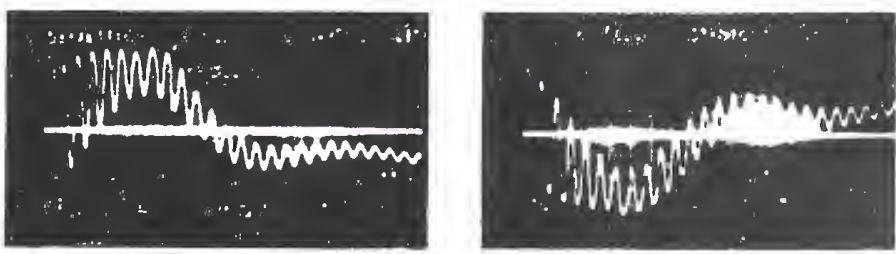

Wieh $20 \mathrm{~mm}$ Vartsiors

All Traces: Sweep: $0.5 \mathrm{~ms} / \mathrm{div}$ Vertical: $500 \mathrm{~V} / \mathrm{d} i \mathrm{y}$
Table 1

FIVE HIGHEST TRANSIENTS IN SEQUENCE OF 10 SWITCHINGS

\begin{tabular}{c|c}
\hline Without Varistors & With Varistors \\
\hline 1450 & 1100 \\
1400 & 1100 \\
1300 & 1050 \\
1300 & 1050 \\
1300 & 1050 \\
\hline
\end{tabular}

\section{DISCUSSION}

Nature of the Transients

The absence of any transient (over 120\% of normal crest) during the 2-hour monitoring period was somewhat surprising, in the context of earlier reports of high counts recorded with Dranetz disturbance analyzers. Frequent checks of threshold levels and variations of the possible trigger modes were made, maximizing the chance of catching an overvoltage, but indeed none occurred. This unusual quiet was also reflected in the chart recording made by the plant personnel, so that the absence of random transients for that period can be accepted at face value.

Therefore, conclusive evidence was obtained that substantial current pulses were absorbed by the varistors during capacitor switching. The magnitude and duration of these pulses were excessive for the capability of $20 \mathrm{~mm}$ disc; many similar drives installed elsewhere do not experience the failures encountered at that particular location.

Another significant finding from these measurements is the fact that the switching transients, generated at the $23 \mathrm{kV}$ level, propagate down to the point of utilization at the $460 \mathrm{~V}$ level. Numerical discussion of this finding is given later in this paper.

\section{Effect of Transients on Varistors}

Published varistor specifications include the "pulse ratings," a family of curves that define, for each varistor type, the number of isolated pulses that a varistor can absorb until its "rating" is reached [4]. The curves show lines relating amplitude, duration, and total number of pulses. Figure 7 shows this family of curves for the original $20 \mathrm{~mm}$ varistor.

Figure 8 shows the same curves for a proposed $32 \mathrm{~mm}$ varistor. It should be noted that the pulse rating does not mean catastrophic failure of the varistor at the end of this rating, but only a $10 \%$ change in the varistor nominal voltage. Although some change is indicated, the varistor is quite capable of staying on line voltage and of clamping surges.

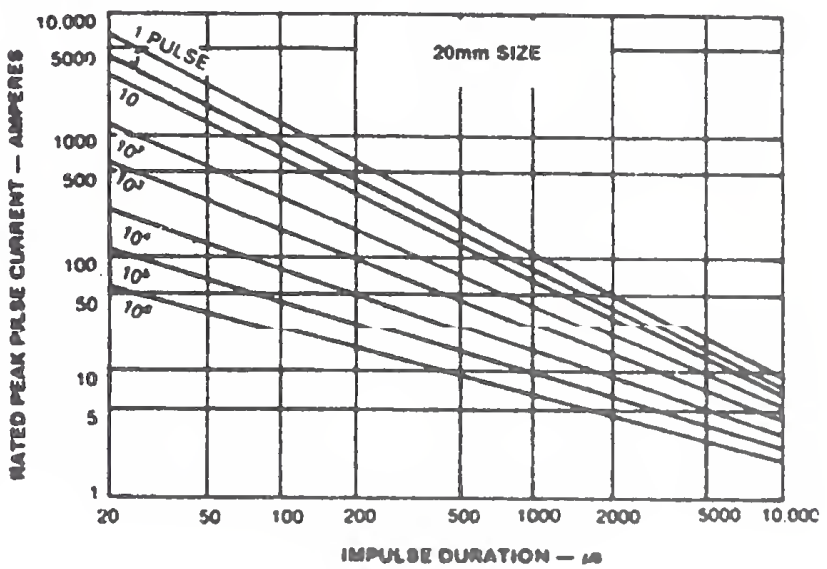

Figure 7. Pulse ratings of $20 \mathrm{~mm}$ varlstor [4] 


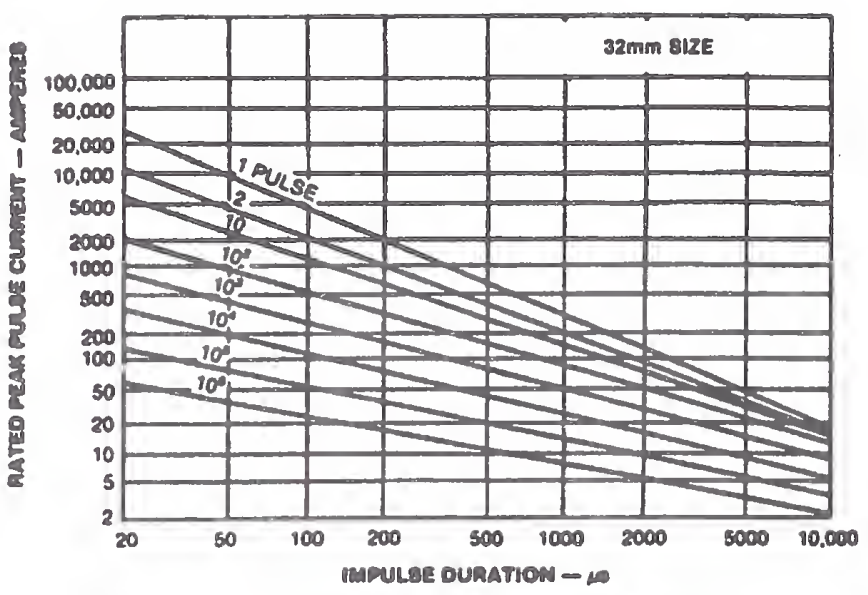

Figure 8. Pulse ratings of 32 mm varistor [5]

A careful examination of the pulse rating curves will show that the duration of the pulses has a strong influence on the number of permissible pulses. Furthermore, the relationship between the increased duration of the pulses and the decreased number of permissible pulses is not proportional. For instance, consider pulses of $100 \mathrm{~A}$ peak and $100 \mu \mathrm{s}$ duration (Figure 9A): the curves show 5000 pulses allowed. Now increase the duration of the pulses to $1000 \mu \mathrm{s}$ (a ten-fold increase), while keeping the amplitude at $100 \mathrm{~A}$ : the curves show the permissible number as one pulse only. Thus, the ten-fold increase in duration does not result in a ten-fold decrease in the number of permissible pulses; the reduction in that number is much greater than the inverse of the increase in duration. Conversely, taking a pulse duration of $1000 \mu \mathrm{s}$, and seeking the amplitude allowable for the same 5000 pulses, Figure 9B shows that the current is $20 \mathrm{~A}$, which is five times less than the original $100 \mathrm{~A}$, not ten times less. Therefore, it would be incorrect to treat the multiple pulses of Figure 5 as five separate short pulses; rather, one equivalent long pulse has to be defined.

The five-pulse burst of Figure 5 has been redrawn in Figure 10 in order to plot an equivalent continuous pulse of approximately equal duration, with a crest such that the i.t integral of the burst and the $\mathrm{j} \cdot t$ of the equivalent pulse are approximately the same. The use of $i \cdot t$ rather than the $i^{2} \cdot t$ integral typically used for fuses or other linear loads is justified by the fact that heat deposited in the varistors is the significant parameter because the nominal voltage change process is temperature related; this heat is the product of the variable $i$ and the nearly constant voltage across the nonlinear varistor during the burst.

The equivalent pulse of Figure 10 can then be used to evaluate, from the pulse ratings of Figure 7, the number of highamplitude switching transients that will consume $100 \%$ of the varistor pulse rating. Inspection of Figure 6 shows that for a $800 \mu \mathrm{s}$ duration and $100 \mathrm{~A}$ amplitude, the pulse rating of the $20 \mathrm{~mm}$ varistor ( $6 \mathrm{kA}$ rating at $8 / 20 \mu \mathrm{s})$ is reached with two such events. With a probability of about $10 \%$ that this highest switching transient would occur during random timing of the switching (the effect decreases rapidly for transients other than the highest) and with 2 to 4 switching operations each day, the pulse rating of the varistors could be reached with 20 operations, failure perhaps stal tius at 40 to 50 operations, or after about 10 dage of expoouro to that power system environment. This estimate is unavoidably imprecise because the pulse rating curves represent a conservative minimum; actual failures will occur only for amplitudes or num. bers of pulses exceeding the rating by a large but imprecise margin to allow for manufacturing variations. However, the order of magnitude of this estimated time to failure is in accord with the observations made at that installation.

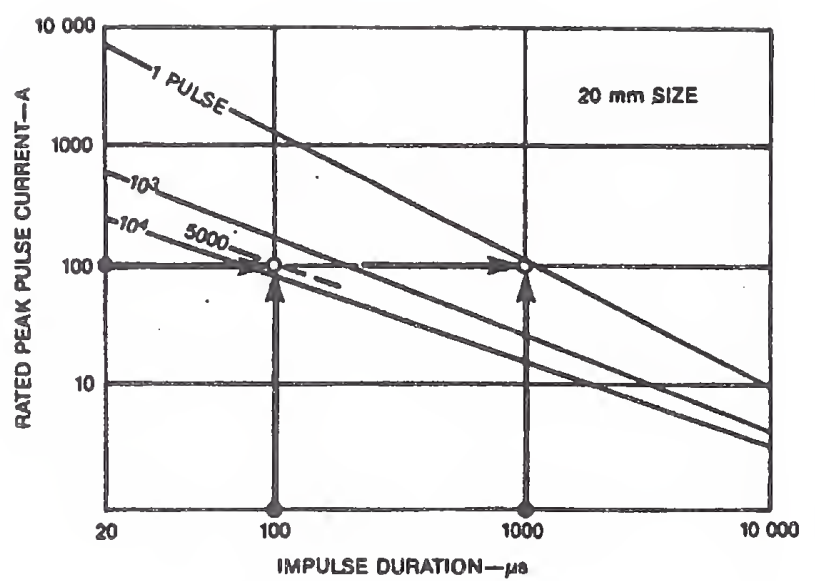

A. Same current, lncreaslng duration

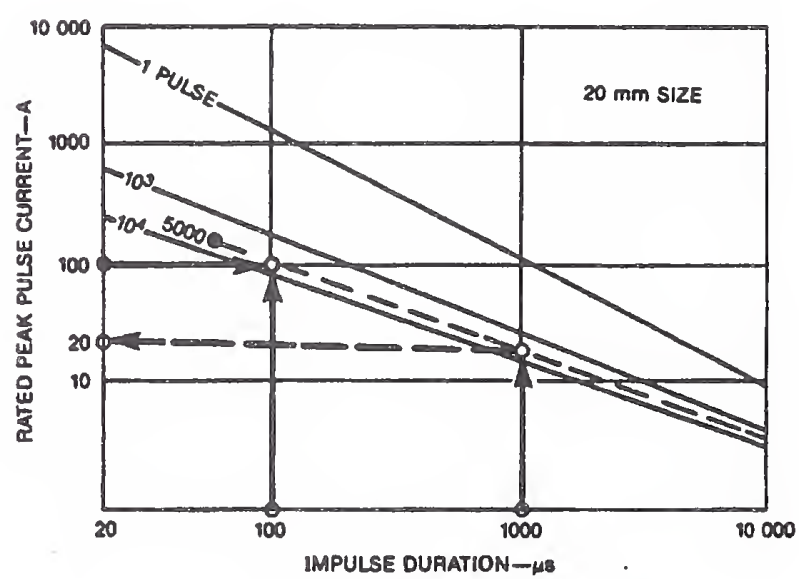

B. Same number of pulses, increasing duration

Figure 9. Readlog pulse ratings curves

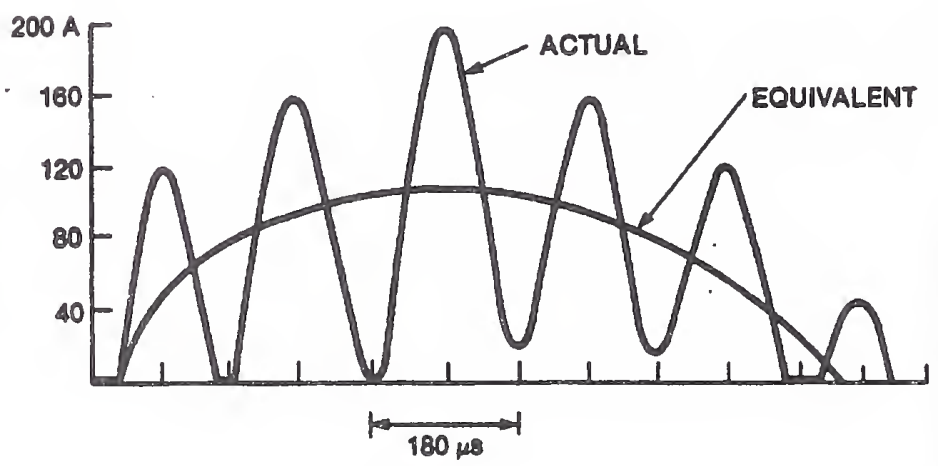

Figure 10. Slagle-pulse cquivalent dolse for multole pulses

Note that two types of events occur. One is the premature blowing of the fuse, which is not caused by a varistor failure but by the $t^{2} \cdot t$ capacity of the fuse being exceeded by the environment [1]. The other is the fuse blowing caused by the varistor end-oflife ultimate failure. 


\section{Alternate Varistor Selection}

An obvious remedy would be to use a varistor with greater energy-handling capability. The $32 \mathrm{~mm}$ size offers such a possibility. Inspection of Figures 7 and 8 shows that the equivalent pulse of Figure $10(800 \mu s$ and $100 \mathrm{~A}$ ) corresponds to a permissible occurrence of 100 pulses for the $32 \mathrm{~mm}$ varistor, in contrast to the two for the $20 \mathrm{~mm}$ varistor. The improvement in the number of pulses is 50 times more pulses until pulse rating is reached. The improvement in the number of pulses until varistor failure occurs, however, is not necessarily 50 times more pulses. Because of the imprecision mentioned previously in the margin between end of pulse rating and ultimate failure, that margin is not necessarily the same for the two sizes, $20 \mathrm{~mm}$ and $32 \mathrm{~mm}$, but it is reasonable to expect the same order of magnitude improvement in the ultimate failure as in the pulse rating. This expectation of a 50 times improvement would change the time between failures from the few days observed with the $20 \mathrm{~mm}$ size to perhaps one year with the $32 \mathrm{~mm}$ size, providing immediate relief and time to make further changes for the long term. Therefore, the change to a $32 \mathrm{~mm}$ size, connected at the same point of the circuit, was immediately implemented for that particular environment.

Further gains could be obtained in the length of time between varistor failures by increasing the clamping voltage of the varistors. This increase would result in lower current pulses for the same open-circuit transient voltage. A $510 \mathrm{~V}$ rating had been selected by the designer of the drive as the result of a trade-off between varistor clamping voltage and the withstand voltage of the thyristors protected by the varistors. If thyristors with higher voltage withstand were used, the solution would be easy.

Of course, the standard varistor product line has a certain tolerance band, reflecting normal production lot variations. In principle, a selection could be requested from the manufacturer that varistors with a narrower band be supplied for this application. The maximum clamping voltage allowed by the drive specifications would be retained, but those varistors in the lower half of the distribution, which draw larger current pulses for a given open-circuit transient voltage, would have been removed from the population of varistors. For instance, the range of nominal voltages for a $575 \mathrm{~V}, 32 \mathrm{~mm}$ varistor (the next higher voltage offered) is 805 to $1005 \mathrm{~V}$ for $1 \mathrm{~mA} \mathrm{dc}$, while the maximum nominal voltage of the same diameter but rated $510 \mathrm{~V}$ is $910 \mathrm{~V}$ for $1 \mathrm{~mA} \mathrm{dc}$. Thus, for a normal distribution of nominal voltages of the $575 \mathrm{~V}$ varistor, $50 \%$ of the devices could theoretically be used without exceeding the upper limit of the $510 \mathrm{~V}$ varistor that is consistent with the drive specifications. To achieve this end, it would be necessary for the supplier or user to make a careful determination of the nominal voltage on a population of $575 \mathrm{~V}$ varistors in order to retain only the lower half of the distribution (Figure 11).

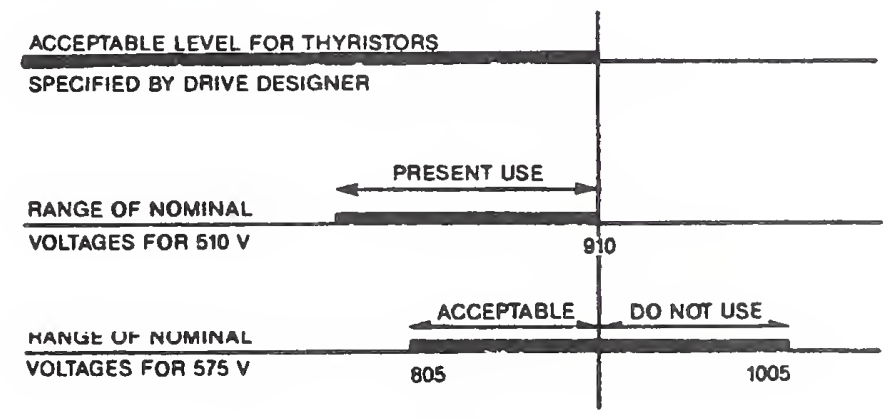

Figure 11. Tolerances bands of $510 \mathrm{~V}$ and $575 \mathrm{~V}$ varistors

\section{Other Remedies}

In addition to the proposed upgrading of protection at the $460 \mathrm{~V}$ level, three other remedies could be considered: installation of surge arresters at the $2300 \mathrm{~V}$ level, installation of surge arresters at the $23 \mathrm{kV}$ level, or a change in the circuits involved in the capacitor switching, designed to reduce the severity of the transients at their origin.

In general, the protection available from surge arresters tends to improve when the arresters are installed a! higher circuit voltages. Thus, it is quite possible that arresters installed at the $2300 \mathrm{~V}$ primary of the $2300 / 460$ transformer could provide a more effective clamping (and at the same time relieve some of the energy stress) than the varistors at the $460 \mathrm{~V}$ level. (It is of course implied that these would be the zinc-oxide type, gapless arresters.) The full benefit of these arresters depends on the configuration of the $2300 \mathrm{~V}$ system and its grounding (solidly grounded neutral in a wye system, resistance-grounded wye, or floating delta) when the arrestors are connected in the conventional line-to-ground mode. In a second phase of the retront described here, $2300 \mathrm{~V}$ arresters were installed at the transformer primary. A discussion of their expected performance, validated by the success of the retrofit, is given later on.

Likewise, arresters on the $23 \mathrm{kV}$ side could be installed at the $23 \mathrm{kV}$ substation to mitigate the capacitor switching transients at their origin, or at the primary of the $23 \mathrm{kV} / 2300 \mathrm{~V}$ substation near the control house, where they would also serve as lightning protection for the overhead $23 \mathrm{kV}$ incoming power line. These arresters, again, must be of the gapless type to obtain the most effective proiection.

The final remedy in the list of alternatives, but perhaps the first in effectiveness when the opportunity exists, would be to attempt reducing the severity of the capacitor switching transients at their origin. Series inductors or damping resistors may be considered, the effectiveness of which would be predictable if a simulation of the power system behavior were performed by computer modeling. While that remedy could not be applied to this particular location, it is a remedy that should be considered for a similar case of exceptionally severe environment.

\section{EXPECTED PERFORMANCE OF THE $2300 \mathrm{~V}$ ARRESTERS}

The measurements made first with open-circuit, then with the $20 \mathrm{~mm}, 510 \mathrm{~V}$ varistors on the $460 \mathrm{~V}$ side have shown a reduction of maximum voltage from $1450 \mathrm{~V}$ to $1100 \mathrm{~V}$ (Table 1) when a current of approximately $200 \mathrm{~A}$ is flowing in the line and varistors (Figure 5).

We can assume that the voltage drop in the line from the substation and two step-down transformers is mostly inductive at $5.5 \mathrm{kHz}$, and that the voltage in the varistors can be treated as the voltage across a resistor at the time of the crest of the current wave. The diagram of Figure 12 shows the relationship between the three voltages $V O C, V L$, and $V V$, respectively, the open-circuit voltage generated by the capacitor switching action, the voltage drop in the line and two transformers, and the varistor voltage at the current peak. Treating this highly nonlinear circuit as a linear circuit is an approximation that will provide at each point of the full range of voltage and current conditions a valid order of magnitude for the purposoo of this disoussion. Nunctinal hitclivuls ate available for rigorous treatment at any instant over the full range of conditions [6]. With this simpifying assumption, we can determine the order of magnitude of the $5.5 \mathrm{kHz}$ current that would flow in an arrester installed at the primary terminals of the 2300 $\mathrm{V} / 460 \mathrm{~V}$ transformer as follows. 
1. From the actual measured voltages shown in Figure 12, we derive the voltage drop, $V L$, in the $23 \mathrm{kV}$ line and two step. down transformers:

$$
\begin{aligned}
V_{L} & =\left(1450^{2}-1100^{2}\right)^{1 / 2} \\
& =940
\end{aligned}
$$

Thus, at $5.5 \mathrm{kHz}$, the impedance between the source and the varistor is

$$
\begin{aligned}
Z L & =\frac{V L}{I} \\
& =\frac{940 \mathrm{~V}}{200 \mathrm{~A}} \\
& =4.7 \Omega
\end{aligned}
$$

Note that this $4.7 \mathrm{\Omega}$ inpedance means that the $5.5 \mathrm{kHz}$ switching transient, generated ot distance of about $3000 \mathrm{~m}$ ( 2 miles) from the point of measurement, and at the $23 \mathrm{kV}$ level, can travel a long distance and pass through two step-down transformers with less attenuation than might be expected from the unsound but popular view that "surges cannot travel that far without substantial aftenuation."

2. We now arbitrarily assign equal values to the three elements of this impedance, $Z_{L}$ : (1) the $23 \mathrm{kV}$ line impedance; (2) the $23 \mathrm{kV} / 2300 \mathrm{~V}$ transformer; and (3) the $2300 / 460 \mathrm{~V}$ transformer. The impedance between the source and the primary of the $2300 / 460 \mathrm{~V}$ iransformer is then two-thirds of the total impedance, $\mathrm{ZL}$, or about $3 \Omega$ for the $460 \mathrm{~V}$ side of the transformer.

3. On the $2300 \mathrm{~V}$ side, the impedance of $3 \Omega$, calculated above, becomes $3 \Omega \times(2300 / 460)^{2}=75 \Omega$ and the open-circuit voltage of $1450 \mathrm{~V}$ which was measured on the $460 \mathrm{~V}$ side becomes $1450 \mathrm{~V} \times(2300 / 460)=7250 \mathrm{~V}$.

4. Knowing the open-circuit voltage and the impedance between the source and the $2300 \mathrm{~V}$ arrester, we can compute the current in the arrester by iteration if we assume some current value and read the corresponding clamping voltage on the I.V characteristic of the arrester:

a) Assume a current crest of $50 \mathrm{~A}$, producing a drop of 50 $x 75=3750 \mathrm{~V}$ in the line and $23,000 / 2300 \mathrm{~V}$ transformer. Adding this voltage to the varistor vollage, corresponding to $50 \mathrm{~A}$, which is read as about $5700 \mathrm{~V}$ on the arrester characteristic curve for minimum discharge voltage (Figure 13), we have $\left(3750^{2}+5700^{2}\right)^{1 / 2}=6780 \mathrm{~V}$, or somewhat below the expected $7250 \mathrm{~V}$ open-circuit voltage, which is 10 equal the quadratic sum of the two voltages VL and VV.

b) Assume, for a new iteration. a crest of $60 \mathrm{~A}$, producing a drop of $60 \times 75=4500 \mathrm{~V}$, while the varistor voltage remains essentially the same, i.e., $5700 \mathrm{~V}$. The quadratic addition becomes $\left(4500^{2}+5700^{2}\right)^{1 / 2}=7210 \mathrm{~V}$, or a value close to the goal of 7250 .

5. Thus, we can expect that the $2300 \mathrm{~V}$ arrester will experience current pulses occurring in bursts not exceeding 60 to $70 \mathrm{~A}$, with durations similar to those found on the $460 \mathrm{~V}$ varistors, i.e., 5 to 7 pulses per train, or a total duration in the order of $1 \mathrm{~ms}$. Information on arrester duty available from the manufacturer indicates that, for a pulse train of that duration and a crest of less than $100 \mathrm{~A}$, no limitation of the number of puises need oe imposed on the arrester as long as enough time is allowed between pulses to permit cooling of the arrester.

Furthermore, she $5700 \mathrm{~V}$ clamping level predicted for the $2300 \mathrm{~V}$ surge arresters at $60 \mathrm{~A}$ would be reflected as a crest of $5700 \mathrm{~V} \times 460 / 2300=1140 \mathrm{~V}$ on the $460 \mathrm{~V}$ side. The $510 \mathrm{~V}$, $32 \mathrm{~mm}$ varistors, connected in series with the impedance of the $2300 / 460 \mathrm{~V}$ transformer, would then be exposed to this maximum

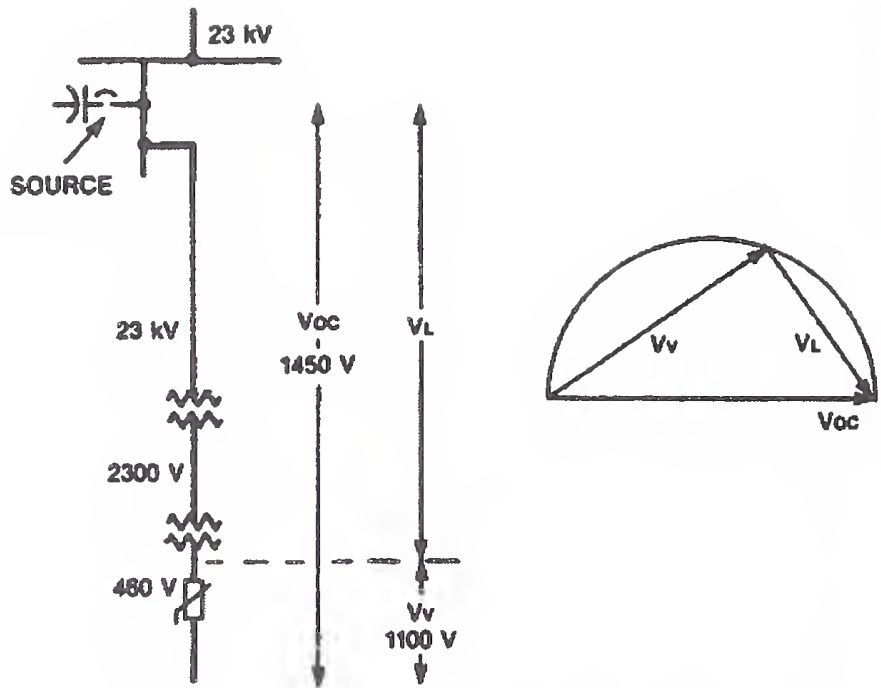

Figure 12. Open-circuit voltage and voltage diops in the syetem

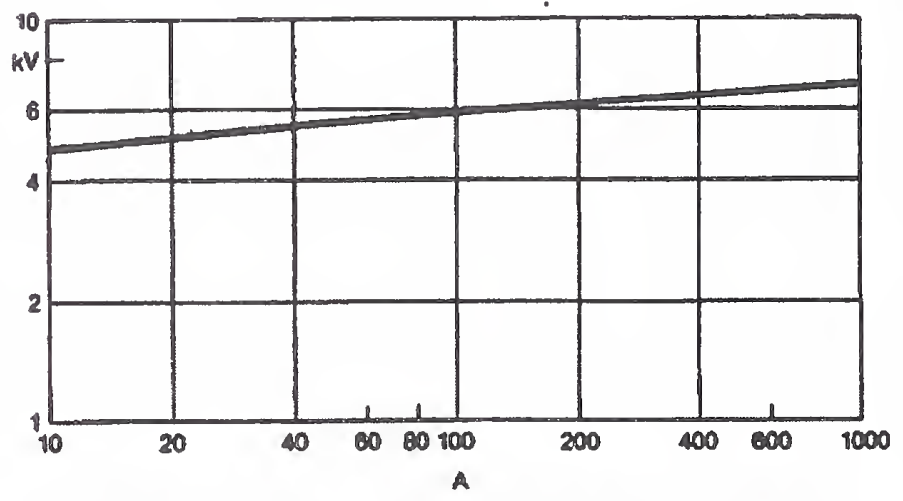

Figure 13. Minimum clamplas voltage characteristle for $2300 \mathrm{~V}$ armester

open-circuit voltage of $1140 \mathrm{~V}$, a value much lower than the $1450 \mathrm{~V}$ open-circuit voltage that was applied to them in the absence of the $2300 \mathrm{~V}$ arresters. For that applied voltage, the current drawn by the varistor would be in the range of 10 to $20 \mathrm{~A}$, values much lower than the $200 \mathrm{~A}$ measured without the $2300 \mathrm{~V}$ arrester. Computing the equivalent pulse, as was done in Pigure 10 for the $200 \mathrm{~A}$ crests, would yield an equivalent crest of about $10 \mathrm{~A}$, for which the pulse rating curves of the $32 \mathrm{~mm}$ series show more than 100,000 pulses before its rating is reached.

To place these large differences of performance and withstand capability into perspective, Table 2 shows the relative sizes and volumes of varistor material applied to the taming of the capacitor switching transient. In other words, the exviromatent bas now beea watched by the copablity of the varlstors.

Table 2

VARISTOR AND ARRESTER DIMENSIONS

\begin{tabular}{c|c|c|c}
\hline \multicolumn{1}{c|}{ Type } & Diameter & Thickness & Volume \\
\hline $20 \mathrm{~mm}$ & $1.8 \mathrm{~cm}$ & $0.35 \mathrm{~cm}$ & $0.9 \mathrm{~cm}^{3}$ \\
$32 \mathrm{~mm}$ & $3.0 \mathrm{~cm}$ & $0.35 \mathrm{~cm}$ & $2.5 \mathrm{~cm}^{3}$ \\
$2300 \mathrm{~V}$ Arr. & $6.1 \mathrm{~cm}$ & $2.4 \mathrm{~cm}$ & $70 \mathrm{~cm}^{3}$ \\
\hline
\end{tabular}




\section{CONCLUSIONS}

Voltage and current measurements made on the $460 \mathrm{~V}$ input to a thyristor motor drive, during staged capacitor switching operations, showed current surges in the varistors originally used in the system that could consume the pulse rating life of these varistors in a few days of typical operation. Short-and long-term remedies were achieved.

For the short term, the change to a larger varistor connected on the $460 \mathrm{~V}$ side of the system was readily implemented to maintain the originally specified protective level, while the fuse-blowing nuisances were eliminated by use of a larger fuse. Available devices for this $460 \mathrm{~V}$ circuit may still have a relatively short life (a few hundred days) in the prevailing environment of the site, but they offered immediate relief and therefore allowed successful startup of the system.

For the long term, further protection was obtained by the installation of conventional station-class surge arresters, of the zinc-oxide, gapless type, at the $2300 \mathrm{~V}$ level. The system has now operated for 3 years without problems.

This case history also illustrates the low attenuation of the switching transient between the distant source at $23 \mathrm{kV}$ (about $3000 \mathrm{~m}$, or 2 miles) and the point of utilization at $460 \mathrm{~V}$.

\section{ACKNOWLEDGMENTS}

J.S. Kresge and B.I. Wolff provided information and guidance on the surge arrester and the varistor characteristics; C.L. Fisher contributed advice in clarifying and unifying the presentation of the concepts. Their contributions are gratefully acknowledged.

\section{REFERENCES}

[1] F.D. Martzloff, "Matching Surge Protective Devices to their Environment," Proc. IEEE/IAS Meeting. October 1983, pp. 387-392. (Also scheduled for IAS Transactions, Jan/Feb 1985.)
[2] ANSI/IEEE Std C62.33-1982, IEEE Standard Test Specifications for Varistor Surge Protective Devices, The Inslitute of Electrical and Electronic Engineers, lnc., New York.

[3] A. Greenwood, Electrical Transients in Power Systems, Wiley Interscience, New York, 1971.

[4] Transient Vollage Suppression Manual, Fourth Edition, Generai Electric Company, Auburn, NY, 1983.

[5] Transient Vollage Suppression Manual, Third Edition, General Electric Company, Auburn, NY, 1983.

[6] H.W. Dommel, "Digital Computer Solution of Electromagnetic Transients in Single and Multiphase Networks," IEEE Transactions on Power Apparatus and Systems, Vol. PAS-88, pp. 388-399, April 1969

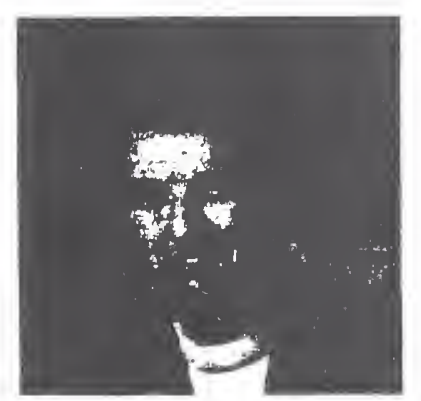

Françols D. Martzloff (M'56, F'83) was born in France, and received his undergraduste degree at the Ecole Spéciale de Mécanique et d'Electricité in 1951; he received the MS in Electrical Engineering degree from Georgia Tech in 1952 and the MS in Indusirial Administration degree from Union College in 1971.

Since 1956 he has been with the General Electric Company, where he gained experience in the Transformer and Switchgear Division. Upon joining General Electric Corporate Research and Development in 1961, he became involved in power semiconductor circuits and overvoltage pro. tection. He has participated in the introduction and applicalion of metal oxide varistors since 1971 .

In IEEE, Mr. Martzloff is active on the Surge Proteclive Devices Committee. He is chairman of the Working Group on Surge Chataclerization in Low-Voltage Circuits. He is also a member of the Ad Hoc Advisory Subcommittee of the USA Advisory Committee on IEC S/C $28 \mathrm{~A}$, ANSI C.62 Subcommittee on Low-Voltage Surge Proteclive Devices, and Chairman of the NEMA Low-Voltage Arresters Technical Committee. He has been awasded 13 U.S. patents, primarily in the field of varistors and transient protection. 


\section{Dlscussion}

J. L. ISoeplinger (Duquesne Light Company, Pittsburgh, PA): The author has addressed one of many mechanisms for producing repetitive overvoltages on low-voltage circuits. In this particular instance, it was possible to obtain controlled conditions so that a measurement could be made of the voltage and currents resulting from the capacitor switching. It would be useful if there was an analytical method presented that correlated the generation of the $5.5-\mathrm{kHz}$ pulses with those measured. Did the suthor attempt to make such a correlation?

This paper points out the need to know the characteristic of the surge so that proper sizing of the protection can be achieved. Therefore it would be desirable to be able to have some analytical tool to permit calculation of the frequency of the surge due to remote capacitor switching.

Manuscript received July 24, 1985.

Fraucols D. Martalof: The paper reported a case history from which useful information may be derived on retrontting corrections of similar problems or, better, on avoiding the problem by foresight. The aituations confronting the author was the need for immediate corrective action rather than complete investigation and mutual validation of analytical methods and field measurements.

The literature is fairly rich in both theoretical and practical papers on the problems associated with capacitor switching, both for energizing and for de-energizing, the latter involving the risk of restrikes. Because of this availability and the limited space available in the Transactrons on one hand, and because of the limitations in scope of the field retrofit mission on the other hand, no attempt was made to correlate the measurements with the power system parameters (which were not readily available to the author). In response to Mr. Koepfinger's suggestion, abstracts are cited below to provide references to both analytical tools and practical results published by other workers.

\section{Bibliography, 1970-1985 : REFERENCES}

[1] M. F. McGranaghan, W. E. Reid, S. W. Law, and D. W. Gresham, "Overvoltage Protection of Shunt-Capacitor Banks Using MOV Arresters," IEEE Trans. Power App. Syst., PAS-103, No. 8, Aug. 1984, pp. 2326-2333.

Protection requirements and surge arrester duties are analyzed for both digital and transient network analyzer (INA) simulations. Simple analytical expressions are developed for evaluating arrester duty as a function of capacitor bank size. Guidelines and limitations for applying arresters at grounded-and ungrounded-wye capacitor banks are developed based on overvoltage characteristics and arrester capabilities.

[2] J. H. Brunke and G. G. Schoeckelt "Synchronous Energization of Shunt Capacitors at $230 \mathrm{kV}$," IEEE PES (Power Eng. Soc.) Winter Meeting, New York, NY; Jan. 20-Feb. 3, 1978; Pub! by IEEE 1977, Paper A78-148-9, p. 4.

This paper reports on the application of synchronous switching to reduce inrush transients when switching a $230-\mathrm{kV}$ shunt capacitor bank. Computer studies determined the required switch performance.

[3] J. D. Cuffman, John Linders, M. A. Zucker, and S. Willima, "Power Factor Correction Capacitors and Their Side Effects," IEEE Conf. Rec., 28th Ann. Conf. Electr. Ens. Probl. Rubber Plast. Ind., Akron, OH, April 5-6, 1976, pp. 37-49.

The major reason for applying capacitors to an electrical distribution system is to correct poor power factor. In the greater majority of installtions it is a routine procedure. In some instances capacitors may cause problems with other in-plant equipment and in other instances they may suffer undesirable side effects that originate in other equipment. Among these problems are switching surges, voltage unbalance due to fuses blowing, and harmonics generated by SCRcontrolled equipment.

[4] II Velland, and C Vallma 0 Vamum Contactare. I atect Development in Their Design and Application," Certif. Ens. V 54, No. 1, Jan. 1981, pp. 824-841.

The paper includes the following topics: Design of vacuum bottles (glass and ceramic); design of the complete vacuum contactor and their panels; panels with on-load isolation, and panels with off- load isolation; vacuum contactor applications (motor control), capacitor switching, arc and other (furnace-switching, transformer switching, mine-winder-reversers). Surge generation by vacuum contactors is considered under the following heads: basic energization and de-energization transients; transients generated when switching inductive loads; assessment of a vacuum contactor from a surge generation point of view; types of surge suppression devices; switching of capacitive loads. An extensive discussion of the paper is appended.

[5] Jack R. Harbaugh and John E. Harder, "Important Considerations for Capacitor Applications in the Petroleum and Chemical Process Industries," IEEE Pet. Chem. Ind. Conf., 27th Ann. Rec. of Conf. Pap., Houston, TX, Sept. 8-10, 1980; IEEE, H80CH1549.5 IA), Piscataway, NJ, pp. 157-167.

The location of capacitors may have a significant effect of the (I 2R losses within the plant transformers and conductors, which is wasted energy. Transients generated by capacitor switching may require attention in the selection of arresters, system insulation, or other equipment. The presence of capacitors amy require some special attention to large motors during system reclosing or load transfer. This study addresses esch of these considerations, providing some guidelines for effective, reliable capacitor application. In addition, a checklist is provided for general industrial capacitor applications.

[6] J. F. Burser, R. J. Santoro, J. W. Stolle, R. E. Owen and C. R. Clinkenbeard, "Comparative Evaluation of Field Test Data and Computer Results on Capacitor Switching Transients," Meeting Minutes PA Electr. Assoc., Eng. Sect., Trans. and Distrb. Comm. West Middlesec, PA, May 15-16, 1979; PA Electr. Assoc., Eng. Sect., Harrisburg, PA 1979.

An arrester failure case was analyzed occurring at the time of substation capacitor bank switching with the use of a transient network analyzer (TNA) and digital computer techniques. The case involved a 12.5-kV ground-wye distribution sytem. Resuits of the TNA study, which were validated by field tests, showed the effects of system configuration magnitude of transient over voltages.

[7] Eldon J. Rosers, and Don A. Gilles, "Shunt Capacitor Switching EMI Voltages, Their Reduction in Bonneville Power Administration Substations," IEEE Trans. Power Appar. Syst. PAS-93, No. 6, Nov.-Dec. 1974, pp. 1849-1860.

Back-to-back switching of grounded wye shunt capacitors cause high frequency, high-magnitude current flow in overhead bus and ground mat conductors. Measurements of induced voltages on control cables and receptacles, transverse voltages on fuse blown PT secondaries and personnel intercept voltages are reported. BPA methods of confining transients to capacitor areas and shielding techniques are reviewed.

[8] Paul C. Krause and William C. Mauser, "On-Line Transient Control of Capacitor Switching to Improve System Stability," IEEE Trans. Power Appar. Syst. PAS-92, No. 1, Jan-Feb. 1973, pp. 321-329.

A simplified voltage-reactance equivalent of the one-machine infinite bus system was used. The material presented in this paper shows that this simplified model does not predict the performance of a onemachine infinite bus system with the accuracy necessary to determine the capacitor switching times so as to achieve the control objectives. However, it is shown that computation accuracy may be improved by including system losses. It appears that in order to apply optimal control techniques it will be necessary to develop more accurate models of the power system components. Also, faster than real time iterative, on-line computation techniques as simulated in this paper should be implemented and used to calculate the switching times. Until these obstacles are overcome, optimal control theory will have little impsct upon the power industry.

[9] D. O. Wiitanen, J. D. Morgan, and G. L. Gaibrois, "Station Capacitor Switching Transients, Analytical and Experimental Results," IEEE Trans. Power App. Syst. PAS-90, No. 4, July-Aug. 1071, PP. 16301615.

Station capacitor bank energization transients predicted by a circuit model are compared to field-test results. Selection of a suitable model is discussed. A computer solution of the model is presented.

Manuscript received September 19, 1985. 


\section{Real, Realistic Ring Waves for Surge Testing}

\author{
François Martzloff \\ National Institute of Standards and Technology \\ Gaithersburg MD 20899 USA \\ f.martzloff@ieee.org
}

\author{
Guiseppe Pellegrini \\ Italian Electricity Board (ENEL) \\ Automatica Research Center \\ Milano, Italy
}

Reprinted, with permission, from

Proceedings, $g^{\text {th }}$ International Zürich Symposium on Electromagnetic Compatibilky, 1991

\section{Significance:}

Part 2 Development of standards - Reality checks

Part 5 Monitoring instruments, laboratory measurements, test methods

Standards for surge testing have a long tradition of using unidirectional waves ("impulses"), in particular a $1.2 / 50$ voltage impulse and an $8 / 20$ current impulse. Many surveys of surge activity in low-voltage AC power circuits have shown that a large number of recordings actually show oscillatory surges rather than unidirectional surges.

This paper provides examples of such waveforms, independently recorded by two organizations, one in the US and one in Italy. These examples draw on field measurements as well as laboratory experiments and are offered to make the case that Ring Waves should be included in the regimen of electromagnetic compatibility tests. 
$\varnothing$ 


\section{REAL, REALISTIC RING WAVES FOR SURGE TESTING}

\author{
Françols D. Martzloff \\ National instltute \\ of Standards and Technology \\ (NIST) \\ Gaithersburg, MD USA
}

\author{
Giuseppe Peilegrini \\ Italian Electrlclty Board (ENEL) \\ Research \& Development Department \\ Automatlca Research Center \\ Milano, ITALY
}

ABSTRACT - Flve Independent investigations on the coupling of surges into low-voltage circults (data or power lines), and of their effects, show that a damped oscillatory translent is a real, realistlc stress for equlpment connected to these lines.

\section{INTRODUCTION}

Traditional surge testing performed on electromechanical equipment has been based on the unidirectlonail $1.2 / 50 \mu \mathrm{s}$ Impulse deemed to represent the threat of ilghtning In power transmission networks. The purpose of these tests was to demonstrate the abillty of high-Impedance Insulation to withstand a voltage stress. As a complement to these traditional tests, a current waveform was defined to demonstrate the ability of low-impedance components, such as surge arresters, to carry the currents associated with slmulated Ilghtning discharges. Application of systematic tests based on these two waveforms, as part of the BasIc Insulation Level concept, was a turning point in ensuring greater reliability of power systems.

These tests, however, were primarily almed at demonstratlng the abllity of equipment to survive In the presence of the ilghtning phenomenon or translents in the low-voltage power cables. The rellabllity of systems In the presence of other electromagnetlc disturbances requlres consldering other tests, dealing not only with equipment withstand capability, but also with its immunity.

With the development and Increasing deployment of improved instrumentation, it became apparent that typlcal waveforms of surges in low-voltage circults are not only the traditional unldirectlonal wave, but also a decaying oscillatory wave. The results of measurements performed over the years in widely different envlronments, however, [1], [2] have demonstrated the prevailing pattern of osclllatory transients.

\section{SPECIFIC INVESTIGATIONS}

Thls paper briefly cltes the results of flve investlgations performed by the authors, which polnt out the need to consider damped oscillatlons as a necessary compiement to the traditionai unldirectional waveforms. Included are two unpubllshed Investlgations of coupling from a high-voliage line into iow-voltage slgnal and control ilnes that were performed at facilitles of the Italian Electrlcity Board, ENEL, in 1969 and 1975, as reported In thls paper by G. Pellegrinl. One investlgation of surge coupling between a grounding conductor and other low-voltage conductors was performed In 1978 In support of IEEE Std C62.41 [3]. [4]. Another Investigation of the propagatlon surges was pertormed in $198 /$ oy NISI at an Industrial building In Californla [5]. Prellminary tests have been conducted in 1990 at the NIST facillties on semiconductor failure modes, iliustrating the Impilcatlons of osciliatory stress on semiconductor failure modes. These last three investigations are reported In this paper by F.D. Martzioff. From these flve Investlgatlons, the concluslon is reached that oscillatory surges - Ring Waves - need to be included in a comprehenstve test program for electromagnetic compatlbillty [6]
1. Surge voltages induced in low-voitage control and signai cabies iocated near transmission lines impacted by lightning

To establlsh realistic surge immunity specification for equipment installed In high-voltage (HV) substatlons, it was imperative to identify the parameters of transient voltages induced In assoclated signal and controf llnes. To that end, Investigatlons were carried out in 1969 at the ENEL "Verderio" HV Substation [7], [8].

Primary phenomena (llghtnlng, switching, and faults) were simulated on the HV line. The resultant surges Induced in control and signal cables running parallel to the line were identified and measured.

1.1 Simulation of primary phenomena - The phenomena considered in the investigation are lightnlng surges and switching surges (energizing and initlal transient of ground faults). Rise time and duratlon were the two most significant parameters. The $1.2 \mu \mathrm{s}$ rise time of the standard $1.2 / 50 \mu \mathrm{s}$ Impulse was seiected as representative of the phenomena considered. The duration of the standard $1.2 / 50 \mu \mathrm{s}$ impulse Is representative of lightning, but too short for switching surges.

Therefore, simulation of the primary phenomena was obtalned by a $1 / 500 \mu \mathrm{s}$ Marx generator $(600 \mathrm{kV}, 18 \mathrm{~kJ}, 75$ ohms Internal Impedance, output capacitance $3 \mathrm{nF}$ ), by applying this unidirectlonal pulse to a $31-\mathrm{km}$ long line (line-to-ground, slngle phase). The resultant voltage pulse applled to the line, unloaded and not terminated on its characterlstic Impedance, was $106 \mathrm{kV}$ peak and the ilne current $264 \mathrm{~A}$ peak.

The waveform of the generator open-clrcuit voltage Is shown In Figure 1 and the resulting voltage applied to the line In Flgure 2 (front of wave and complete waveform). The oscillograms show how the unidrectlonal impuise produces a wave characterized by a unldirectlonal component plus oscillatlons caused by the Impedance mismatching at the end of the llne and also along $\mathrm{tt}$. the latter assoclated with llne towers having dlfierent heights.

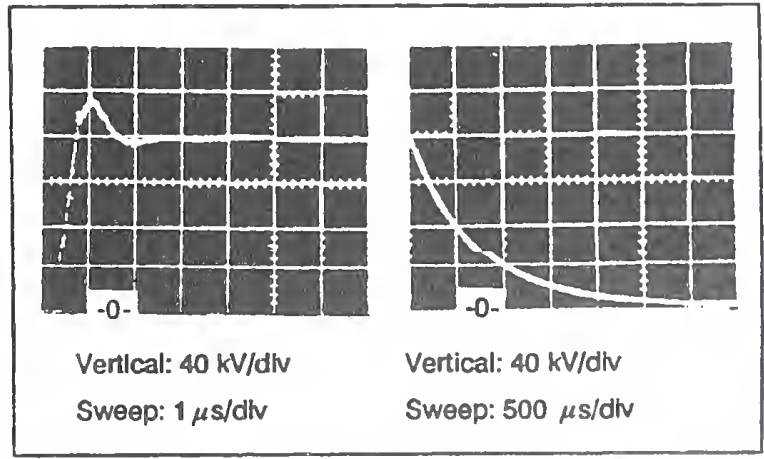

Figure 1. Open-circuit Voltage of Surge Generator Simuiating Lightning on the Transmission Line 


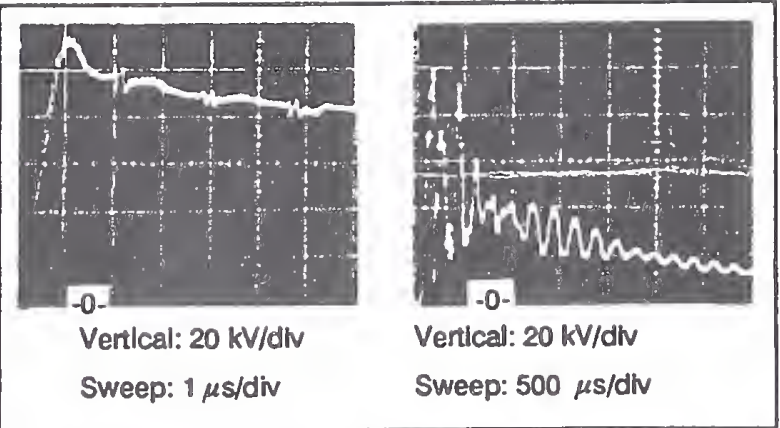

Figure 2. Surge Voltage Applied to the High-Voltage Line

1.2 Measurements on cables - Twelve types of cables were included in the test program. in the present summary, results are clted for typlcal unshielded and shielded cables, including coaxlai and trlaxilal cabies. For each cable, several measurements were made, including common and differential modes, with various comblnatlons of earth connection for the shlelds and terminating Impedances. Space IImitation in the present paper prevent presentation of detalled test configurations and results; these can be supplied to Interested partles by $\mathrm{G}$. Peliegrinl. Flgure 3 lliustrates one of the types of connectlons and comblnatlons of grounding for one example of cable. The major point of this paper is to call attention to the occurrence of osclllatory waveforms in the cabies, rather than detailed numerical values. For each cable, the characteristics of the voltages are summarized below, and selected osclllograms (Flgures 4-7) illustrate the waveforms.

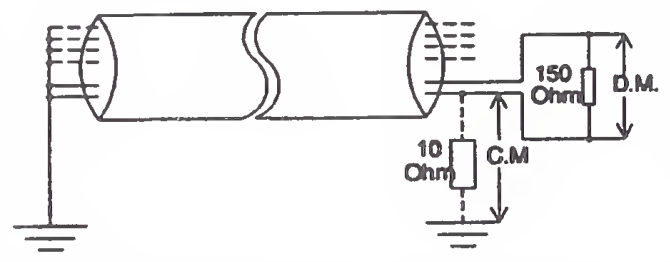

C.M. = Common Mode $\quad$ D.M. = Differential Mode

Figure 3. Typical Connections for Cable Measurements

Control cable. unshielded (Flgure 4)

Common mode voltage: $200 \mathrm{kHz}$ damped oscillation.

Differential mode voltage: $250 \mathrm{kHz}$ damped oscillatlon.

Telephone cable, 20 oairs, aluminum iape shield (Figure 5)

Shleld-to-earth voltage: $200 \mathrm{kHz}$ damped oscillatlon.

Common mode voltage of the pairs (shield earthed at both ends): unidlrectlonal component with a few microseconds duratlon and superimposed $400 \mathrm{kHz}$ oscillation.

Differential mode voltage: not shown, but negligible value (less than $1 \mathrm{~V}$.

\section{Coaxlal cable. BG 58/U (Figure 6)}

Shield-to-earth voltage: $300 \mathrm{kHz}$ damped oscillatlon.

Conductor-ta-shleld voltage (shield earthed at both ends): unidirectlonal component with about $40 \mu$ s duration

\section{Iriaxialcable, RG 58A/U (Figure 7)}

The outer shield-to-earth voltage presents the same general wavelorm as the one observed for the coaxial cable. The Inner shleld-to-earth voltage, with the outer shieid earthed at the ends Is similar, but the unidirectional component has $400 \mathrm{kHz}$ osclllatlons superimposed. The same situation occurs for the conductor-to-earth voltage, with an amplitude of about $15 \%$ of the first case, due to the higher shlelding efficiency.

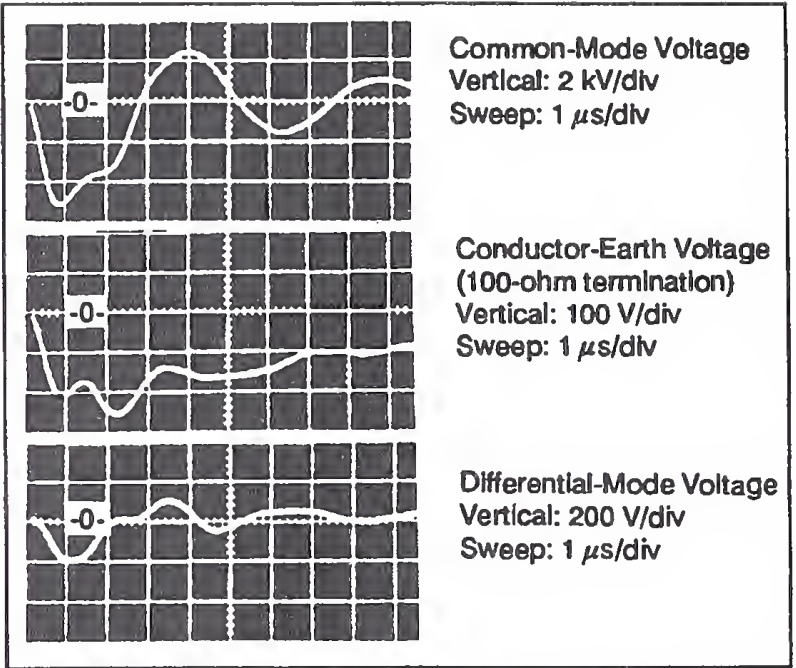

Figure 4. Transients Induced in Unshielded Control Cabie

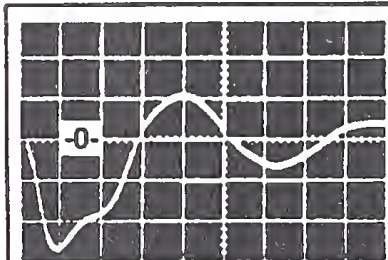

Shleid-Earth Voltage Vertical: $2 \mathrm{kV} / \mathrm{dlv}$ Sweep: $1 \mu \mathrm{s} / \mathrm{dl} \mathrm{V}$

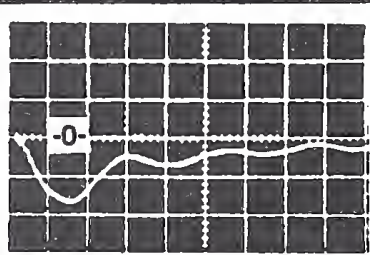

Common-Mode Voltage Vertlcal: $100 \mathrm{~V} / \mathrm{dh}$ Sweep: $1 \mu \mathrm{s} / \mathrm{dW}$
Figure 5. Transients Induced In Shleided Telephone Peir

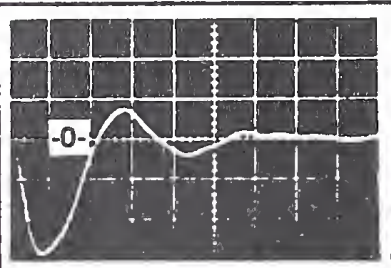

Shield-Earth Voltage

Ventcal: $2 \mathrm{kV} / \mathrm{dl} \mathrm{l}$

Sweep: $1 \mu \mathrm{s} / \mathrm{dlv}$

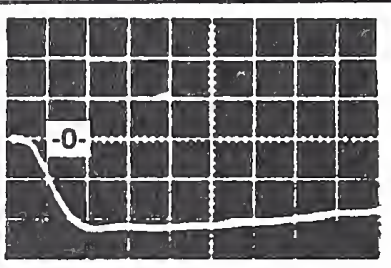

Conductor-Shield Voltage Vertlcal: $10 \mathrm{~V} / \mathrm{div}$ Sweep: $1 \mu \mathrm{s} / \mathrm{d} / \mathrm{v}$
Figure 6. Transients induced in Coaxial Cable

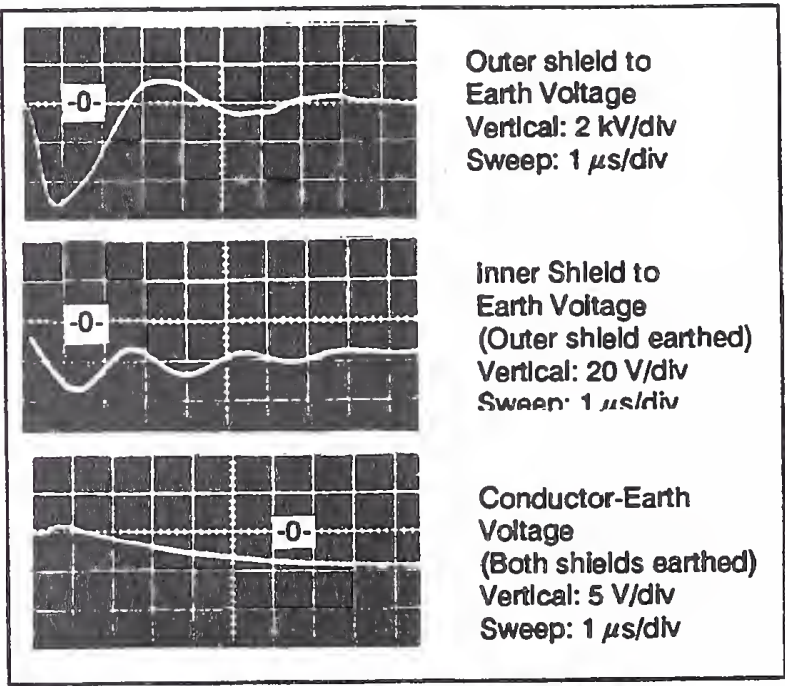

Figure 7. Transients induced in Trlaxial Cable 
1.3 Discussion of results - The shape of a unidirectional pulse Impressed onto a line though a generator is subjected to modifications due to the practical impossiblity of terminatlng the line on Its characterlstlc impedance. The actual phenomenon occurring on the IIne and Impactling the secondary low-voltage cabling is quite different from the theoretical double exponential pulse. This Interaction between the surge generator and its load occurs whenever a similar pulse Is applled to other networks or structures.

Whenever the predominant coupling Is Inductlve, the surges in the victlm cables have a damped osclllatory waveform at a frequency that may range from 100 to $300 \mathrm{kHz}$, with a damping dependent on the type of cable shield and the propagation of the Induced voltage. When there is a cornmon impedance coupling of the cables with the primary phenomenon, as in the case of the shleld earthed at the ends, with consequent transient current flowing in it, the Induced voltage shows a unidirectional component with superimposed damped osclllations.

\section{Surges induced in control and signal cables near $6 \mathrm{kV}$ and $380 \mathrm{~V}$ cables}

Thls Investigatlon, complementing the Verderio measurements, was carried out In 1975 at the ENEL "Turblgo" Power Plant. The purpose was to identify the surges induced In control and low-level ( $m A$, $m$ V) measurement cables Installed along power cables in power plants, as well as In Industrlal plants [8]. [9].

The causes of dlsturbances considered were the switchlng of power clrcuits at $6 \mathrm{kV}$ and $380 \mathrm{~V}$, occurring under worst case conditions of switching at the crest of the power-frequency voltage.

2.1 Primary Phenomena - The power circuits used for the investlgatlon were a $6 \mathrm{kV}$ cable feedlng a $700 \mathrm{~kW}$ load In an operatling power plant; the $380 \mathrm{~V}$ cables were connected to an artfilclal load of $2.5 \Omega$ (120 A peak). The waveform of the $6 \mathrm{kV}$ surges occurring at the closing of a clrcult breaker is given in Figures $B$ and 9. The waveform related to the $380 \mathrm{~V}$ cable is given in Figure 10. The waveform of the surge in the $6 \mathrm{kV}$ cable (difflcult to read in the reproduced oscillograms) has a rise time less than $1 \mu \mathrm{s}$, with a step after $4 \mu \mathrm{s}$ due to the reflectlon In the proximlty of the load (it has been verifled that the waveform is Independent on the presence of a load). Because the shield of the $6 \mathrm{KV}$ cable was eanthed only at the switchgear cell, the voltage between shleld and earth at the other end of the shield was also measured (Figure 9), as this voltage may be the most ilkely to couple disturbances inte adjacent control lines. The surge In the $380 \mathrm{~V}$ circult has a rise Ilme of about $50 \mathrm{~ns}$.

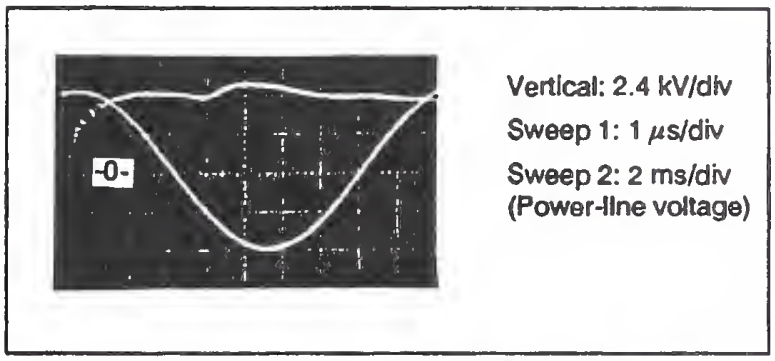

Figure 8. Surge Occuming on 6 kV Cable, between Conductor and Shield

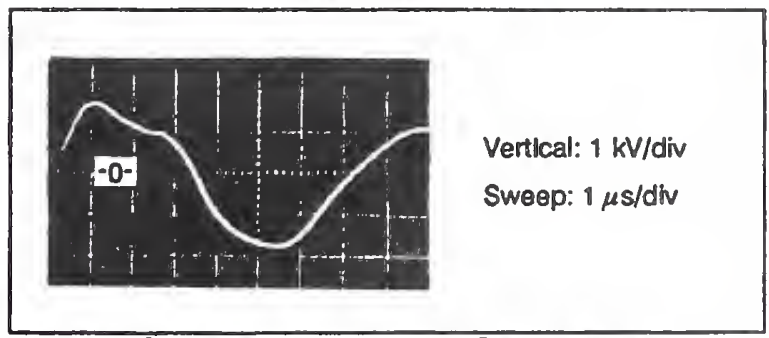

Figure 9. Surge Occurring on 6 kV Cable, between Shleld and Earth, at Floating End of Shield

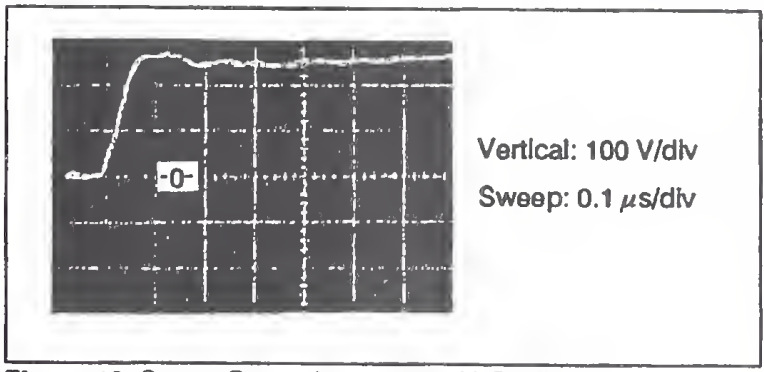

Figure 10. Surge Occurring on $380 \mathrm{~V}$ Cable

2.2 Measurements on cables - Two different sets of control and low-level cables, of the sarne type used In the operating plant, were included In the measurements of Induced surges: one set lald down on the same tray as the $6 \mathrm{kV}$ cables and near them, and another set In a PVC tube. For both the cable sets, two values of separation were used, a few centlmeters and $0.3 \mathrm{~m}$ from the power cables. The length of the parallel runs of power cables and control cables varled between 100 and $300 \mathrm{~m}$.

In this procedure the actual control and low-level cables were not used so that measurements could be carrled out under reference condition Independently of the service operating condition at the tIme of measurement. Using separate cables permitted changing the earthing conditlon of the shields at the process Instrumentation In the field or at the supervlsory system side.

The cables for which the measurement results are cited as representative examples (the complete test schedule Included other types) were a 1-palr twisted thermocouple cable, and a 1 -palr twlsted, low-level slgnal cable.

The measurements wore made with earthing of the slgnal source and of the cable shleld at the field end (process Instrumentation) or at the supervlsory system end (accordlng to some manufacturers speciflcatlons). At the signal source (process instrumentation slde) the cable clrcuits were short-circuited. At the measurement side, the pairs were lett in open-circuit condition, in order to simulate the real operating condition (normally corresponding to the multiplexer Input).

For each cable, the characteristlcs of the voltages are summarized below, and selected oscillograms (Figures 11-14) Illustrate the waveforms. For the sake of brevity, the oscillograms are given only for the common mode (CM) and differential mode (DM) measurements with the earthing of the signal clrcult and of the cable shlelds at the process instrumentation $\mathrm{In}$ the case of the $0.3 \mathrm{~m}$ cable separation.

The results depend on the condition of earthing of the slgnal clrcuit and cable shield at the slde of the computer and for a few $\mathrm{cm}$ separatlon from power cables present values (differential mode only) that are generally higher, up to one order of magnitude. The waveforms, however, present the same charecteristlcs (frequency of osclllatlon, damplng). Once again, the major object of citing these results In the context of thls paper ls to show waveforms, not detailed data.

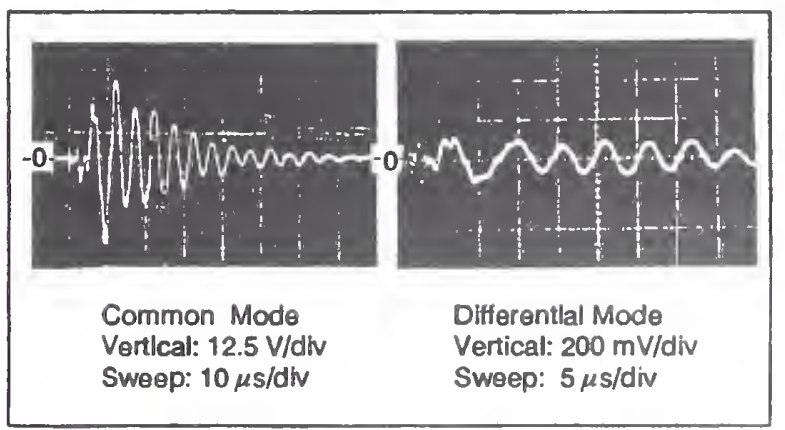

Figure 11. Translents induced In Thermocouple Palr by Surge Occurring in 6 kV Cable 


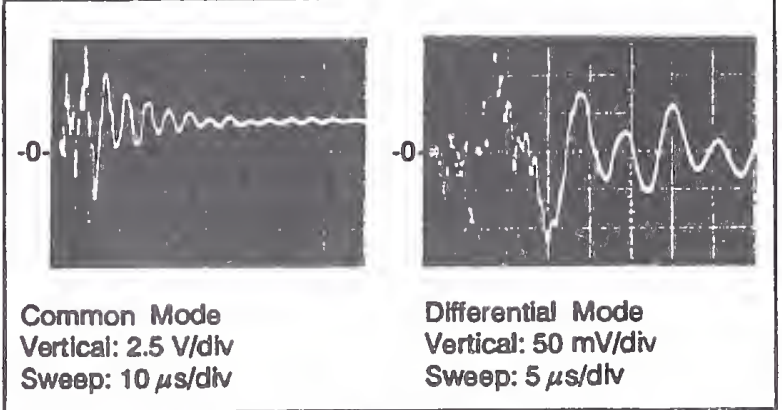

Figure 12. Translents Induced In Thermocouple Palr by Surge Occurring in 380 V Cable

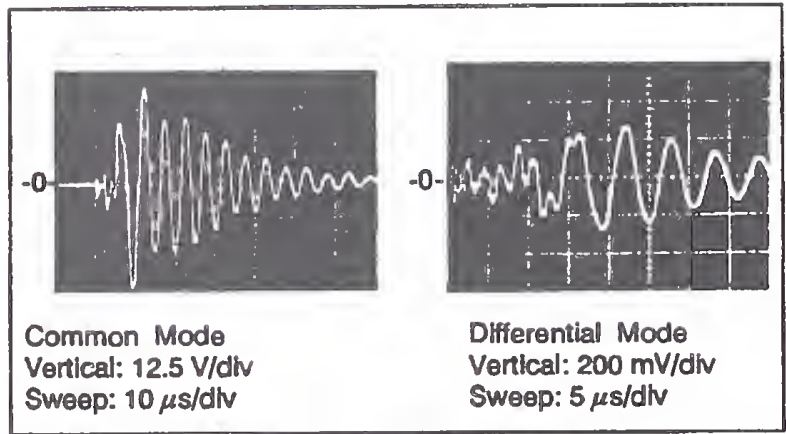

Figure 13. Transients Induced in Signaf Pair by Surge Occurring in $\mathbf{B} \mathrm{kV}$ Cable

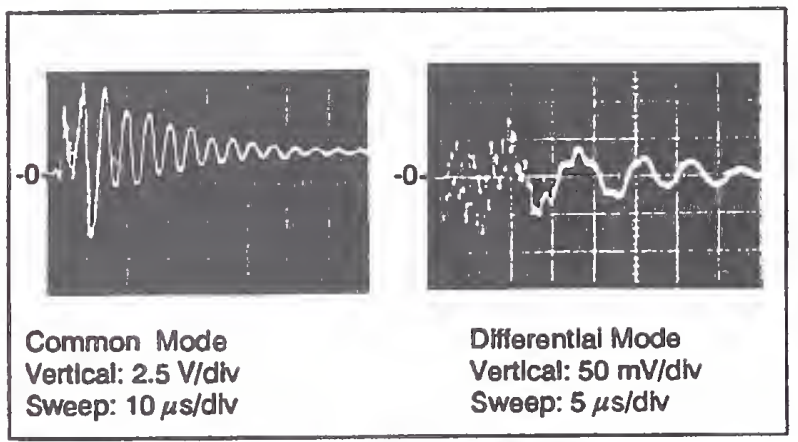

Flgure 14. Translents Induced in Signal Pair by Surge Occurring in $380 \mathrm{~V}$ Cable

2.3 Discussion of the results - The surges induced In the measurement cables have common-mode levels of less than $100 \mathrm{~V}$ peak and differential-mode leveis of less than $1 \mathrm{~V}$ peak mode on the signai lines (pairs).

The waveforms are substantlaily damped osclllatory waves (sIngie shot), affected by a damplng dependent on the propagation characteristics of the $6 \mathrm{KV}$ and $380 \mathrm{~V}$ cables. The frequency of the oscllations ranges from about 100 to $200 \mathrm{kHz}$; higher values are observed for the common mode and lower for the differentlal mode voltages. The propagations affect each other; it is Important to note that, in practlcal cases, the final waveform parameters of induced surges cannot be predlcted or preciseiy deflned due to the varlablltty of the Installation parameters (length of cables, dielectric constant of the inoulation, osparation from tho ground of roforonoo, oto.).

It Is evident that, in particular for the differential mode, the Induced surges do not include a unidirectional component. Such a component appears only in iimited amount for the commonmode on the pairs within a cable, whenever the surges are induced by the transients on the $380 \mathrm{~V}$ power cable. In this case, because these $380 \mathrm{~V}$ cables are unshielded, the capacitive coupiling occurs in the low frequency range.
3. Conversion of unidisectlonal ilghtining current in ground conductors into oscillatory surges

Tests were performed In the General Electric High Voliage Laboratory [3], almed at simulating the passage of current in the grounding (protective earth) conductor of the service drop to a building. The mottvation for the test was part of a general investigation on propagation of surges in low-voltage wiring without a preconcelved notlon on the waveform of the surges. As it turned out, the Injection of a unidirectlonal current produced an oscillatory voltage.

The bullding wiring system was simulated by erecting a service entrance panel and several branch circults, in a geometry representative of the normal wiring practlce applied in the U.S. The service drop was simulated by using a pole-type distrlbution transformer including its connectlon to the earth reference (the ground plane of the laboratory in this test), a three-conductor service drop, and the prescrlbed grounding of the neutral at the service entrance (Figure 15). The service drop conductor conflguration was the conventlonal, three-conductor "messenger wire" strung between the poie and the building. This messenger wire serves as a mechanlcal support as well as the multiple-grounded neutral conductor, with the two other conductors wrapped in a long pltch around the messenger.

Unidirectional $8 / 20 \mu$ s current impulses were injected between the neutral terminal of the distribution transformer and the ground plane. For the Initlal scenario of $30 \mathrm{kA}$ in the messenger wire, resulting from an assumed $100 \mathrm{kA}$ stroke (Figure 15), several flashovers were observed in the branch circuit wirlng. The current had to be reduced to $1.5 \mathrm{kA}$ for flashovers to stop. The resulting voltages were then measured between the phase and neutral conductors at varlous points of the branch clrcuits. In ali cases, a large oscillatory component at $500 \mathrm{kHz}$ was present in the measured voltage, in addition to a unidirectlonal component. Figure 16 shows the injected unidirectional current and Figure 17 shows the Induced voltage appearing at one of the receptacies at the end of a branch clrcult.

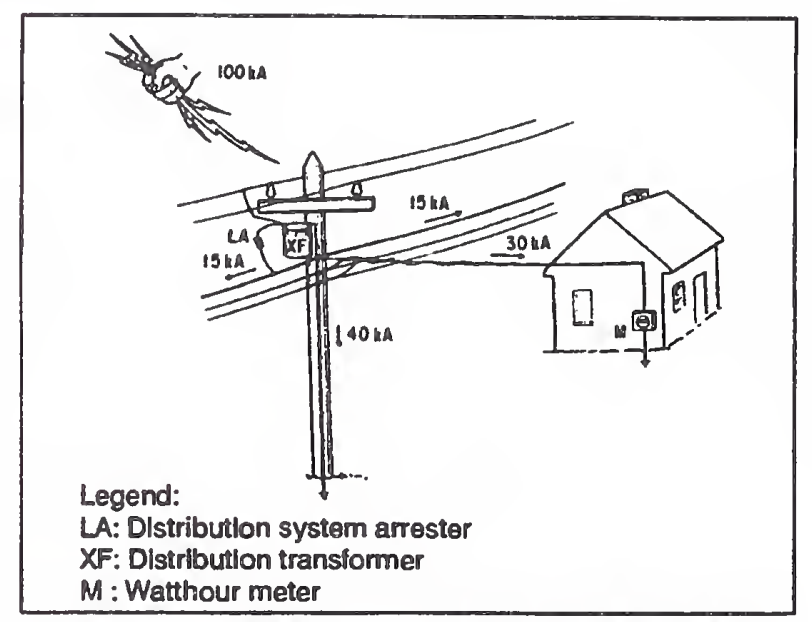

Figure 15. Conflguration SImulatlng LIghining Current in Messenger Wire of a Service Drop to a House

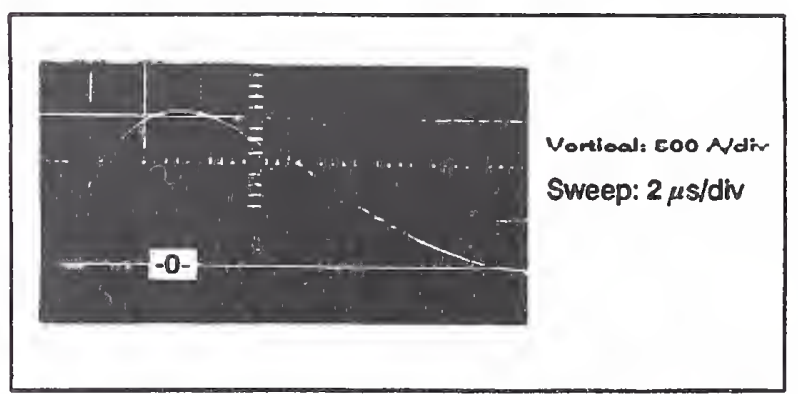

Figure 16. Injected Current in Messenger of Service Drop 


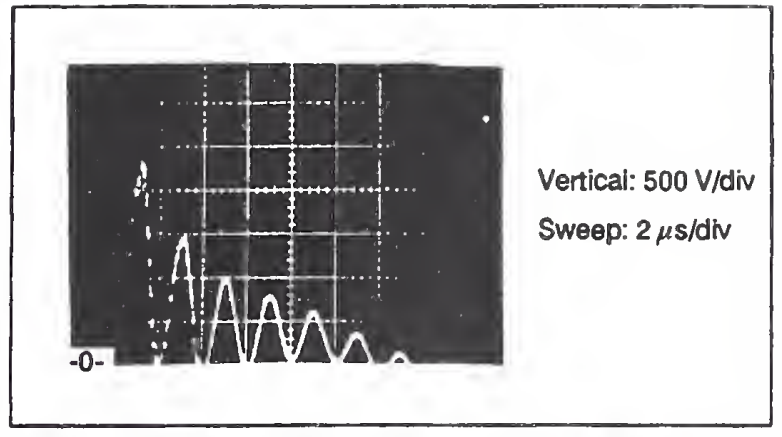

Figure 17. Translent Induced as 2.2 kV Differential Mode by $1.5 \mathrm{kV} 8 / 20$ us Impulse in Messenger Wire

4. Response of a building wiring system to a unidirectional surge appiled at the service entrance of the bullding

During a series of measurements almed at defining the surge propagation characteristics of an actual bullding wiring [5], it was found that appiying a unidirectional surge at the service entrance of the buliding, on the primary side of the transformer instalied within the buliding, results in osclilatory transients. In contrast with the previous test where current surges were Injected In the grounding conductors, in this test series voltage surges were Injected phase-to-phase on the transformer primary. Figure 18 shows the voltage waveform at the transformer primary resulting from a standard $1.2 / 50$ surge voltage. Note the occurrence of a small oscillation (12\%) at the crest, but the predominant waveform of the surge is unidirectional, a sltuation somewhat different from the interactlon between the Marx generator and the mismatched high-voltage llne seen in Figure 2.

The resulting transient inside the building is a superposition of a unidirectional component and an osciliation (Figure 19), that Is, the same situation of common Impedance discussed in paragraph 1.3. This transient then propagates throughout the wiring inside the bullding.

In Figure 19, a line has been drawn on the osclllogram to show the unidirectional component in the resulting oscillatory transient. Note that the first cycle of the osciliation has an ampiltude of three times the unidirectional component, compared to the $12 \%$ ring of the applied unidirectional surge. Details of the propagation characteristics are presented in Ref [5]. A slgnificant finding was that for the dimensions of the building (length of the conductors), the faster front $(0.5 \mu \mathrm{s})$ of the $100 \mathrm{kHz}$ Ring Wave produced reflections which would not occur with a slower $1.2 / 50 \mu$ s impuise. On the other hand, much faster waves, such as the $5 / 50$ ns burst [10] were found to be quickly attenuated. Thus, this ring wave produces a unique stress on equipment connected to the end of a branch circuit, such as an electronic control circult in standby mode, the subject of the next investigation.

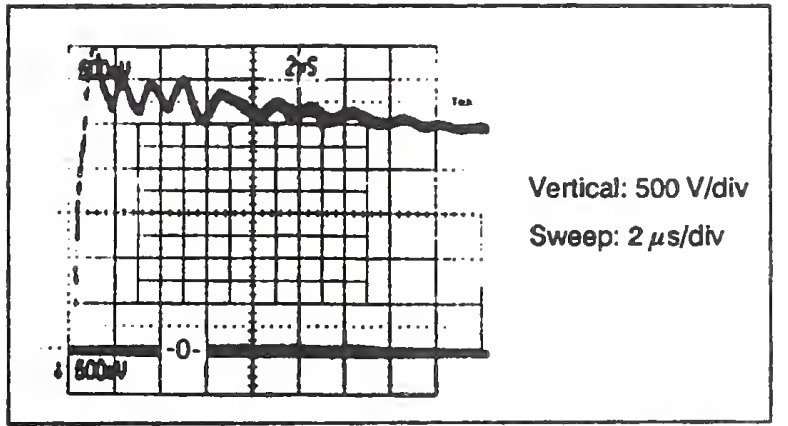

Figure 18. Applled Unldirectlonal 1.2/50 us Voltage at Prlmary of Service Trensformer of Bullding

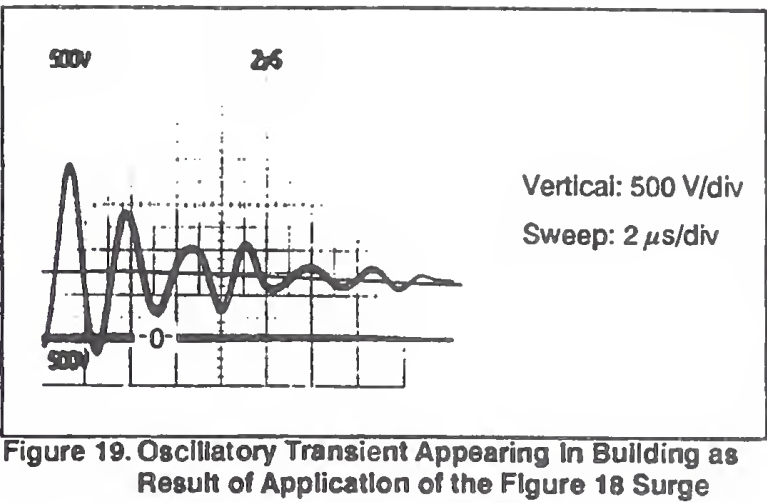

\section{Effects of osclllatory surges on semiconductors}

Various pubilshed and unpubilshed test results [11], [12] have reported that the reversal of blas on a semiconductor junction produced by applying an oscillatory surge can have a strong effect on the surge withstand capability of the device. The failure is aiso more likely when polartty reversals are applied during conduction, forcing the junction from a forward blas to a reverse blas.

Thls uncontested but not wideiy acknowledged finding was recently iliustrated again by a series of measurements performed at NIST in preparation of qualfilication tests for an equipment using triacs for power control. The test schedule calied for both the unidlrectional wave, described as "Combination Wave" [13], and the $100 \mathrm{kHz}$ Ring Wave defined in several U.S. standards and under consideration In IEC standards in progress [14].

Figure 20 shows one example of faliure of the semiconductor occurring, not at the crest of the first part of the oscillation which wouid be the expectation under a unidirectional stress but upon reversal of the polarty during a Aing Wave test. This observation has rekindied interest in the issue and further tests are planned to better characterize the behavior of power semiconductors under ring wave stress.

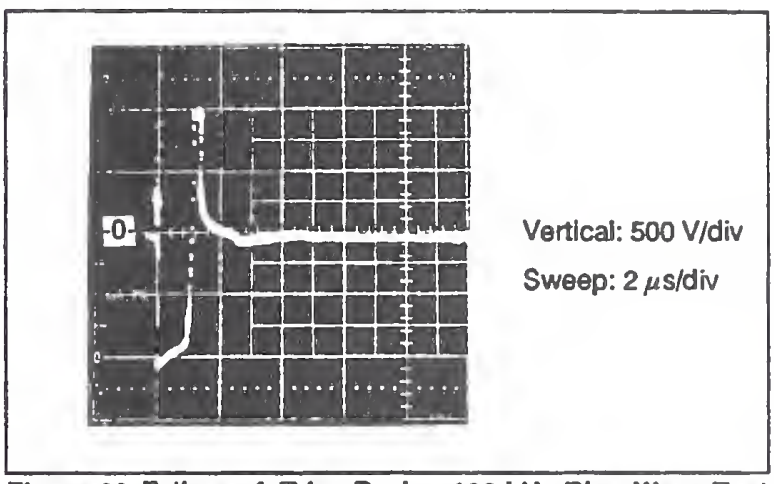

Flgure 20. Fallure of Trlac During $100 \mathrm{kHz}$ Alng Wave Test

\section{SURGE IMMUNITY SPECIFICATIONS AND TESTS}

The four Independent experiments clted in this paper include Induced transients and injected transients, carrled out at different times, countries, and installations. The results show that the surge environment of low-voltage clrcuits, for ac power systems as well as for control systems, is dominated by damped oscillations with a frequency range of $100-500 \mathrm{kHz}$.

This observation, especlally for surges of large amplitude, should not be misconstrued as denying the signiflicance of other surge test stresses, such as the Electrical Fast Translent [10] 
where the interference aspects of the test are its major objectlve. Furthermore, in the high-voltage power apparatus domain, the traditional, "slow-rising" 1.2/50 $\mu$ s impulse has often been complemented by a chopped wave, introducing transitlon times much shorter than $1.2 \mu \mathrm{s}$. Low-voltage equipment, however, is generally not required to pass a chopped-wave test.

On the other hand, for a device sensitive to total energy deposited in the device, unidirectional waveforms provide a sultable stress level. This three-part stress range - fast, low-energy; medium fast, medium-energy; slow, high-energy has recently been emphasized in a revision of Rof [4], now In the final stages of approval by the IEEE, where the range of recommended surge lests includes the EFT, the $100 \mathrm{kHz}$ Ring wave, the 1.2/50-8/20 $\mu$ s Combinatlon Wave, a new $5 \mathrm{kHz}$ Ring Wave, and a new unidirectional, high-energy 10/1000 $\mu$ s wave. The latter Is similar to the $100 / 1300 \mu$ s fest under consideration by IEC TC77 [6], although the latter may involve extremely high energy levels encountered only under special clrcumstances [15], [16].

Discussions in IEC standard-writing groups produced the argument that the amplitude density spectrum of the $1.2 / 50 \mu \mathrm{s}$ impulse is so wide that it would cover the spectrum of the damped oscillatory ring wave. in fact, the ring wave shows a peak that extends almost one order of magnitude higher in frequency, as shown in Figure 21 [17]. Furthermore, the reversal of polarity effects discussed above are not produced by the $1.2 / 50 \mu$ s impulse. In the IEC, both wavelorms are considered In the general overview of immuntty tests [6] and in dedicated basic standards [13], [14].

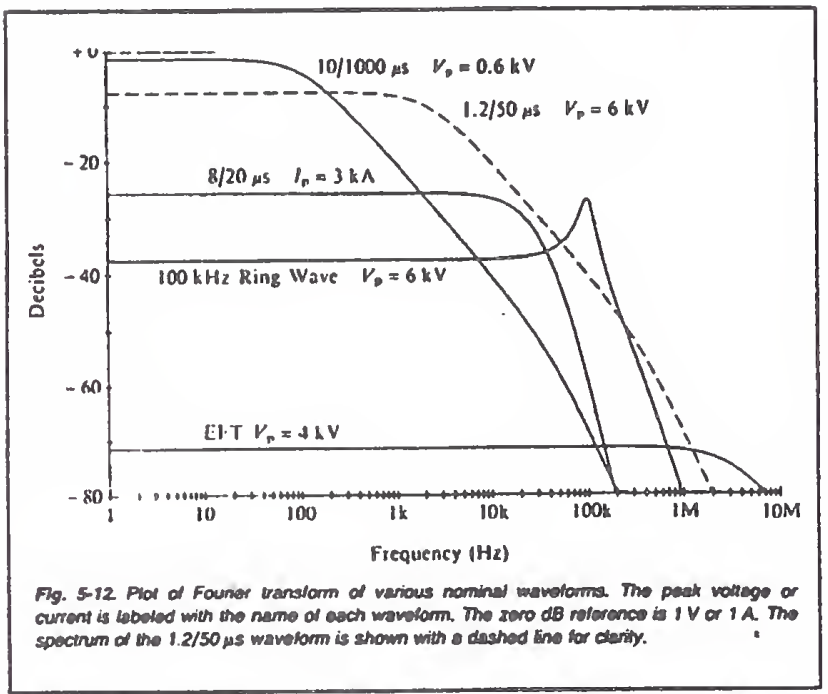

Figure 21. Frequency Spectra of Various Test Surges

Source: Standler [17]

\section{CONCLUSIONS}

1. The Inve independent examples chted in the paper provide converging evidence that there is a difference in the environment and its offect between power transmission systems, where the unidirectional test impulse relgns, and the low-voltage utlizatlon circuits, where ring waves are a more realistic representation of the stresses encountered by modern electronlc equipment.

2. To evaluate withstand capablity of bulk solid insulation, tt may be stressed adequately by unidirectional Impulses. However, more complex devices such as windings or semiconductors may exhibit failure modes that will be more prevalent under ring wave test conditions.
3. The two basic surge waveforms, the Combination as well as the Ring Wave, should be taken into consideratlon for damaging as well as upsetting disturbances. Depending on the nature of the equipment, Its characteristics, and Installatlon type, one waveform may be preferred to the other. The cholce is the responsibility of relevant product committees, best qualifted for assessing the exposure of their equipment, on the basis of a comprehensive menu of real, realistic waveforms.

\section{REFERENCES}

[1] F.D. Martzloff \& T.M. Gruzs, Power Quality Site Surveys: Facts, Fiction, and Fallacles, IEEE Transactions IA-24 No.6, Now/Dec 1988.

[2] J.J. Goedbloed, Transients In Low-Voltage Supply Newworks, IEEE Transactions EMC-29, No.2, May 1987.

[3] F.D. Mantloff \& K.E. Crouch, Coordination de la protection contre les surtenslons dans les réseaux basse tension résidentiels, Proceedings, 1978 IEEE Canadian Conference on Communications and Power, 78CH1373-0.

[4] ANSI/REEE C62.41-1980 Guide for Surge Voltages in Low-Voitage AC Power Circuits.

[5] F.D. Martzloff, Coupling, Propagation and Side Effects of Surges in an Undustrial Building Wiring System, IEEE Transactions 1A-26 No.2, March/Aprll 1990.

[6] IEC 77B(Central Office), Overviow on Electromagnetic Compatibility immunity Tests, January 1990.

[7] G. Pellegrind, Transient Disturbances in Cables Connecting Telecontrol and Electronic Equlpment Installed In High-Voltage Substatlons, (intemal 1969 ENEL - R\&O Report No. S6/15)

[8] ENEL - R\&D Electromagnetic Compatlbility Problems in the Control of Electrlcal Systems (internal 1978 Publication No. 38)

[9] G. Pellegrinl, Investigation at the Turbigo Power Statlon on Disturbances of the Supervisory and Control System Cables of Thermoeiectric Power Stations, (internal 1975 ENEL-R\&D Report No. G5/4-1).

[10] IEC Standard No. 801-4 (1988), Electromagnetlc Compatibility for Industrial Process Measurement and Control Equipment - Part Four: Electrical Fast Transient/Burst Requirements.

[11] F.D. Martzl off, Transient tests on IN679, (Internal 1964 General Electric report, cited in Ref [4] above).

[12] P. Chowdhuri, Transient Voitage Characteristics of Silicon Power Recthiers, VEEE Transactions IA-9, Sept-Oct 1973.

[13] IEC Basic Standard (in progress) 65(Secretarlat) 137, Surge immunity Requirements, January 1990.

[14] IEC Basic Standard (in progress) 77B(Secretariat)73, Oscilliatory Waves, August 1990.

[15] C. Fenimore and F.D. Martzloff, Valldating Surge Test Standards by Fleld Experience: High-Energy Tests and Varlstor Performance, Conference Record, IEEE-IAS Annual Meeting, Seattle WA, October 1990

[16] C. Fenimore and F.D. Marzloff, Incompatiblity Between the 100/1300 Surge Test and Varistor Fallure Rates, Proceedings, 1991 Zürich EMC Symposium.

[17] A.B. Standler, Protoction of Electronics Circuits from Overvoltages, John Wiley \& Sons, 1989, p.106. 


\title{
Incompatibility Between the 100/1300 Surge Test and Varistor Failure Rates
}

\author{
Charles Fenimore and François Martzloff \\ National Institute of Standards and Technology \\ Gaithersburg MD 20899 USA \\ f.martzloff@ieee.org
}

Reprinted, with permission, from

Proceedings, $g^{\text {th }}$ International Zürich Symposium on Electromagnetic Compatibility, 1991

\section{Significance:}

Part 2 Development of standards - Reality checks

Demonstration ad absurdum:

Accepting the premise of prevalent 100/1300 high-energy surges and modeling the response of typical metal-oxide varistors leads to the conclusion that most of the billions of varistors in service should fail at alarming rates - but we know they do not. Ergo, the premise is not valid.

(See also paper "VDE 0160 " in this Part 2 for an experimental demonstration.) 


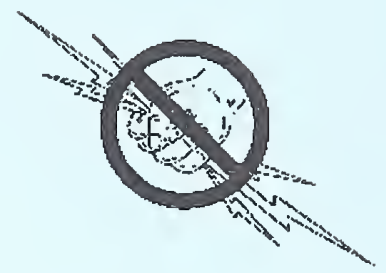




\title{
INCOMPATIBILITY BETWEEN THE 100/1300 SURGE TEST AND VARISTOR FAILURE RATES
}

\author{
Charles Fenimore and François D. Martzloff \\ National Institute of Standards and Technology \\ Gaithersburg, MD USA
}

\begin{abstract}
A proposed high-energy surge test featuring a $100 / 1300 \mu$ s waveform and a peak voltage of 2.3 times the peak voltage of the low-frequency mains is under consideration by the IEC. The energy storage capacitor suggested for the surge generator, originally specified as high as $25000 \mu \mathrm{F}$, has been scaled down but is still at a level of several thousand microfarads. To determine the energy dissipated in various surge tests, numerical integratation is applied to a simple but realistic mathematical model of a test circuit. The energy that would be deposited into a varistor of the voltage rating commonly used in protecting load equipment, if subjected to this test, far exceeds the capability of the varistor, but reported varistor failure rates do not reflect such a situation. Thus, a re-examination of the premises that led to the $100 / 1300 \mu$ s test specifications appears necessary.
\end{abstract}

\section{INTRODUCTION}

The IEC Technical Committee TC77 is considering a surge test requirement based on the scenario of currentlimiting fuses clearing a fault at the end of a cable, where the energy trapped in the system inductance causes a large transient at the time the fuse interrupts the current [1]. That scenario was first described and quantified by Meissen [2], and incorporated in German Standard VDE 0160 [3]. However, there seems to be an inconsistency between the predictable failure of varistors that would be subjected to this test, and the reported failure rate of varistors, considering that several hundred million of these varistors are currently connected across the mains in a wide variety of load equipment.

Accepting the premises that led to the specification of this test, the authors developed a simple circuit model that produces the specified waveform, with an cnergy storage capacitor having the value specified in the current amendment to VDE 0160 [4]. Applying the surge available at the output of the circuit model to varistors of the ratings commonly used in load equipment results in an amount of energy deposited in the varistor that exceeds by far the capability of the varistor.
If the scenario of fault-clearing by fuses occurs at a frequency such that a universal test should be required to simulate its effect on all equipment, then one would expect a substantial failure rate among the varistors incorporated in equipment in actual service. This expectation follows from the computations which show that typical varistors used in mains-connected equipment cannot survive such a test. While equipment failure rates are not widely published, anecdotal information and the sharing of field experience in the engineering community do not support the existence of a large failure rate attributable to that scenario. Therefore, the authors suggest that the premises that led to the specification of the test, the consequences of the test on in-service varistors, and the actual failure rates of these varistors should be examined to resolve the apparent inconsistency.

\section{THREE FORMS OF THE 100/1300 TEST SPECIFICATION AND VARISTOR RATINGS}

Figure 1 shows the parameters of the $100 / 1300 \mu \mathrm{s}$ surge described in Ref [1]. The voltage level is specified as $2.3 \times U_{p k}$, the peak of the mains voltage. However, under the clause addressing the test generator specification, one finds the interim statement 'Under Consideration'. The VDE 0160 documents do not include specifications for the test circuit, but leave the circuit design to private industry [5]. Referring to working documents and the original and later amendments of VDE 0160 , the test circuit essentially consists of an energy storage capacitor up to $25000 \mu \mathrm{F}$ discharged into the equipment under test.

A subsequent VDE amendment shows a table of capacitance values ranging from $700 \mu \mathrm{F}$ for $660 \mathrm{~V}$ rms mains to $6000 \mu \mathrm{F}$ for $220 \mathrm{~V}$ rms mains. According to the amendement, the capacitor charging voltage may be set at one of two levels, respectively $2.3 \times$ and $2 \times U_{p k}$, the peak of the mains voltage. Furthermore, two durations are also stated, the original $1300 \mu \mathrm{s}$ and one reduced to $400 \mu \mathrm{s}$. 


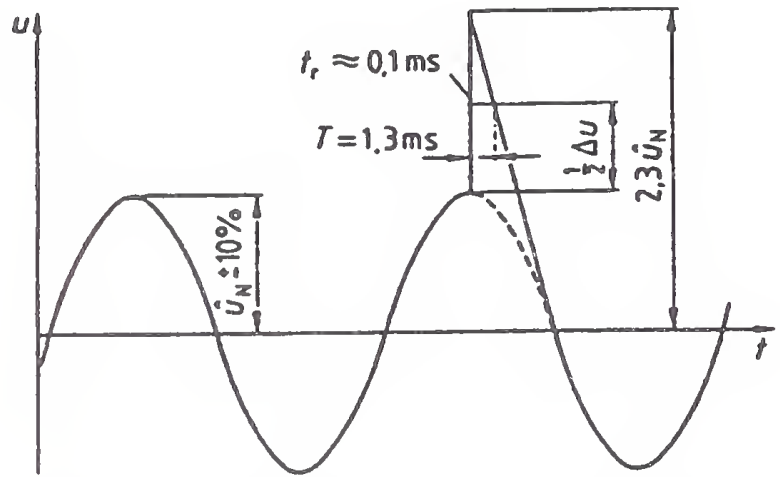

Figure 1. Parameters of the $100 / 1300 \mu$ s surge test waveform from VDE 0160 [3].

For the sake of exploring the implications, the authors accept the $100 / 1300 \mu \mathrm{s}$ at $2.3 \times U_{p k}$ proposal and will develop conclusions on varistor performance under this proposed test, the more severe of the two levels and two durations. However, an ambiguity exists on the test procedure. Two different interpretations of the VDE 0160 text can lead to different test procedures: providing a fixed charging voltage for the energy storage capacitor or re-adjusting the voltage after connecting the test specimen.

These two different interpretations result in two approaches with two sets of different values for the model parameters. A first method, based on using fixed charging voltage, is the approach generally used in surge testing [6], [7], often described as "let it rip." However, the VDE 0160 standard contains a sentence that reads: "The test apparatus is used to generate the test voltage impulse between the terminals of the test specimen while it is operating." This statement would suggest a second method, that is, adjust the charging voltage with the test specimen connected. The implications of the two interpretations will be shown below.

A further statement reads "... under certain conditions, the required half-peak duration of the pulse of $1.3 \mathrm{~ms}$ cannot then be reached. In this case it shall be ensured that not less than $80 \%$ of the energy stored in the test device is supplied to the sample." A simple capacitor discharge circuit, as implied by Figure 14 of VDE 0160, reproduced here as Figure 2, will require a parallel resistance to pull the voltage of the $6000 \mu \mathrm{F}$ capacitor down to half-value in $1.3 \mathrm{~ms}$. The surge generator shown as "Test Equipment" in Figure 2 does not explicitly include such a resistance. Such a resistor will drain enough energy from the capacitor that it is not clear how $80 \%$ of the capacitor energy will be left for the sample. Thus, the computations presented here include three approaches:

\section{Fixed initial charging voltage ("let it rip")}

2. Fixed peak surge voltage (readjust initial voltage)

3. Expend $\$ 0 \%$ of the capacitor energy into the test specimen.

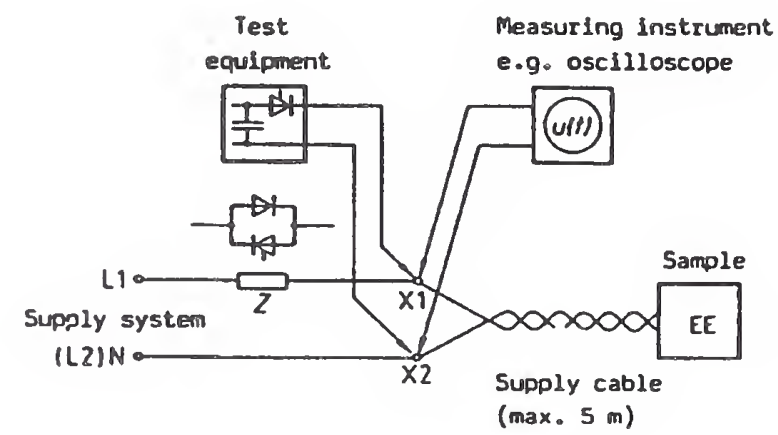

Figure 2. Schematic test circuit for the $100 / 1300 \mu \mathrm{s}$ surge test waveform from VDE 0160 [3].

Metal-oxide varistors offered by manufacturers include ratings of $130 \mathrm{~V}$ rms for applications in $120 \mathrm{~V}$ systems and $250 \mathrm{~V}$ rms for application in $220 \mathrm{~V}$ systems. The motivation for using these varistor ratings in electronic equipment is, of course, the desire to provide the lowest possible clamping voltage to protect sensitive equipment [8]. Therefore, the model developed in this paper is applied to a $220 \mathrm{~V}$ system and a $250 \mathrm{~V}$ varistor. For these values, the peak surge voltage is $220 \times 1.41 \times 2.3=715 \mathrm{~V}$, and the varistor voltage (at $1 \mathrm{~A}$ ) is $485 \mathrm{~V}$.

\section{ENERGY DEPOSITION IN VARISTORS FOR THREE TEST CRITERIA}

A simple, but realistic model of a capacitor discharge through a wave-shaping circuit can produce the specified surge rise and duration of $100 / 1300 \mu$ s. Referring to Figure 1 , this $1300 \mu$ s half-maximum is that of the surge, which is superimposed on the mains sine wave. Thus, the surge duration of $1300 \mu \mathrm{s}$ corresponds to the level of $U_{p k}+\frac{1}{2}\left(1.3 \times U_{p k}\right)$, that is $1.65 \times U_{p k}$.

Figure 3 shows a simple test circuit which is the basis for the mathematical model. Without the metal oxide varistor (MOV) in place, the circuit is configured for the open-circuit discharge test of a model test generator. Using circuit component values of $C=6000 \mu \mathrm{F}, L=25 \mu \mathrm{H}$, and $R_{s}=R_{p}=0.27 \Omega$, the open-circuit voltage response is generated numerically and is shown in Figure 4.

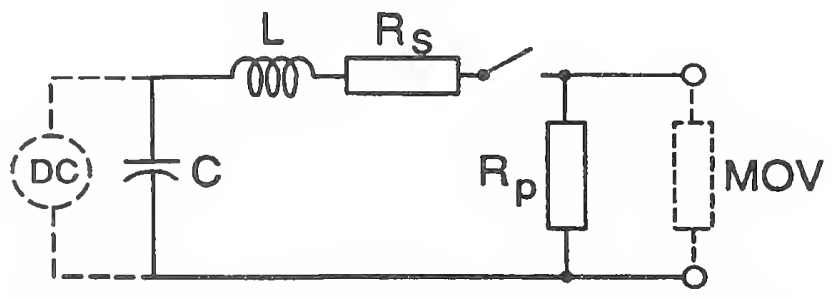

Figure 3. Schematic test circuit for the $100 / 1300 \mu \mathrm{s}$ surge test waveform used for the mathematical model. (The open-circuit test is performed without the MOV.) 


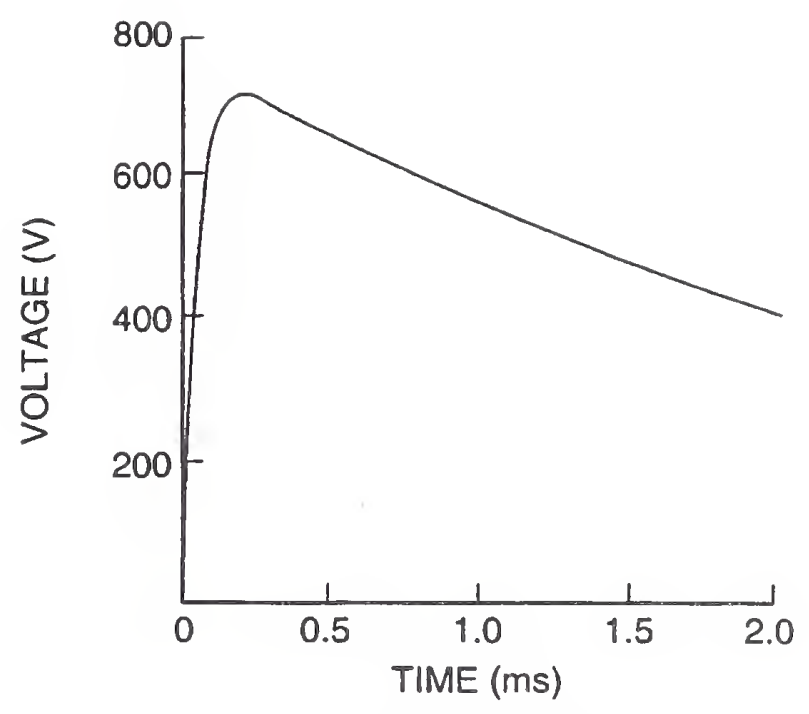

Figure 4. Plot of the open circuit voltage waveform obtained by discharging the capacitor in Figure 3 without the varistor in place.

The basic model is then modified by placing the varistor across the open-circuit terminals of the circuit in Figure 3. The non-linear I-V character of the MOV is expressed by the 'equation of state':

$$
v_{m}=\lambda\left(\frac{i_{m}}{i_{1}}\right)^{1 / p}+R_{m} i_{m}
$$

in which $i_{m}$ is the current through and $v_{n}$ is the voltage across the MOV. This equation is a two-term reduction of the full five-term model for a varistor [9]. It is appropriate to the slow waveforms in this surge testing environment. The unit current, $i_{1}$, should be chosen to be characteristic of the problem. In the present application, $i_{1}=1 \mathrm{~A}$. Where doing so causes no ambiguity, we have suppressed the current unit, $i_{1}$, in the analysis. $R_{m}$ is the series resistance of the MOV, in the examples used here, $0.12 \Omega$. The voltage threshold for the MOV, $\lambda$, has a nominal value of $485 \mathrm{~V}$. The exponent, $p$, is nondimensional and in the present calculation has been given the typical value of 31 [9].

The circuit model is formulated to produce a system of differential equations which are solved for $q$, the stored charge on the capacitor, $i_{m}$, and $e_{m}$, the energy deposited in the varistor. The voltage drops around the circuit must satisfy

$$
v_{L}+v_{R_{\bullet}}+v_{m}+v_{C}=0
$$

which yields

$$
L \frac{d i}{d t}+R_{s} i+v_{m}+\frac{q}{C}=0
$$

It is possible to express (2) as a differential equation in $i_{m}$ because $v_{m}$ is a function of $i_{m}$ and Kirchoff's Law implies that $i$ is a function of $i_{m}, i=i_{m}+v_{m} / R_{p}$. The evolution equations for $q, i_{m}$, and $e_{m}$ are thus:

$$
\begin{aligned}
\frac{d q}{d t} & =-i \\
{\left[L \frac{d i}{d i_{m}}\right] \frac{d i_{m}}{d t} } & =-R_{s} i-v_{m}-\frac{q}{C} \\
\frac{d e_{m}}{d t} & =i_{m} v_{m},
\end{aligned}
$$

where

$$
\frac{d i}{d i_{m}}=1+\frac{R_{m}}{R_{p}}+\frac{\lambda}{p R_{p}} i_{m}^{1 / p-1}
$$

The non-linear system (4-5) is equivalent to a second order equation for $i_{m}$. The initial conditions for $i_{m}$ and $e_{m}$ are zero, while $q(0)$ is chosen to generate the maximum voltage required by the test as specified below. The solution of the system is computed using a general purpose ordinary differential equation solver, PLOD, which permits a variable time-step size and handles stiff systems (those with widely differing time constants) [10].

\section{Results with fixed initial charging voltage}

Figure 5 shows the voltage, $v_{m}$, and current, $i_{m}$, waveforms at the varistor under the 'let-it-rip'mode, a procedure under which the open-circuit voltage of the generator is preset and no adjustment is made after connecting the test specimen. The desired waveform is generated with $q(0)=9 \mathrm{C}$. Note that the additional path in the circuit with the varistor in place reduces the peak voltage below that for the opencircuit test, from $715 \mathrm{~V}$ to $680 \mathrm{~V}$. Figure 6 displays the time-resolved deposition of energy in the varistor, and compares it to the allowable energy deposition.

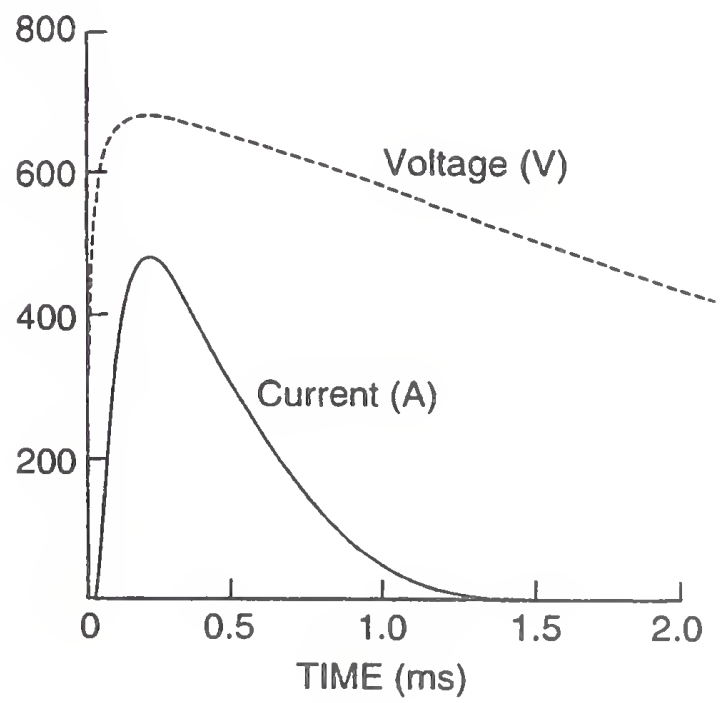

Figure 5. Plot of the current and voltage waveforms at the varistor with charge $q(0)=9 \mathrm{C}$ and with $\lambda=485 \mathrm{~V}$. 


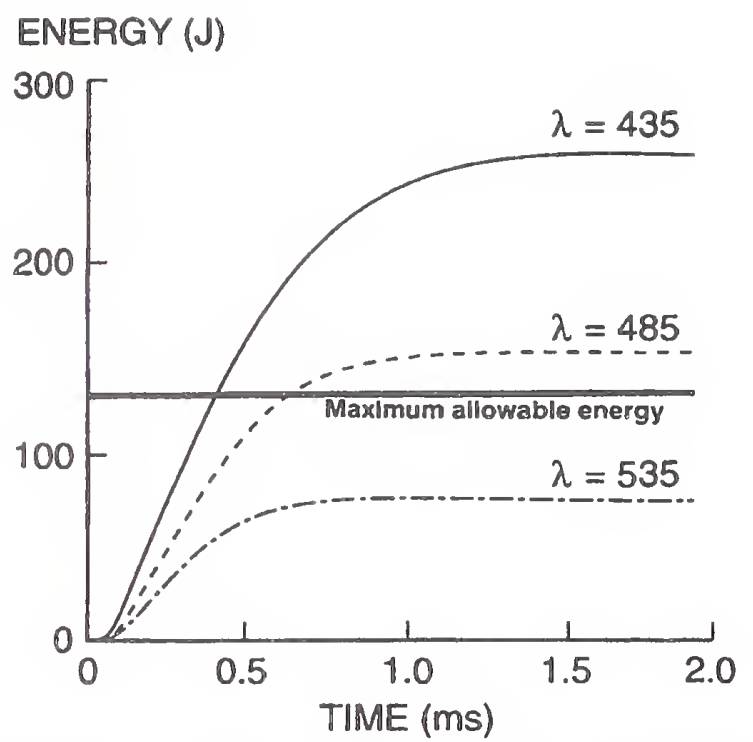

Figure 6. Energy waveforms at a fixed charge, $q(0)=9 \mathrm{C}$, for dissipation in the MOV at three ratings of the varistor, $\lambda=435 \mathrm{~V}, 485 \mathrm{~V}$, and $535 \mathrm{~V}$.

The three energy curves correspond to three values of the parameter $\lambda$, the voltage rating of the MOV. The values are $\lambda=435 \mathrm{~V}, 485 \mathrm{~V}, 535 \mathrm{~V}$, which are the lowest, mid, and highest values for acceptable ratings from the manufacturer ( $\pm 10 \%$ band about the nominal value of a varistor rated at $250 \mathrm{~V}$ ). The typical energy rating for a $20-\mathrm{mm}, 250-\mathrm{V}$ varistor is 130 joules. Denoting by $e_{m}(t, \lambda)$ the energy as a function of time and of voltage rating, the total amount of energy deposited by the pulses, $e_{m}(\infty, \lambda)$, is displayed in Table 1. Only the highest voltage rating survives. This fundamental model suggests a gross inconsistency between the failure rate that the test would produce and the available information on actual failures of inservice varistors. The Appendix confirms these conclusions based on an analytical, inductance-free model for the test circuit.

TABLE 1

Energy deposited in a $20-\mathrm{mm}$ dia, 250-V MOV as a function of tolerance on voltage rating, at fixed initial voltage ("let it rip")

\begin{tabular}{l|c|c|c}
\hline Voltage tolerance $(\%)$ & -10 & 0 & +10 \\
\hline Varistor voltage $\lambda(M)$ & 435 & 485 & 535 \\
\hline Energy $e_{m}(\infty, \lambda)(J)$ & 257 & 152 & 74 \\
\hline Peak $v_{m} M$ & 615 & 645 & 673 \\
\hline
\end{tabular}

\section{Results with readjusted charging voltage}

The authors note that VDE-0160 is not unambiguous on the character of the test procedure. The standard may be construed to require that the voltage maxi- mum with the MOV in the circuit remain $2.3 \times U_{\text {pk }}$, rather than accept whatever value will occur under the 'let-it-rip' mode. Under this interpretation, the charging voltage of the generator must be increased to obtain the required level; additional energy is stored in the capacitor and destruction of the MOV is assured at all permissible tolerances, Figure 7. Thus, for the three values of the voltage tolerances given above the initial charges on the capacitor, $q(t, \lambda)$ to reach the voltage maximum, $715 \mathrm{~V}$, and the energy deposited are displayed in Table 2. In each case, the energy rating of the MOV, $130 \mathrm{~J}$, is exceded substantially.

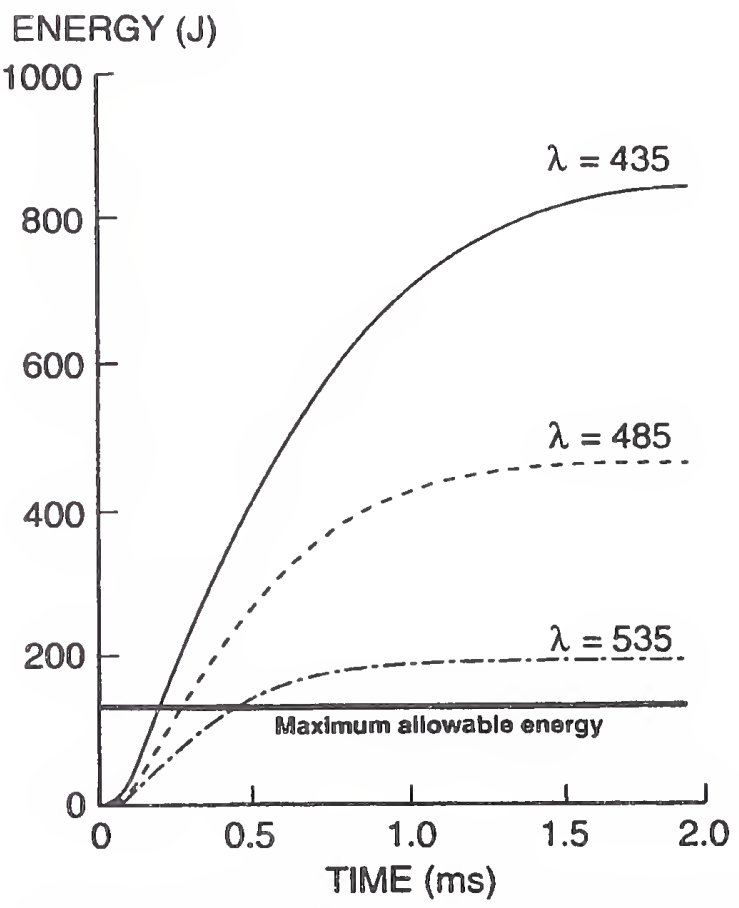

Figure 7. Energy waveforms with the peak voltage fixed, $V_{\max }=715 \mathrm{~V}$. The energy dissipated in the MOV is shown at three ratings of the varistor, $\lambda=435 \mathrm{~V}, 485 \mathrm{~V}$, and $535 \mathrm{~V}$.

TABLE 2

Energy deposited in a $20 \cdot \mathrm{mm}$ dia, $250-\mathrm{V}$ MOV as a function of tolerance on voltage rating, at fixed (readjusted) peak voltage

\begin{tabular}{l|c|c|c}
\hline Voltage tolerance $(\%)$ & -10 & 0 & +10 \\
\hline Varistor voltage $\lambda(N)$ & 435 & 485 & 535 \\
\hline Energy $e_{m}(\infty, \lambda)(J)$ & 839 & 459 & 192 \\
\hline Initial charge $q(0)(C)$ & 11 & 10.75 & 10 \\
\hline
\end{tabular}

\section{Expend $80 \%$ of capacitor energy in specimen}

An alternate criterion suggested by VDE 0160 is that $80 \%$ of the capacitor energy be dissipated in the MOV. For the simple circuit on which the present model 
is based, a ready calculation using the capacitively stored energy, $q^{2} / 2 C$ (of order $5000 \mathrm{~J}$ ), shows that no more than $10 \%$ of the stored energy is spent in the MOV in the simulations according to the two approaches discussed above. Yet, these two tests are already destructive of the device. It seems likely that a test that would meet the $80 \%$ criterion would provide an even more severe stress to the equipment, and provide a greater disparity between the model results and field experience.

Thus, the authors suggest that a reexamination of the premises that led to the VDE 0160 Standard should be considered before incorporating a blanket requirement for such a test into new IEC surge immunity standards. The authors plan to perform actual tests on typical varistors to further support the computations presented in this paper.

\section{CONCLUSIONS}

1. A mathematical and derived computational model has been presented which permits the evaluation of many aspects of varistor performance over a range of conditions which are characteristic of the actual operating environment and also of the test environment contemplated by VDE 0160 and other surge standards.

2. Computer model predictions of the impact of the proposed $100 / 1300 \mu$ s surge test on the millions of varistors in service shows that these varistors should experience a greater failure rate than indicated by available information on actual failures. The simplified inductance-free model provides analytical confirmation of this result. This inconsistency raises serious questions on the proposed requirement of such a severe test to a wide range of equipment.

3. The lingering ambiguity on setting a constant opencircuit voltage or adjusting the voltage while the specimen is connected needs to be clarified. A constant open-circuit voltage is the generally accepted practice in surge testing. The premises that led to this new surge test may justify adjusting the charging voltage after the test specimen has been connected to the surge generator; that adjustment, however, results in larger amounts of energy being dissipated in surge protective devices, making the apparent incompatibility identified above even greater.

4. The criterion that $80 \%$ of the capacitive energy must be transferred to the test specimen may be difficult to satisfy and needs clarification. The authors have been unable to identify a simple circuit which satisfies the criterion while maintaining the required rate of decay under open circuit conditions.
5. While the authors do not question the validity of the fuse-blowing scenario, they recommend a critical review of the statistics of the occurrence of fuse blowing, of the use of varistors with low clamping voltage, and of the distribution of actual clamping voltage within manufacturing tolerances. The sensitivity model developed in this paper may be a useful tool in evaluating the effect of these tolerances. The authors also urge all users to share information on the observed failure rates, as well as to perform validating tests, in order to provide a broader perspective on these issues.

\section{REFERENCES ${ }^{1}$}

[1] IEC Document 77B(Central Office)4, Overview on Electromagnetic Compatibility - Immunity Tests.

[2] MEISSEN, W., Überspannungen in Nicderspannungsnetzen, Elektrotechnische Zeitschrift, vol. 104, 1983.

[3] VDE 0160 Ausrüstung von Starkstromanlagen mit elektronischen Betriebsmitteln, May 1988. (The quotations appearing in this paper from the text of this standard are made from the official Enylish translation available from the British Standards I $n$ stitution).

[4] VDE 0160A1 Änderung 1 zu DIN VDE 0160/05.88, April 1989.

[5] MEISSEN, W., Private communication, 1990.

[6] WEISINGER, J., Hybrid-Generator für dic Isolationskoordination, Elektrotechnisclıe Zeitschrift, vol. 104, 1983.

[7] ANSI/IEEE C62.45-1987, Guide on Surge Testing for Equipment Connected to Low-Voltage AC Power Circuits.

[8] MARTZLOFF, F.D. and LEEDY, T.E., Selecting Varistor Clamping Voltage: Lower is not Better!, Proceedings, 1989 Zürich EMC Symposium.

[9] Transient Voltage Suppression Devices, HARRIS CORP., Somerville, NJ, USA, 1990.

[10] E. ARGON, I.L. CHANG, G. GUNARATRA, D.K. KAHANER, and M.A. REED, "Mathematical Software: PLOD," IEEE Micro, vol. 8(4), August 1988.

\footnotetext{
${ }^{1}$ Certain software is identified in this paper in order to adequately specify the procedures used to produce the numerical results. Such identification does not imply that the software is necessarily the best available for the purpose.
} 


\section{APPENDIX - SENSITIVITY OF $e_{m}(\lambda)$}

The sensitivity of the energy deposited in the varistor, $e_{m}(\infty, \lambda)$, to changes in the voltage rating of the MOV is given by

$$
\frac{d e_{m}(\infty, \lambda)}{d \lambda} .
$$

This quantity can be determined by numerically integrating the model (4-7). However, this sensitivity can also be analyzed in closed form by considering the inductance-free, $(L=0)$, version of the model (Eq. 2 or 3). In this case, an algebraic expression for the sensitivity can be derived. It is shown to be accurate to within $15 \%$ over a significant range of values of $\lambda$.

The sensitivity of the energy dissipated in the MOV to changes in $\lambda$ is most easily expressed in terms of the initial current through the varistor and the sensitivity of that current to changes in $\lambda$. In the inductancefree case, the initial conditions must be reformulated so that $i_{m}(0)$ is non-zero. When the initial data is the capacitor charge, $q(0)$, as was the case with the inductive model, it is possible to find $i_{m}(0)$ by finding the root of the non-lineas expression given by:

$$
\begin{aligned}
F\left(i_{m}, \lambda\right) & =\left(R_{m}\left(1+\frac{R_{s}}{R_{p}}\right)+R_{o}\right) i_{m} \\
& +\left(1+\frac{R_{s}}{R_{p}}\right) \lambda i_{m}^{1 / p}+\frac{q(0)}{C} \\
& =0
\end{aligned}
$$

which is a direct translation of (3) in the case that $L=0$.

This equation can be solved for $i_{m}(0)$ using a few iterations of Newton's (gradient) method. Furthermore, the sensitivity of $i_{m}$ to changes in $\lambda$ is given by:

$$
\begin{aligned}
\frac{d i_{m}}{d \lambda} & =-\frac{\partial F}{\partial \lambda} / \frac{\partial F}{\partial i_{m}} \\
= & -i \frac{1}{m}\left(R_{m}+\frac{R_{s} R_{p}}{R_{a}+R_{p}}+\frac{\lambda}{p} i_{m}^{1 / p-1}\right)^{-1} .
\end{aligned}
$$

To find the energy deposited in the MOV, first consider the evolution of the varistor current, $i_{m}$. This time evolution is given by differentiating equation (3) and applying ( 1 ) and (6):

$$
\begin{aligned}
& R_{a} \frac{d i}{d t}+\frac{d v_{m}}{d t}=\frac{i}{C} \quad \text { or } \\
& \left(R_{a} \frac{d i}{d i_{m}}+\frac{d v_{m}}{d i_{m}}\right) \frac{d i_{m}}{d t}=\frac{i}{C}
\end{aligned}
$$

This equation is separable, that is it has the form

$$
d t=G\left(i_{m}\right) d i_{m} .
$$

Evaluating $G\left(i_{m}\right)$ and reducing one has

$$
\begin{aligned}
& G\left(i_{m}\right)=\frac{C}{i}\left(R_{0} \frac{d i}{d i_{m}}+\frac{d v_{m}}{d i_{m}}\right) \\
= & C \frac{\left(R_{s} R_{p}+R_{s} R_{m}+R_{p} R_{m}\right) i_{m}+\left(R_{0}+R_{p}\right) i_{m}^{1 / p} \lambda / p}{\left(R_{p}+R_{m}\right) i_{m}+\lambda i_{m}^{1 / p}} .
\end{aligned}
$$

As a result of separability, the energy may be written as a time-independent integral in which $\lambda$ appears as a parameter:

$$
\begin{aligned}
e_{m}(\infty, \lambda) & =\int_{0}^{\infty} v_{m} i_{m} d t \\
& =\int_{i_{m}(0)}^{0} v_{m} i_{m} G\left(i_{m}\right) d i_{m} . \\
=C I I \int_{i_{m}(0)}^{0}\left(\Sigma i_{m}\right. & \left.+\frac{\lambda}{p R_{m}}\left[\frac{1}{R_{s}}+\frac{1}{R_{p}}\right] i_{m}^{1 / p}\right) \\
& \times \frac{\lambda i^{1 / p}+R_{m} i_{m}}{\lambda i^{1 / p}+\left(R_{m}+R_{p}\right) i_{m}} d i_{m},
\end{aligned}
$$

where

$$
\begin{aligned}
& \Pi=R_{\theta} R_{p} R_{m} \quad \text { and } \\
& \Sigma=\frac{1}{R_{v}}+\frac{1}{R_{p}}+\frac{1}{R_{m}} .
\end{aligned}
$$

Expansion in $\lambda$ about the nominal voltage threshold for the varistor, that is in powers of $\Delta \lambda$ where $\lambda=$ $\lambda_{\text {nom }}+\Delta \lambda$, gives the leading term for the sensitivity of $e_{m}$ to changes in $\lambda$ :

$$
\frac{d e_{m}(\infty, \lambda)}{d \lambda}=C R_{s} R_{p} R_{m}\left(\frac{1}{R_{s}}+\frac{1}{R_{p}}+\frac{1}{R_{m}}\right) i_{m} \frac{d i_{m}}{d \lambda}
$$

The sensitivity (17) may be evaluated algebraically once $i_{m}$ is known from solving (8-9). A comparison with the inductive model is displayed in Figure 8. The curve shows numerically determined values of $e_{m}(\lambda)$ for the inductive model in 'let-it-rip' mode. The straight line has a slope determined by evaluating expression (17). The same expression may be used without recomputing the initial current in the case that the voltage, and hence the current, is adjusted to a fixed value.

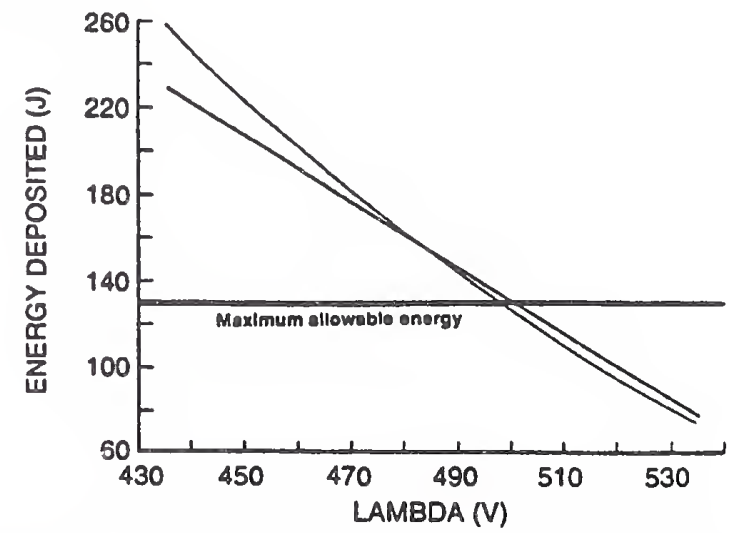

Figure 8. The energy dissipated in the MOV is displayed as a function of varistor rating, $\lambda=435$ to $535 \mathrm{~V}$. The straight line has a slope determined by Equation (17).

In either case, the sensitivity of $i_{m}$ to changes in $\lambda$ is small because $i_{m}^{1 / p}$ in expression (11) depends so weakly on $i_{m}$. This may explain why, even though it is derived from the non-inductive model, this estimate of the sensitivity of the varistor energy deposition is so accurate. 


\title{
Testing Varistors Against the VDE 0160 Standard
}

\author{
François Martzloff, Life Fellow, IEEE \\ National Institute of Standards and Technology \\ Gaithersburg MD 20899 USA \\ f.martzloff@ieee.org
}

Reprinted from Proceedings, Open Forum on Surge Protection Application, NISTIR4654, August 1991

\section{Significance:}

Part 2 Development of standard - Reality checks

Demonstration ad absurdum:

Accepting the premise of prevalent $100 / 1300$ high-energy surges and subjecting typical metal-oxide varistors to the stress from a test performed with a prototype generator leads to the conclusion that most of the billions of varistors in service should fail at alarming rates - but we know they do not. Ergo, the premise is not valid.

(See also paper "Validating Surge Tests ..." in this Part 2 for a demonstration by numerical modeling.) 


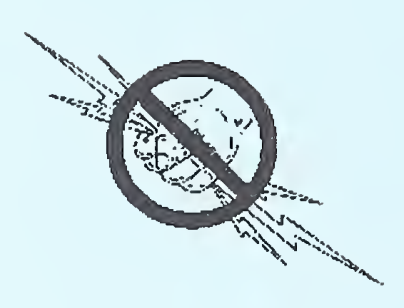

.

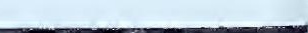




\title{
Testing Varistors Against the VDE 0160 Standard
}

\author{
François D. Martzloff \\ National Institute of Standards and Technology
}

\begin{abstract}
High-energy surge tests have been performed on metal-oxide varistors of a type in common use, according to a proposed IEC standard derived from German Standard VDE 0160 . The surge generator used for the test was a prototype commercial device developed especially to deliver the 100/1300 us waveform specified by VDE Standard 0160. Depending on the position of the varistor within its manufacturing tolerance band, failure or degradation can occur, validating the concern that this test requirement may be too severe for universal application.
\end{abstract}

\section{INTRODUCTION}

Concerns over the occurrence of high-energy surges associated with current-limiting fuse operation (Meissen, 1983 [1]) have led the German standards organization (VDE) to specify a high-energy surge test to be applied to electronic equipment installed in industrial environments (VDE 0160, 1988 [2]). Essentially, the test requires discharging into the ac line interface of the equipment under test (EUT) a capacitor of such capacity that the specified waveform is generated, initially charged at a voltage suitable for producing a peak of 2.3 times the power-system sine-wave peak (Figure 1). Technical Committee 77 of the IEC has included this test in its menu of surge immunity tests (TC77B/WG3, 1990 [3]), without limiting the scope of application to industrial environments intended by the Meissen paper. Thus, this test is likely to become a general requirement imposed on commercial and consumer equipment, unless its implications are recognized. In the absence of a readily available surge generator, computer modeling of the test had previously been performed (Fenimore \& Martzloff, 1990 [4], 1991 [5]). The findings of these simulations have shown that typical varistors, of which many millions have been installed and continue to operate satisfactorily, cannot survive the proposed IEC/VDE test because excessive energy would be deposited in these varistors during the surge. The recent availability of a prototype surge generator made it possible to subject typical varistors to the VDE/IEC surge, as reported in this paper.

\section{TESTING VARISTORS WITH HIGH-ENERGY SURGES}

Schaffner*, a manufacturer of surge generators, has now developed a prototype that can produce the VDE 0160 surge; in response to an invitation to try out this prototype, an informal work session was conducted at the Schaffner facility to subject typical varistors to the VDE 0160 surge. The generator includes the specified capacitor, up to $6000 \mu \mathrm{F}$, the necessary dc supply to charge the capacitor, a 220-V ac supply (for European environments), and suitable means to decouple the test specimen circuit from the laboratory ac system. Details of the circuits are still proprietary, and only the output of the generator is described in this paper. A chronological recitation of the work session would require first a discussion of the various considerations and conditions of the test. Recognizing the natural curiosity of the readers, let it be stated here that one varistor was destroyed during the test, and the other (barely) survived, consistent with the predictions of the computer modeling. Having thus given away the outcome, let us now proceed with the detailed recitation of these considerations and conditions.

\footnotetext{
* As a policy, the National Institute of Standards and Technology disclaims any implied endorsement of a commercial product when identifying such products for the sole purpose of adequately describing the equipment used in the experiment. In this particular case, the prototype generator used in the tests was the only one known to be available. Furthermore, there is no certainty that Schaffner will offer a commercial product based on this prototype.
} 
Voltage across the test specimen and current delivered by the surge generator were recorded with the instrumentation available at the Schaffner engineering demonstration facility. The software package included in the digital storage oscilloscope did not have the capability of computing the power $(i \times v)$ dissipated in the varistor and integrating it into total energy deposited. Manual integration of the recorded traces was performed after the tests. This computation yields results of sufficient magnitude (that is, large overstress of the varistor) to make precise computing unnecessary in evaluating the outcome of the test.

The test specimens (EUT) were 20-mm diameter varistors, consisting of two 130-V rms rated devices connected in series, a good approximation of the practice of applying $250-\mathrm{V}$ rated varistors in the $220-\mathrm{V}$ equipment used in Europe (Martzloff and Leedy, 1989 [6]). The nominal voltage, $\mathrm{V}_{\text {nom }}$, of each varistor (voltage measured with $0.5 \mathrm{~mA}$ or $1 \mathrm{~mA} \mathrm{dc}$ injected in the varistor) was determined before the test for each device. One varistor pair (referred to as EUT \#1) had a nominal voltage of $392.6 \mathrm{~V}$, the other pair (EUT \#2), 399.5 V. The nominal voltage for a $250-\mathrm{V}$ rms varistor is $390 \mathrm{~V}$, the minimum $354 \mathrm{~V}$, and the maximum $429 \mathrm{~V}$ (Harris Manual, 1990 [7]). Thus, EUT \#1 is situated at $1 \%$ above the nominal value of a $250-\mathrm{V}$ rated varistor, while $E^{\text {T }} \mathrm{T}$ \#2 is at $2.5 \%$ above the nominal value.

To rest the varistors under the worst case condition (that is, the varistor at $10 \%$ below nominal, thus drawing energy from the generator for a longer portion of the surge waveform), the test voltage should be raised above the voltage specified for nominal test conditions. To place the varistor under conditions equivalent to those prevailing for a $-10 \%$ specimen, a varistor at some tolerance level must be subjected to the same current as that occurring for a $-10 \%$ varistor at the nominal test voltage. With the nominal VDE 0160 test voltage of 2.3 times the $220-\mathrm{V}$ peak $(714 \mathrm{~V})$, the available EUT varistor specimen can be tested in a manner equivalent to a $-10 \%$ tolerance varistor by raising the test voltage.

For EUT \#1 which is $1 \%$ above the $\mathrm{V}_{\text {nom }}$ of a $250-\mathrm{V}$ rated varistor, the test voltage should be $10 \%$ higher than the nominal $714-\mathrm{V}$ peak, plus $1 \%$, that is, $792 \mathrm{~V}$. For EUT $\$ 2,2.5 \%$ above the $\mathrm{V}_{\text {nom }}$, the test voltage should be $12.5 \%$ higher, $803 \mathrm{~V}$. This increased test voltage will place the varistor at the correct value of current on its I-V characteristic, but raises the power dissipated in the varistor by the same percentage. Thus, the energy deposition in varistors other than $-10 \%$ tested under the artificially raised test voltage received $11 \%$ or $12.5 \%$ more energy than what a varistor at $-10 \%$ would have received. However, considering the energy levels observed in the tests reported below (about $200 \%$ of rated levels, this $11-12.5 \%$ excess does not affect the conclusions. The significant parameter to be observed is the current level, and that correct level was indeed achieved by raising the test voltage.

The VDE 0160 document states that the specified surge test voltage should be maintained across the terminals of the EUT, rather than the usual method of having a preset open-circuit voltage, and then connect the EUT without changing the generator setting (the so-called 'let-it-rip' mode [5], and (ANSI/IEEE C62.41-1987, [8]). Meissen confirmed this interpretation of the document [9], so that the charging voltage of the generator capacitor was increased toward obtaining the specified voltage with the EUT connected, using an expendable EUT varistor during preliminary tests. However, the prototype generator output voltage, with maximum charging voltage and with varistor connected, could only be raised to 774 volts (Figure 2) instead of the $792 \mathrm{~V}$ or $803 \mathrm{~V}$ necessary to place the \#1 and \#2 varistors in the $-10 \%$ tolerance situation. Thus, EUT $\# 1$ was actually tested in a condition corresponding to $774 / 792=98 \%$ of the worst case level, and EUT \#2 at $774 / 803=96 \%$ of the worst case level. In other words, EUT \#1 was tested as if it were at a $-8 \%$ tolerance level, and EUT \#2 at a $-6 \%$ tolerance level with respect to a $0 \%$ tolerance on their $\mathrm{V}_{\text {nom }}$.

The manufacturer's specifications [7] show a 70-J single-pulse energy rating for the 130-V varistor, or $140 \mathrm{~J}$ for two in series. Figure 3, from Ref [5], shows the predicted energy deposition as a function of the varistor position in its tolerance band, for the test condition where the voltage is maintained across the EUT by readjusting the surge generator charging voltage. 
The VDE 0160 document shows an elementary circuit diagram (Figure 4) with a maximum of $5 \mathrm{~m}$ of leads between the input port of the test specimen and the point of injection of the surge. Accordingly, the test circuit set up by Schaffner included approximately $5 \mathrm{~m}$ of leads "suitable for a $16 \mathrm{~A}$ load" between the varistor and the output of the generator. Thus, the impedance presented by the test specimen to the applied VDE 0160 surge includes a resistance that will reduce the stress of the varistor; however, this reduction is not readily recognized by the simple mention in the figure of a 5-m maximum lead length, and the cross-section of the conductors is not specified. Operators can interpret the test procedure in a way producing maximum stress (a short lead of large cross section) or a minimum stress (maximum of $5 \mathrm{~m}$ of leads with small cross section).

In accordance with the interpretation of the Figure 4 diagram, the voltage measured and shown in Figure 2 is the total of the voltage developed across the varistor and the lead drop. To evaluate the implications of this interpretation, the next test was performed, without changing the generator setting (at its maximum available voltage), with the voltage measurement made at the varistor terminals (Figure 5). Note the $700-\mathrm{V}$ peak in this test, or a 74-V difference (10\%) from the value recorded in Figure 2. In the modeling of References [4] and [5], the effect of this 5-m test lead had not been included, so that the conclusions of the modeling are more pessimistic than the consequences of a test condition with a lead length included. Thus, the varistor would be under $10 \%$ less voltage stress (keep in mind the nonlinear relationship between voltage and current) than the model prediction, and possibly could survive.

\section{THE DEATH OF A VARISTOR}

According to a subsequent amendment to the VDE 0160 test specification, the maximum* capacitor value and the duration of the surges may be reduced to $300 \mu$ s for equipment installed in circuits protected by fuses of less than 35 A continuous rating. This reduction will provide significant relief to varistors included in nonindustrial environments. However, the IEC document [3] does not include that reduction. The test sequence for EUT \#1 included two surges with this reduced stress (Figure 6), followed by surges with the full $6000 \mu \mathrm{F}$ capacitance and full $1300 \mu \mathrm{s}$ duration, at the maximum available generator voltage, as shown in Figure 2. Before and after each surge, the varistor $V_{\text {nom }}$ was recorded to track any shift in characteristics, comparing it to the maximum shift of $10 \%$ allowed in the manufacturer's specifications.

The test sequence and results for EUT \#1 (a specimen in the $-8 \%$ tolerance position), starting with no prior surges applied, were the following:

Shot 1: $\quad 718 \mathrm{~V}$ crest, $400 \mu$ s duration, $V_{\text {nom }}$ shift of $1 \%$ (Figure 6)

Shot 2: $\quad 768 \mathrm{~V}$ crest, $1100 \mu$ s duration, $\mathrm{V}_{\text {nom }}$ shift of $1 \%$

Shot 3: $\quad 774 \mathrm{~V}$ crest, $1400 \mu$ s duration, $V_{\text {pom }}$ shift of $1 \%$ (Figure 2)

Shot 4: $\quad$ Repeat, same settings as shot 3 (voltage measured at varistor, Figure 5),

Varistor (a) of pair punctured

Varistor (b) of pair externally intact, but $\mathrm{V}_{\text {nom }}=0$ (short circuit)

Energy deposited in the varistor; approximately $300 \mathrm{~J}$ (215\% of rating)

The same test sequence was then applied to EUT \#2, that is, first two shots at reduced stress, and then full stress for shot 3 and four additional shots. The $\mathrm{V}_{\text {nom }}$ shift grew from $1 \%$ after the first shot to $6 \%$ after the last shot, as measured after cooling down following the test. By the time the author had returned to the United States ( 20 days later), the shift in $V_{\text {nom }}$, determined by more systematic measurement at NIST, was reduced to $4 \%$. The difference between the $6 \%$ immediately after the test and the $4 \%$ after 20 days may be the effect of a slow recovery of the material, or a difference in the precision of the measurements, or both.

* The surge duration is the specified parameter in the VDE 0160 document, therefore the required value of the capacitor is dependent upon the impedance of the EUT. 
Notwithstanding the shift in $V_{\text {nom }}$, no apparent external damage was visible, except for some darkening of the red epoxy coating. Thus, while EUT \#2 did survive a test corresponding to a $-6 \%$ tolerance position, the onset of permanent change leading to failure was observed.

\section{DISCUSSION OF THE RESULTS}

From the simulation predictions, it was expected that the varistors would be destroyed by the test, even though the (late) realization of the stress reduction provided by the lead length does somewhat change the situation. In other words, the $10 \%$ loss of voltage caused by the leads places the varistors used in these tests at respec eiy $+2 \%$ and $+4 \%$ in the tolerance band, a condition that the prediction describes as marginal surviv A. The joule rating specified by the manufacturer tends to be conservative, so that it may take more than $140 \mathrm{~J}$ to destroy a varistor. Furthermore, a larger population of test specimens may produce a distribution of more failure as well as more survivals as only two test points can only provide an indication, not a certainty. However, the conclusion is clear, that varistors of common use in commercial and consumer equipment would be in severe jeopardy if the full $100 / 1300 \mu$ s surge were applied, even with the mitigating effect of the 5-m lead length. Discussing the test results with Meissen, we agreed on the following conclusions:

1. There is no disagreement that the basic phenomenon of fuse blowing can lead to the high-energy surges described by Meissen in the heavy industrial environment (circuits with fuses above $35 \mathrm{~A}$ ).

2. The prediction of varistor failure through modeling is consistent with the tests; the mitigating effect of the allowable EUT lead reduces the forecast of widespread failures, but varistors in the lower tolerance bands are still at risk.

3. The amendments to VDE 0160 providing for reduced maximum capacitance values (see the footnote on page

3 ) and reduced duration make the test more realistic. Further evaluation of these reduced stress levels would show appropriate limits of application.

4. However, this stress reduction has not yet been acknowledged by the IEC proposals (Figure 1, showing only one value of $1.3 \mathrm{~ms}$ is excerpted from the IEC document, not the amended VDE 0160 where the alternate duration of $0.3 \mathrm{~ms}$ is shown). This paper is therefore submitted to the engineering community at large as a recommendation of limiting the full duration of a $1300 \mu$ s surge and its high energy to the industrial environment for which it was first proposed.

5. The concept of readjusting the surge generator charging voltage to maintain a specified test voltage across the specimen is different from the usual practice of maintaining a fixed open-circuit voltage for the generator. However, it may be compared to the practice of readjusting the surge generator used for surge arrester tests at a specified test current level. As long as the implications of the procedure are recognized, either method may be suitable, if uniformly interpreted.

6. In its present form, the VDE 0160 document leaves open the possibility of different interpretations by different operators. Should the principle of a high-energy test be adopted by the IEC, more detailed specifications need to be developed and agreed upon by interested parties. 


\section{ACKNOWLEDGEMENTS}

This successful work session was made possible through the cooperation of $T$. Hilger and $M$. Ryser of Schaffner. W. Meissen made the long journey from Erlangen, Germany to Luterbach, Switzerland to participate in the test, and reviewed the manuscript of this paper. The simulation predictions of References [4] and [5] were developed by C. Fenimore. All these contributions toward a better understanding of the VDE 0160 test implications are gratefully acknowledged.

\section{REFERENCES}

[1]. Meissen, W., Überspannungen in Niederspannungsnetzen (Overvoltages in low-voltage networks), Elektrotechnische Zeitschrift, Vol. 104, 1983.

[2]. German Standard VDE 0160, Ausrüstung von Starkstromanlagen mit electronischen Betreibsmitteln (Equipment with electronic operating controls for use on power systems), May 1988, amended April 1989.

[3]. IEC Draft Standard DIS 77B(CO)10(c), Electromagnetic Compatibility - Part 4: Testing and measuring techniques - Overview on electromagnetic compatibility tests, 1991.

[4]. Fenimore, C. and Martzloff, F.D., Validating Surge Test Standards by Field Experience: High-Energy Tests and Varistor Performance, Conference Record, IEEE/LAS Annual Meeting, October 1990.

[5]. Fenimore, C. and Martzloff, F.D., Incompatibility Between the 100/1300 $\mu$ S Surge Test and Varistor Failure Rates, Proceedings, 1991 Zürich EMC Symposium.

[6]. Martzloff, F.D. and Leedy, T.F., Selecting Varistor Clamping Voltage: Lower is not Better!, Proceedings, 1989 Zuirich EMC Symposium.

[7]. Transient Voltage Suppression Devices, Harris Corporation, 1990.

[8]. IEEE Guide on Surge Testing for Equipment Connected to Low-Voltage AC Power Circuits, ANSI/IEEE C62.45-1987.

[9]. Private communications, March 15 and May 15, 1991. 


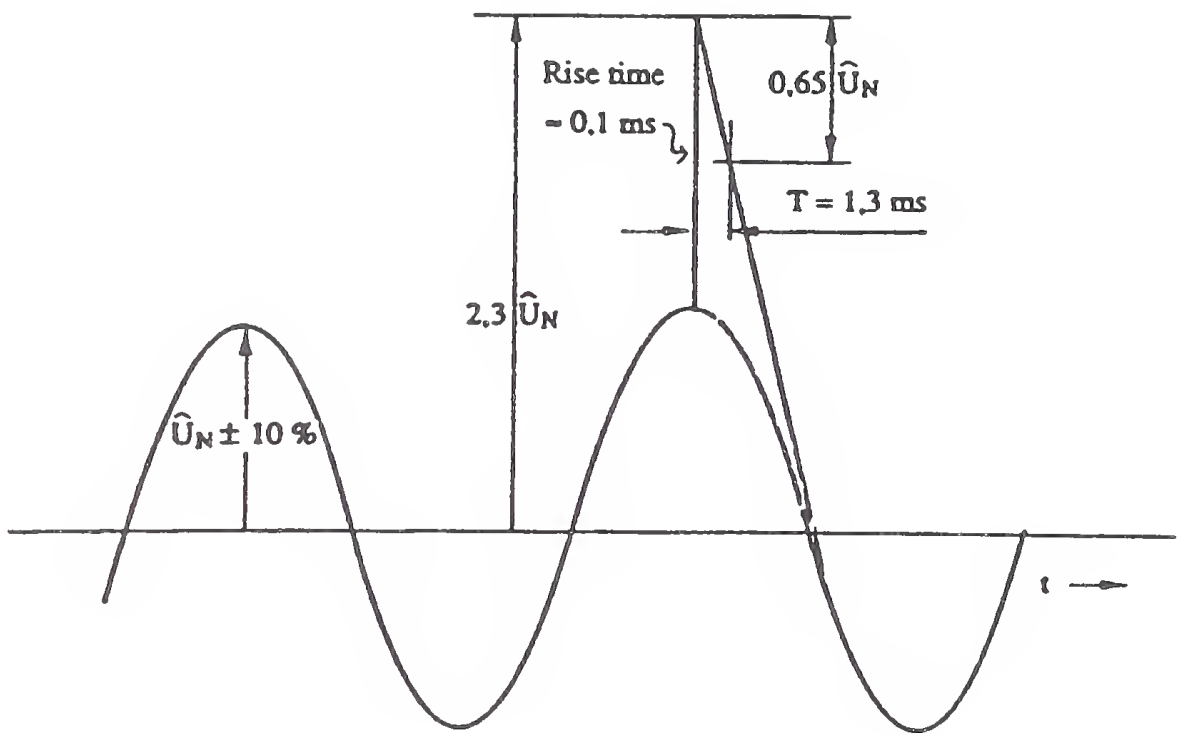

Figure 1. High-energy waveform specification (From Ref. [3])
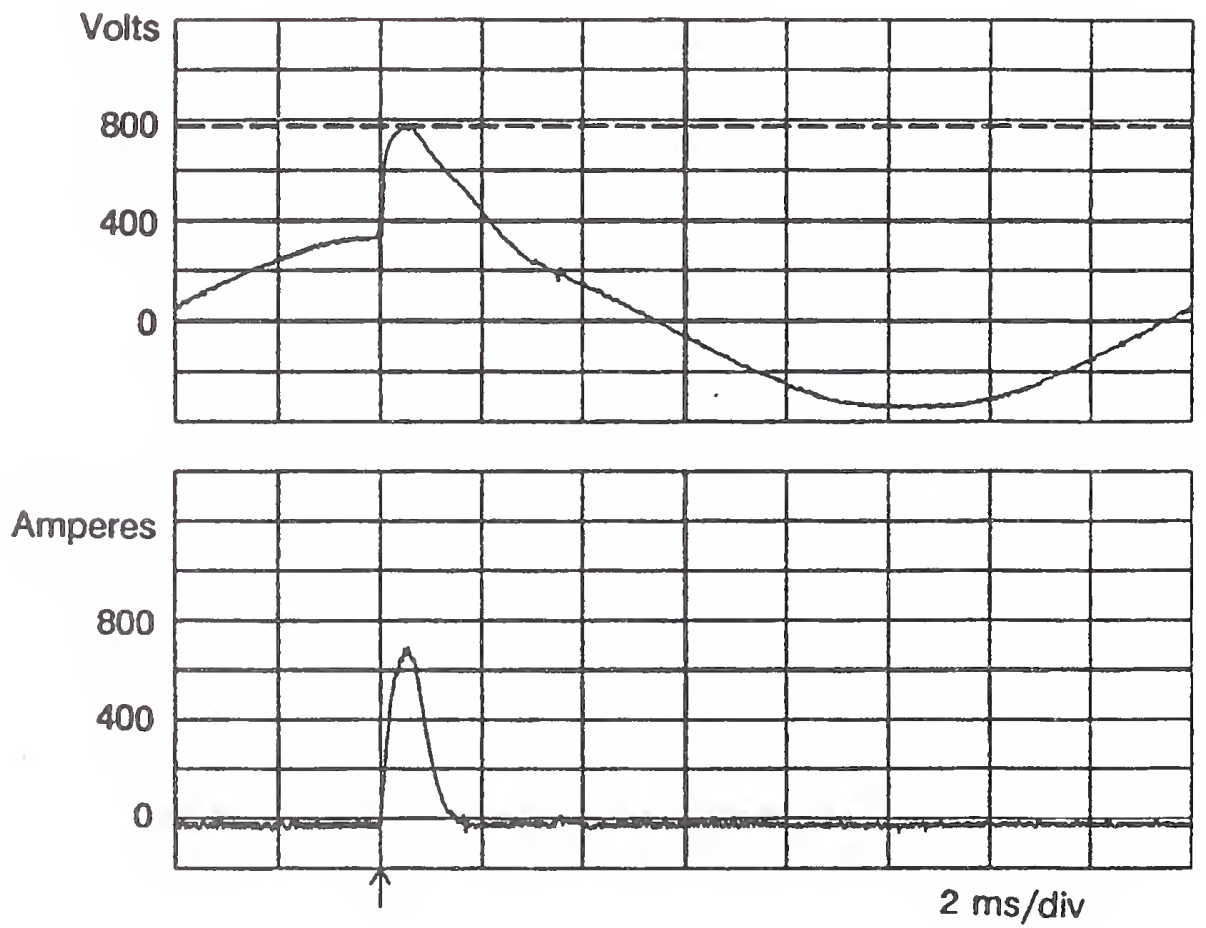

Figure 2. Voltage across and current through EUT \#1 


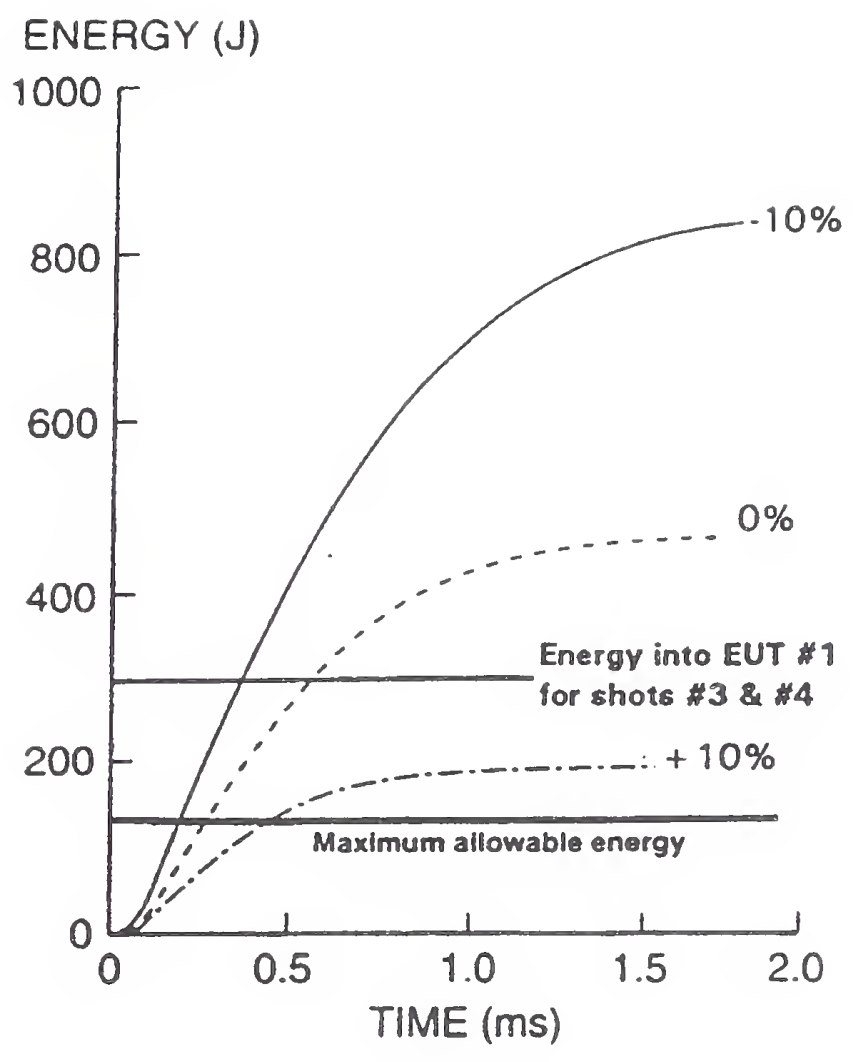

Figure 3.

Energy deposited in varistor as a function of tolerance of device compared to nominal value (From Ref. [5])

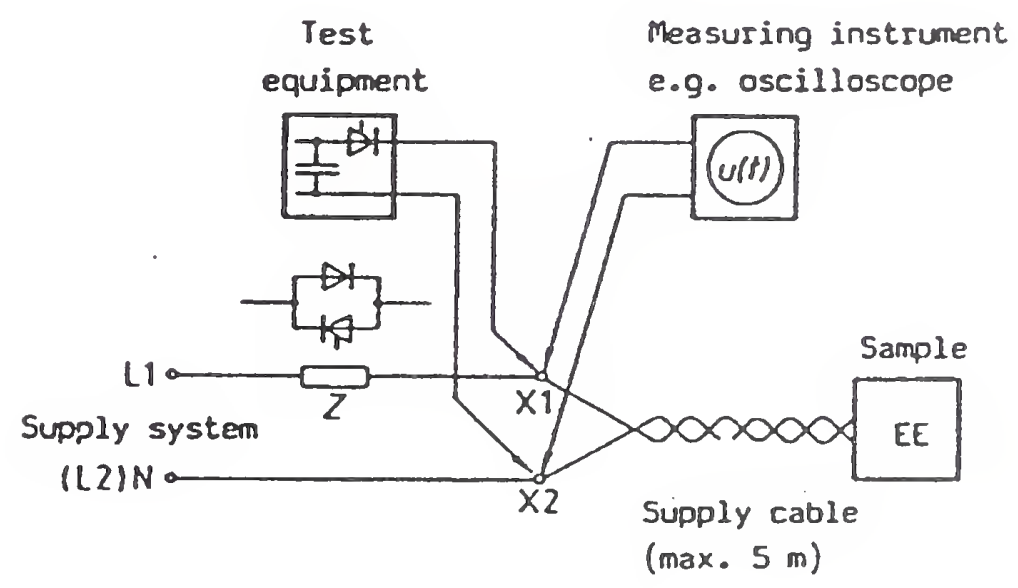

Figure 4. Elementary test circuit diagram (From Ref. [2]) 

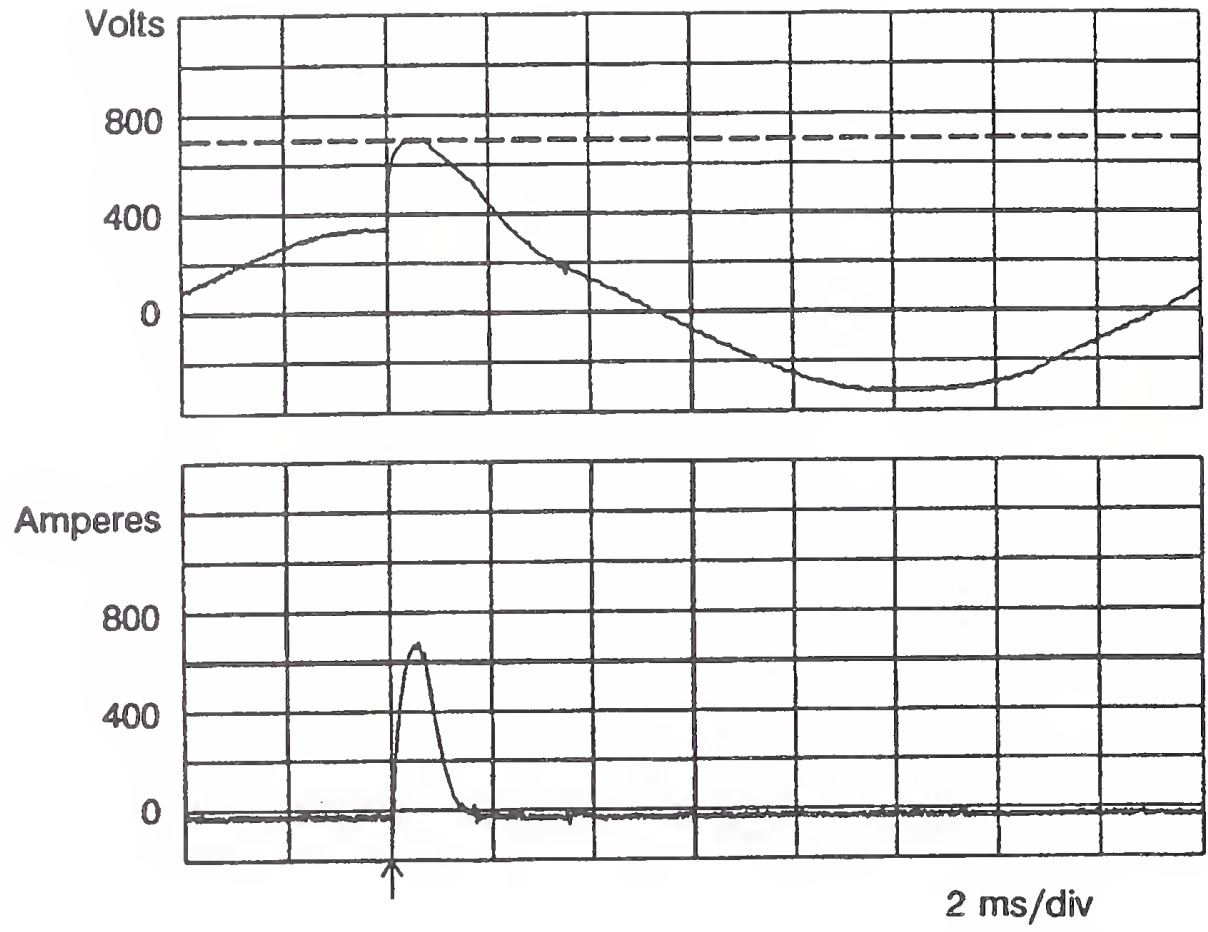

Figure 5. Voltage across and current through varistor only
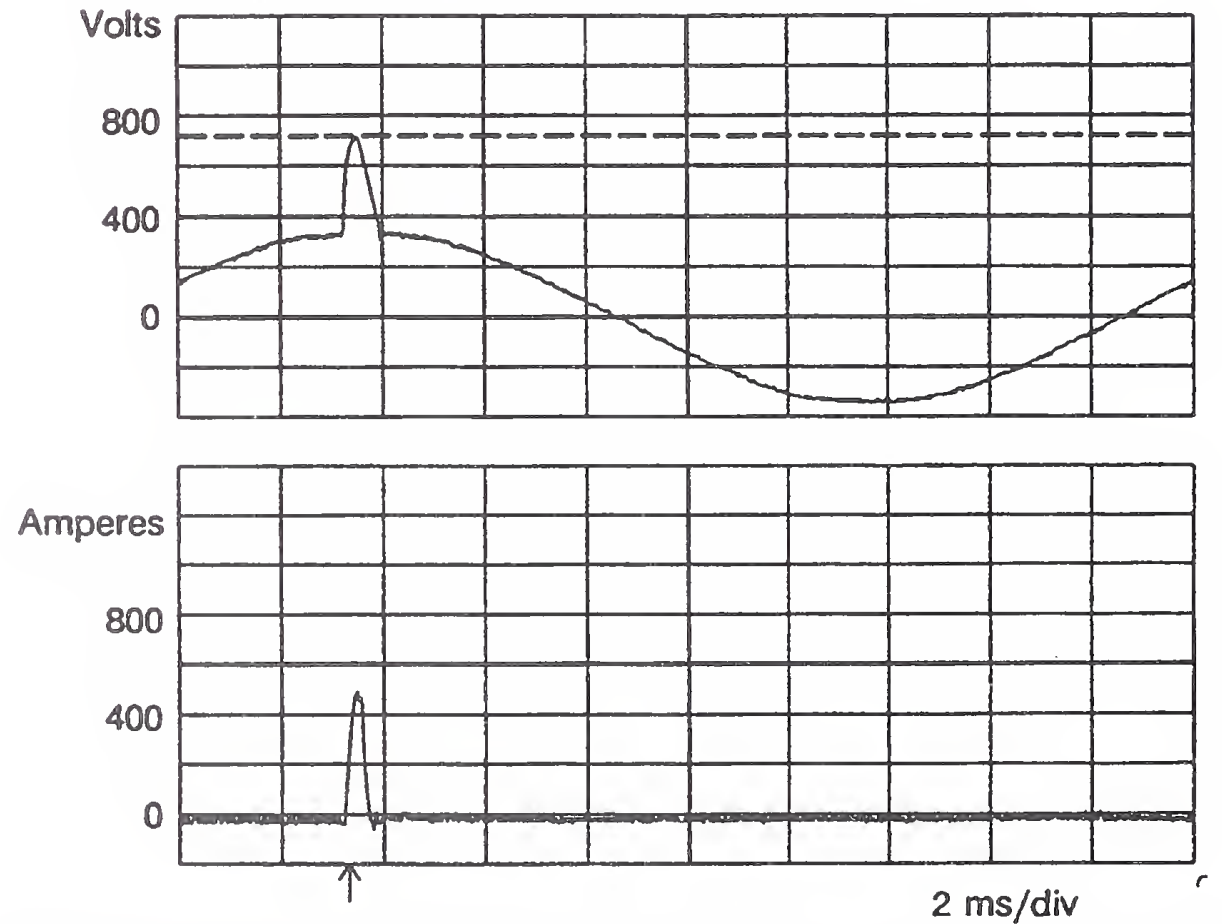

Figure 6. Voltage across and current through varistor with reduced stress 


\title{
Validating Surge Test Standards by Field Experience: High-Energy Tests and Varistor Performance
}

\author{
Charles Fenimore, Member, IEEE and François Martzloff, Life Fellow, IEEE \\ National Institute of Standards and Technology \\ Gaithersburg MD 20899 USA \\ f.martzloff@ieee.org
}

(C) 1992 IEEE

Reprinted, with permission, from

IEEE Transactions on Industry Applications, Vol.28, No.6, November/December 1992

\section{Significance:}

Part 2 Development of standards - Reality checks

Demonstration ad absurdum:

Accepting the premise of proposed IEC 100/1300 high-energy surges being representative of the environment, and modeling the response of typical metal-oxide varistors, leads to the conclusion that most of the billions of varistors in service should fail at alarming rates - but we know they do not. Ergo, the premise is not valid and the proposed high-energy test should not be considered as an across-the-board requirement.

(See also paper "MOV - VDE" in this Part 2 for an experimental demonstration.)

On the other hand, the tests proposed in IEEE Std C62.41 would not result in systematic failure of commonly used varistors and consequently appear more realistic 
$\varnothing$ 


\title{
Validating Surge Test Standards by Field Experience: High-Energy Tests and Varistor Performance
}

\author{
Charles Fenimore, Member, IEEE, and François D. Martzloff, Fellow, IEEE
}

\begin{abstract}
New, high-energy surge tests are emerging in IEEE and IEC standards. Field experience offers a valuable criterion for validating or invalidating proposed standards. A proposal under consideration by the IEC involves so much energy that a varistor of the voltage rating commonly used in protecting load equipment, if subjected to this test, would almost certainly fail. Yet, reported varistor failure rates do not reflect such a situation. Thus, a reexamination of the premises that led to the proposed test specifications appears necessary. Proposals for high-energy tests as additional waveforms in the new version of IEEE C62.41, on the other hand, lead to current and energy levels that do not place typical varistors in immediate jeopardy. Thus, they appear more consistent with field experience.
\end{abstract}

\section{INTRODUCTION}

A NATURAL approach in defining the surge tests to be performed on any equipment is to attempt duplicating the conditions observed in site measurements. However, this approach would lead to a situation where general conclusions are drawn from limited measurements of specific surge occurrences. It has, in fact, led to a multitude of proposals for test standards that may subsequently be applied outside of their original, correct context because no other standard is available at the time. An example of this situation may be developing with the proposal by Technical Committee 77 of the International Electrotechnical Commission (IEC) for a high-energy $100 / 1300-\mu$ s surge test.

To evaluate the effects of various proposed or existing high-energy stress tests on commonly used varistors, this paper presents a simple yet effective model of a surge generator. The evaluation proceeds by quantifying the current through the varistor and the corresponding energy deposited in the varistor. The computed results are compared with the published device ratings to predict the likelihood of failure. This likelihood is then compared

Paper IPCSD 90-40, approved by the Power Systems Protection Committee of the IEEE Industry Applications Society for presentation at the 1990 Industry Applications Society Annual Meeting, Seattle, WA, October 7-12. This work was supported by the Building Industry Consulting Service International (BICSI) and by the U.S. Army Research, Development, and Engineering Center. Manuscript released for publication September 24, 1991.

The authors are with the Electricity Division, National Institute of Standards and Technology, Gaithersburg, MD 20899.

IEEE Log Number 9203290 with the available information from field experience on failure rates.

Any immunity test should be conducted with an objective that is more subtle than the goal to "duplicate the environment." A test stress is applied to a device not to demonstrate that it can survive any of the stresses that it will encounter in nature but only to demonstrate for the benefit of both manufacturer and purchaser that the device can survive an agreed-on, simple, and reproducible stress. From surviving the test stress, the inference is made, subject to confirmation by field experience, that the device does have the ability to survive the infinite variety of stresses that it will encounter during its life in the real world. In other words, simple test stresses are useful because they can be reproduced over a period of time at the same facility and between facilities, providing a common language and a standard of comparison that is essential to conduct orderly transactions. Test standards should not, however, be misconstrued as representing natural phenomena. They are effective only if they discriminate between those devices with a potential for long field survival and those that are likely to fail.

The proposed $100 / 1300-\mu$ S IEC test should be reexamined with this philosophy in mind because it appears that commonly used varistors would be expected to fail when subjected to this test. Anecdotal experience does not support the prediction of failure in the field, raising questions as to the general validity of this test. On the other hand, high-energy tests derived from new proposals contained in the revised version of IEEE Std. C62.41 do not lead to contradiction between field experience and predicted test results.

\section{Proposed IEEE ANd IEC High-Energy Tests}

Metal-oxide varistors that suppress surges by absorbing energy have proliferated in low-voltage ac power circuits. Consequently, new high-energy tests have been proposed to assess the ability of these varistors to withstand the corresponding stress. In a major revision of the IEEE Guide C62.41 [1] (emerging as a Recommended Practice [2]), an additional waveform has been proposed to assess this ability. The proposal is a $10 / 1000-\mu$ s surge, with three "system exposure" levels, which are defined below. The IEC Technical Committee TC77 is considering a 
surge test requirement based on the scenario of currentlimiting fuses clearing a fault at the end of a cable, where the energy trapped in the system inductance causes a large transient at the time the fuse interrupts the current [3]. That scenario was first described and quantified by Meissen [4] and incorporated in German Standard VDE 0160 [5].

The new C62.41 Recommended Practice proposes, among other waveforms, a high-energy stress defined by an open-circuit voltage and a source impedance at three "system exposure" levels. For the "low exposure" level, no high-energy stress is proposed; for the "medium exposure" level, the surge environment involves a crest of two times the system peak voltage with a source impedance of $1 \Omega$. For the "high exposure" level, the crest is 2.3 times the system peak voltage, whereas the source impedance is only $0.25 \Omega$.

The IEC proposal appears to be based on the VDE 0160 standard, which specifies the direct discharge of a large capacitor-thousands of microfarads -into the equipment under test (EUT). The VDE test procedures are not quite clearly outlined at this point but might be interpreted as readjusting the capacitor charging voltage after connecting the EUT to the surge generator in order to maintain the specified test voltage across the EUT. That approach would be diametrically opposed to the generally accepted practice of performing a surge test with a generator having the capability of delivering a well-defined open-circuit voltage and short-circuit current or an open-circuit voltage associated with a specified source impedance (see Fisher and Martzloff [6] and the IEEE Guide on Surge Testing [7]).

Another ambiguity in the VDE 0160 test specification is that it might be acceptable to perform a test where the voltage waveform is less than the specification, provided that $80 \%$ of the energy stored in the surge generator capacitor is delivered to the EUT. However, there is no provision in the test procedure for measuring this energy, and it is doubtful that this condition can be achieved with a surge generator containing the parallel resistor that is necessary to achieve the specified rate of decay (or duration of the tail of the wave) when the EUT offers a high impedance.

Metal-oxide varistors offered by manufacturers include ratings of $130 \mathrm{~V}$ rms for applications in $120-\mathrm{V}$ systems and $250 \mathrm{~V}$ rms for application in $220-\mathrm{V}$ systems. The motivation for using these varistor ratings is, of course, the desire to provide the lowest possible clamping voltage to protect sensitive equipment. A paper presented at the Zürich EMC Symposium suggests that premature varistor aging may result from this close clamping (see Martzloff and Leedy [8]). However, the $130-$ and $250-\mathrm{V}$ varistor ratings are still widely used by equipment manufacturers who take the position that they are not afflicted by unacceptable failure rates. Thus, the authors accept that position as reflecting actual field experience and will apply it as a criterion for validating or questioning the proposed high-energy test standards.

\section{SUMMARY OF RESULTS}

This paper reports the results of modeling the application of a surge test to a family of commonly used varistor sizes $(14,20$ and $32 \mathrm{~mm}$ in diameter). For each varistor size, the computations were performed for three levels of manufacturing tolerances on the varistor: nominal value, $-10 \%$, and $+10 \%$. A varistor with its clamping voltage at the maximum acceptable tolerance level (the level shown on published $I-V$ curves) will tend to absorb less energy than a varistor with a lower clamping voltage because it will divert current for a smaller part of the surge. The maximum energy deposition in the varistor will occur for a varistor having the lowest acceptable clamping voltage (typically $20 \%$ below the maximum), as indicated by the $\pm 10 \%$ tolerance on varistor nominal voltages. Should the test generator parameters be at the most severe conditions within its uncertainties (higher peak voltage and longer duration than nominal within allowable tolerances), the stress on the varistor would be even greater.

The circuit model used in the computations reported in this paper is a simple capacitor-discharge circuit that can produce the $10 / 1000-\mu \mathrm{s}$ waveform of $\mathrm{C} 62.41$ or the $100 / 1300-\mu$ s waveform of VDE 0160 , where each has the appropriate selection of the components values. The modeling results, which are discussed in detail below with supporting information in the Appendix, indicate that the smaller size varistors would not be damaged at the "medium exposure" level of C62.41 but would be damaged at the "high exposure" level. The $32-\mathrm{mm}$ varistor would easily accept several applications of the "high exposure" level, whereas the $20-\mathrm{mm}$ varistor would have a limited life. On the other hand, few varistors will survive the VDE 0160 stress.

Table II presents this information in the form of the number of surges that a varistor can survive for the three sizes and three tolerance values of varistors and for the three type of tests: VDE 0160, C62.41 "high exposure," and C62.41 "medium exposure." The results with C62.41 are in good agreement with anecdotal (unpublished) field experience, that is, $14-\mathrm{mm}$ varistors installed at the service entrance are often in jeopardy, 20-mm varistors have a better chance, and 32-mm varistors are generally successful. Failure rates are not reported formally in the literature, but anecdotal information does circulate. The response of industry to the Zürich paper alerting the community to the risk of premature aging caused by repeated swells [8] was that 20 - and $32-\mathrm{mm}$ varistors do not suffer from an unacceptable or alarming failure rate.

The predicted survival rates of Table II appear to be consistent with actual field experience, thus validating the stress levels proposed by IEEE C62.41. In contrast, for the VDE 0160 stress, the predicted survival rate is so low that a conclusion appears inescapable: The VDE 0160 stress involves an exceptionally high energy level, making the application of the test questionable if interpreted as a general requirement. The authors do not question the scenario leading to this stress level but do question the 
TABLE I

Predicted Number of High-Energy SURges that a Varistor Can Survive as a Function of Size and Clamping VOLTAGE TOLERANCE

\begin{tabular}{ccccr}
\hline \multirow{2}{*}{$\begin{array}{c}\text { Varistor } \\
\text { Clamping } \\
\text { Voltage } \\
\mathrm{mm}\end{array}$} & $\begin{array}{c}\text { VDE 0160 } \\
\text { Tolerance }\end{array}$ & Class 2 & $\begin{array}{c}\text { C62.41 } \\
\text { High }\end{array}$ & $\begin{array}{c}\text { C62.41 } \\
\text { Medium }\end{array}$ \\
\hline 14 & $-10 \%$ & none & none & 80 \\
& $0 \%$ & none & 1 & 3000 \\
20 & $+10 \%$ & none & 8 & $>10^{6}$ \\
& $-10 \%$ & none & 1 & 500 \\
& $0 \%$ & none & 3 & 8000 \\
32 & $+10 \%$ & 1 & 20 & "indefinite" \\
& $-10 \%$ & none & 8 & 20000 \\
& $0 \%$ & 1 & 80 & 200000 \\
& $+10 \%$ & 5 & 800 & "indefinite" \\
\hline
\end{tabular}

IEC proposal to require an across-the-board test at that level for all equipment.

The dramatic effect of the tolerance value on survival rate is also apparent. Greater reliability can be achieved if users would accept - better yet, request - a slightly higher clamping voltage than the lowest clamping voltage offered by the manufacturers of varistors and by the manufacturers of packaged suppressors.

\section{Modeling a Surge Test}

The normal practice in surge testing of low-voltage equipment, as described in the IEEE Guide on Surge Testing [7], is to specify an open-circuit voltage and a short-circuit current to be delivered by the surge generator. With these two parameters specified, the surge generator is considered to be defined for any test involving a specimen of high impedance (typically insulation) or low impedance (typically a surge diverter). For the unidirectional surges of $10 / 1000$ and $100 / 1300 \mu \mathrm{s}$, a simple four-component model circuit can produce these waveforms. An actual surge generator, of course, requires careful attention to avoid problems of parasitic impedances, but the simple circuit model of Fig. 1 can deliver the required waveforms, as shown in Fig. 2 for the case of the nominal C62.41 $10 / 1000-\mu$ s waveform.

In the specification of that waveform, the tolerances allowed by C62.41 recognize the fact that the open-circuit voltage will inescapably have a longer duration but shorter rise time than the short-circuit current. Because the high-energy aspect of this test makes the current waveform the most significant parameter, the values of the components in the model were selected to most closely approximate the nominal $10 / 1000 \mu$ s for the short-circuit current while allowing the open-circuit voltage to go to the longest duration permitted by the tolerances. For the VDE 0160 model, the values of the components were selected to comply with the $6000-\mu \mathrm{F}$ requirement while producing the specified open-circuit voltage.

In predicting varistor failure rates, the model can take into consideration the possible combinations of manufacturing tolerances on the varistors and the uncertainties of the test (which is something that is more difficult to do by

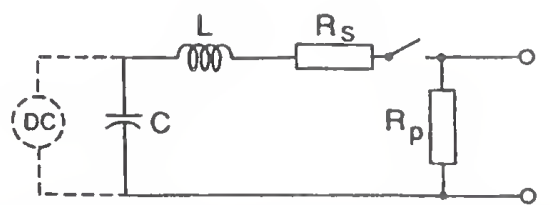

Fig. 1. Four-component circuit for 10/1000- and 100/1300- $\mu$ s surge modeling.

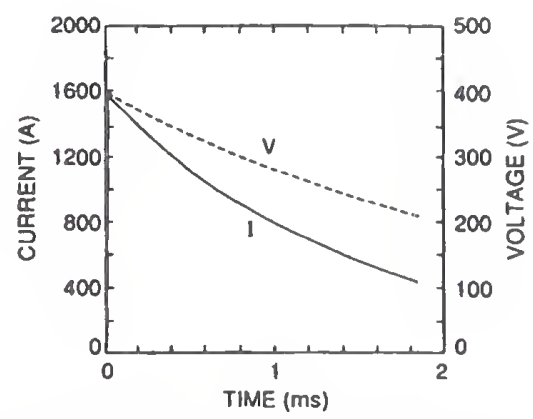

Fig. 2. Open-circuit voltage $V$ and short-circuit current $I$ produced by circuit model with parameters set for the C62.41 10/1000- $\mu$ s waveform.

tests on random samples). In the simple computations reported here, three cases have been computed with the varistor at the midpoint and the two extremes of its manufacturing tolerance. The surge generator parameters were set to produce the nominal current waveform in order to make a midrange rather than a worst-case prediction. The conclusions on survival rates and validation of the proposed tests presented above would not be dramatically affected if the surge generator parameter tolerances were included in the computation.

The component values of the circuit shown in Fig. 1 may be selected to generate the desired waveforms of the various standards. The selection method is described below. In order to determine the response of the circuit with the nonlinear varistor, numerical techniques are used as shown in the second step below.

In the circuit of Fig. 1, the capacitance $C$ is charged to an initial voltage $V_{c}$. The surge generator has a series resistance $R_{s}$ and a parallel resistance $R_{p}$. A small inductance $L$ is tuned to provide the specified rise time. This simple LRC circuit is described by a characteristic equation

$$
L \lambda^{2}+R \lambda+\frac{1}{C}=0
$$

where $R$ is defined below. The two decay constants are

$$
\lambda^{ \pm}=-\frac{R}{2 L} \pm \sqrt{\left(\frac{R}{2 L}\right)^{2}-\frac{1}{L C}} .
$$

The response of the circuit is a "double exponential" waveform [9].

Using the allowed tolerances of C62.41 for the model, the waveshape of the short-circuit current (in which case $R$ is $R_{s}$ ) was set at $10 / 1000 \mu \mathrm{s}$. For the open-circuit voltage (in which case $R$ is $R_{s}+R_{p}$ ), the maximum 
duration allowed by C62.41 is $2000 \mu s$. The decay times, which are expressed as full width at half maximum (FWHM) for these two waveforms are designated as $t_{\text {, }}$ and $t_{V}$, respectively. The effective source impedance is defined in C62.41 as the ratio of the peak open-circuit voltage $V_{p}$ to the peak short-circuit current $I_{p}$. Its value $Z=V_{p} / I p$ has the dimension of an impedance.

Because the time constants are widely separated, the determination of the circuit component values from the values of $t_{l}, t_{V}, Z$, and $V_{p}$ can be simplified to produce approximate values. The characteristic decay values $\lambda^{+}$ and $\lambda^{-}$are given by

$$
\begin{aligned}
& \lambda^{+} \cong-\frac{1}{R C} \\
& \lambda^{-} \cong-\frac{R}{L} .
\end{aligned}
$$

In particular, for long times $t$, the short circuit current $I_{s c}$ and open-circuit voltage $V_{o c}$, are given by

$$
\begin{gathered}
I_{s c}(t) \cong I_{p} e^{-t / R_{s} C} \\
V_{o c}(t) \cong V_{p} e^{-t /\left(R_{s}+R_{p}\right) c} .
\end{gathered}
$$

At half maximum, one has

$$
t_{l}=\log 2 \cdot R_{s} \cdot C
$$

and

$$
t_{V}=\log 2 \cdot\left(R_{s}+R_{p}\right) \cdot C .
$$

With a small value of the inductance

$$
V_{p} \cong V_{c} \frac{R_{p}}{R_{s}+R_{p}}
$$

and

$$
\frac{1}{R_{s}}+\frac{1}{R_{p}}=\frac{1}{Z}
$$

These relations lead to the four equations:

$$
\begin{gathered}
R_{p}=\frac{t_{V}}{t_{l}} \cdot Z \\
R_{s}=\frac{t_{V}}{t_{V}-t_{l}} \cdot Z \\
C=\frac{t_{I}}{\log 2 \cdot R_{s}} \\
V_{c}=\frac{t_{V}}{t_{V}-t_{l}} \cdot V_{p} .
\end{gathered}
$$

The inductance is determined by considering the 10-90\% rise time $t_{R}$. The widely separated time constants allow the fast component of the current to be estimated by

$$
I_{s c} \cong I_{p} e^{-R t / L}
$$

at short times $t$.
Applying a logarithm yields

$$
L \cong \frac{R \cdot t_{R}}{\log .9-\log .1}=\frac{R \cdot t_{R}}{\log 9} .
$$

The expressions (1)-(5) uniquely define the characteristics of the circuit for given values of the time constants, the source impedance, and the peak open-circuit voltage.

With the parameters of the model test circuit thus defined, the solution of the response of the current and energy in the varistor is obtained numerically using the ordinary differential equation package PLOD [10]. The varistor is presumed to contain an internal series resistance $R_{m}$ and have the $I-V$ relationship

$$
V_{m}=\left(\frac{I_{m}}{k}\right)^{1 / \alpha}+R_{m} I_{m} .
$$

The first-order system of equations to be solved is given by the definition of the capacitor current $I$ and by Ohm's law

$$
\begin{gathered}
\frac{d Q}{d t}=-I \\
L \frac{d l}{d t}=\frac{Q}{C}-R_{s} I-V_{m} .
\end{gathered}
$$

The varistor current $I_{m}$ and $I$ are related by (6) and by

$$
I=I_{m}+\frac{V_{m}}{R_{p}}
$$

By exploiting this relationship, a direct numerical solution for the varistor current is possible. In addition, the energy in the varistor $E_{m}$ is found by integrating

$$
\frac{d E_{m}}{d t}=I_{m} \cdot V_{m}
$$

The initial charge is given by $C \cdot V_{c}$, and the initial current and energy in the varistor are zero. The computations were performed for the two C62.41 exposure levels and for the maximum VDE 0160 stress, as described below.

\section{MODELING RESULTS}

\section{C62.41-10/1000- $\mathrm{es}$ Stresses}

To evaluate the effects of the test on varistors, a simple model of an equivalent circuit of the varistor is connected to the terminals of the model generator. The charging voltage of the generator is, of course, left unchanged. For the range of frequencies involved in these waveforms, the only two significant elements of the varistor equivalent circuit (Fig. 3) are the pure varistor $R_{x},\left(I=k V^{\alpha}\right)$ and the series resistance $R_{O N}, R_{s}$ in the model. The parallel resistance $R_{\text {OFF }}$, capacitance $C$, and the series inductance 


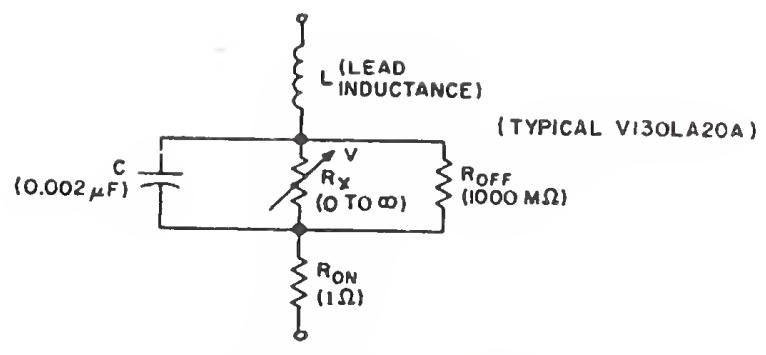

Fig. 3. Equivalent circuit of a varistor (Source: [14]).

$L$ of the complete equivalent circuit can be neglected. Three diameters of $130-\mathrm{V}$ rated varistors were considered, each with its characteristic clamping at $-10,0$, and $+10 \%$ of the nominal value published by one manufacturer. Fig. 4 shows the type of plots obtained from the model where the current through the varistor and the cumulative energy deposited in the varistor are computed as a function of time. Showing the complete set of results for all combinations would require excessive space; a summary of the results is presented in the Appendix. In the typical example of Fig. 5, three curves show the cumulative energy for a $14-\mathrm{mm}$ varistor with nominal rating of $130 \mathrm{~V}$ rms and three tolerance values $-10,0$, and $+10 \%$ clamping voltage when exposed to the C62.41 "high exposure" stress level.

\section{VDE $0160100 / 1300$ - $\mu$ s Stress}

Fig. 6 shows the parameters of the $100 / 1300-\mu$ s surge, Class 2 described in the most recent amendment to VDE 0160 [11] and in the IEC proposal [3]. The voltage level is specified as 2.3 times the peak of the ac power system voltage. (The amendment also cites a Class 1 category with a level of only 2.0 times the peak of the ac power system voltage and a shorter duration). Accepting for the moment the premises that led to the specification of this test, the authors applied the same circuit model used for the IEEE waveforms to produce the specified VDE waveform with an energy storage capacitor having the value specified in the latest amendment to VDE 0160. (Earlier versions of the VDE 0160 standard suggested a $25000-\mu \mathrm{F}$ capacitor. In the amendment, this value has been scaled down to a range of 700 to $6000 \mu \mathrm{F}$, perhaps implying that the issue is still unsettled, and thus, the IEC proposal is still open to feedback from users.)

In this case, because the VDE places emphasis on maintaining the voltage waveform, the model parameters were set to obtain an open-circuit voltage close to the $100 / 1300-\mu$ s values, with the exception of the resulting short-circuit current, for which VDE 0160 does not specify a value. Fig. 7 shows the open-circuit voltage and short-circuit current computed by the model.

The computations were performed for the $250-\mathrm{V} \mathrm{rms}$ rating because the VDE 0160 does not provide specifications for system voltages of less than $220 \mathrm{~V}$ rms. Details of the results are presented in the Appendix together with the corresponding results from the C62.41 stress levels.

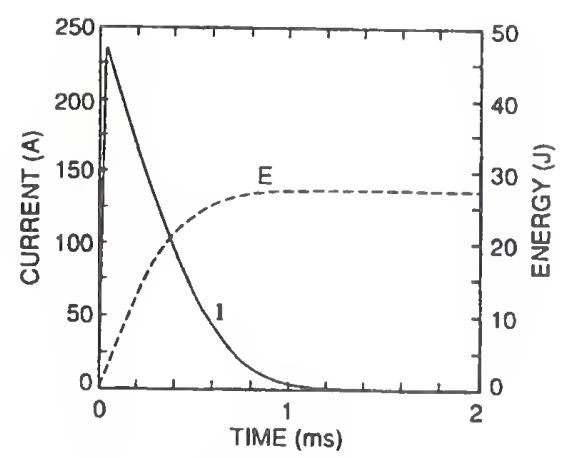

Fig. 4. Energy deposition $E$ and current $I$ in a $20-\mathrm{mm}$ varistor with nominal clamping characteristic ( $0 \%$ tolerance) during the "High Exposure" $10 / 1000-\mu$ s C62.41 surge.

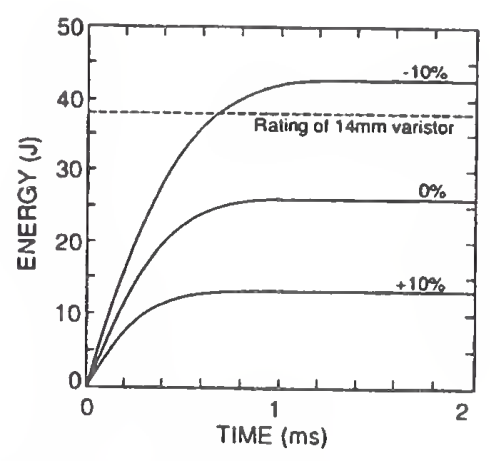

Fig. 5. Energy deposition in $14-\mathrm{mm}$ varistors at $-10,0$, and $+10 \%$ values of clamping characteristics during a "high exposure" $10 / 1000-\mu \mathrm{s}$ C62.41 surge.

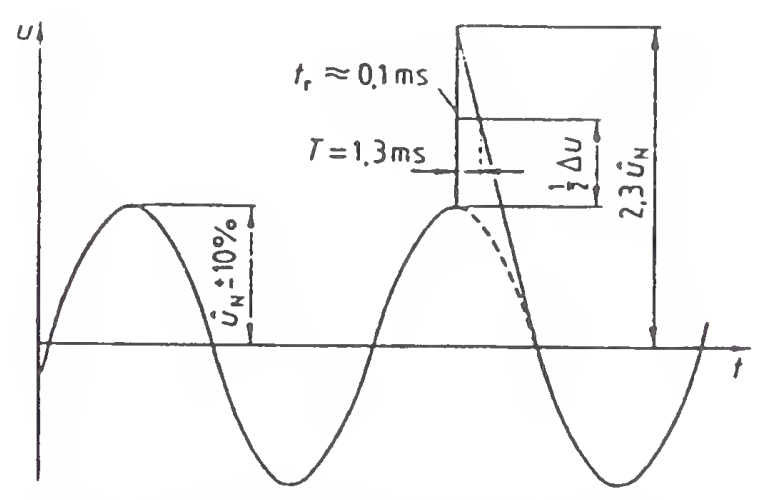

Fig. 6. Voltage waveform of the $100 / 1300-\mu$ s surge specified by VDE 0160 and proposed by IEC (Source: [5]).

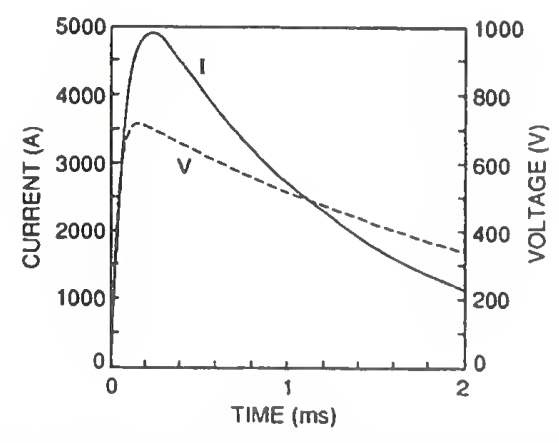

Fig. 7. Open-circuit voltage $V$ and short-circuit current $I$ produced by model with parameters set to approximate the VDE 0160 voltage wave-
form. 
COMPARISONS OF RESULTS FROM MODEL WITH VARISTOR RATINGS

Typical manufacturer specifications [12] include a joules rating for maximum single pulses; however, industry standards (Section 6, IEEE Standard on Varistor Test Specifications [13]) raise some questions on the application of such a simple criterion.

The cumulative energy levels for the three varistor sizes (each at three tolerance levels) were computed with the model for the C62.41 and VDE 0160 stress levels. The results are shown in Table II, together with the typical, single-pulse joule rating published for these sizes. By using this somewhat oversimplified joule criterion (more than $10 \%$ change in nominal voltage may occur if joule rating is exceeded), it would appear that only the 14- and $20-\mathrm{mm}$ varistor, for the low values of tolerance, might be in jeopardy.

Using the criterion of "pulse rating" proposed by manufacturers [11], [14], where the current peak and duration are taken into consideration leads to more detailed and reliable conclusions, which also agree with field experience (see Martzloff [15]).

Therefore, the current peak and its duration (FWHM) were also computed for the nine combinations of varistor parameters and compared with the "pulse rating" corresponding to the duration and peak in each case. The detailed results, which are the basis for the summary of Table I, are presented in tabular fashion in the Appendix, together with a discussion of the finer points of the analysis.

\section{CONCLUSIONS}

1) Predictions of the impact of the $100 / 1300-\mu$ s surge test proposed by the IEC and based on the VDE 0160 standard show that the millions of varistors in service should experience a greater failure rate than that indicated by available information on actual field failures. This inconsistency raises serious questions on the proposed requirement of such a severe test to a wide range of equipment.

Furthermore, the lingering ambiguity in the VDE 0160 standard (and, consequently, in the IEC proposal) on whether to set constant open-circuit voltage or to adjust the voltage while the specimen is connected needs to be clarified. A constant, specified open-circuit voltage combined with a well-defined source impedance is the generally accepted practice in surge testing.

2) The energy levels and currents resulting from application of a waveform described in the revised IEEE C62.41, on the other hand, range from benign for typical large varistors to severe for small varistors. Thus, this set of stress levels appears to be more consistent with field experience, at least as inferred from available anecdotal information.

3) Although the authors do not question the validity of the fuse-blowing scenario, which is the basis for the VDE 0160 and proposed IEC test, they recommend a critical
TABLE II

Single-Pulse Results and Ratings (IN JOUles)

\begin{tabular}{|c|c|c|c|c|c|c|c|}
\hline $\begin{array}{l}\text { Va } \\
\text { Size } \\
\mathrm{mm}\end{array}$ & $\begin{array}{c}\text { Tolor } \\
\text { Tolet- } \\
\text { ance } \\
\%\end{array}$ & \multicolumn{2}{|c|}{$\begin{array}{c}\text { VDE 0160 } \\
\text { Class } 2 \\
250 \mathrm{~V} \\
\text { varistor }\end{array}$} & \multicolumn{2}{|c|}{$\begin{array}{c}\text { C62.41 } \\
\text { High } \\
130 \mathrm{~V} \\
\text { varistor }\end{array}$} & \multicolumn{2}{|c|}{$\begin{array}{c}\text { C62.41 } \\
\text { Medium } \\
130 \mathrm{~V} \\
\text { varistor }\end{array}$} \\
\hline & & Result & Ratiog & Result & Ratiog & Result & Ratiog \\
\hline \multirow[t]{3}{*}{14} & -10 & 212 & & 43 & & $\overline{6}$ & \\
\hline & 0 & 126 & 72 & 26 & 38 & 3 & 38 \\
\hline & +10 & 62 & & 13 & & 1 & \\
\hline \multirow[t]{3}{*}{20} & -10 & 257 & & 45 & & 6 & \\
\hline & 0 & 181 & 130 & 27 & 70 & 3 & T0 \\
\hline & +10 & 86 & & 14 & & 1 & \\
\hline \multirow[t]{3}{*}{32} & -10 & 306 & & 46 & & 6 & \\
\hline & 0 & 181 & 330 & 28 & 200 & 3 & 200 \\
\hline & +10 & 86 & & 15 & & 1 & \\
\hline
\end{tabular}

NOTES:

1. Five oumbers are printed in bold face io she results columos for two values of tolerances in the 14- $\mathrm{mm}$ and 20-mm varistors. These values exreed the ratiog of the varistor, and thus would indicate a bigh likelibood of failure at that stress level

2. The varistor model postulates the same $I=\mathrm{kV}^{a}$ selation for the three ratings, with a series re estance that decreases as the diameter of the varistor iocreases. The lower series rebistance iovites a greater carreot diversion into the varistor in the opturn regioo of the $1 \cdot V$ characteristic, where itn effect is more ooticeable, especially for the VDE 0160 and the lower tolerance case for the varistorn

review of the statistics of the occurrence of fuse blowing, the use of varistors with low clamping voltage, and the distribution of actual clamping voltage within manufacturing tolerances. They also urge all users to share information on the observed failure rates and thus attain a broader perspective on these issues.

\section{APPENDIX}

\section{Detalled Results for Current Peaks and Duration}

This Appendix provides a summary of the 54 separate computations made to determine the current in the varistor resulting from the three high-energy tests discussed in the paper. Three varistor sizes were considered $(14,20$, and $32 \mathrm{~mm}$ ), and their "pulse rating" obtained from [12] and [14]. The 32-mm size has been dropped from the current product line of [12] and might appear obsolete. However, it was selected because it has been applied in the past [14], and thus, more field experience is available for that size than for the $40-\mathrm{mm}$ size, which is the present offering.

The computed results are presented in Table AI for the VDE 0160 Class 2 and the C62.41 "high exposure" and "medium exposure" stresses. In each major section of the table, the computed current peak and FWHM are tabulated. Next to these computations, the corresponding current peaks are shown from the "pulse ratings" in [12] or [14] for the computed duration and for 1, 10, and 100 applications of that peak of current pulse.

The usual description of a unidirectional surge is based on the FWHM, and therefore, the computations of the current in the varistor were aimed at characterizing this description of the current waveform. However, the "pulse rating" curves in both [12] and [14] are based on an "impulse duration" defined as the time from virtual origin of the wave and the virtual time to half value. In the case of the C62.41, with a front time of $10 \mu \mathrm{s}$ and a FWHM of $1000 \mu \mathrm{s}$, the difference between the FWHM and the "impulse duration" is negligible. In the case of the IEC $100 / 1300-\mu \mathrm{s}$ waveform, the difference is more significant, 
TABLE AI

Modeling Results Versus Device Ratings-Current and Duration

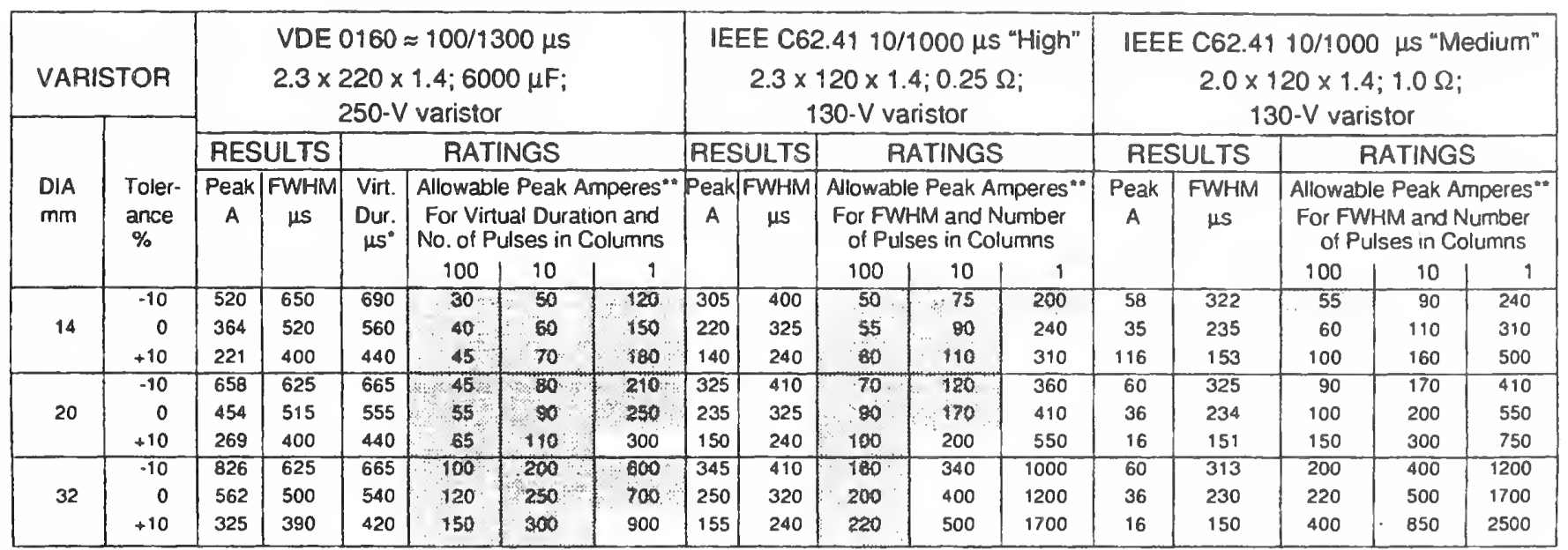

"Adjustment of approximately helf of the rise time made to account for the difference between the computed FWHM and the "virtual duration" used in manufacturers specifications. For the short rise time of the C62.41, the difference is negligible.

"When allowable peak current tor the corresponding duration and number of pulses exceeds the rated peak current at that duration, the varistor is deemed in jeopardy; this siluation is shown by shading the corresponding area in the rating columns. The unshaded areas represent "survival" of the varistor through the high-energy stress.

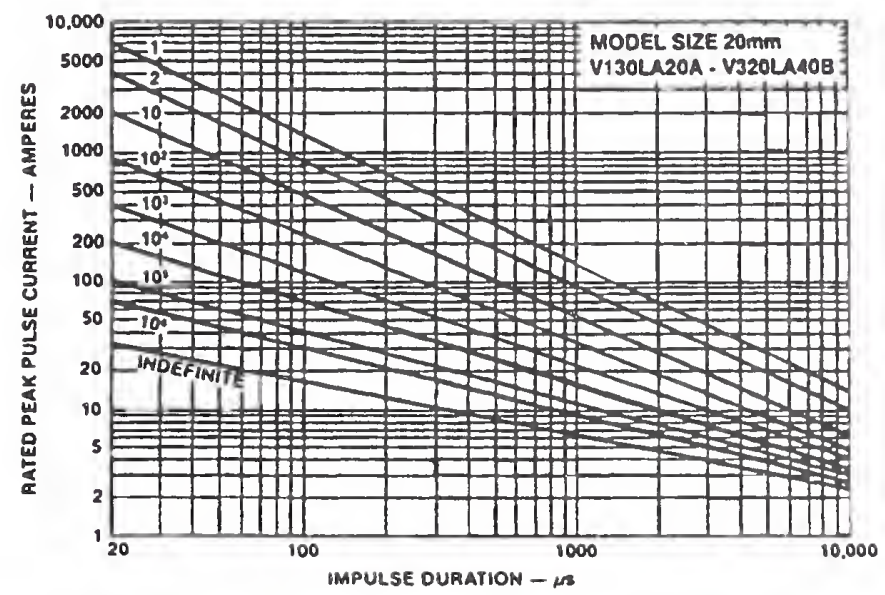

Fig. Al. Typical published family of "pulse rating" curves showing amplitude, duration, and number of allowable pulses.

and therefore, the comparisons of Table AI include a $40-\mu$ s adjustment in the duration (about half of the rise time).

The peak values of the current shown in the table that exceed the "pulse rating" have been identified by shading the area in the columns. At a glance, it becomes apparent that the survival rate to a VDE 0160 exposure can be expected to be extremely low; it will be moderate for the C62.41 "high exposure" and will be at its maximum for the C62.41 "medium exposure" stresses.

\section{ACKNOWLEDGMENT}

The authors acknowledge the contribution of T. Key in presenting this paper at the 1990 Annual Meeting of the Industry Applications Society when, on short notice, they were unable to travel to Seattle.

\section{REFERENCES}

[1] ANSI/IEEE C62.41-1980, Guide on Surge Voltages in Low-Voltage ac Power Circuits.
[2] ANSI/IEEE C62.41-1991, Recommended Practice on Surge Voltages in Low-Voltage ac Power Circuits.

[3] IEC Document 77B(Central Office)4, Overview on Electromagnefic Compatibility -Immunity Tests.

[4] W. Meissen, “Überspannungen in Niederspannungsnetzen," Elektrotechnische Zeitschrift, vol. 104, 1983.

[5] VDE 0160 Ausrüstung von Starkstromanlagen mit elektronischen Betriebsmitteln, May 1988.

[6] F. A. Fisher and F. D. Martzloff, "Transient control levels: A proposal for insulation coordination in low-voltage systems," IEEE Trans. Power App. Syst., vol. PAS.95, 1976.

[7] ANSI/IEEE C62.45-1987, Guide on Surge Testing for Equipment Connected to Low-Voltage ac Power Circuits.

[8] F. D. Martzloff and T. E. Leedy, "Selecting varistor clamping voltage: Lower is not better!," in Proc. 1989 Zürich EMC Symp.

[9] A. Greenwood, Electrical Transients in Power Systems. New York: Wiley-Interscience, 1971.

[10] E. Argon, I. L. Chang, G. Gunaratra, D. K. Kahaner, and M. A. Reed, "Mathematical software: PLOD," IEEE Micro, vol. 8, no. 4 pp. 56-61, Aug. 1988.

[11] VDE 0160A1 Änderung 1 zu DIN VDE 0160/05.88, Apr. 1989.

[12] Transient Voltage Suppression Devices, Harris Corp. 1990.

[13] ANSI/IEEE C62.33-1982, IEEE Stand. Test Spec. Varistor SurgeProtective Devices.

[14] Transient Suppression Manual, 5th Ed., General Electric Company, 1986.

[15] F. D. Martzloff, "Varistor versus environment: Winning the rematch," IEEE Trans. Power Delicery, vol. PWRD-1, no. 2, Apr. 1986.

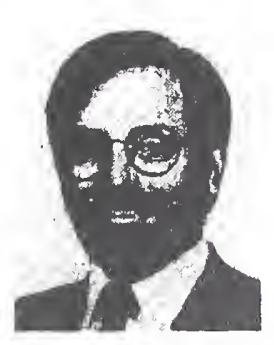

Charles Fenimore (M'88) received the B.S. degree from Union College, Schenectady, NY, in 1966 and the Ph.D. degree from the University of California, Berkeley, in 1978.

He is an applied mathematician in the Electricity Division of the National Institute of Standards and Technology, Gaithersburg, MD. His interests include modeling and computing the nonlinear characteristics of high-energy/highvoltage electrical systems. He is the author of numerous papers on the breakdown of dielectric liquids, high-voltage measurements, and the solution of partial differential equations.

Dr. Fenimore is a member of the Dielectrics and Electrical Insulation Society and the Circuits and Systems Society of the IEEE. 


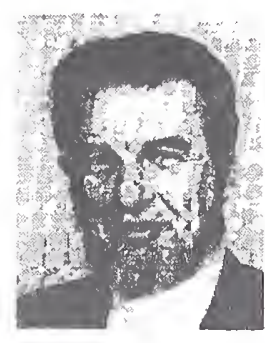

François D. Martzloff (F'83) was born in France, where he completed his undergraduate training, and came to the United States in the 1950's to continue his graduate studies.

In 1985, he joined the staff of the National Bureau of Standards (NBS, now NIST) to expand NBS activities in the field of conducted electromagnetic interference with more recent emphasis on power quality and surge protection issues. Prior to joining NBS, his long career at General Electric included high-voltage fuses and bushings development, power electronics, transient measurements, surge protection of electronics, applications of varistors, and electromagnetic interference protection.

He is contributing to the work of several IEEE committees, in particular, the revision of ANSI/IEEE C62.41, Guide on Surge Voltages, into the Recommended Practice as discussed in the paper, and an update of C62.45, Guide on Surge Testing. He is serving as vicechair of the IAS IEEE Standards Coordinating Committee on Power Quality. In the IEC Technical Committee 77 on Electromagnetic Compatibility, he is serving as chair of $\mathrm{SC77B}$ (industrial systems) and secretary of WG2B (installation and mitigation). 


\section{Applying Reality Checks to Standards on the Surge Environment}

Arshad Mansoor Power Electronics Applications Center Knoxville TN 37932 USA Amansoor@epri-peac

François Martzloff National Institute of Standards and Technology Gaithersburg MD 20899 USA f.martzloff@ieee.org

Doni Nastasi Power Electronics Applications Center Knoxville TN 37932 USA DNastasi@epri-peac.com

Reprinted with permission from Proceedings, 23 International Conference on Lightning Protection, Florence, 1996

\section{Significance:}

Part 2 Development of Standards - Reality checks

Three examples of reality checks are given that shed some light on issues raised during standards development

- The apparent reduction in surge voltage activity is explained by the proliferation of surge mitigating devices.

- A proposed high-energy surge would cause failure of ubiquitous SPDs, but they do not fail in the field.

- Allegedly frequent high-level surges would cause frequent failure of light bulbs, but they do not in the field 
$\varnothing$ 


\section{APPLYING REALITY CHECKS TO STANDARDS ON THE SURGE ENVIRONMENT}

\author{
Arshad Mansoor and Doni Nastasi \\ Power Electronics Applications Center \\ Knoxville TN USA
}

\begin{abstract}
The paper identifies several realities of surge environment and equipment survival that are sometimes ignored in surge-protection practices. It questions the quest for what could be overly conservative requirements for surge immunity or surge mitigation by presenting "reality checks" based on field experience or laboratory data. A first check focuses on the fact that some recent field recordings of surges may be misleadingly low in today's surge environment. Additional checks, aimed at moderating the overly conservative requirements, include the case history of a proposed high-stress $100 / 1300 \mu \mathrm{s}$ surge test, data on failure levels of clock motors and light bulbs that can serve as benchmarks for severity levels, and measurements, validated by parametric modeling, showing that large currents cannot propagate into long cables without causing a flashover of the wiring devices at the beginning of the cable, effectively limiting the energy-delivery capability of a surge at the end of the cable.
\end{abstract}

\section{Introduction}

Some proposals for standards on equipment surge immunity or on performance of surge-protective devices are driven by the commendable quest for conservative ratings. However, when this quest produces compounded safety factors, the result may not be cost-effective.

The purpose of our paper is to present facts and rationalizations in support of the development of realistic standards on the surge environment in low-voltage ac power systems. In addition to contributors to the ICLP Conferences, two major players in the development of international standards on the lightning surge environment are IEC Technical Committee 77 on Electromagnetic Compatibility and Technical Committee 81 on Lightning Protection. Other contributors addressing switching surges as well as lightning surges include IEC Subcommittee 28A on Insulation Coordination, Subcommittee 37 A on SurgeProtective Devices, and the IEEE Committee on SurgeProtective Devices. The standards developed by these bodies reflect the collective experience of individual contributors as well as the "corporate memory" of these groups. In this paper, four items are described that may serve as foundations, or reality checks, to be added to this corporate memory. The first check can be seen as a reminder note to resist the mistake of dismissing surge threats because contemporary recordings show benign occurrences of surge voltages. The three other checks can serve as a tempering note, to avoid economically unjustified over-specification of surge protection.

\footnotetext{
Electriciry Division, Electronics and Electrical Engineering Laborasory. Technology Administrasion. U.S. Department of Commerce.
}

\author{
François D. Martzloff \\ National Institute of Standards and Technology * \\ Gaithersburg MD USA
}

\section{The ninety-five percent rule}

Debates and definitions concerning compatibility levels, immunity limits, or emissions limits generally acknowledge that requirements drawn from these considerations cannot apply simultaneously to $100 \%$ of the cases and $100 \%$ of the time. The term "high probability" appears in many definitions, rather than a hard number. This avoidance of hard numbers is the result of the difficulty to secure a consensus from individuals who represent different communities of end-users with different perceptions of what is an acceptable level of probability.

The military and aerospace communities often speak of zero tolerance or zero defects where economics is downplayed. In contrast the commercial, mass-production communities speak of realistic requirements where costeffectiveness is a very prominent factor.

An intermediate position can be found in industry where a rational balance is sought between the costs of exhaustive mitigation and the consequential costs of limited mitigation.

Our reality checks are offered as a guide to striking such a balance, recognizing the diversity of circumstances and expectations from a diversity of end-users.

\section{Shrinking surges $\mathrm{vS}$. expanding mitigation}

A reality check can explain an apparently puzzling development which has been observed since the beginning of studies concerning the characterization of the surge environment: starting in the sixties, results published by researchers monitoring the occurrence of surges have reported a gradual decrease in the relative severity of surges (Martzloff \& Hahn, 1970 [1]; Allen \& Segall, 1974 [2]; Bull \& Nethercott, 1975 [3]; Goldstein and Speranza, 1982 [4]; Goedbloed, 1987 [5]; Dorr, 1995 [6]).

This puzzling trend can be explained by reference to the reality: the spectacular expansion of surge-protective devices (SPDs) in low-voltage ac power circuits now makes it almost impossible to make measurements at a site where there is not some hidden SPD. Monitors will now report the residual voltage of these SPDs, not the true surge activity in the environment (Aspnes et al. and discussion, 1985 [7]). So, it is not that surges have shrunk, but rather that mitigation has greatly expanded, masking the persistent occurrence of transients which remain a potential threat. This threat has shifted from observed surge voltages -now mitigated -- to the possibility of excessive surge currents into candidate mitigation means with low limiting voltage which would be particularly attractive to the surges. 
Future surveys of the occurrence of surges in lowvoltage ac power systems should shift from the recording of surge voltages to the recording of surge currents [8]. Unless this shift is implemented, the false sense of security will be further promoted that potentially damaging surges are less frequent than once believed. The 1980 title of a seminal IEEE document on the occurrence of surges (Guide on Surge Voltages in Low-Voltage AC Power Circuits [9]) was appropriate at the time, but should now be amended to reflect the shift.

\section{The saga of the proposed $100 / 1300 \mu$ surge}

A proposal was made in the early eighties to require a high-stress surge test for industrial equipment. A reality check would have revealed the contradiction between the failure rates that would result from such a test and the observed field failures.

Starting with observations of the occurrence of long duration surges, typically associated with fuse blowing, the proposal was to require an additional test with a surge longer than the classic 1,2/50 - 8/20 $\mu$ s impulse (Meissen, 1983 [10]; VDE 0160, 1989, [11]; IEC 1000-4-1, 1990 [12]). The proposed surge would be characterized by a $100 / 1300 \mu$ s waveform, with peales as high as 1,3 per unit, added to the ac sine wave peak. In the original VDE 0160 implementation, the test circuit involved the discharge of a $24000 \mu \mathrm{F}$ energy-storage capacitor. An amendment to the VDE 0160 standard [13] scaled the capacitance value down to $6000 \mu \mathrm{F}$, still a large stress for the equipment under test.

For instance, such surges would impose large stresses to the millions (or perhaps billions) of small varistors now installed in low-voltage ac power systems. One would observe a conspicuous failure rate in the field as typical 20-mm diameter varistors cannot survive such surges, but one does not observe this failure rate. An objection to this surge specification was first proposed on the basis of computer simulation of the event (Fenimore \& Martzloff, 1990 [14]) because no generator was commercially available to produce that surge. Table 1 shows an excerpt from [14] where the current that would be caused by the proposed $100 / 1300 \mu$ s surge in a $20-\mathrm{mm}$ varistor rated $250 \mathrm{~V}$ ms was computed and compared to the published varistor pulse rating for current-handling capability. Only a varistor at the high end of its $\pm 10 \%$ tolerance band could survive one application of that surge (the corresponding computed current peak is only $269 \mathrm{~A}$, compared to a rating of $300 \mathrm{~A}$ ). In all the other cases, the varistor rating is exceeded and likelihood of failure increases for lower tolerances and for more than one pulse.

Later on, when a prototype generator capable of delivering this surge was developed by a surge generator manufacturer, tests witnessed by one of the authors and by W.Meissen (the originator of the $100 / 1300 \mu \mathrm{s}$ surge proposal), did confirm the fact that 20-mm varistors are destroyed by that surge (Martzloff, 1991 [15]). We now understand that the IEC proposals and the VDE 0160 requirements for the $100 / 1300 \mu$ s surge have been pulled back or are being reconsidered.
Table 1

Computed peak currents for a postulated $100 / 1300 \mu$ s surge and varistor rated peak current

\begin{tabular}{|c|c|c|c|c|c|}
\hline $\begin{array}{c}\text { Tolerance } \\
\text { on varistor } \\
\text { nominal } \\
\text { voltage } \\
\text { rating } \\
(\%)\end{array}$ & $\begin{array}{c}\text { Computed results: } \\
\text { Current peak and } \\
\text { duration of surge } \\
\text { in the varistor }\end{array}$ & \multicolumn{2}{|c|}{$\begin{array}{c}\text { Varistor rating: Allowable } \\
\text { peak A for number of } \\
\text { pulses of computed } \\
\text { FWHM }\end{array}$} \\
\cline { 2 - 6 } & $\begin{array}{c}\text { Peak } \\
(\mathrm{A})\end{array}$ & $\begin{array}{c}\text { FWHM } \\
(\mu \mathrm{s})\end{array}$ & $\begin{array}{c}100 \\
\text { pulses }\end{array}$ & $\begin{array}{c}10 \\
\text { pulses }\end{array}$ & $\begin{array}{c}1 \\
\text { pulse }\end{array}$ \\
\hline-10 & 658 & 625 & 45 & 80 & 210 \\
0 & 454 & 515 & 55 & 90 & 250 \\
+10 & 269 & 400 & 65 & 110 & 300 \\
\hline
\end{tabular}

"FWHM: Full width at halt maximum

\section{Failure levels of clock motors and incandesceat light bulbs}

Two simple devices have been in service in millions of households and can be seen as surge threshold detectors: motor-driven clocks (before the advent of digital clocks) and still today, the ubiquitous incandescent light bulb. We have some knowledge on the failure rate of some of these devices under surge conditions, from which we can derive some inferences on approximate limits on the level of frequent surges. As we will see in the following two subsections, the data are not precise and are subject to undetermined statistical variations. However, the large number of observations does give some value to the inferences, compared to the limited number of observations obtained by more precise recording instruments.

\subsection{Failures of motor-driven clocks}

In the sixties, a report was published citing a 100:1 reduction in the failure rate of clock motors when the withstand level of the motor was raised from $2 \mathrm{kV}$ to $6 \mathrm{kV}$ [9], thus providing a verification of the "slope" of surge occurrence rate vs. peak reported by many researchers [16].

Figure 1 shows a plot of the frequency of occurrence of surge voltages versus their peak amplitude as reported by many researchers, and the two-point line of the 100:1 relationship between $2 \mathrm{kV}$ and $6 \mathrm{kV}$ occurrences. The parallel position of all these lines is remarkable. While the plots reported by the researchers are generally limited to a few thousand hours of observation, at only a few locations, the clock data represent the integration of more than 10000 clocks over a period of two to three years.

Because the data reflect only the number of clocks returned by dissatisfied customers, the exact number of clocks involved in "monitoring" the surge voltages, and the duration of the observation are not known. Therefore, rigorous statistical analysis would be meaningless. The point of our reality check, however, is still that a very large number of observation points were involved, for a period of several years, something that no survey could do - but for this particular case history, it was all done before the environment began to be tamed by the proliferation of the new generation of low-voltage SPDs. 


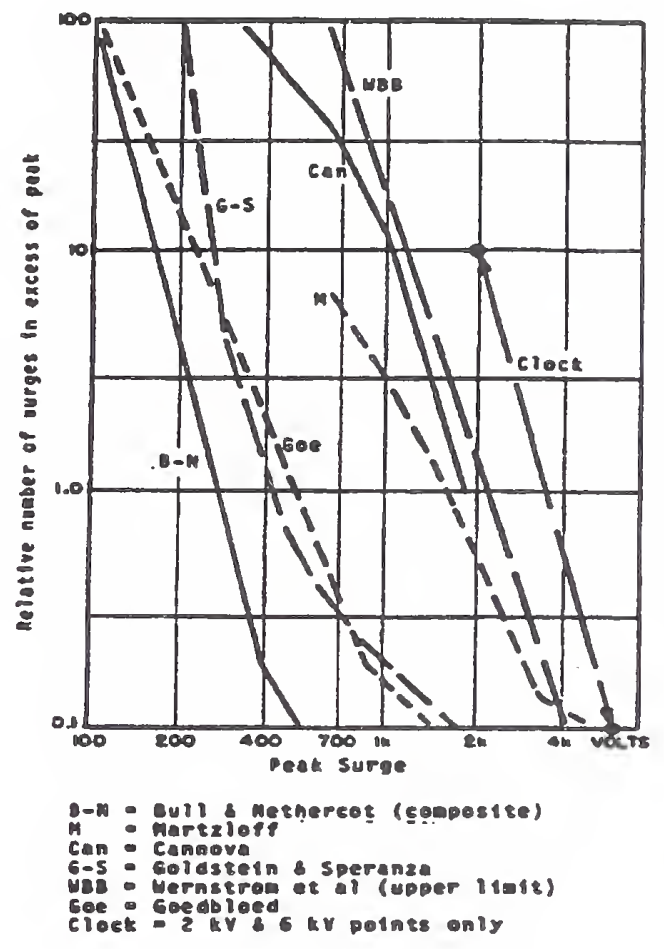

Figure 1 - Plots of frequency of occurrence versus peak amplitude reported in 1970-1987 surveys by independent researchers. The line marked "clock" only shows the slope from $2 \mathrm{kV}$ to $6 \mathrm{kV}$, not the actual frequency of occurrence. Note how the lines are essentially parallel. (Plot reproduced from [16].)

\subsection{Failure of incandescent light bulbs under surges}

Tests recently performed by the authors on $120-\mathrm{V}$ incandescent light bulbs show that few bulbs will survive surges in excess of 1200 to $1500 \mathrm{~V}+$, and that a surge of as little as $800 \mathrm{~V}$, when it occurs under the most sensitive condition, can trigger the failure. Limited tests performed on $240 \mathrm{~V}$ bulbs yield similar results. Comparison of tests performed by a researcher in Austria and by the authors on both $120 \mathrm{~V}$ and $240 \mathrm{~V}$ bulbs might be available at the time of presentation of this paper.

Since we do not hear reports of endemic failure of light bulbs beyond what can be expected from their known service life, we must conclude that the reality is that there is not a high rate of occurrence of surges at levels in excess of $1500 \mathrm{~V}$.

† The measurements reported in this paper hove been made with instrumentation for which the combined uncertainty should not exceed \pm 5 to $\pm 6 \%$. Given the process of applying the measurement results to the failure levels of light bulbs exposed to environments with characteristics that are at best lonown within an order of magnitude, this level of uncertainty does not affect the practical conclusions.
This observation merits a brief summary of our findings about the mechanism of bulb failure triggered by a surge. We emphasize the triggered aspect because surges of relatively low amplitude do not cause directly the failure of the bulb, but cause a secondary flashover at the power frequency that burns out the filament. Surges of higher amplitudes can deposit enough energy into the filament to melt it, but our point for the reality check is that even lowamplitude surges can result in failure of the bulb.

Figures 2, 3, 4, and 5 present oscillograms of the voltage across an energized $120-\mathrm{V}$ bulb and of the current flowing in the bulb. Figure 2 shows a narrow window commensurate with the duration of the surge delivered by a $1,2 / 50 \mu \mathrm{s}-8 / 20 \mu \mathrm{s}$ surge generator. We observe the chopping of the voltage wave, typical of a gap sparkover, and the rise of the surge current after the sparkover. The scale of the current trace selected to record the surge (hundreds of amperes) does not show the normal current (1 A) in the bulb. Observations during this test include hearing a pinging noise and seeing a bright flash of light, followed by darkness as the filament can then be seen broken at its points of attachment to the stems.

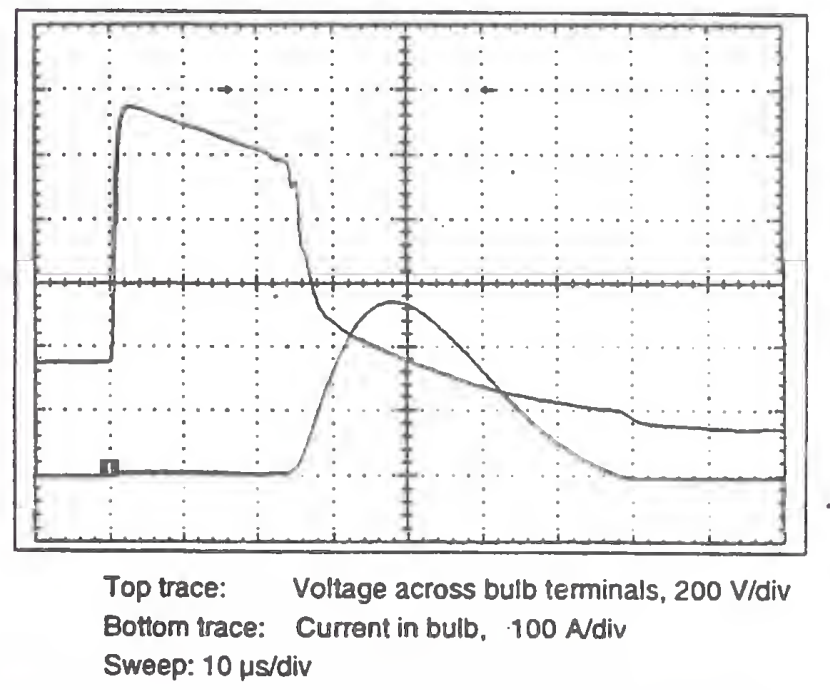

Figure 2 - Voltage and current in light bulb during application of a $1,2 / 50 \mu \mathrm{s}-8 / 20 \mu \mathrm{s}$ surge, resulting in surge sparkover

Figure 3 was recorded (for a new bulb) with a longer window to display two full cycles of the power frequency. At that sweep rate, the surge is no longer resolved, and its apparent peak on the trace may be lower than the actual peak because not enough data samples are collected around the peak. However, the timing of the surge, and the events following the surge are what is important in this figure. The surge event appears as a voltage spike and a current spike, followed by return to practically normal voltage and no visible large current. Then, suddenly, a pulse of power-frequency current appears, with a large amplitude .. the source of the observed flash. We believe that it is this current that causes the burn-out of the filament, not the "trigger" surge. 


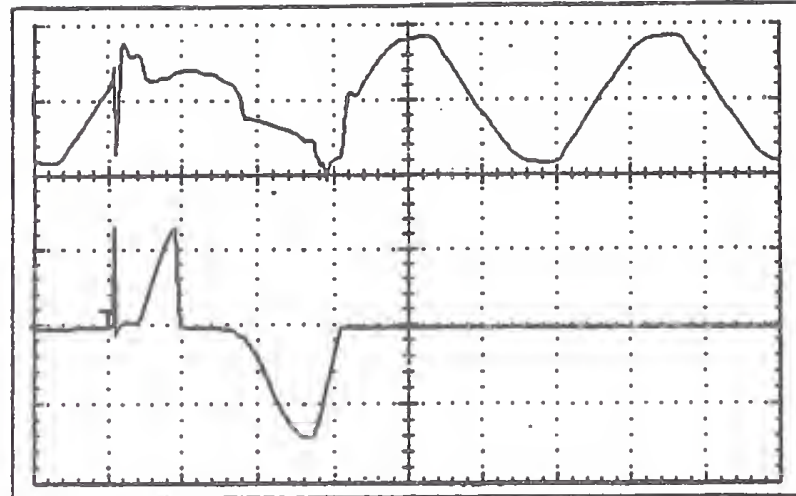

Top trace: Voltage across bulb terminals, 200 V/div

Bottom trace: Current in bulb, 100 Adiv

Sweep: $5 \mathrm{~ms} / \mathrm{div}$

Figure 3 - Voltage and current in light bulb during application of a $1,2 / 50 \mu \mathrm{s}-8 / 20 \mu \mathrm{s}$ surge at $30^{\circ}$, resulting in surge sparkover, followed by power-frequency flashover

This belief is supported by the recordings shown in Figures 4 and 5. Figure 4 is actually the recording of a surge application to the bulb of Figure 3, in a test that preceded the fatal surge recorded in Figure 3. The applied surge was the same (900 V) for both Figure 3 and Figure 4. The randomness of the process of igniting the power arc is such that in the case of Figure 4, the power arc was not ignited, while in the subsequent surge application on the same bulb (Figure 3 ) and in the same conditions, the power arc was ignited, resulting in burn-out of the filament.

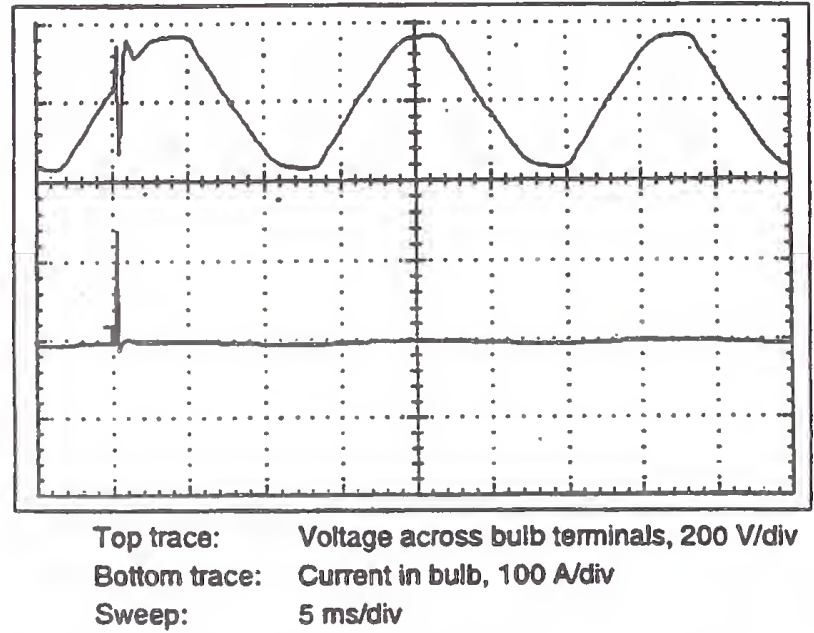

Figure 4 - Voltage and current in light bulb during application of a $1,2 / 50 \mu \mathrm{s}-8 / 20 \mu \mathrm{s}$ surge at $30^{\circ}$, with surge sparkover but no power-frequency flashover

As further evidence, Figure 5 shows the process (in a new bulb) when the surge was applied at zero degrees, the time at which there is the least power-frequency voltage to ignite a power arc. In that test sequence, the first applied surge had an amplitude of $1000 \mathrm{~V}$. Sparkover under the impulse did occur (the pinging noise was heard), but the power-frequency arc was not ignited and the bulb survived.

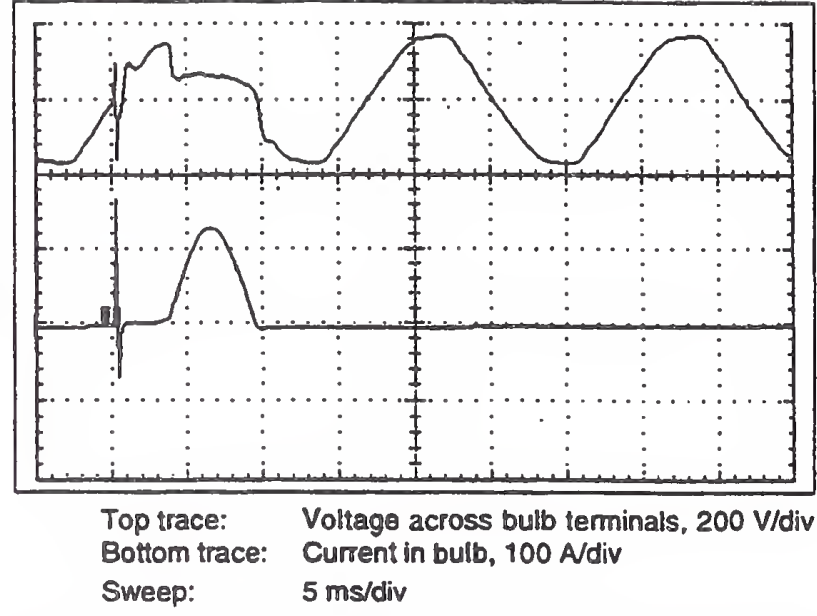

Figure 5 - Voltage and current in light bulb during application of a 1,2150 $\mu \mathrm{s}-8 / 20 \mu \mathrm{s}$ surge at $0^{\circ}$, resulting in surge sparkover and delayed power-frequency flashover

The applied surge was then raised in $100 \mathrm{~V}$ steps, still with pinging heard but no fatal power-frequency arc. Figure 5 was recorded when the applied surge voltage was increased to $1300 \mathrm{~V}$. At that level of energy deposited by the surge, enough plasma was generated in the path of the surge current to eventually ignite the power-frequency arc, but it had to wait until the power-frequency voltage had reached its peak.

To conclude this summary. Table 2 shows the relationship between the timing of the surge with respect to the sine wave and the amplitude of the surge sufficient to trigger ignition of the power-frequency arc. When the surge is applied at 90 degrees (the peak of the sine wave, making immediate ignition of the power arc easiest), a surge of $800 \mathrm{~V}$ is sufficient to trigger the power arc. At zero degrees, the surge must be raised to $1500 \mathrm{~V}$ to produce sufficient plasma to result in a subsequent powerfrequency arc.

The phenomena are of course subject to the statistical variations of sparkover. The values shown in Table 2 are the averages of tests performed on a total of 20 bulbs of the same manufacturer, rated $100 \mathrm{~W}$, replicating the test at several timing angles. This paper is not the medium for reporting in detail our series of experiments with other manufacturers and other watt ratings which produced similar results; the point is, however, that our inferences are not based on just the 20 bulbs of Table 2 .

Table 2

Relationship between timing argle of the surge and amplitude necessary to produce a fatal power-frequency flashover

\begin{tabular}{|c|c|c|c|c|c|c|c|c|}
\hline Angle $\left(^{\circ}\right)$ & 0 & 15 & 30 & 45 & 90 & 135 & 150 & $165 *$ \\
\hline Peak (V) & 1500 & 1200 & 900 & 800 & 800 & 850 & 850 & 1100 \\
\hline
\end{tabular}

- One specimen produced "pinging" starting at $1000 \mathrm{~V}$, but no power arc. Eventually, the butb failed at $1600 \mathrm{~V}$ without power arc, as a direct result of the energy dumped into the filament by the surge alone. 
6. Limits to pushing surges into branch circuits

Some proposals have been made to require SPDs intended for installation on indoor circuits to withstand surges with relatively high peaks and short rise time. Such a requirement would mean that a substantial voltage drop would be developed $(L \cdot d i / d t)$ along the wiring. Added to the limiting voltage of the SPD at the end of the line, the voltage necessary to drive such a surge at the origin of the line would very likely cause flashover of wiring devices at the origin of the line.

This flashover, occurring during the rising part of the surge, would effectively shut off further propagation of the surge toward the SPD (except for the energy stored in the line during the current rise, which is easily dissipated by the SPD). Thus, the requirement of a large surge capability for SPDs installed with even a modicum of line length would be unrealistic. In support of this statement, we present here a summary of measurements on actual wiring and EMTP [17] computer simulation of a range of parameters.

Figure 6 shows the experimental circuit with a varistor connected at the downstream end of a "branch circuit" consisting of two copper conductors of $2-\mathrm{mm}^{2}$ cross-section (\#12 AWG), typical of residential wiring. The first current transformer monitors the total current impinging at the upstream end. The second current transformer monitors the current flowing toward the downstream end, which will be imposed on the varistor. The clearances at the upstream end, such as clearances in a service-entrance panel, are represented by a discrete gap that can be set to produce sparkover at some given voltage during the test as well as in the model.

To determine the response of the circuit without the clearance limitation and verify that the model produces the same result, the gap setting was adjusted for this particular test so that no sparkover occurred at the upstream voltage developed for the current delivered by the generator. Once the model was validated, parametric variations could be performed for any combination of circuit length, applied surge, and clearance (gap) sparkover.

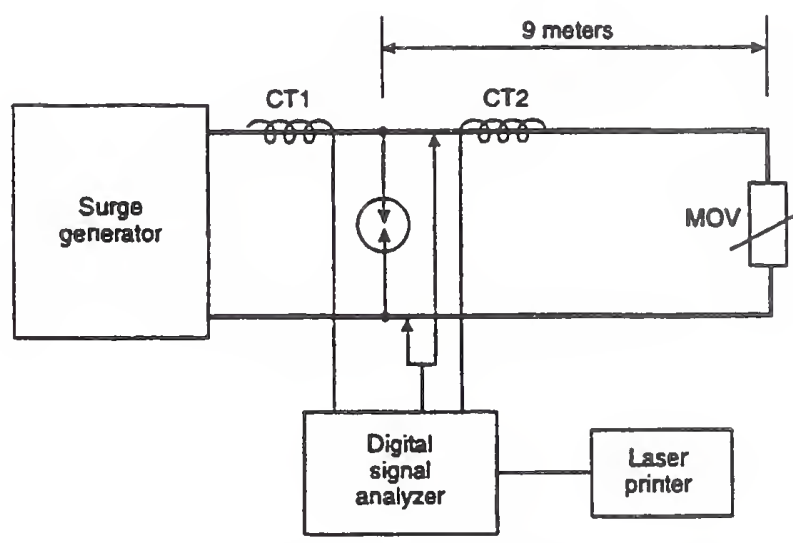

Figure 6 - Test serup for driving surges into a varistor installed at the end of a $9 \mathrm{~m}$ branch circuit.

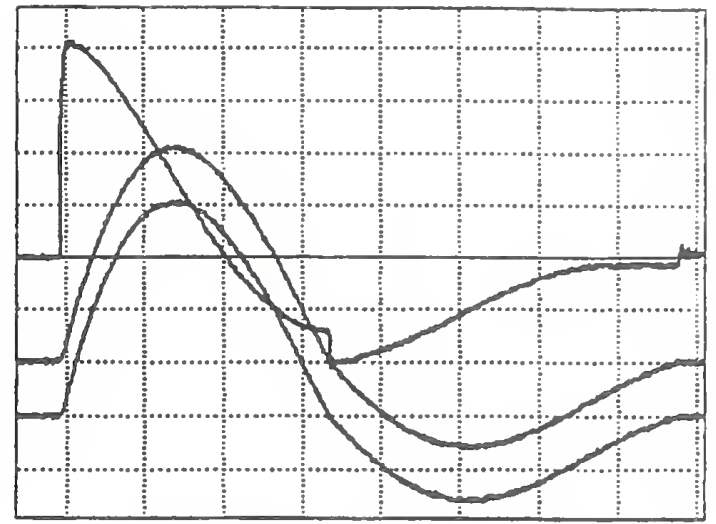

Top trace: Gap voltage, 500 V/div Center trace: Total current, $500 \mathrm{Addiv}$ Bottom trace: MOV current, $500 \mathrm{~A} / \mathrm{div}$ Sweep: $10 \mu \mathrm{s} / \mathrm{div}$

Figure 7 - Voltage and currents measured in the circuit of Figure 6

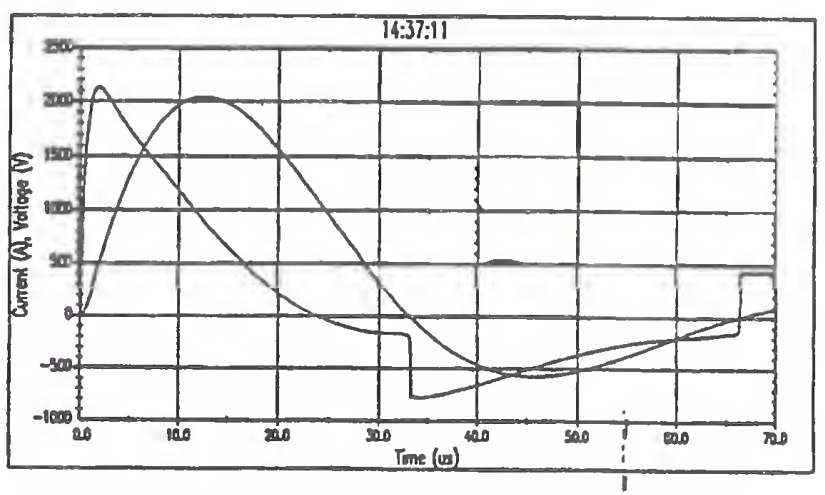

Figure 8 - Plot from model of voltage across the gap (compare with voltage trace of Figure 7) and impinging current (compare with the two current traces of Figure 7) for the circuit of Figure 6

Inspection of Figures 7 and 8 clearly shows the agreement between real-world measurements and model. The voltage traces are quite comparable. In Figure 7, the two current traces are identical since no current is diverted in the arrester. In Figure 7, the current trace is the one postulated in the modeling. This correspondence allows us to make parametric variations in the model with postulated impinging surges of higher values, such as those being proposed for consideration in some standards-writing groups. Another advantage of the model is that it allows postulating a current source - the consensus choice among lightning researchers - rather than using a surge generator which is only a charged capacitor with a wave-shaping network Consequently, the surge generator interacts with the circuit into which the surge is injected, changing the waveform and losing the postulated constant waveform. This changing of the waveform makes it more difficult to perform parametric tests, compared to the ease of modeling. Table 3 below shows the results of such computations for the current waveform of Figures 7 and 8. 
Table 3

Computed upstream voltage (in $\mathrm{kV}$ ) necessary to drive a current of the peak value shown (columns) and rise time of $10 \mu \mathrm{s}$ into a branch circuit of length as shown (rows), terminated with a $130-V$ rated varistor

\begin{tabular}{|c|c|c|c|c|c|}
\hline $\begin{array}{l}\text { Peak } \\
\text { Length }\end{array}$ & $2 \mathrm{kA}$ & $3 \mathrm{kA}$ & $5 \mathrm{kA}$ & $7 \mathrm{kA}$ & $10 \mathrm{kA}$ \\
\hline $\begin{array}{l}10 \mathrm{~m} \\
30 \mathrm{~m} \\
50 \mathrm{~m}\end{array}$ & $\begin{array}{l}2,3 \\
5,8 \\
9,3\end{array}$ & $\begin{array}{c}3,3 \\
8,5 \\
13,7\end{array}$ & $\begin{array}{c}5,2 \\
13,9 \\
22,7\end{array}$ & $\begin{array}{c}7,2 \\
19,4 \\
31,6\end{array}$ & $\begin{array}{l}10,1 \\
27,0 \\
45,0\end{array}$ \\
\hline
\end{tabular}

As mentioned above, the insertion of an inductance in the load connected to the surge generator increased the rise time beyond the standard $8 \mu \mathrm{s}$, In making the parametric computations, we chose to stay with this $10 \mu \mathrm{s}$ value to maintain continuity with the test/model validation.

Typical wiring devices used in $120-\mathrm{V}$ installations have minimum flashover points in the range of 5 to $8 \mathrm{kV}$ (this as a result of prevailing clearance requirements rather than insulation withstand levels as recommended by IEC Publication 664 [18]). Comparing this flashover level with the voltage values of Table 3 shows that, indeed, there is a strong possibility that within the range of current levels and branch circuit lengths of the table, a flashover would occur to throttle further propagation of the surge toward the varistor at the end of the branch circuit. In other words, postulating ever-larger surge currents into ever-longer branch circuits leads to a contradiction with the physical reality of the eventual occurrence of self-limiting flashover. This paradox has been discussed in greater details in a paper dedicated to that very subject [19].

\section{Conclusions}

1. Reality checks on the surge environment can bring a sense of perspective and help developing realistic standards for performance and application of surgeprotective devices. This perspective can help avoid both over- and under-specification.

2. The proliferation of surge-protective devices in low-voltage ac power systems has made the recording of surge voltages practically irrelevant at best, and misleading at worst because the recorders indicate the let-through voltage of the SPDs, not the impinging surge. Surveys of the surge environment should focus on the ability (threat) of a surge to deliver a current to those ubiquitous surgeprotective devices.

3. Field failure rates of various devices for which the failure level is known can provide some realistic and useful information on the rate of occurrence and level of surges in the environment.

4. Modeling the propagation of surges in a circuit, in particular computing the resulting voltages and comparing them with the known withstand level of insulation can provide a restraining influence on over-specifying surge protection requirements.

\section{Acknowledgments}

Support for the development of this paper was provided by the Power Quality research groups of Delmarva Power \& Light, and Pacific Gas \& Electric. Support for the testing and modeling was provided by the Electric Power Research Institute.

\section{References}

1. Marzloff, F.D. and Hahn, G.J., "Surge Vollages in Residential and Industrial Power Circuits," IEEE Transactions PAS-89, No.6, July/August 1970.

2. Allen, G.W. and Segall, D., 'Monitoring of Computer Installations for Power Line Disturbances," IEEE Winter Power Meeting Conference Paper WINPWR C74, 1974.

3. Bull and Nethercotr 'The Frequency of Occurrence and the Magnitude of Short Duration Transients in Low-voltage Supply Mains," The Radio and Electronic Engineer, Sept 1964.

4. Goldstein, M. and Speranza, P., "The Quality of U.S. Commercial AC Power," IEEE-INTELEC Conference Proceedings, 1992.

5. Goedbloed, J." "Transients in Low-Voltage Supply Networks," IEEE Transactions EMC-29, No.2, May 1987.

6. Dorr, D.S., "Point of Utilization Power Quality Study Results," IEEE Transacrions IA-3I, No.4, July/August 1995.

7. Aspnes, J.D., Evans, B.W., and Merritt, R.P., "Rural Alaska Electric Power Quality." IEEE Transactions PAS-104, No.3, March 1985.

8 Martzloff, F.D., "Surge Recordings That Make Sense: Shifting Focus from Voltage to Current Measurements," Proceedings, EMC '96 Roma, September 1996.

9. IEEE Std 587-180, IEEE Guide on Surge Volkages in AC Power Circuits, now updated as ANSIIEEE C62.41-1991, Recommended Practice on Surge Volvages in AC Power Circuits.

10. Meissen, W., "Überspannungen in Niederspannungsnetzen Eleksrotechnishe Zeitschrift." Vol. 104, 1983.

11. VDE 0160, Ausristung von Starkstromanlagen mit elektronishen Betriebsmirzeln, May 1988.

12. IEC Publication 1000-41, Electromagnetic Comparibility, Part 4: Immunity Tests, Section 1: Overview of Immunity rests, 1992.

13. VDE 0160A 1, Anderung I zu DIN VDE 0160/05.88, 1989.

14. Fenimore, C. and Marzaloff, F.D., "Validating Sutge Test Standards by Field Experience: High-Energy Tests and Varistor Performance," Conference Record, IEEE-IAS Annual Meeting. 1990. Also in IEEE Transactions IA-28 No.6, 1992.

15. Martzloff,.F.D., "Testing Varistors Against the VDE 0160 Standard," Open Forum on Surge Protection Application. NISTIR-4654, 1991.

16. Martzloff, F.D. and Gruzs, T.M., "Power Qualiry Site Surveys: Facts, Fiction, and Fallacies," IEEE Transactions IA-24, No.6, 1988.

17. EPRI, 'Electromagnetic Transient Program (EMTP), Version 2.0; Volume 1: Main Program; Volume 2: Auxiliary Routines," EPRI Report EL-6421-L. July 1989.

18. IEC Report 664-1980, Insulation coordination wirhin low-volvage systems, including clearances and creepage distances for equipment.

19. Mansoor, A. and Martzloff, F.D., "Driving High Surge Currents into Long Cables: More Begets Less," Presented at IEEE-PES Summer Meeting, Denver CO, July 1996, to be published in IEEE Transactions PWRD at later date. 


\section{Using Incandescent Lamp Failure Levels for Assessment of the Surge Environment}

\author{
Hubert Bachl \\ Cooperative Testing \\ Institute \\ Vienna, Austria
}

\author{
François Martzloff \\ National Institute of Standards \\ and Technology \\ Gaithersburg MD 20899 USA \\ f.martzloff@ieee.org
}

\author{
Doni Nastasi \\ Power Electronics Applications \\ Center \\ Knoxville TN 37932 USA \\ DNastasi@epri-peac.com
}

Reprinted, with permission, from

Proceedings, $12^{\text {th }}$ Internationa/Zürich Symposium on Electromagnetic Compatibility, 1997

\section{Significance: \\ Part 2 Development of standards - Reality checks}

Investigations were conducted in the US as well as in Austria, on $120-\mathrm{V}$ and $240-\mathrm{V}$ incandescent lamps to determine the levels of surges that can trigger an internal flashover of the hot filament, resulting in filament burnout. Repetitive surge application below the threshold do not result in premature failure of the lamp, but above the threshold, a single application can trigger a fatal flashover. By combining measurement of currents and voltage during the event with high-speed video recording, the mechanism has been clearly determined.

Depending on the characteristics of the surge (waveform, amplitude, and timing with respect with the powerfrequency sinewave), thresholds of failure range between $800 \mathrm{~V}$ and $2000 \mathrm{~V}$. Very few bulbs survive surges above $2200 \mathrm{~V}$. Therefore, the conclusion is inescapable: if such surges were occurning frequently - according to some SPD advertizing claims - lamps would fail very promptly. We know they do not, ergo the alleged frequency of occurrence is incorrect. 
$\varnothing$ 


\section{USING INCANDESCENT LAMP FAILURE LEVELS FOR ASSESSMENT OF THE SURGE ENVIRONMENT}

\author{
Hubert Bach! \\ Cooperative Testing \\ Institute \\ Vienna, Austria
}

\author{
François Martzloff \\ National Institute of Standards \\ and Technology \\ Gaithersburg MD USA
}

\author{
Doni Nastasi \\ Power Electronics \\ Applications Center \\ Knoxville TN USA
}

\begin{abstract}
The paper reports a joint in vestigation of the failure modes and levels of incandescent lamps ("light bulbs") exposed to surges occurring in low-voltage AC power systems. Tests were performed in one European laboratory and in one U.S. laboratory on typical 100 -W bulbs used in the two environments, the North American $120-\mathrm{V}$ systems, and the $230-\mathrm{V}$ European systems. Through complementary tests and high-speed video observation of the flashes, more detailed understanding of the parameters has been obtained. Having determined what it takes to fail a light bulb by a surge, this information can be used to assess the surge environment by noting that frequent bulb failures do not occur, therefore surges above the failure threshold must be infrequent.
\end{abstract}

\section{Introduction}

Some proposals for standards on equipment surge immunity or on performance of surge-protective devices are driven by the commendable quest for conservative ratings. However, when this quest produces compounded safety factors, the result might not be cost-effective. The purpose of our paper is to present information on the failure mechanisms and levels of incandescent lamps ("light bulbs" or "bulbs" for short) under surge conditions, in support of the development of realistic standards on the surge environment in low-voltage ac power systems. Since we do not hear reports of endemic failure of light bulbs beyond what can be expected from their known service life [1], we must conclude that the reality is that there is not a high rate of occurrence of line-to-neutral surges at levels in excess of the threshold voltage at which bulb failure occurs.

The concept of applying reality checks to standards on the surge environment has been presented in earlier papers [2]. [3]. producing discussions on what the mechanism of bulb failure might be and how repeatable test results might be to define a representative threshold. This interest motivated further research into the subject at a U.S. laboratory where the initial measurements were made and at an Austrian laboratory for possible replication.

Therefore, we embarked on a systematic comparison where bulb specimens and test methods would be identical in the two laboratories. The test bulbs were taken from two shared batches, a 120 -V type manufactured in Canada. and a 230-V type manufactured in Europe. Each laboratory planned to use a "Combination Wave" surge generator to apply the surges to the bulbs under similar conditions.

As it tumed out, the test equipment available in the two laboratories were not identical, so that some unavoidable differences crept into the initial plan of exact replication. However, as the tests progressed in the two laboratories. enough other significant parameters affecting the outcome were found for a given generator, so that the generator variations became less significant, and the final conclusions cover a range of parameters rather than a single threshold value. This finding does not affect the conclusion that a pragmatic range of surge levels can be identified, beyond which high bulb failure rates would become noticeable (which historically they have not been), thus providing a reality check on possible occurrence of frequent line-to-neutral surges.

\section{Preliminary tests on $\mathbf{1 2 0}-\mathrm{V}$ bulbs}

In these preliminary tests, first reported in [3] and summarized here, the test circuit used in the U.S. laboratory consisted of a Combination Wave surge generator capable of applying surges to the light bulb which was powered through the back-filter typically included in commercial surge generators. The phase angle of surge application with respect to the power frequency sine wave could be set at any value within 360 degrees. Monitoning the event was performed by a multi-channel digital oscilloscope with differential voltage probes.

Figures 1, 2, 3, and 4 present oscillograms of the voltage across an energized $120 . \mathrm{V}$ bulb and of the current flowing in the bulb. Figure 1 shows a narrow window, commensurate with the duration of the surge delivered by a $1.2 / 50-8 / 20 \mu \mathrm{s}$ surge generator. We observe the chopping of the voltage wave, typical of a gap sparkover, and the rise of the surge current after the sparkover. The scale of the current trace selected to record the surge (hundreds of amperes) does not show the normal current ( $1 \mathrm{~A})$ in the bulb. ' Observations during this test include hearing a pinging noise and seeing a bright flash of light, followed by darkness. After the test, the filament can be seen broken at one or both its points of attachment to the supporting connccting stems.

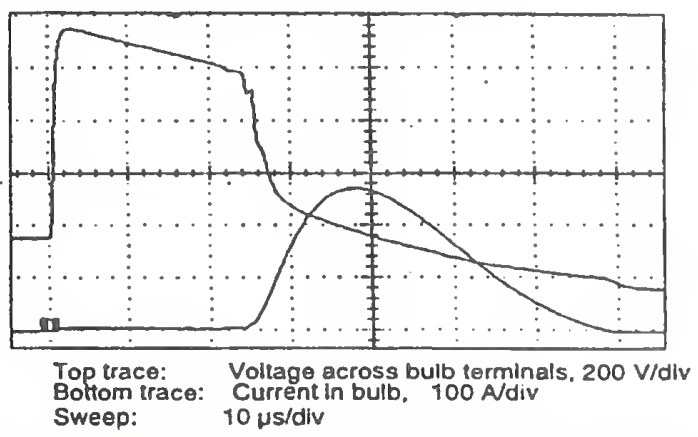

Figure 1: Voltage and current in bulb during application of a $1.2 / 50 \mu s-8 / 20 \mu s$ surge, resulting in surge sparkover

I The measurements reparted in shis paper have been made with instrumentation for which the combined uncerainty should not exceed $\pm 5 \%$ to $\pm 6 \%$. Given the process of applying the measurement results to the failure levels of light bulb.s exposed is environments with characteristic.s that are as best known within an order of magnisude. this level of uncertainty does not affect the practical conclusion.s. 


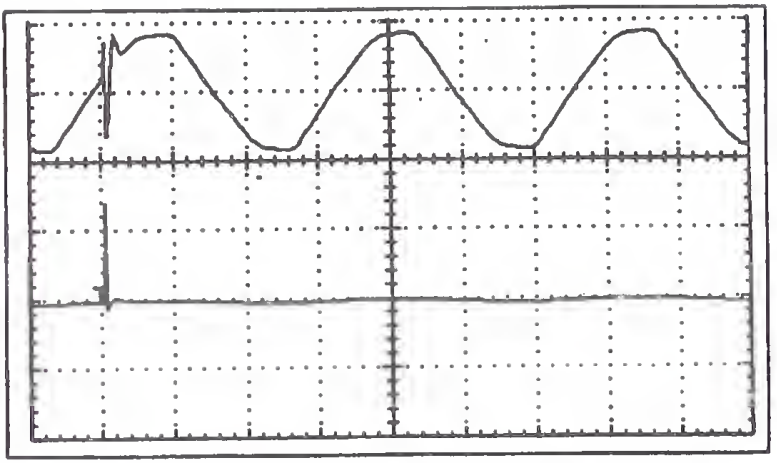

Top trace: Voltage across bulb teminals, 200 V/div Bottom trace: Current in bulb, 100 Adlv Swoep: $5 \mathrm{~ms} / \mathrm{dlv}$

Figure 2: Voltage and current in bulb during application of a $1.2 / 50$ - $8 / 20 \mu s$ surge at $30^{\circ}$, with surge sparkover but no power-frequency Ilashover

Figure 2 was reconded (with a new bulb) with a longer window than Figure 1, so as to display three full cycles of the power frequency. At that sweep rate, the surge is no longer resolved, and its apparent peak shown on the trace may be lower than the actual peak because not enough data samples are collected around the peak. However, the timing of the surge, not its amplitude is what is important in this figure. The surge event appears as a voltage spike and a current spike, followed by return to practically normal voltage and no visible large powerfrequency current.

Figure 3 shows for the same bulb as that of Figure 2 the events during a subsequent shot under the same conditions. At first, after the surge, the pattern is identical to Figure 2. Then, suddenly, a pulse of power-frequency current appears, with a large amplitude -- the source of the observed flash. We believe that it is this current that causes the bum-out of the filament not the "trigger" surge. The randomness of the process of igniting the power are is such that in the case of Figure 2, the power arc was not ignited, while in the subsequent surge application on the same bulb (Figure 3 ) and in the same conditions, the power arc was ignited, resulting in burm-out of the filament - a threshold situation.

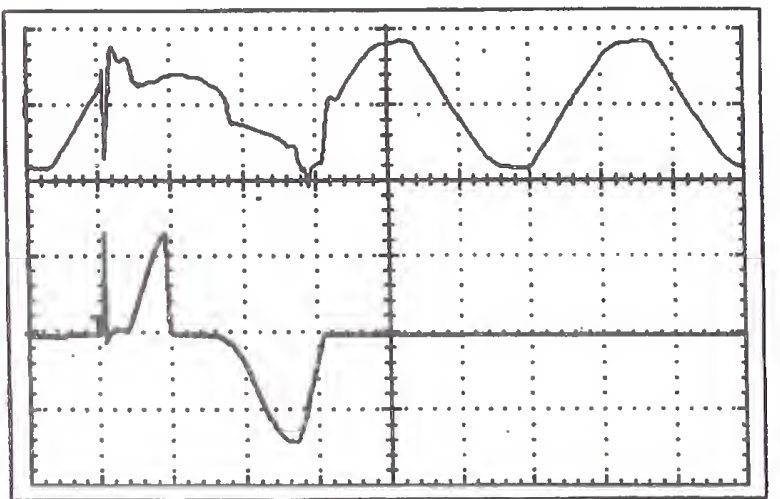

Top irace: $\quad$ Voltage across bulb teminals, $200 \mathrm{~V} / \mathrm{dl}$ Bottom trace: Current in bulb, $100 \mathrm{Ad}$ Sweep: $\quad 5 \mathrm{~ms} / \mathrm{dlv}$

Figure 3: Voltage and current in bulb during application of a 1.2/50 - 8/20 ps surge at $30^{\circ}$, resulting in surge sparkover, with delayed two-pulse power-irequency fishover

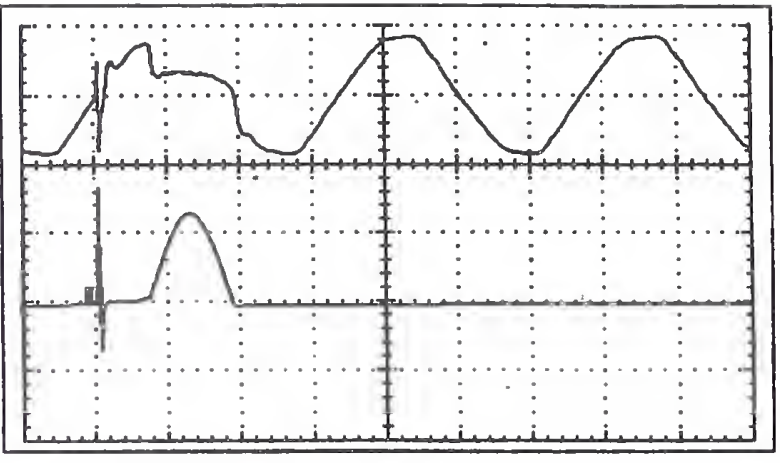

Top trace: Voltage across bulb terminals, $200 \mathrm{~V} / \mathrm{dl} / \mathrm{V}$ Bottom trace: Current in bulb, 100 Adliv Sweop: $5 \mathrm{~ms} / \mathrm{dlv}$

Figure 4: Voltage and current im bulb during application of a $1.2 / 50-8 / 20$ pus surge at $0^{\circ}$, with surge sparkover and delayed single-pulse power-frequency flashover

As further evidence, Figure 4 shows the process (in a new bulb) when the surge was applied at $0^{\circ}$, requiring more energy for ultimately igniting the power-frequency flashover. At zero degrees, there is the least power-frequency voltage to ignite a power arc. Figure 4 shows the last of a seven-shot sequence in which the first applied surge had an amplitude of $1200 \mathrm{~V}$. The applied surge was then raised in $100-\mathrm{V}$ steps to $1500 \mathrm{~V}$. still with pinging heard but no fatal power-frequency arc. To explore the hypothesis that the filament might be burned out by the surge energy, we held the surge at $1500 \mathrm{~V}$ for the next three shots. Only the last of the three triggered the fatal flashover, recorded in Figure 4. At that level of energy deposited by the surge, enough plasma was generated in the path of the surge current to eventually ignite the power-frequency arc, but for that shot it had to wait until the power-frequency voltage had reached its peak, again indicating a threshold situation.

To conclude this summary of preliminary findings, Table 1 shows the relationship between the timing of the surge with respect to the sine wave and the minimum peak amplitude of the surge sufficient to trigger ignition of the power-frequency arc. When the surge is applied at 90 degrees (the peak of the sine wave, making immediate ignition of the power arc easiest), a surge of $800 \mathrm{~V}$ is sufficient to trigger the power arc. At zero degrees, the surge must be raised to $1500 \mathrm{~V}$ to produce sufficient plasma to result in a subsequent power-frequency arc. The phenomena are of course subject to the statistical variations of sparkover.

The values shown in Table 1 are the lowest of several tests performed on a total of 20 bulbs of the same manufacturer, rated $100 \mathrm{~W}$, replicating the test at several timing angles. At and near 90 degrees, the values were identical, at and near zero degres, there was up to $200 \mathrm{~V}$ difference among tests. There is not enough space in this paper for reporting in detail our series of experiments (involving several hundred bulbs) on other manufacturers and other watt ratings. These produced similar resulits, so that our inferences are not based on just the 20 bulbs tested under the conditions of Table 1 .

Table 1: Rellationship between timing angle of the Combination Wave surge and theshold amplitude necessary to produce fatal power-frequency Inashover

\begin{tabular}{|c|c|c|c|c|c|c|c|c|}
\hline $\begin{array}{c}\text { Angle of surge } \\
\text { opplication }\end{array}$ & 0 & 15 & 30 & 45 & 90 & 135 & 150 & 165 \\
\hline $\begin{array}{c}\text { Open-circutt } \\
\text { voltage setting of } \\
\text { generator (M) }\end{array}$ & 1400 & 1100 & 800 & 800 & 800 & 800 & 850 & 1100 \\
\hline
\end{tabular}




\section{Comparative tests at two laboratories}

One of the motivations for comparing the tests at two laboratories was that preliminary data indicated some possible behavior differences between $120-\mathrm{V}$ bulbs and $230-\mathrm{V}$ bulbs, as well as some differences in the laboratory facilities and procedures. To alleviate this uncertainty, researchers on both sides of the Atlantic joined forces, hence the multinational authorship of this paper. As mentioned in the introduction, we started out with the goal of exact replication in the two laboratories: lamps from the same manufacturing batches, generators with similar characteristics, and power-frequency supplies with comparable available fault current.

However, practical limitations of available equipment and resources made that goal elusive. Instead, we then focused on identifying similarities in general behavior rather than identical numerical results. We also recognized that many independent parameters would affect the numerical results. Since our goal was to find the range of threshold values where failures begin to occur, our main concern became one of confirming the initial hypothesis that the failure was triggered by a surge and thus provide insights on the surge characteristics at the threshold of bulb failures. With that narrower goal, we made some side experiments by changing the parameters to develop a set of anecdotes, allowing us to identify the most sigmificant parameters of the surges, and thus make inferences on their (limited) occurrence in the real world, given the absence of endemic bulb failures.

\subsection{Influencing parameters}

The influencing parameters that we considered involve lamp characteristics, surge characteristics, and power-frequency supply characteristics. The list below is given as an indication of the possible complexity of a comprehensive experiment -which was not our goal -- as well as an invitation to other researchers who might be interested in lamp behavior. Clearly that level of detail is not in the scope of an EMC concern, and we will not give it much space, save for a few intriguing observations.

\section{Lamp characteristlcs}

Geometry (axial or longitudinal, straight or c-shaped filament); Base position (up, down, horizontal);

Nature of the gas fill (breakdown tendency);

Temperature gradient near the filament;

Characteristics of the fuse contained in the stem.

Surge characteristics

Waveform (peak, duration, Combination or Ring Wave);

Source impedance (ability to deposit energy in the arc);

Timing with respect to power-frequency sinewave.

Powerofrequency supply

Voltage;

Available fault current (ability to establish stable arc).

\subsection{Typical test results}

Figures 5, 6, and 7 show typical recordings obtained at the Austrian laboratory during application of a $1.2 / 50 \mu \mathrm{s}-8 / 20 \mu \mathrm{s}$ surge with a peak amplitude sufficient to produce a sparkover, either immediately or after a short delay. (In the figures, the surge peaks are not resolved at the millisecond sweep rate.)

In Figure 5, a $230-\mathrm{V}$ bulb shows the occurrence of a singlepulse of power-frequency flashover occurring immediately after the surge sparkover. Figures 6 and 7 show the occurrence of a delayed flashover with a single or double pulse, similar to the pattem for $120-\mathrm{V}$ bulbs, respectively in Figures 4 and 3 .

The peak values of the power-frequency flashover observed in the Austrian laboratory are different from those obtained in the U.S. laboratory because the available generators in the two laboratories have different effective back-filter impedances.

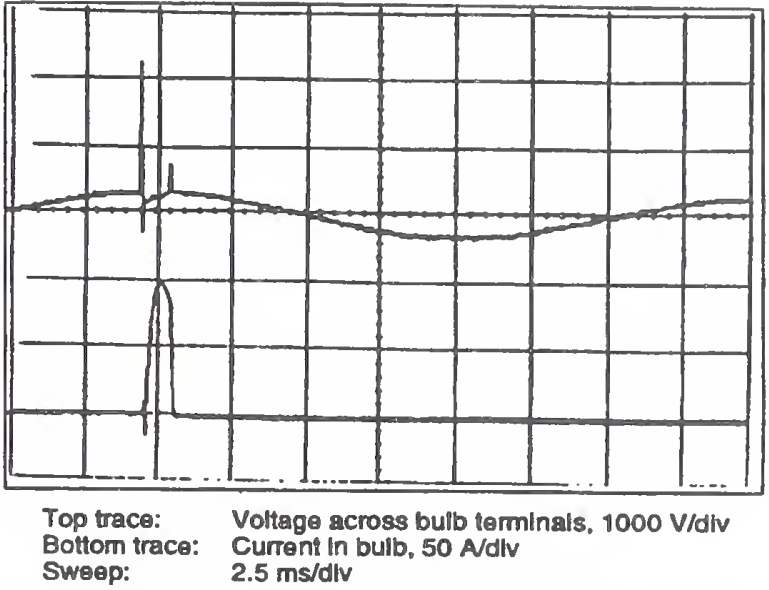

Figure 5: Voltage and current in $230-\mathrm{V}$ bulb during application of a $1.2 / 50 \mu \mathrm{s}-8 / 20 \mu$ surge at $90^{\circ}$. Surge sparkover is followed immediately by power-frequency fiashove

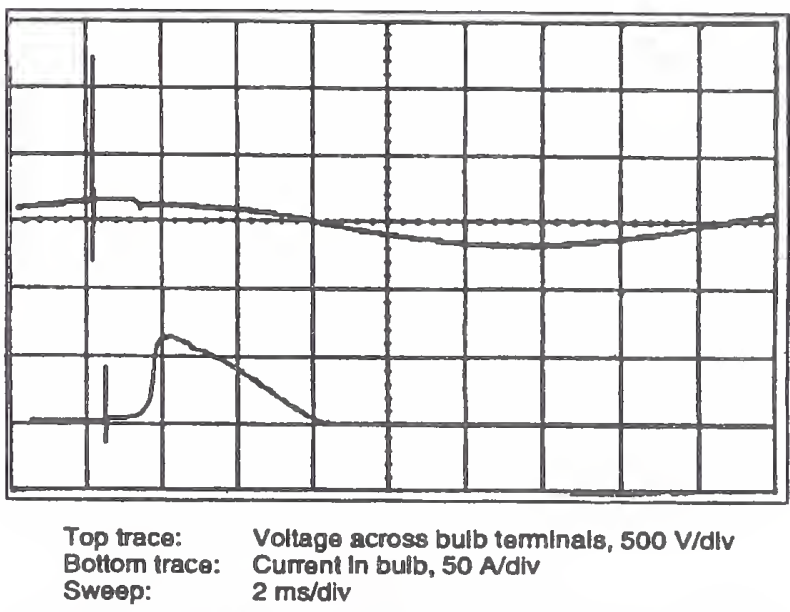

Figure 6: Voltage and current in $120-\mathrm{V}$ bulb during application of $21.2 / 50 \mu \mathrm{s}-8 / 20 \mu \mathrm{s}$ surge at $90^{\circ}$. Surge sparkover and delayed one-pulse power-frequency flashover

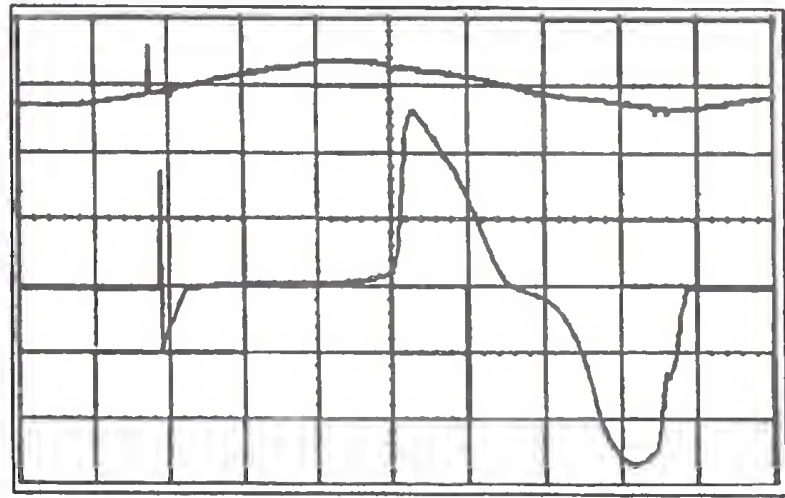

Top trace: Voltage across bulb teminals, $500 \mathrm{~V} / \mathrm{dlv}$ Bottom trace: Current In bulb, 20 Adlv Sweep: $\quad 2.5 \mathrm{~ms} / \mathrm{dll}$

Figure 7: Voltage and carrent in $120-\mathrm{V}$ bulb during application of a $1.2 / 50 \mu s-8 / 20$ us surge at $350^{\circ}$. Surge sparkover and delayed two-pulse power-frequency flashover 
Table 2 shows a summary of test results obtained in the Austrian and U.S. laboratories for $120-\mathrm{V}$ bulbs and $230-\mathrm{V}$ bulbs, under various parameters of surge application. These results show some differences in the thresholds for the tests conducted on the same type of bulbs.

Table 2 - Comparison of results from Austrian and U.S. laboratories

\begin{tabular}{|c|c|c|c|c|c|c|}
\hline & \multicolumn{3}{|c|}{ Austrian Laboratory } & \multicolumn{3}{|c|}{ U.S. Laboratory } \\
\hline $\begin{array}{l}\text { Lamp } \\
\text { Type }\end{array}$ & $\begin{array}{l}\text { Surge type } \\
\text { Source imp. }\end{array}$ & Angle & $\begin{array}{c}\text { Typlcal } \\
\text { threshold }\end{array}$ & $\begin{array}{l}\text { Surge type } \\
\text { Source imp. }\end{array}$ & Angle & $\begin{array}{c}\text { Typical } \\
\text { Ihreshold }\end{array}$ \\
\hline \multirow{2}{*}{$\begin{array}{l}120 \mathrm{~V} \\
100 \mathrm{~W}\end{array}$} & $\begin{array}{c}\text { "Combination' } \\
24 \Omega\end{array}$ & $\begin{array}{l}90 \\
30\end{array}$ & $\begin{array}{l}1100 \mathrm{~V} \\
1400 \mathrm{~V}\end{array}$ & $\begin{array}{c}\text { Combination } \\
2 \Omega\end{array}$ & $\begin{array}{l}90 \\
30 \\
\end{array}$ & $\begin{array}{r}800 \mathrm{~V} \\
1500 \mathrm{~V}\end{array}$ \\
\hline & $\begin{array}{c}\text { Aing Wave } \\
22 \Omega\end{array}$ & $\begin{array}{l}90 \\
60\end{array}$ & $\begin{array}{l}1600 \mathrm{~V} \\
2600 \mathrm{~V}\end{array}$ & $\begin{array}{c}\text { Aing Wave } \\
12 \Omega\end{array}$ & 90 & $2100 \mathrm{~V}$ \\
\hline \multirow{2}{*}{$\begin{array}{l}230 \mathrm{~V} \\
100 \mathrm{~W} \\
("=75 \mathrm{~W}) \\
("=40 \mathrm{~W})\end{array}$} & $\begin{array}{c}\text { Combination' } \\
24 \Omega\end{array}$ & $\begin{array}{l}90 \\
60\end{array}$ & $\begin{array}{l}2200 \mathrm{~V}=4 \\
2800 \mathrm{~V}\end{array}$ & $\begin{array}{c}\text { 'Combination' } \\
10 \Omega\end{array}$ & 90 & $1800 \mathrm{~V}$ \\
\hline & $\begin{array}{c}\text { Aling Wavo } \\
22 \Omega\end{array}$ & 90 & $3100 \mathrm{~V}$ & $\begin{array}{c}\text { Ring Wave } \\
30 \Omega\end{array}$ & 90 & $2200 \mathrm{~V}^{\circ}$ \\
\hline
\end{tabular}

The differences in the threshold levels observed for the two types of lamps shown in Table 2 are likely the results of many parameters, as listed in paragraph 3.1. One is probably the filament configuration. In the $120-\mathrm{V}, 100-\mathrm{W}$ bulbs, the filament is a $22 \mathrm{~mm}$ long straight section strung between the two stems, with a single support at mid-span which does not affect the straight line aspect. This configuration offers the easiest path for a sparkover to occur. In the $230-\mathrm{V}, 100-\mathrm{W}$ bulbs, the $25 \mathrm{~mm}$ long filament has a shallow c-shape obtained by two intermediate supports that deflect the filament from a straight line between the two stems. This configuration creates a slightly longer path than that of the $120-\mathrm{V}$ bulbs. In a few anecdotal tests on a $120-\mathrm{V} 40$-W bulb which has a $40 \mathrm{~mm}$ long horseshoe shape, we found that sparkover occurs along the filament or straight from stem to stem, typically about $4000 \mathrm{~V}$.

Another possible reason for the higher threshold voltages found in the Austrian laboratory using its "Combination Wave" generator might be that its source impedance is $24 \Omega$, compared to the Combination Wave generator used in the U.S. laboratory, with its conventional $2 \Omega$ source impedance. The difference will be in the surge current following sparkover, creating less plasma in the case of the Austrian laboratory, and therefore requiring a higher surge voltage to ignite the flashover. Nevertheless, oscillograms show similar patterns.

\section{High-speed video observations}

On the basis of the oscillograms, the most likely mechanism which we could propose was that a sparkover occurs when a surge of sufficient voltage amplitude is applied, producing an ionized path which enables the much lower power-frequency voltage to initiate an arc. In turn, this arc would produce enough heat at its point of attachment to cause local melting of the filament. During discussions with colleagues, other possible mechanisms were mentioned, such as a local melting of the filament caused by the surge current alone, mechanical shock on the hot filament, and the possibility that the reignitions of the power-frequency arc, such as that of Figure 2 and 7 might be associated with a broken filament that would oscillate and sweep by the stem close enough for a reignition.

In an attempt to settie this uncertainty, we obtained a highspeed video system consisting of two image converters, a digital acquisition memory, display monitor, and video recorder. The image converters had a capability of 1000 full frames per second, with the possibility of multiple scans of a limited field during the $1 \mathrm{~ms}$ basic full-frame scan time.
Figure 8 shows the arrangement of the two converters, with the left converter $(\mathrm{L})$ controlled to perform four scans limited to the filament area, and the right $(\mathbb{R})$ converter controlled to perform a full-frame view of the filament and fuse contained in the base stem of the bulb. The recording systern was triggered by a signal from the surge generator, providing the beginning of the reconding a few milliseconds before the surge, and lasting about $100 \mathrm{~ms}$ after the surge.

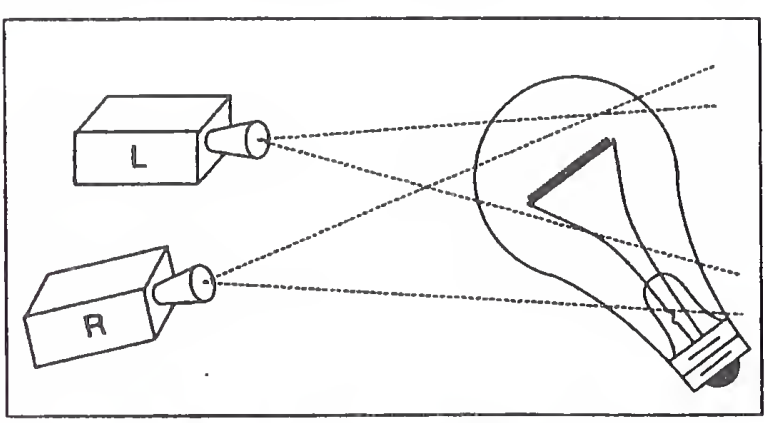

Figure 8: Arrangement of image converters to scan sparkover and flashover limited to the filament $(L)$ and a full frame $(\boldsymbol{R})$ including the base where the fuse is located

With this arrangement, recordings such as those shown in Figure 9 and Figure 10 were obtained. As an example of many oscilloscope recordings, Figure 9 shows the electrical record of the failure of a $230-\mathrm{V}, 100$-W bulb triggered by a $100 \mathrm{kHz}$ Ring Wave applied 60 electrical degrees after the zero crossing. At time $\mathrm{Tl}$, sparkover of the filament occurs, accompanied in this case by immediate flashover of the power frequency arc, which rises to a first peak at T2, about $2.3 \mathrm{~ms}$ after its beginning. At that time, the cumrent is throttled while the voltage increases sharply, indicating operation of the fuse. The fuse does not force a current zero at cime $T 3$, but allows a second peak of current at time T4, before decaying to a natural current zero at time TS.

This type of oscilloscope recording was the only one that was available until the video system was obtained. From such oscillograms we could only draw speculative inferences on the mechanism and behaviour, hence the motivation to enhance our tests by video recording. Figure 9 shows the voltage across the lamp terminals (top trace) and the current through the lamp (bottom trace). With the sweep set to cover 2 cycles of the power frequency, neither the surge voltage nor the surge current are resolved in this oscillogram. In this test series performed after the preliminary series, a separate oscilloscope with faster sweep was used to record the surge voltage and the surge current, as was done in the case of Figure 1. To conserve space, these surge recordings are not shown here, but the peak values of the resulting sparkover voltages recorded by the second oscilloscope are listed in Table 2 in the column "Typical threshold".

We now will examine in Figure 10, opposite page, four frames of video recording corresponding to the electrical record of Figure 9. The left half of the screen shows four scans from converter $\mathrm{L}$ of Figure 8 , proceeding from top to bottom and each scanned in $250 \mu \mathrm{s}$. The right side of the screen shows the full frame, scanned over a period of $1 \mathrm{~ms}$. The timing of the frame is shown in the lower right corner of the picture, such as " $\mathrm{ET}+0000000010$ " which indicates the $1 \mathrm{~ms}$ window during which the surge was initiated. Other descriptive data in the margins are not sigmificant to our story. Figure 10 shows the four frames respectively in the sequence from top to bottom for 0-1 ms; 1-2 ms; 2-3 ms; anid 4-5 ms. 


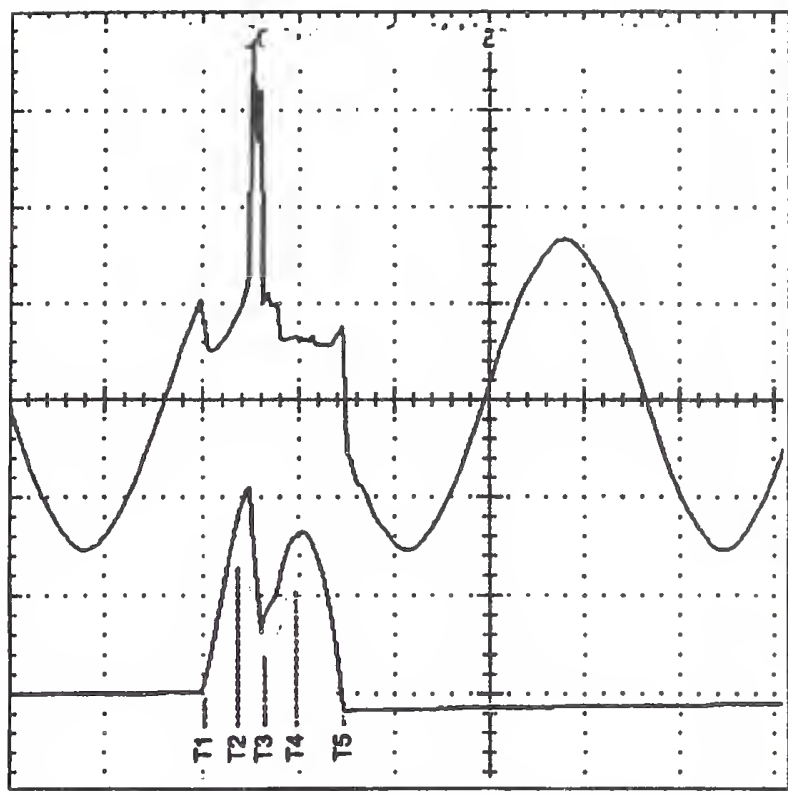

Top trace: Vollage across bulb teminal, $200 \mathrm{~V} / \mathrm{dlv}$ Bottom trace: Current in bulb, 20 Avdly

Swoep: $\quad 5 \mathrm{~ms} / \mathrm{dlv}$

Figure 9: Failure of a 230-V, 100-W bulb triggered by a $100 \mathrm{kHz} z \mathrm{Ring}$ Wave applied at $30^{\circ}$, showing fuse operation

In the first frame, 0-1 ms, the Ring Wave sparkover is not visible because of its relatively low intensity/duration. The first $250-\mu$ s scan (top) of the left side shows only the filament glow. Starting with the second scan, the beginning of the flashover (time T1 in Figure 9) is visible, while the right side scan, adjusted for less sensitivity, only shows the filament glow without the flashover beginning.

In the second frame, the flashover growth is visible on the four left scans (T1-T2 in Figure 9), while the right scan now has enough light integrated over the full $1 \mathrm{~ms}$ time to show the flashover.

In the third frame, the first two (top) left scans still show the flashover around the filament, but the last two (bottom) scans show the flashover current being starved as the fuse in the lamp base begins to operate and transfers the current to the space around the fuse. This corresponds to the time T2-T3 in Figure 9. The right side scan shows the beginning of the glow in the base of the lamp as the current around the fuse grows.

In the fourth frame, the four left scans show the fillament still glowing, but unchanged (not yet broken), while the right scan shows the integrated glow of the fuse operation, corresponding to the time interval T4-T5 of Figure 9.

These four frames, typical of many others recorded during our experiments, clearly show the mechanism of a flashover at the power-frequency current, and in this particular test sequence, the operation of the fuse in the base of the bulb. Other records taken with different light sensitivity show an intense glow near the connection of the filament, where the arc is concentrated at its point of attachment (the cathode hot spot) while the path around the filament is more diffuse. The concentrated heat near the point of attachment eventually causes a local melting of the filament. In other records, the filament is then seen separating from the stem and slowly falling in the time frame of about 20-50 ms after the flashover.
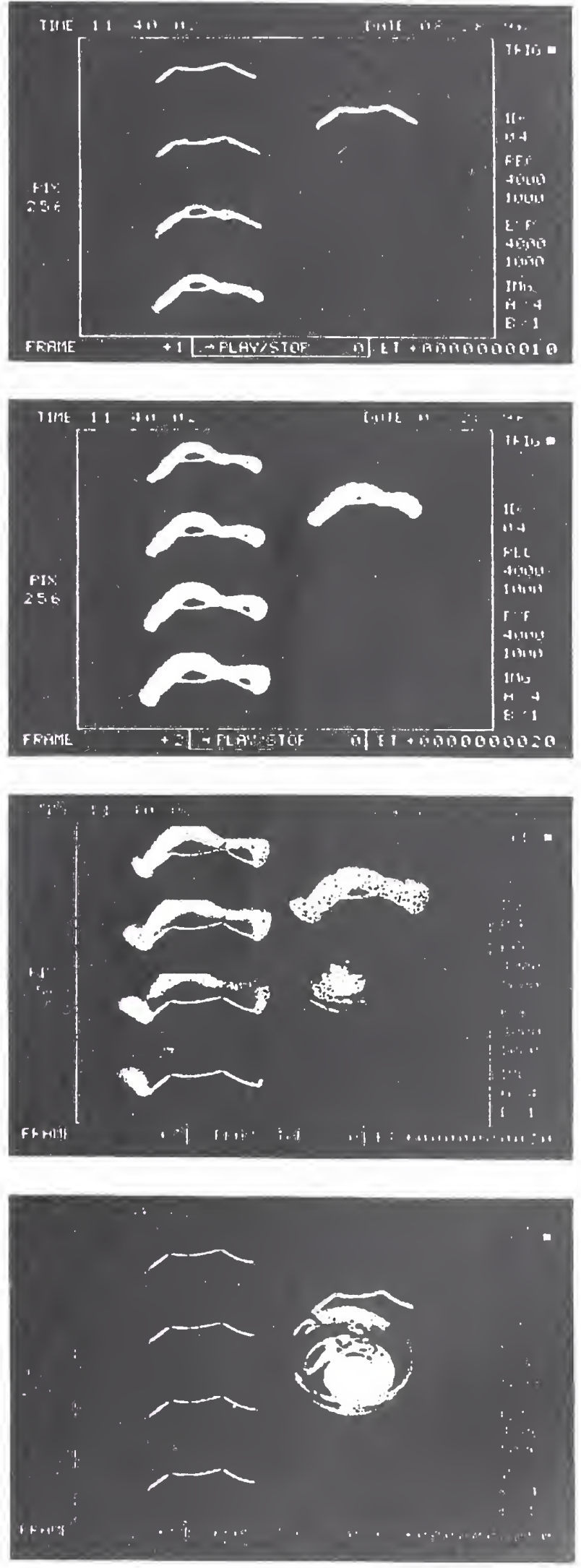

Figure 10: Sequence of nashover and fuse operation corresponding to the oscillogram of Figure 9 


\section{Discussion}

Observation of the failure mechanisms and the levels of surges necessary to trigger the fatal power-frequency flashover as recorded in the two laboratories are consistent with each other and point out that a two-stage process is involved at lower amplitudes of the impinging surge, as shown by the video recordings and inspection of the oscillograms.

When the surge current ceases, and after some variable delay influenced by the instantaneous voltage of the power system voltage at that time, a flashover fed from the power-frequency source occurs slong the path pre-ionized by the surge plasma.

It is noteworthy that the path along the filament is longer than the clearance between the two stems as they emerge from the glass envelope at the base of the bulb and yet the sparkover and the flashover occur at the longer (but hotter) clearance along the filament. By comparison, we found that a surge sparkover in a cold bulb which is not energized occurs for a much higher surge level, typically in the order of $5 \mathrm{kV}$ to $6 \mathrm{kV}$, and that sparkover in that case does not occur near the filament but at the point where the metal stems emerge from the glass base, the shortest clearance.

According to this understanding of the mechanism, we can expect that a surge with a different waveform, the $100-\mathrm{kHz}$ Ring Wave for instance, would require a different level to produce a sufficient amount of plasma necessary for ignition of the power-frequency arc. This is indeed the case as seen in Table 2. Applying the $100-\mathrm{kHz}$ Ring Wave, sparkover can occur for open-circuit levels as high as $3 \mathrm{kV}$ (pinging is heard) but without the following power-frequency flashover. Thus, the assessment of the surge environment severity given by the thresholds of bulb failure not only tracks the amplitude of the surge but also its waveform. There is a blessing as well as a curse in this situation: the assessment we can obtain reflects the energy-delivery capability of the surge as well as the peak voltage level of the surge. The two are not separable and thus the information remains imprecise, but still valuable as giving an indication of the severity of the surge environment.

This application of bulb failure levels to assess the surge environment must be made with the understanding that it rests on observations of in-use failure rates, a common experience to millions of users, noted before the proliferation of surgeprotective devices (SPDs). Nowadays, the observed surges in low-voltage power systems are much lower than the threshold levels identified in this paper for bulb failures because of this proliferation of SPDs [4], [5].

It should also be noted that this assessment is limited to the surges occurring in the line-to-neutral mode at the location of the bulb. Depending upon the neutral grounding practices of the installation, surges impinging at the service entrance will propagate toward the victim light bulb in different manners. In the U.S. practice, where the neutral and earth conductors are bonded at the service entrance, a surge impinging from the power system in the common mode is converted into a differential mode, that is, a line-to-neutral surge is always applied to the bulb. In some countries where the service entrance bond is not present, an impinging surge in the common mode remains as such as it propagates within the house wiring, and thus the stress applied to the bulb from an extermal surge, such as a lightning-induced surge, may have different consequences for the light bulb. This point is important and should serve as a reminder of the significant differences in the effectiveness of surge-protection schemes according to the grounding practices in use among different countries.

\section{Conclusions}

\section{Light bulbs foulleres levels and mechanism}

1. The principal failure mode of light bulbs involves a powerfrequency flashover triggered by the surge which produces a sparkover and sufficient plasma around its path to ignite an arc fed by the power-frequency source. This arc then melts the filament at its point of attachment. High-speed video recordings confirm tentative conclusions derived from observation of the current and voltage oscillograms.

3. The surge level necessary to trigger the power-frequency flashover depends on the phase angle of the surge with respect to the power-frequency sine wave. When applied near the peak voltage, the necessary voltage may be less than $1000 \mathrm{~V}$ peak for an $8 / 20$ surge. When applied near zero crossing, the necessary voltage may be twice that sufficient near the peak.

4. Tests performed at two different laboratories show good agreement on the mechanism, with some differences attributable to some differences in the surge generators which could not be matched exactly. Such a difference serves to show that the phenomenon covers a range of thresholds, not a single sharp value.

5. For surges with high energy delivery capability, such as the $1.2 / 50-8 / 20 \mu$ s Combination Wave, typical $120-\mathrm{V}$ bulbs experience failures with surges as low as $800 \mathrm{~V}$ under the most sensitive phase angle of timing. For typical 230-V bulbs, the corresponding level is as low as $1800 \mathrm{~V}$.

6. For surges with low energy delivery capability, such as the $100 \mathrm{kHz}$ Ring Wave, typical $120 \mathrm{~V}$ bulbs experience failures with surges as low as $2100 \mathrm{~V}$ under the most sensitive phase angle of timing. For typical 230-V bulbs, the level at the most sensitive time is as low as $2200 \mathrm{~V}$.

\section{Application to standards on the surge envinomment}

Knowledge of failure mechanisms of light bulbs and the levels at which failure occurs in a surge environment brings a sense of perspective and helps developing realistic assessment of the surge environment because surge-induced failures are rare. From this assessment, proposed standands for performance and application of surge-protective devices can be reconciled with reality and avoid under- or over-specification of the devices.

\section{Acknowledgments}

Support and encouragement for this work was provided by the parent organization of each author. Additional support was received from Delmarva Power Company, and from Pacific Gas \& Electric Company. Tom Conrad, Gerald FitzPatrick, and Don Worden contributed comments on the draft.

\section{References}

[1] Horacsek, K. "Properties and Pailure Modes of Incandescent Tungsten Filaments," IEE Proceedings, Vol 127-A No.3. April 1980 (58 references).

[2] Martzloff, F.D., "Keeping up with the Reality of Today's Surge Environment," Conference Proceedings, Power Quality Solutions, Intertech Pub., Ventura CA, USA, September 1995 (15 references).

[3] Mansoor, A., Martzloff, F.D., and Nastasi, D, "Applying Reality Checks to Standards on the Surge Environment," Proceedings. 23rd Intemational Conference on Lightning Protection (ICLP), Florence, September 1996 (19 references).

[4] Dorr, D. "Point of Utilization Power Quality Results," IEEE Transactions LA-31, No.4, July/August 1995 (15 references).

[5] Martzloff, F.D." "Surge Recordings that Make Sense: Shifting focus from voltage to current measurements," Proceedings. EMC'96 ROMA Symposium, Rome, September 1996 (18 references). 


\section{Developing a Consumer-Oriented Guide on Surge Protection}

Thomas Key, EPRI-PEAC, 942 Corridor Park Blvd, Knoxville TN 37932 TKey@epri-peac.com

François Martzloff, National Institute of Standards and Technology, Gaithersburg MD 20899 f.martzloff@ieee.org Roger Witt, State Farm Insurance Co., 1 State Farm Plaza, Bloomington IL 61710

Jim May and Stacey Black, Illinois Power Company, 500 South $27^{\text {th }}$ Street, Decatur IL 62525

Reprinted from Proceedings, PQA'97 Conference, 1997

\section{Significance:}

Part 2 Development of Standards - Reality checks

Caught among contradictory stories on the need for surge protection as well as unsupported anecdotes of surgerelated failures, the typical consumer is in a quandary on how to best allocate personal resources to protect the expensive electronic equipment found in a modem household.

To help provide some answers to this quandary, a team of experts developed and engineering guide on the basics of surge protection. One of the recommendations addresses the issue of ineffective configuration of utility connections that are responsible for surge-induced failures. This paper served as a progress report, documenting the status of the project at the end of 1996. An update on this project was reported under Key et al. 1999, which is included in Part 6 of this Anthology 



\title{
Developing a Consumer-Oriented Guide on Surge Protection
}

\author{
Thomas Key \\ EPRI-PEAC \\ 10521 Research Dr. \\ Knoxville, TN 37932
}

\author{
François Martzloff \\ National Institute of \\ Standards and Technology* \\ Gaithersburg MD 20899
}

\author{
Roger Witt \\ State Farm Insurance Co. \\ 1 State Farm Plaza \\ Bloomington, IL 61710
}

\author{
Jim May and Stacey Black \\ Illinois Power Company \\ 500 South $27^{\text {th }}$ Street \\ Decatur, IL 62525
}

\begin{abstract}
Caught among contradictory stories on the need for surge protection as well as unsupported anecdotes of surgerelated failures, the typical consumer is in a quandary on how to best allocate personal resources to protect the expensive electronic equipment found his in a modern household. To help provide some answers to this quandary, a team of experts is currently developing a practical application guide on the basics of surge protection, providing a tutorial suitable for the "average consumer." This paper shows how the guide intends to take the reader through the thicket of surge protective devices and applications.

The guide covers a range of application issues from basic information on the occurrence of lightning and switching surges to the selection of cost-effective and technically sound mitigation methods. It explains how protection applications must be suitable for the geographic area (lightning flash density), power distribution type (urban or suburban), and grounding practices (recent NEC or grandfather). The ultimate goal is that the guide will become the basis for better mitigation practices, will decrease losses and the number of loss claims, and will reduce the fear and frustration levels among end-users relative to surge-related upset or damage to their appliances and electronics.
\end{abstract}

\section{INTRODUCTION}

Each year lightning is estimated to be responsible for 250 to 500 million dollars in property damage in the United States. This estimate is based on an analysis of insurance claims compared to cloudto-ground lightning flash data by operators of the National Lightning Detection Network, described by Byerley et al [1]. Since about 1989 this system has provided a very accurate count and location of lightning flashes to ground and of the resultant ground flash density in the United States. For some insurance companies the data have been used to confirm or deny lightning damage claims.

An analysis of 5500 detailed claims found more than half of the loss was related to telephone and electronic appliances. Considering that many of these losses are preventable, the insurance companies that pay millions of dollars per year replacing lightning- or other surge-damaged appliances are highly motivated to help prevent such damage. As a first step toward minimizing surge damage, State Farm Insurance Companies, Illinois Power, and EPRI have joined forces to devise a recommended practice for residential surge protection, wiring, and grounding. To achieve

"Electricity Division, Electronics and Electrical Enginecring Laboratory, Technology Administration, U.S. Department of Commerce. Contributions from the National Institute of Standards and Technology are not subject to United States copyright. 


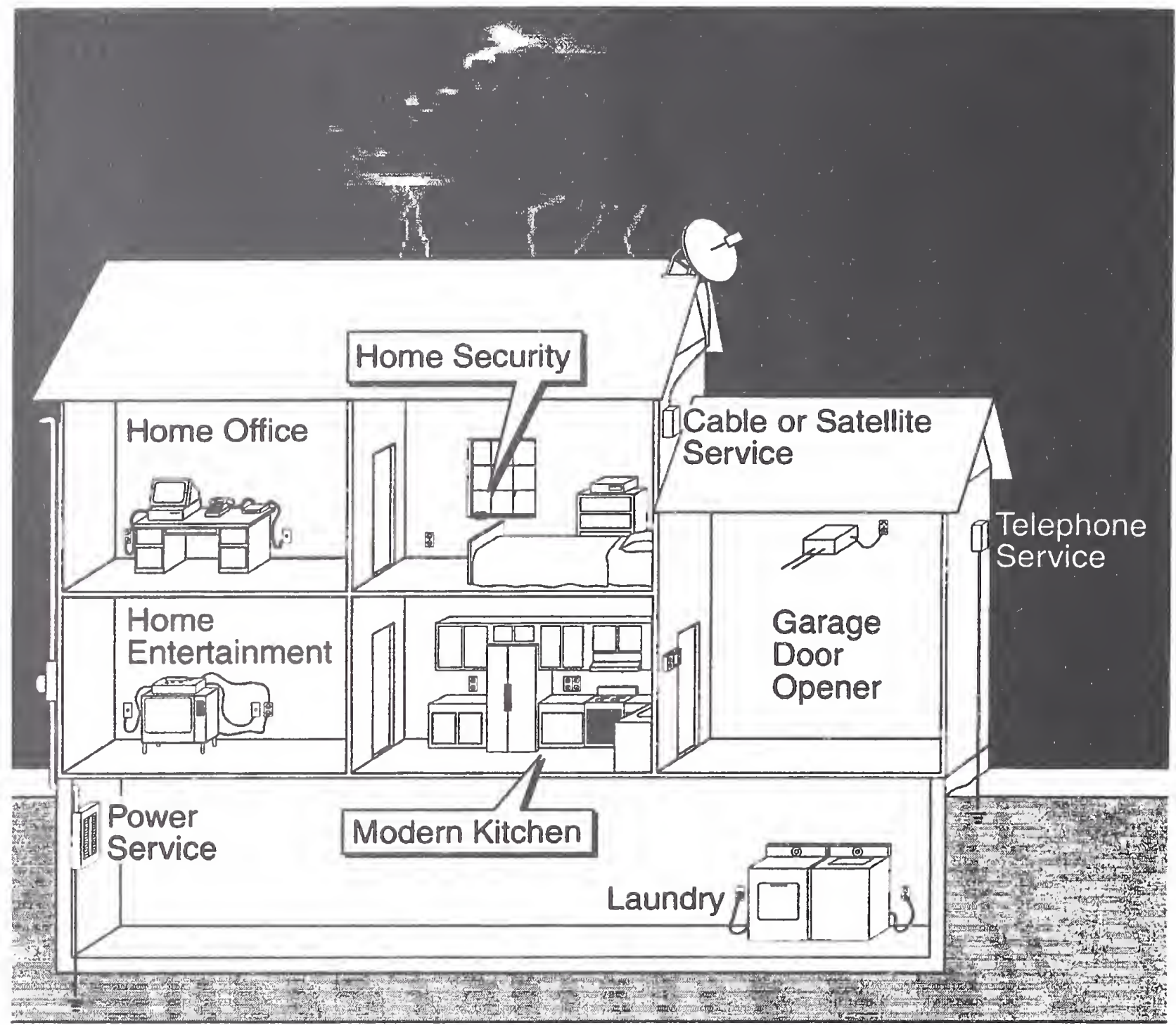

Figure 1. Typical candidate appliances and systems for surge protection in a residence

this goal, the project team is completing three specific tasks: 1) initial fact-gathering, 2) a workshop to discuss surge protection issues, and 3) completion of the manual of recommended practice.

A typical modem residence contains many electronic and multi port appliances. In order to identify specific protection practices, a typical residence was defined with electronic appliances and systems illustrated in various rooms as shown in figure 1. The main systems are home entertainment including cable TV, home office including telephone, and electronic kitchen appliances. Other common vulnerable systems are home security, intercom, satellite receiver, garage door opener, and laundry equipment. Generally, any system with micro-electronics plus exposure due to power and signal wiring can be found in lightning damage claim reports.

Technical inputs were gathered on the expected surge threat and the key elements of protection. 
These including lightning, surge propagation, grounding, surge protection practice, and built-in appliance immunity. The workshop was successful in building consensus despite the fact that different experts had different backgrounds and experiences. At the end all agreed on essential principles of how to protect sensitive equipment. However, specific devices and procedures that could be applied case by case were more difficult to obtain. Also, there is currently no information about compatibility levels and points of vulnerability for many modern residential electronic appliances and systems. Consequently, specific installation methods and precise recommendations on how to protect these electronic systems from surge threats are not yet fully developed.

A few appliances seem to have varying susceptibility to surges. The most notable losses, according to insurance claim records, are telephones and modems, computerized equipment, TV, VCR and satellite receiver systems. These are generally multi-port appliances—that is, appliances connected to several different systems, such as an entertainment center connected to power, cable, and telephone or a security system connected to power, sensor, and control. These multiple connections, and the likelihood of potential differences between them, are believed to be major factors in surge damage susceptibility of many residential appliances and systems.

\section{Essentials of SuRge Protection}

Lightning is not the only threat, but remains a dominant one.. Most of the Continental United States experience at least two cloud-to-ground (C-G) flashes per square kilometer per year. About one half of the area will see three C-G flashes per $\mathrm{km}^{2}$, which is equivalent to about 10 discharges per square mile per year. The maximum flash densities are found along the southeastern Gulf Coast and the Florida peninsula, where the values approach $20 / \mathrm{km}^{2}$ or $50 / \mathrm{mi}^{2}$. Overall about 30 million C-G flashes strike the United States each year, and lightning is clearly among the nation's most severe weather hazards.

In high lightning areas, perhaps a threshold of three C-G flashes per square km per year, some degree of structural lightning protection is recommended. This threshold may be economically justified by the growing value, and vulnerability, of residential electronic systems. There is good information available on how to accomplish this protection. Basic lightning protection practices are well defined in the Lightning Protection Code, NFPA 780. An illustration of the basic elements of this protection is provided in figure 2. These protection techniques will not eliminate surges that enter the residence either via different wiring systems - including the grounding electrode system-or coupled into wiring from nearby flashes. In addition to the lightning threat, some basic household appliances can act as surge generators, for example a light switch or a furnace igniter.

Protection against these surges can take several forms. The possibilities are: preventing the surge at its origin (impossible for lightning and difficult for surges associated with normal operation of the power system), diverting the surge to ground as it impinges on the building, before it enters the building (the most effective approach), and finally, clamping by a surge protective device (SPD) at the equipment (either by an add-on, plug-in, or built in SPD). Of these three approaches, only the service entrance and add-on SPDs are options available to the end-user. Service entrance protection may be offered by the local utility. If not, a licensed electrical contractor may offer installation service. In either case installation of service entrance protection must be done by a professional. Various locations for power line or transient-voltage surge suppressors (TVSS) are shown in figure 3. 


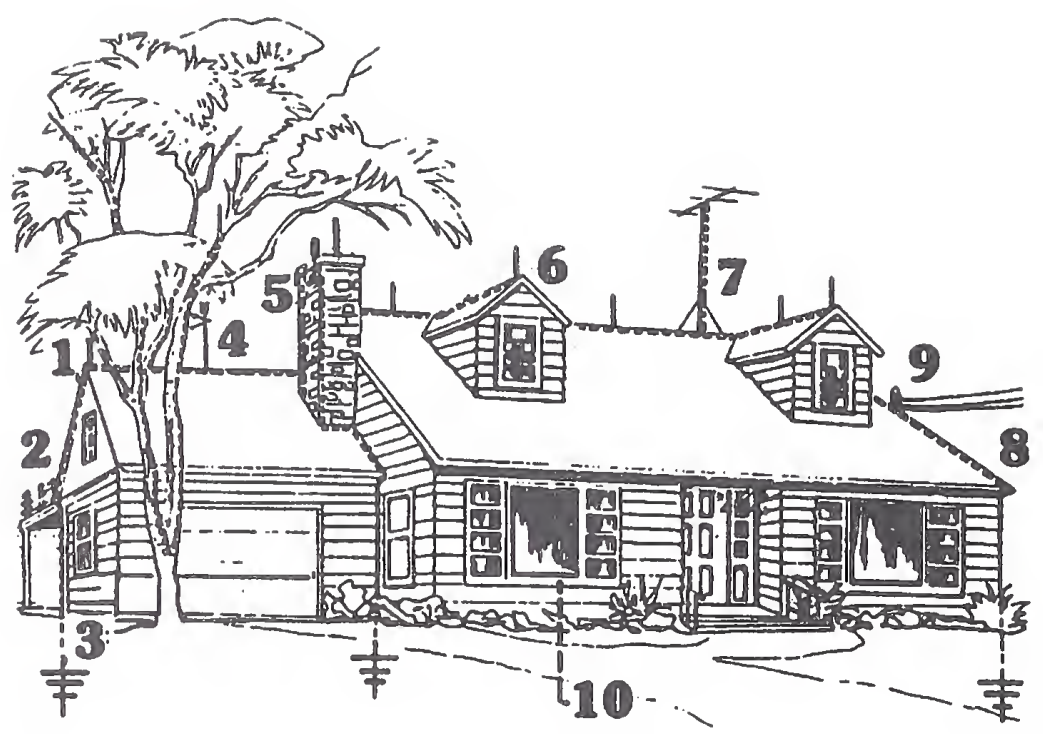

Legend

1. Air terminal spaced 6 meters ( 20 feet) apart along ridges and within 0.6 meter ( 2 feet) of ridge ends

2. Down conductors (minimum of two)

3. Grounding rods; minimum of two, at least 3 meters (10 feet) deep

4. Roof projections such as weather vanes connected to grounding system

5. Air terminals located within 0.6 meter ( 2 feet) of outside corners of chimney

6. Dormers protected with air terminals

7. Antenna mast bonded to roof ground conductor

8. Gutters and other metal objects bonded to grounding system

9. Surge arrester installed at service panel to protect appliances

10. Transient voltage surge suppressors installed at receptacles powering sensitive electronics

Figure 2. Typical comprehensive lightning protection of a residence (reprinted with permission from Underwriters Laboratory Inc.)

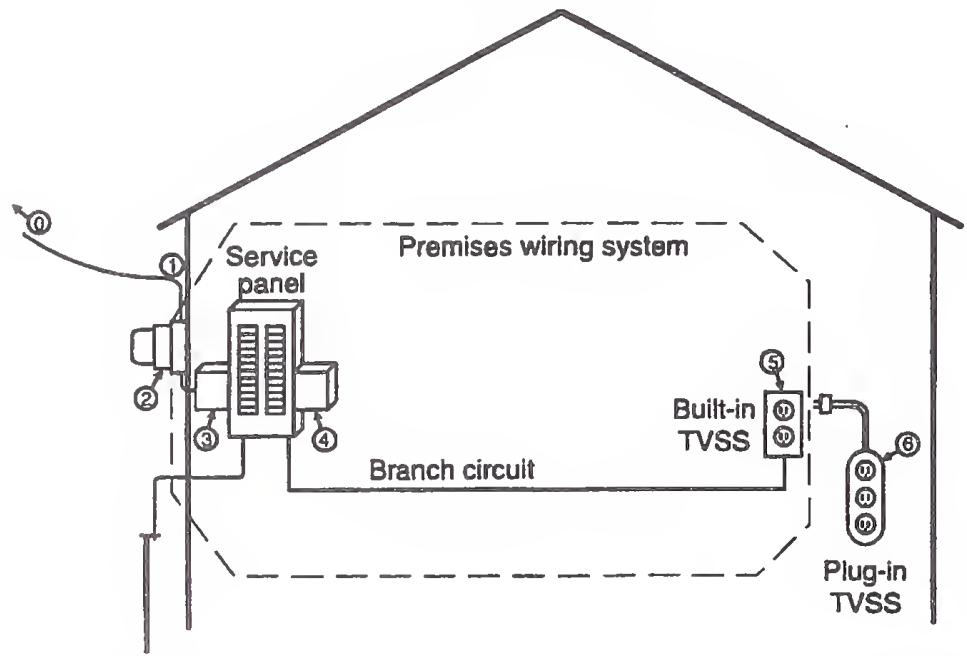

\section{Power Line Surge Protectors}

Service Entrance Arresters (0,(1),(2),(3)

Branch Circuit Suppressor (4)

Receptacle Plug-in Suppressor (5)

Plug Strip with Suppressor (6)

Figure 3. Options for power-line surge protection in a residence 


\section{BASICS OF APPLICATION}

A fundamental application issue in surge protection is grounding. Proper grounding is critical for the case of ground-seeking surges such as lightning currents. However, even more critical for multiport appliances or systems is the difference in ground reference between port connections. This vulnerability issue is addressed in the National Electric Code (NFPA 70), which requires that the grounding conductors of all systems entering a facility be bonded together. As shown in figure 4 (left), a split bolt is used to bond different system grounding conductors to the power system grounding electrodes. Unfortunately this bonding is not always done and a common, but incorrect and dangerous to personnel and equipment, scenario is shown in figure 4 (right).
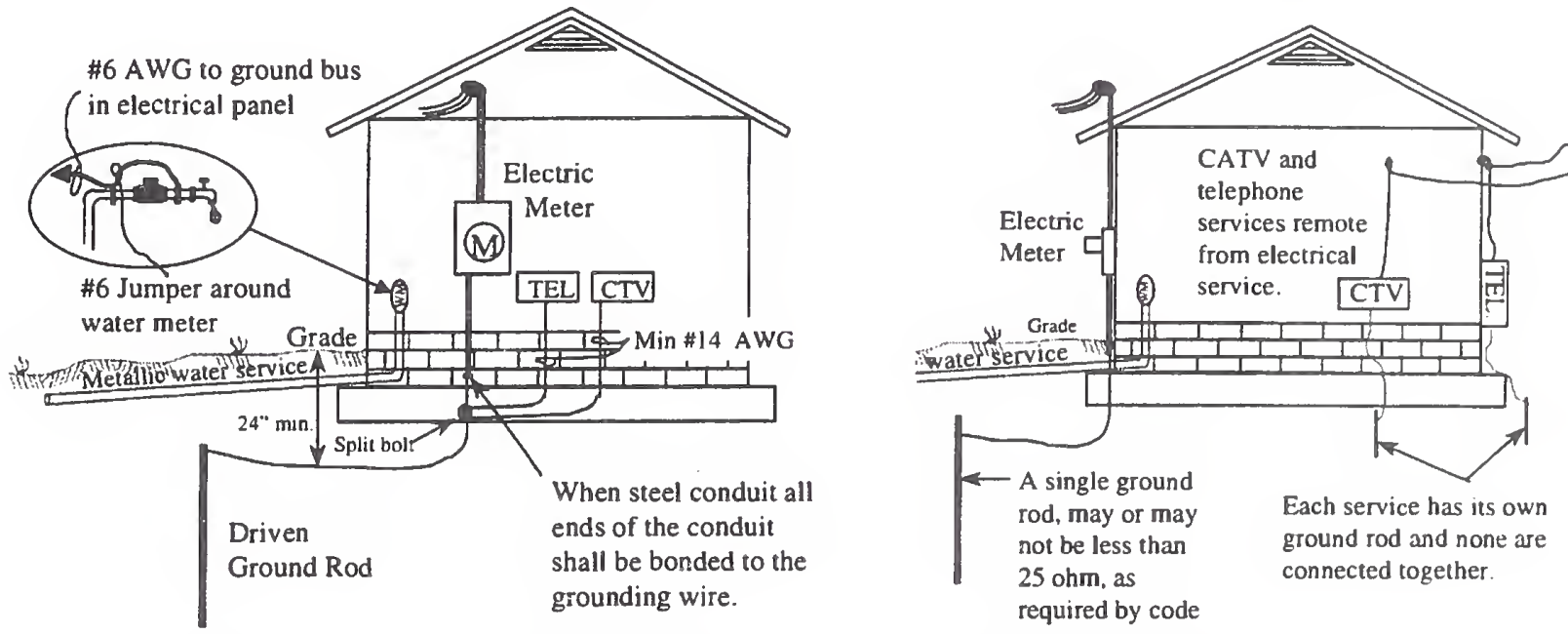

Figure 4 - Minimum code-required service grounding (left) and commonly found, but incorrect grounding of existing house (right)

The incorrect grounding of the house, figure 4 right side, was identified by the study group as the primary problem in residential system surge protection. Even with independent surge protection of the power and communications ports, smart electronic appliances are left vulnerable to surges. During a surge, an elevation of only one of the port reference potentials relative to the other(s) can upset or damage appliances. The problem is depicted in figure 5 , which shows the connection of a facsimile machine (FAX), to both the power system and communication system. The SPD (also called TVSS in the industry jargon) on the power port of the FAX can be built-in or installed externally by the end user. The arrester at the service entrance, shown in dotted lines, may or may not be present. According to standard practice, the telephone company has installed a network interface device (NID) at the point of entry. The NID is installed primarily to protect the telephone system and human users from hazards of faults and surges that travel from the premises toward the telephone system, rather than to protect from surges impinging from the telephone system into the premises. Nevertheless, should a surge impinge on the telephone system, the NID will divert it to ground, in this case the nearest cold water pipe.

Consider the case of a surge impinging on the entrance of the telephone system. The surge current shown as "Surge i" in figure 5 flows in the long path from the entrance of the telephone system to the grounding point in common with the power system entrance. The inductance of this path is typically tens of micro-henries, and the surge current can rise to several hundred amperes in one microsecond. The resulting voltage drop along the current path from the telephone port to ground 
is $L x$ di/dt (voltage elevation at the FAX communications port). In contrast, the FAX power port is not affected by the surge because none of the power port conductors carry any surge current. Assuming $10 \mu \mathrm{H}$ for $\mathrm{L}$ and $500 \mathrm{~A} / \mu$ s for di/dt, the voltage drop that appears between the power port and telephone port of the FAX is Vdifference $=10 \mu \mathrm{H} \times 500 \mathrm{~A} / 1 \mu \mathrm{s}=5000 \mathrm{~V}$. This voltage is likely sufficient to cause a flashover on the printed circuit boards, or a semiconductor failure in the FAX. Most FAX failures can be readily explained by the elevated reference potential associated with independent surge protection of the two ports.

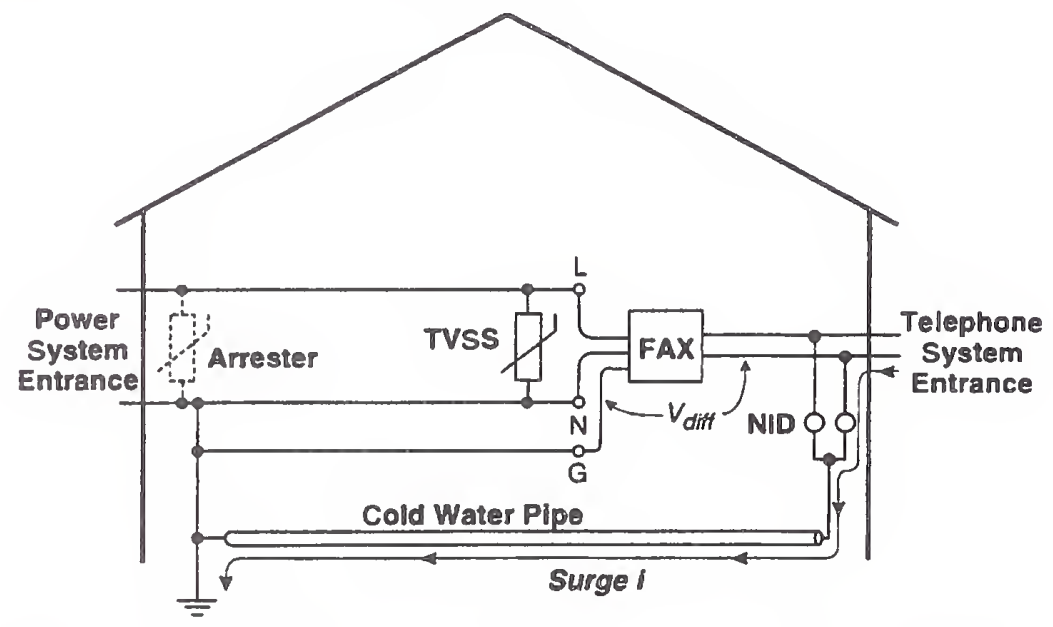

Figure 5. Surge voltage potential difference develops between two protected ports of appliance

The INTERSYSTEM BONDING POINT for connection of telephone, television, and radio antenna grounding wires.

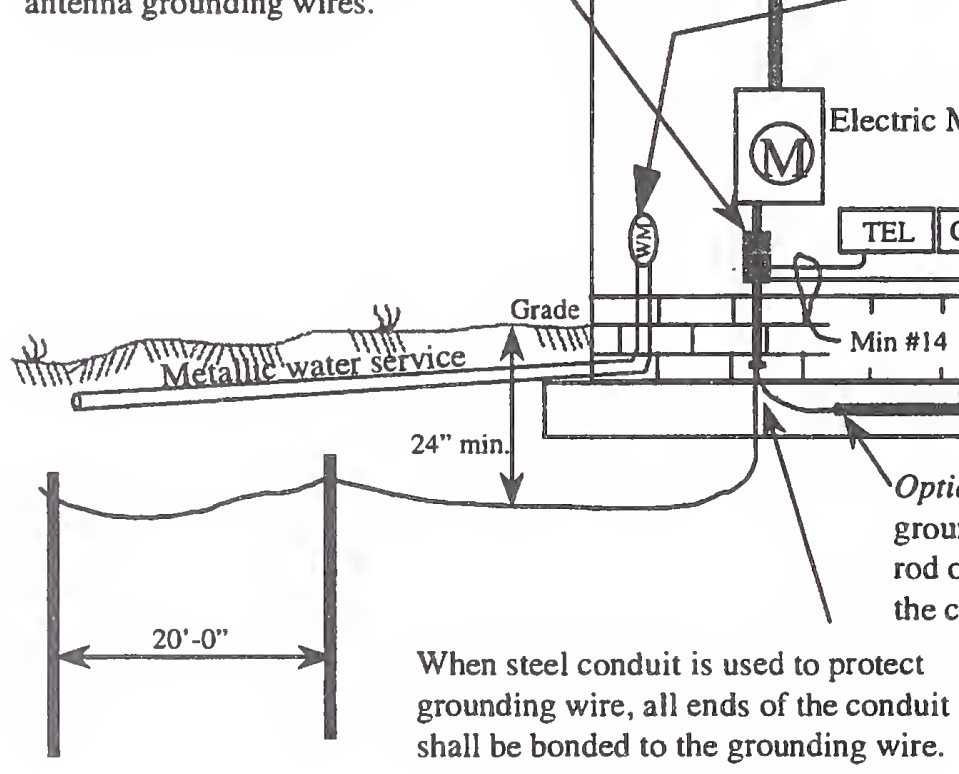

Figure 6. Recommended service grounding for enhanced surge immunity 
The recommended practice to avoid the problem discussed above is an "intersystem bonding point," as shown in figures 6 and 7. This approach addresses the issue on a facility basis. The two services, power and telephone, must enter at the same point and must be bonded together at that point. The NEC requires bonding together the two service grounds, but does not require entry at the same point. As shown in figure 5 system bonding is provided by the cold water pipe, which is electrically common to both services. But the voltage potential difference still occurs because of the separated entry points. Figure 7 shows the details of how an inter-service bonding point might be constructed and installed.

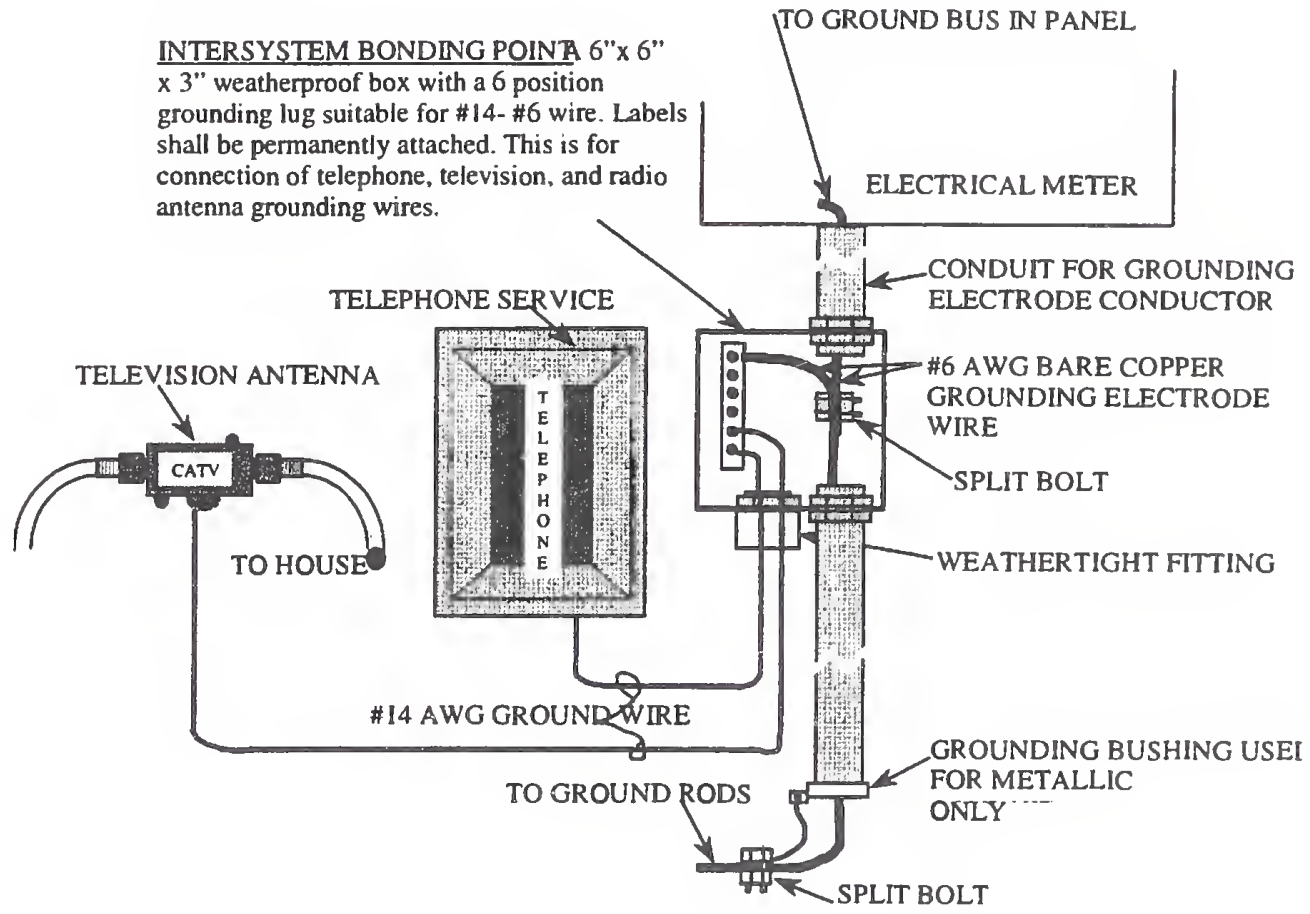

Figure 7. Details of the essential intersystem bonding point

Beyond grounding, for a surge-protective device (SPD) to be effective it must provide a protective level, or surge clamping, below a level potentially harmful to the equipment. But the level should not be so low that the device absorbs energy to the point that its life is reduced or it fails prematurely under the stresses resulting from a temporary overvoltage. This principle holds for power, signal, telephone or cable, albeit at different threshold levels. The SPD must also have a surge current handling capability commensurate with the surge currents that might occur at that location.

The application of an SPD satislying the criteria cited above must also take into consideration the rest of the circuit where the device is to be applied. For instance, operation of the SPD must not cause adverse side effects. In the case of protection of load equipment which is connected to the power system as well as to a communication system (telephone, cable or satellite TV) particular attention must be given to this issue. It is possible that protecting the two interfaces of the equipment, each with a separate SPD, might leave the equipment in jeopardy as the result of overvoltages appearing between the two separate systems, see Key, Martzloff, [2,3].

Because effeclive operation of an SPD involves diverting the surge to ground, the actual grounding system and its connections in a residence must be taken into consideration. The impedance of the 
grounding system to "true earth" is far less important than the integrity of the bonding of the various parts of the grounding system. As noted earlier the worst possible mistake-and a violation of the NEC-is to provide separate grounds for the power system and for the communications system. Even so, many instances are found of such multiple grounding practice in residences, either intentionally, or by accident. A typical example is services such as cable TV that used the metal pipe of an outdoor faucet as its grounding connection. This arrangement was an acceptable ground at the time of installation, but can easily be defeated when the water piping inside or outside the house is replaced with plastic. So an improper separation of grounds is camouflaged by the short link of steel pipe going through the foundation wall and sealed in the concrete.

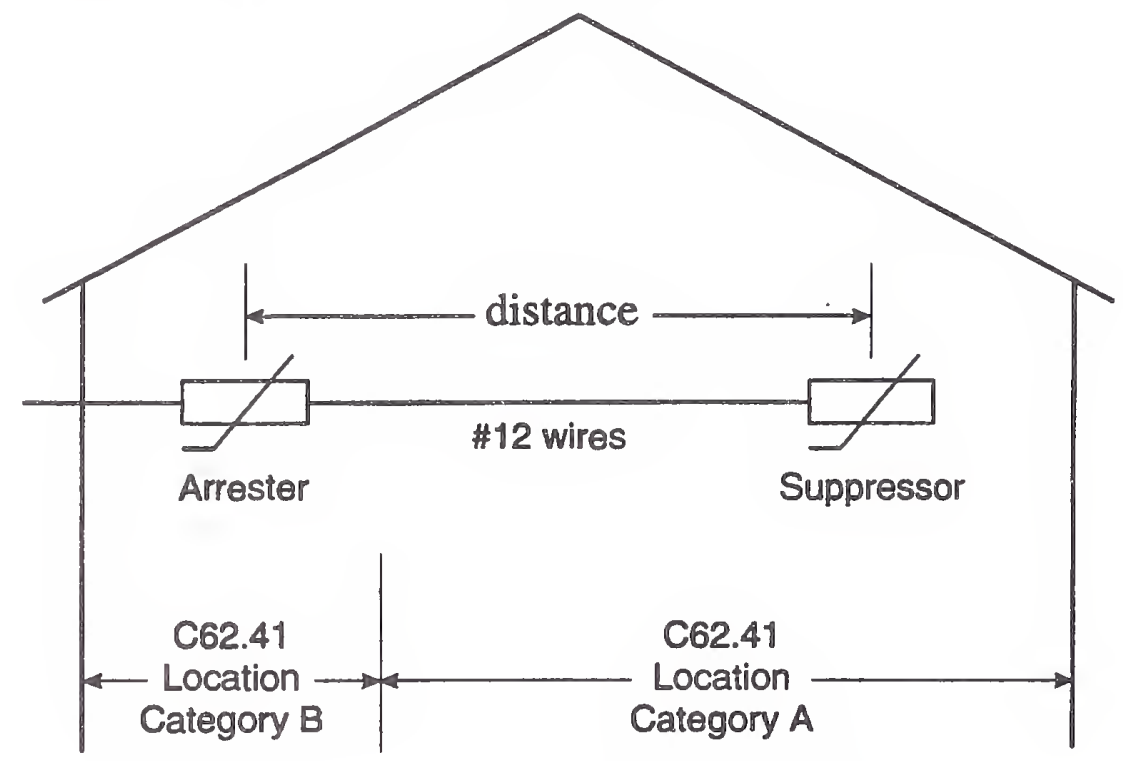

Figure 8. Cascade arrangement of upstream and downstream SPDs

\section{OPEN AND UNRESOLVED ISSUES}

Several issues remain open at this point and will be addressed in the Guide. We hope that the Guide will resolve some of these issues, but others might take more research to resolve. In some cases an iterative process will be required among end-users, utilities, and equipment manufacturers to optimize the process instead of exchanging blame.

One important problem that can be resolved by future research is the coordination of an SPD cascade, (see figure 8). If the selection of a service entrance SPD is appropriately coordinated with the installation of appropriate SPDs within the residence, then the resources will be allocated in an effective manner, both technically and economically (see Martzloff, Lai [4,5]). Clearly, this coordination can only be achieved by cooperation of the utility, SPD manufacturers, and premise occupants and full knowledge of the characteristics of the SPD's and the surge itself.

Another problem that can be resolved is the effective protection of equipment connected to two different systems. The concept of equalizing ground references has now been sufficiently advocated to motivate SPD manufacturers to offer SPDs with both power and telephone protection, or both power and TV protection, in the same enclosure (see figure 9). The IEEE designation of "Surge Reference Equalizer" was published in 1992, [6]. It has not yet found general use in the 
industry, but for most residential applications the device can be found in electronics supply stores. Still, a possible problem in that solution is the absence of industry standards on the performance of surge reference equalizers. At this point, the user is left with some uncertainty as to how effective a particular brand may be compared to another. In this intensely competitive market, claims and counter claims need to be sifted via experiment, a role that some utilities might be willing to assume, or that consumer organizations should address.

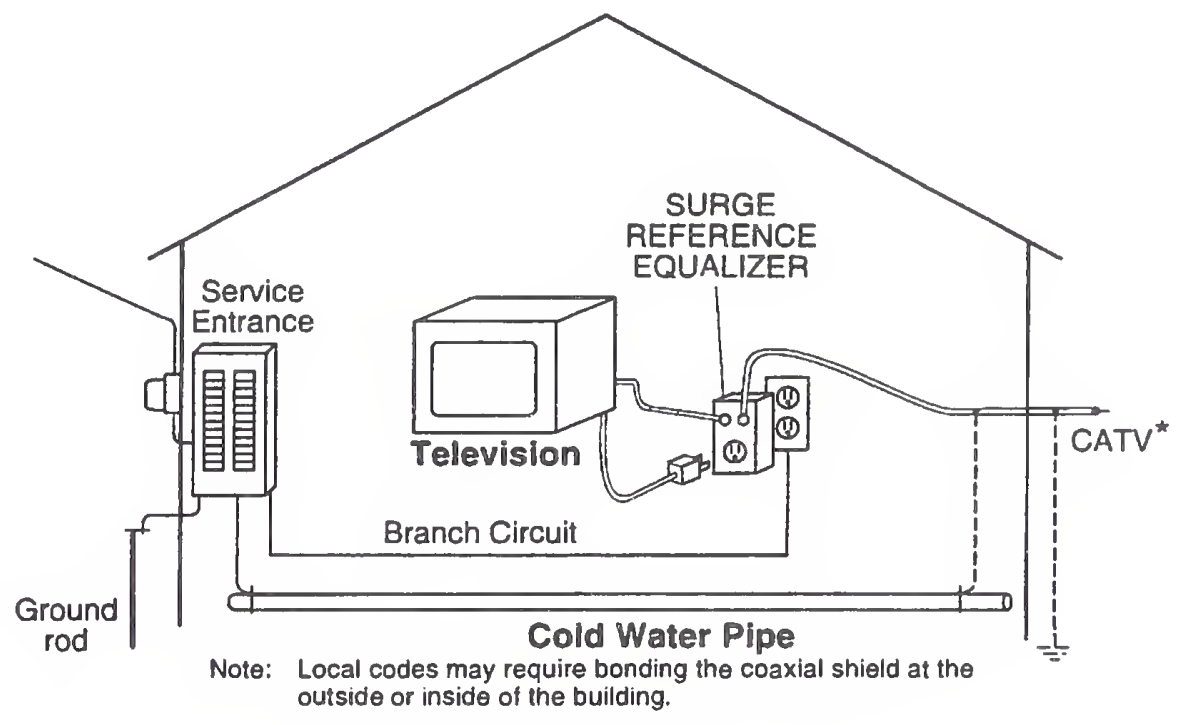

Figure 9. Surge reference equalizer to protect multi-port appliances

Last but not least, application of SPD or lightning protection must consider risk analysis. Protection of appliances against surges generated within a building, or impinging at the power service entrance, can be accomplished with relatively low cost. However additional investment may be required if multiple services (telephone, TV, and power), and multiple grounds are present. External protection against a direct lightning strike may also be needed with cost depending on the structure and location. In any case good practice should be sought in the face of an "act of God" event, where damage can be minimized by observing appropriate rules of grounding, bonding, and protection, as the Guide will propose. However, even with the best practices some degree of risk will always remain.

\section{CONCLUSION}

More attention to surge protection practices is warranted by the increased use and inherent surge vulnerability of residential electronic systems and appliances. While there is consensus on the basic principles of protection, specifics and installation procedures for cost-effective applications are not readily available. By applying data and practices for grounding, lightning and surge protections to specific appliance sets, these needed details are beginning to take form. To be successful a Consumer-Oriented Guide on surge protection will have to address complex topics of whole-house protection including such techniques as multi-port devices and cascade coordination. When complete, the Guide should provide a comprehensive document that insurance companies can use to educate their policyholders, employees, and agents about how to reduce damage resulting from surges caused by lightning. 


\section{REFERENCES}

1. L.G. Byerley III, et al, Measurement and Use of Lightning Ground Flash Density," Proceedings of the International Aerospace and Ground Conference on Lightning and Static Electricity Williamsburg, VA, September 26-28, 1995.

2. Key, T.S. and Martzloff, F.D., "Surging the Upside-Down House: Looking into Upsetting Reference Voltages: Proceedings, PQA'94 Amsterdam, October 1994.

3. Martzloff, F.D., Mansoor, A., Phipps, K.O., and Grady, W.M., "Surging the Upside Down House: Measurement and Modeling Results," Proceedings, PQA'95 New York, May 1995.

4. Martzloff, F.D. and Lai, J.S., "Cascading Surge Protective Devices: Coordination versus the IEC 664 Staircase," Proceedings, PQA'91 Paris, October 1991.

5. Lai, J.S. and Martzloff, F.D., "Cascading Surge Protective Devices: Options for Effective Implementations," Proceedings, PQA'92 Atlanta, September 1992.

6. IEEE Standard 1100-1992, The Emerald Book, IEEE Recommended Practice for Powering and Grounding Sensitive Electronic Equipment. 


\section{Driving High Surge Currents into Long Cables: More Begets Less}

\author{
Arshad Mansoor, Member, IEEE \\ Power Electronics Applications Center \\ Knoxville TN 37932 USA \\ Amansoor@epri-peac.com
}

François Martzloff, Life Fellow, IEEE National Institute of Standards and Technology

Gaithersburg MD 20899 USA f.martzloff@ieee.org

\section{(C) 1996 IEEE}

Reprinted, with permission, from IEEE Transactions on Power Delivery, Vol.12, No.3, July 1997

\section{Significance:}

Part 1 Development of Standards - Reality checks

Part 4 Coupling and propagation of surges

In the propagation of a surge current injected at the service entrance of a building, two significant factors can prevent the propagation of a postulated "large" surge current to the end of the branch circuits of the facility.

1. The combination of the inherent inductance of the wiring and the high rate of current change for such a current to begin flowing into the branch circuit results in a high voltage at the driving end $(V=L \times d i / d t)$.

2. In the absence of a surge=protective device at the service entrance, the withstand voltage of the wiring devices at the driving end - the service entrance - is very likely to be exceeded by the voltage that this rising current will develop along the branch circuit.

The resulting flashover will abort further propagation of the surge current toward the far end, thus establishing a limit to what is physically possible. If there is a surge-protective device at the service entrance, the scenario becomes a matter of cascade coordination.

The paper provides quantitative information on this limitation, as a function of wiring length and current rate of rise. 
$\varnothing$ 


\section{Driving High Surge Currents into Long Cables: More Begets Less}

\author{
Arshad Mansoor, Member, IEEE \\ Power Electronics Applications Center \\ Knoxville, TN 37932 USA
}

\author{
François D. Martzloff, Life Fellow, IEEE \\ National Institute of Standards and Technology ' \\ Gaithersburg, MD 20899 USA
}

\begin{abstract}
Reality checks can and should be applied to proposals for characterizing the surge environment and application of surgeprotective devices (SPDs) to end-user, low-voltage power systems. One such check is the fact that driving a large current with steep front toward an SPD installed at the far end of a branch circuit cable could require such a high voltage that the connections at the near end of the cable will flashover, limiting the stress applied to the far-end SPD. Tests and numerical modeling were performed to support this thesis. The results of real-porld measurements and modeling, presented in the paper, are in good agreement and validate each other. From that point on, the model allows parametric variations of cable length and surge current amplitude and waveform, of which several examples are presented.
\end{abstract}

\section{INTRODUCTION}

In the never-ending quest for better data on the frequency of 'occurrence and level of threat of overvoltages, we should not overlook some "reality checks" that can be applied to proposals for characterizing the surge environment. One such check is the fact that forcing a large surge current with steep front toward a surge-protective device (SPD) installed at the far end of a branch circuit cable could require such a high voltage that the wiring device connections at the near end of the cable will flashover, limiting the stress applied to the far-end SPD.

'Electricity Division, Electronics and Electrical Engineering Laboratory, Technology Administration, U.S. Department of Commerce

96 SM 399-6 PWRD A paper recommended and approved by the IEEE Surge Protective Devices Committee of the IEEE Power Engineering Society for presentation at the 1996 IEEE/PES Summer Meeting, July 28 - August 1, 1996, in Denver, Colorado. Manuscript submitted December 28. 1995; made available for printing June 19, 1996.
Large surge currents considered by standards-writing bodies and discussed in this paper are presumed to impinge from the outside of a building, as a result of a direct or indirect lightning flash. These involve postulated rise times in the order of a few microseconds, with a duration ranging from a few tens to a few hundreds of microseconds. While there are different propositions made on what duration should be considered as "representative" waveforms, there is a consensus on rise times ranging from about $4 \mu$ s to $20 \mu$ s [1]. However, consensus on what value to select for "representative" amplitude(s) has been challenged by proposals to increase the current surge capability of devices intended for installation at the end of branch circuits.

A growing trend in the application of SPDs to residential or commercial installations is to provide "whole-house protection" with an upstream SPD connected at the service entrance, and downstream SPDs in the form of plug-in devices installed at receptacles. Selecting the ratings for these two devices is the subject of some debate. The voltage rating of the devices introduces the issue of cascade coordination which has been addressed at length in the literature [2]-[8] and will not be discussed here. At this point in time, the vast majority of installations do not include an upstream SPD intentionally connected at the service entrance, other than a gap in the revenue-meter socket. This gap is provided by the meter manufacturer to protect the meter more than the downstream installation. Nevertheless, there are other "gaps" at the service panel -- the clearances of the wiring devices, which have some limits to their voltage withstand capability.

\section{SURGE PROPAGATION IN WIRING}

The possibility of a clearance flashover is the basis of our thesis: If a large surge current is postulated as propagating downstream (and then taken as a requirement for the downstream SPD), the propagation characteristics of this surge current would result in high voltages at the service entrance, upstream. In turn, the high voltage would cause flashover of upstream clearances, acting as a relief valve for the surge energy headed for the downstream SPD. This relief action would then contradict the proposed requirement for high energy-handling capability of the downstream SPD. Thus, appropriate selection of current ratings for the downstream SPD, in the light of our thesis, should take into consideration this reality check that defines an upper limit for the current rating required for the downstream SPD. 
The surge propagation characteristics mentioned in the preceding paragraph are controlled by three parameters: the impinging surge, the impedance of the wiring from the service entrance to the downstream SPD, and the I-V response of the downstream SPD. The impinging surge could be considered either as a voltage source or as a current source. The present consensus is to consider it as a current source, resulting from the coupling and subsequent division of a lightning surge, part of which impinges on a given service entrance.

The impedance of the wiring is that of two parallel wires of known dimensions and separation. It can be represented either by lumped parameters -- series $\mathrm{R}$ and $\mathrm{L}$ and parallel $\mathrm{C}$-- or by a "short" transmission line. The reason for placing quote marks around the qualifier of "short" is that the term is to be viewed by comparing travel time over the length of the transmission line and duration of the traveling pulse -- another subject discussed in the literature [9] that we will not discuss here, with the exception of a brief comparison of results obtained when modeling the propagation with lumped parameters or with a transmission line.

When using the lumped RLC model, during the rise of the surge current, the significant parameter of the wiring impedance is its inductance, $L$. The voltage at the upstream end resulting from driving the surge current into such an impedance is primarily $L \times d i / d t$, with $d i / d t$ determined by the amplitude and rise time.

By performing surge measurements on real-world wiring components, followed by numerical modeling with the Electromagnetic Transients Program (EMTP) ${ }^{2}[10]$, this proposition can be verified and applied to a range of postulated surge waveforms and typical configurations found in the premises wiring of lowvoltage systems. These results will allow developing realistic recommendations for the rating of SPDs offered for surge protection at the equipment location -- either as plug-in additions by the end-user, or as permanently wired devices at the end of typical branch circuits. The measurement results also show the need to consider the possibility of "blind spots" in the protection schemes, and illustrate our title paradox of "more begets less."

Measurements were conducted on a simple circuit consisting of 9 meters of nonmetallic jacket cable typical of residential installations, with a metal-oxide varistor connected downstream at the far end. A Combination Wave surge generator, suitable for producing the waveform described in IEEE/ANSI C62.411992 [1] was used to inject a surge current at the upstream end of the cable. Current and voltage waveforms were recorded. The current waveform resulting from this injection was duplicated in a closed-form equation to be applied as the postulated surge current injected into the EMTP model of the circuit, allowing computation of the corresponding voltages.

\footnotetext{
${ }^{2}$ Certain commercial instruments and software packages are identified in this paper in order to adequately specify the experimental procedure. Such identification does not imply recommendation or endorsement by the National Institute of Standards and Technology, nor does it imply that these are necessarily the best available for the purpose.
}

\section{MEASUREMENTS AND MODELING}

\section{A. Characterizing the varistor}

First, the varistor to be connected at the far end was tested to determine its I-V response and demonstrate that the model to be used for this highly nonlinear component would be adequate to simulate its behavior in the circuit when connected at the downstream end. Figure 1 shows the test circuit used for making that measurement. The surge generator used for the tests was the KeyTek 711 with a P7 wave-shaping output network.

The varistor used in these tests was a 20 -mm diameter metaloxide varistor (MOV) disc, rated $130 \mathrm{~V} \mathrm{rms} \mathrm{(200} \mathrm{V} \mathrm{at} 1 \mathrm{~mA} \mathrm{dc}$ ). The inductance $L p$ shown in series with the varistor is not a deliberate addition of a real component, but is the representation of the coupling between the loop where the surge current flows and the voltage measurement loop formed by the varistor leads and the two probes used for the differential measurement. That inductance is included in the model as a discrete series inductance, with a value of $0.5 \mu \mathrm{H}$ selected to emulate the observed voltage at the point of measurement -- which is not the "pure" varistor voltage, as discussed in the narrative of Figure 2.

Figure 2 shows the recording obtained for a particular setting of the surge generator, and Figure 3 shows the result of modeling the circuit shown in Figure 1 for an injected current surge corresponding to the actual current surge recorded in Figure 2. The equation used for the modeling is a damped sine wave that allows a close approximation of the current delivered by typical Combination Wave generators into inductive loads [7]. It is known that actual generators tend to produce an "undershoot" when connected to an inductive load, and this test was no exception. However, computational artifacts occur when using a simple damped sine wave because its di/dt derivative (a cosine) is not zero at time zero. Furthermore, we know that nature does not allow an instantaneous jump of current from zero to a steep rise. By adding a multiplier term $\left[1-\mathrm{e}^{(-t)}\right]$, these artifacts are eliminated and the waveform has a "gentle toe" which is a better model of reality. This improved equation is then:

$$
I=4200 * \sin (0.126 t) * \mathrm{e}^{(-t 28.1) *\left[1-\mathrm{e}^{(-t)}\right]}
$$

with $I$ in amperes and $t$ in microseconds.

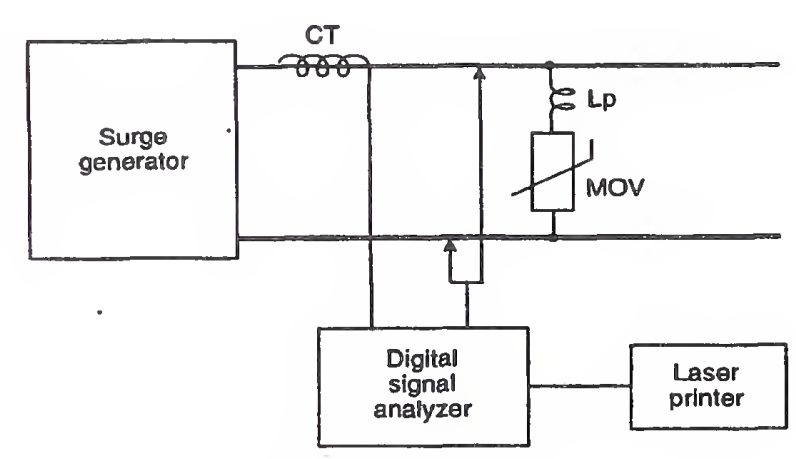

Figure 1 - Test circuit for determination of the I-V characteristics of the varistor 


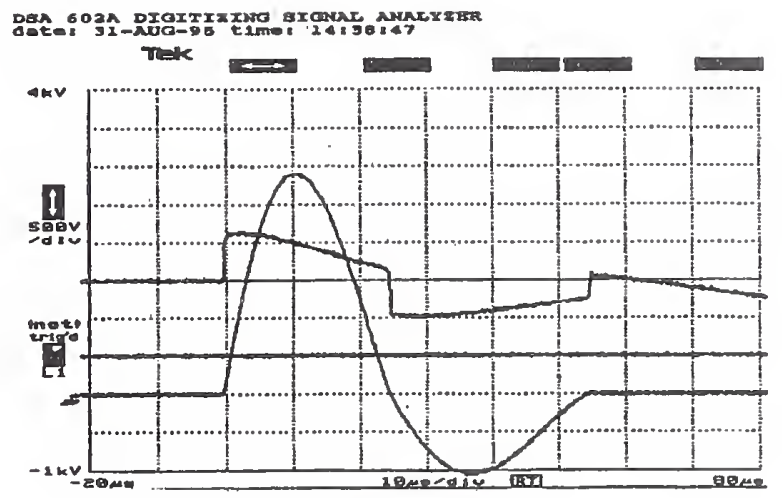

Top trace: Voltage, $500 \mathrm{~V} / \mathrm{dlv}$

(Center trace: inactive)

Bottom trace: Current, $500 \mathrm{~A} / \mathrm{div}$

Sweep: $10 \mu \mathrm{s} / \mathrm{div}$

Figure 2 - Real-world recording

Inspection of Figures 2 and 3 clearly shows the agreement between real-world measurements ${ }^{3}$ and model, and thus merits some observations. One might have expected a flat-top voltage waveform reflecting the clamping action of the varistor. Instead, a drooping waveform is observed. This droop is caused by the parasitic inductance $L p$ in series with the ideal varistor. At the time of current peak $(d i / d t=0)$, the "true" varistor voltage is seen on the oscillogram. Before the peak, the positive $L p \times d i / d t$ adds a spurious voltage to the recording. After the peak, the Inegative $L p \times d i / d t$ subtracts the spurious voltage.

These observations are significant in appreciating the allimportant inductive effects during the rise and fall of a surge current in the wiring of branch circuits. The issue of the importance of inductance versus other circuit parameters [11] hopefully has been put to rest by the surge and impedance measurements with corresponding computations performed in the so-called "Upside-Down House" [12], a real-world replica of a typical residential wiring system. In [12], it was shown that inductive effects prevail, so that rate of rise of the surge current and circuit inductance, more than any other parameter, are the significant parameters for the voltage necessary at the upstream end to drive a given current into the branch circuit.

The model used in the simulation for the varistor is derived from the published varistor I-V characteristic (general shape and slope of the curve) with one specific point defined by the "true" varistor voltage read from the oscillogram of Figure 2 at the point of zero $L p \times d i / d t$ contribution. In turn, this varistor model will be used for the modeling of a varistor connected at the downstream end of a branch circuit, as discussed in the following reported measurements and simulations.

3 The measurements reported in this paper have been made with instrumentation for which the cumulative uncertainty should not exceed 5 to $6 \%$. Given the process of applying the measurement results to the response of surge-protective devices exposed to enviropment with lcharacteristics that are at best known within an order of magnitude, this level of uncertainty does not affect the practical conclusions.

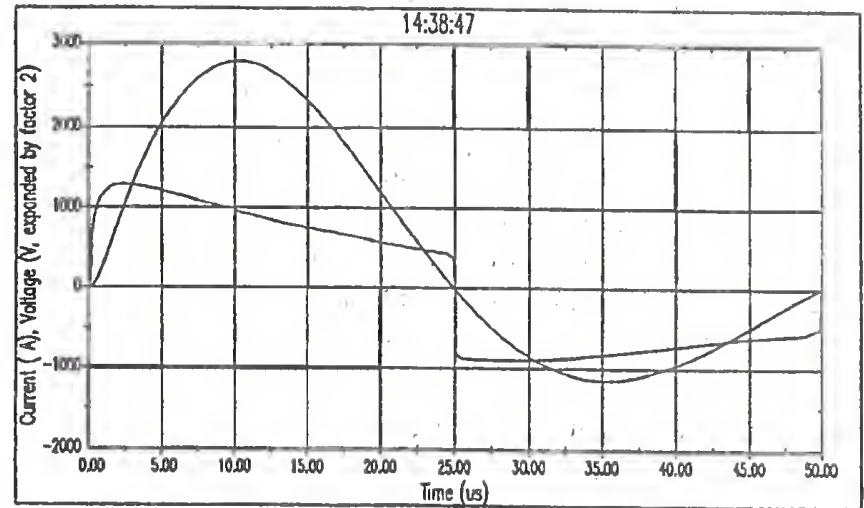

Note: the voltage trace has been expanded by a factor of 2 to enhance resolution on the vertical scale.

Figure 3 - Modeling the circuit of Figure 1 with the impinging current set to match the test current, as shown in Figure 2

\section{B. Measurement and modeling with varistor installed at the downstream end of a branch circuit}

The circuit of Figure 4 shows the varistor characterized by the test and modeling in the preceding paragraphs, connected at the downstream end of a "branch circuit" consisting of two copper conductors of 2- $\mathrm{mm}^{2}$ cross-section (\#12 AWG) with solid insulation and a separation of $6 \mathrm{~mm}$ between centers. The first current transformer monitors the total current impinging at the upstream end. The second current transformer monitors the current flowing toward the downstream end, which will be imposed on the varistor. The clearances at the upstream end, such as clearances in a service-entrance panel, are represented by a discrete gap that will be set to produce sparkover at some given voltage during the test as well as in the model.

Figure 5 shows the recording obtained with the circuit of Figure 4, with the surge generator left at the same setting as that used for Figure 2. To determine the response of the circuit without the clearance limitation, the gap setting was adjusted for this test so that no sparkover occurred at the upstream voltage developed for the current delivered by the generator.

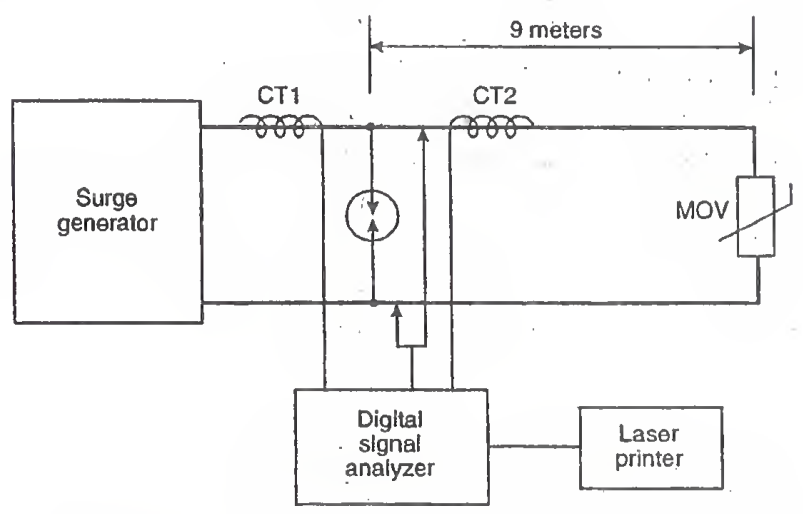

Figure 4 - Test circuit for determination of the voltage necessary at the sending end to drive a given current into the far-end SPD 


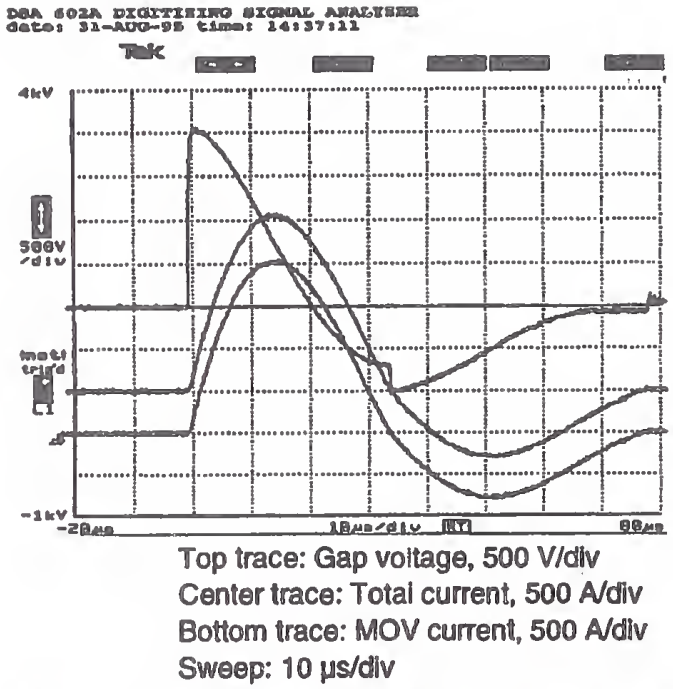

Figure 5 - Real-world recording of sending-end voltage with gap set for no sparkover

Comparing the traces of Figure 5 and Figure 2, the addition of the inductance of the 9 meters of branch circuit changes the load on the surge generator, reducing the current peak from the $2.8 \mathrm{kA}$ in Figure 2 down to $2 \mathrm{kA}$ in Figure 5.

The two current traces of Figure 5 are identical. Since there is no current diverted by the gap, the current in the branch circuit is the same as the current delivered by the surge generator.

Another effect of the added inductance is the increase in the time from origin to the first current zero, $33 \mu \mathrm{s}$ in Figure 5, compared to $25 \mu \mathrm{s}$ in Figure 2. In the subsequent model, that change of the actual impinging current surge is taken into consideration by modifying the current equation as follows:

$$
I=3571 * \sin (0.095 t) * \mathrm{e}^{(-8 / 26.1)} *\left[1-\mathrm{e}^{(-t)}\right]
$$

with $I$ in amperes and $t$ in microseconds.

Turning to the modeling, Figures 6 and 7 show the waveforms of the impinging current, as defined by Eq. (2), and the resulting voltage at the upstream end. To address some concerns expressed by colleagues in discussions of this subject, the EMTP modeling was also done with the transmission-line model which is readily available in the EMTP code. Figure 6 was obtained with the lumped-parameter circuit model, and Figure 7 was obtained with the transmission-line model.

Inspection of the two figures reveals no difference in the results. The only difference is in the consumption of computing time: with the transmission line model, the computation timestep has to be significantly shorter $(0.02 \mu \mathrm{s}$ in this case $)$ than the travel time for the reflections, while in the case of the lumped model, the time-step can be longer ( $0.1 \mu \mathrm{s}$ in that case). The result is that the simulation of Figure 6 took 43 seconds on a 486-based PC, compared to 263 seconds for Figure 7. Therefore, the lumped-parameter model is perfectly adequate to represent reality, and performing a transmission-line analysis [5] is an unnecessary consumption of computing time and resources.

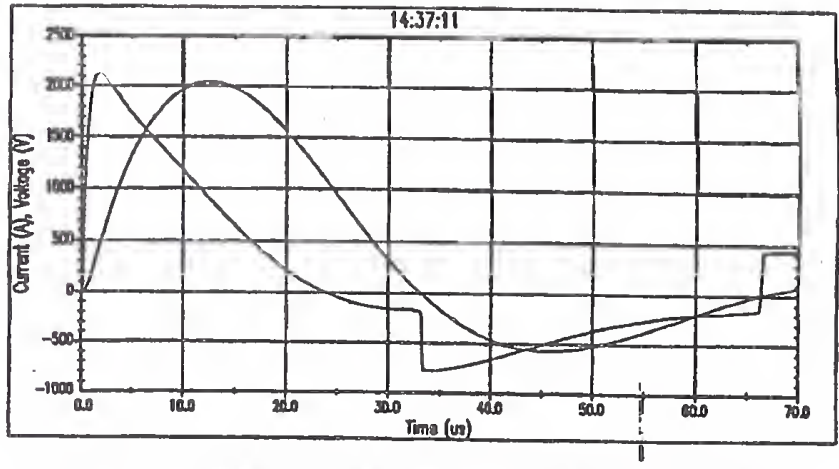

Figure 6 - Impinging current and resulting upstream voltage as computed with lumped-parameters model

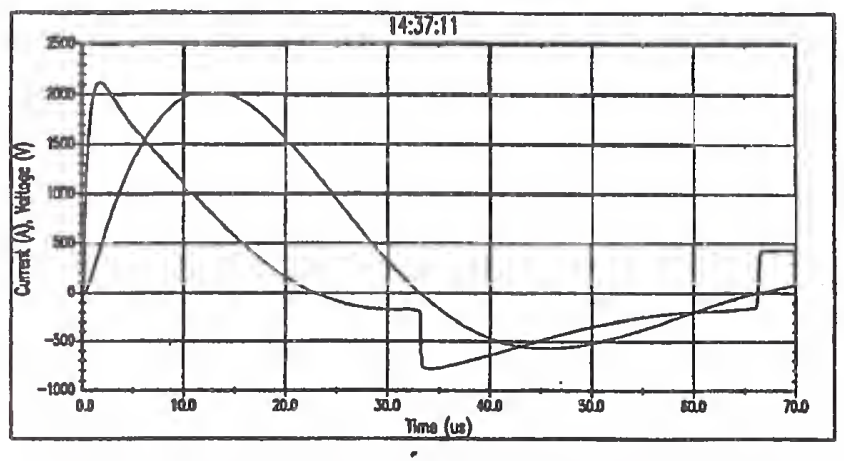

Figure 7 - Impinging current and resulting upstream voltage as computed with transmission-line model

In both Figures 6 and 7, the effect of the branch circuit inductance on the resulting voltage is apparent as the peak voltage occurs at the beginning of the rise (as soon as the "gentle toe" effect ceases), not at the peak of the current. The step change in the voltage trace corresponds to the reversal of the current in the varistor, showing the relative contributions of the varistor effect and of the inductive effect as seen from the upstream end.

Table 1 below shows the results of such computations for the waveform of Figures 5,6 and 7. As mentioned above, the insertion of an inductance in the load connected to the surge generator increased the rise time beyond the standard $8 \mu \mathrm{s}$. In making the parametric computations, we chose to stay with this $10 \mu \mathrm{s}$ value to maintain continuity with the test/model validation.

\section{TABLE 1}

Upstream voltage (in' $\mathrm{kV}$ ) necessary to drive a current of the peak value shown (columns) and rise time of $10 \mu \mathrm{s}$ into a branch circuit of length as shown (rows), terminated with $₫ 130 . V$ rated varistor

\begin{tabular}{cccccc}
\hline Length $\backslash$ Peak & $2 \mathrm{kA}$ & $3 \mathrm{kA}$ & $5 \mathrm{kA}$ & $7 \mathrm{kA}$ & $10 \mathrm{kA}$ \\
\hline $10 \mathrm{~m}$ & 2.3 & 3.3 & 5.2 & 7.2 & 10.1 \\
$30 \mathrm{~m}$ & 5.8 & 8.5 & 13.9 & 19.4 & 27.0 \\
$50 \mathrm{~m}$ & 9.3 & 13.7 & 22.7 & 31.6 & 45.0 \\
\hline
\end{tabular}




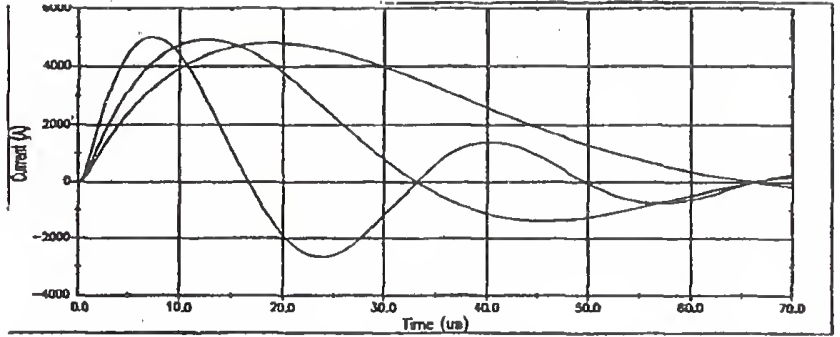

Figure 8 - Three surge current waveforms with different rise times used to compute the values of Table 2

Figure 8 shows three waveforms of same amplitude, with nominal rise time of $5 \mu \mathrm{s}, 10 \mu \mathrm{s}$, and $20 \mu \mathrm{s}$, obtained by taking half or double of the frequency used in Eq. (2). The actual rise time [1.25 $\times$ (time from $10 \%$ to $90 \%$ )], as opposed to the nominal rise time used to describe the waveforms, was computed as well as the maximum rate of rise for each wave. The maximum rate of rise (which is obtained when the second derivative of the current is equal to zero) occurs initially, once the gentle toe is over, and determines the maximum resulting voltage produced by the inductive effect. Table 2 shows the corresponding values of the rise time, maximum rate of rise, and resulting voltage for a branch circuit length of $10 \mathrm{~m}$ and amplitude of $5 \mathrm{kA}$. Note that for a 1-to-4 increase in nominal rise time, the maximum di/dt decreases only by one half, with the same decrease appearing in the resulting voltage, showing once again that initial rate of rise is more important than rise time and amplitude.

TABLE 2

Effect of the rate of rise of the postulated current on the resulting voltage at the upstream end of the branch circuit

\begin{tabular}{lccc}
\hline Nominal rise time, $\mu \mathrm{s}$ & 5 & 10 & 20 \\
\hline Actual rise time, $\mu \mathrm{s}$ & 4.3 & 9.5 & 13.5 \\
\hline Maximum di/dt, $\mathrm{A} / \mu \mathrm{s}$ & 1250 & 850 & 630 \\
\hline Resulting voltage, $\mathrm{k} \cdot \mathrm{V}$ & 7.0 & 5.2 & 3.6 \\
\hline
\end{tabular}

In the scenario tested and modeled so far, no flashover possibility was considered. Nevertheless, the values shown in Table 1 clearly indicate that some real-world circuit lengths and surge parameters postulated in some SPD application standards under development can produce high upstream voltages that will cause a flashover of the upstream wiring devices.

\section{The paradox of "more begets less"}

Common-sense intuition might lead the unwary to expect that higher surge currents would impose a greater stress on the circuit components, including the downstream varistor. Also, a longer branch circuit, with its corresponding higher inductance, could be expected to have the capability of storing more energy during build-up of the surge current toward the downstream varistor, into which that stored energy ultimately has to be dissipated. Cascade coordination studies [4], [6], [8], have shown that in some cases, the downstream varistor continues to carry current long after the impinging surge current has gone past its peak.
To explore the validity of such expectations, we performed tests and modeling, with an actual gap in the test circuit, and a switch in the model circuit, to bypass the current at the upstream end when sparkover voltage is attained. By measuring the current that flows in the branch circuit toward the downstream varistor and the voltage across the varistor, the energy deposited in the varistor during the total surge event can be determined. Likewise, the modeling can determine the current in the varistor, hence the voltage across it, and allow computation of the energy.

In [4], agreement was reported between, on the one hand, computing the deposited energy through actual measurement of the current and voltage, followed by computation of the energy by means of the digital signal analyzer used for measurements and, on the other hand, the model computations. Therefore, in the tests reported here, we were satisfied to verify waveform agreement between the actual varistor current measurement and the computed varistor current, and let the model alone compute the energy deposited in the downstream varistor.

Figure 9 shows the real-world recording of the situation that develops for a "clearance" sparkover of $2 . \mathrm{kV}$. This relatively low value, compared to the $6 \mathrm{kV}$ to $10 \mathrm{kV}$ level that we might expect from typical low-voltage wiring devices, is made necessary for the test case where only 9 meters of branch circuit were considered, and the setting of the surge generator was maintained at the same nominal $3 \mathrm{kA}$ short-circuit current. The object, of course, is to demonstrate that the clearances are likely to flash over, as indicated by progressively higher values of the necessary upstream driving (or resulting) voltage shown in Table 1.

Under the conditions of Figure 9, sparkover of the gap occurred at approximately $1 \mu \mathrm{s}$. After sparkover, the current delivered by the surge generator is the sum of the currents in the gap and in the branch circuit. Its peak $(3.2 \mathrm{kA})$ is greater than those of Figures 2 and 5 because the generator does not need to overcome the varistor that reduced the voltage available for driving the current, nor the impedance of the 9 meters of cable.

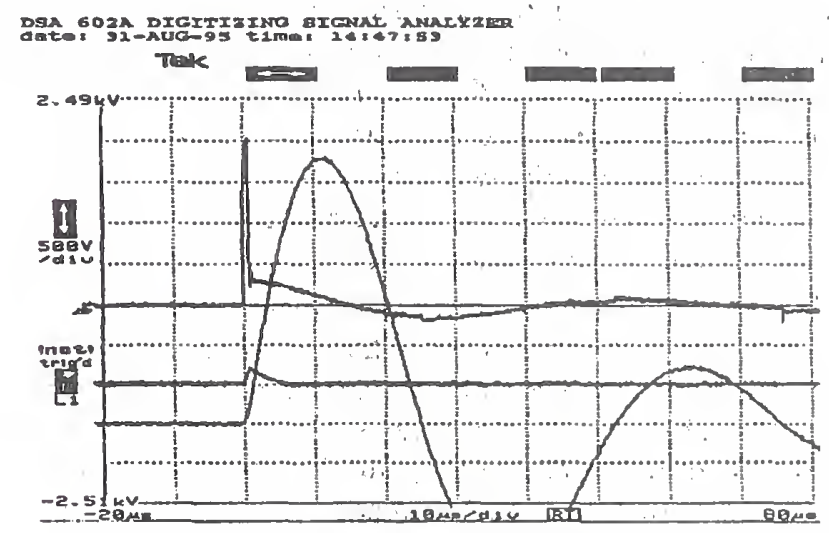

Top trace: Resulting voltage, $500 \mathrm{~V} / \mathrm{div}$

Center trace: MOV current, $500 \mathrm{Addiv}$

Bottom trace: Total current, $500 \mathrm{~A}$ div Sweep: $10 \mu \mathrm{s} / \mathrm{div}$

Figure 9 - Voltage and currents with gap sparkover at $2 \mathrm{kV}$ 
Figures 10 and 11 show the results obtained by the model for voltages and current in the circuit. In the modeling, only one current waveform was applied to the circuit, the one prevailing until flashover occurs, which the postulated current-source real world would maintain. In contrast, the surge current delivered by the surge generator (Figure 9) increases after the flashover, but that is not relevant to our consideration of what happens to the circuit before and up to the time of flashover.

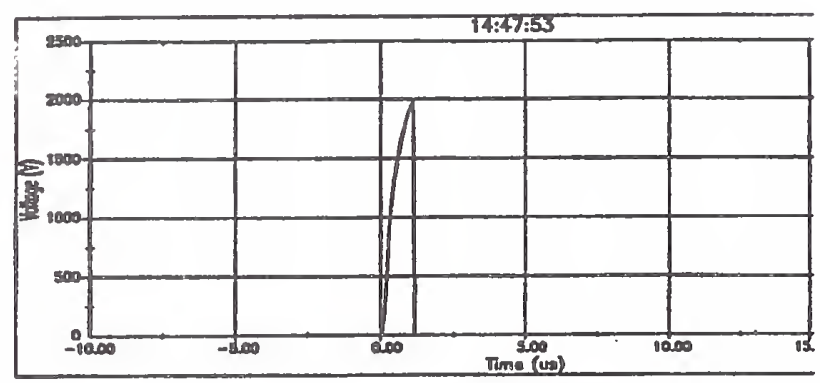

Figure 10. Voltage across the gap set to sparkover at $2 \mathrm{kV}$

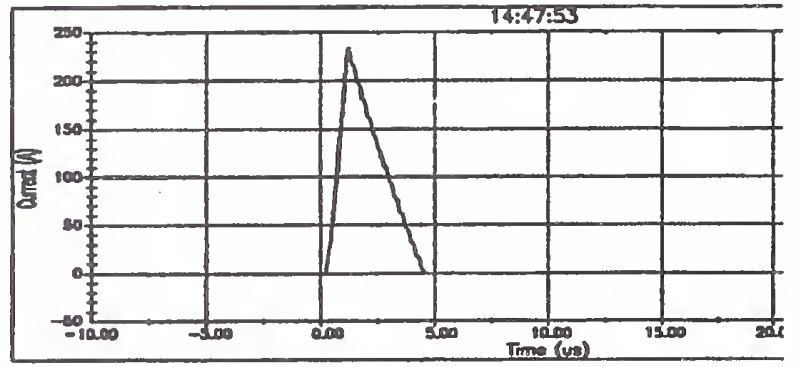

Figure 11 - Current in downstream varistor

The waveforms of Figures 10 and 11 are shown with an expanded scale, compared to that of Figure 9, that gives a better resolution for the gap voltage and current in the varistor. There is good correspondence between the waveforms of the two traces and the gap voltage and downstream current traces of Figure 9. In Figure 10, however, the gap voltage collapses to zero, while it does not in Figure 9. The difference is that the real-world circuit has a parasitic inductive voltage added to the true gap voltage, already discussed for the varistor of Figure 2. Figure 11 shows the linear ramps typical of current changes in an inductance.

As mentioned above, we can expect that the energy deposited in the downstream varistor for a given impinging surge will be influenced by the length of the branch circuit. Using the model developed and validated according to Figures 5 and 6, the energy can be readily computed. In the case described by Figures 9,10 , and 11 , the gap sparkover voltage was preset at $2 \mathrm{kV}$ so that sparkover could indeed occur for the surge current available from the reall-world generator and the resulting upstream voltage.

Now that we are in the (validated) model-world, we can arbitrarily set the sparkover voltage at a level more typical of the flashover point of clearances, say $6 \mathrm{kV}$. Of course, we have the possibility of assessing energy for a wide range of parameters.
In the example reported below, we kept the same three values of branch circuit length and performed the computations for the same five values of impinging current as those used for the computations of Table 1. Table 3 shows the energy deposited in the downstream varistor for these combinations of branch circuit length and peak current values, for the applied current waveform of Figure 5, and a $6 \mathrm{kV}$ flashover point.

\section{TABLE 3}

Energy deposited into a $130-V$ rated far-end varistor as a function of the branch circuit length shown (rows), current peak (columns) of waveform shown in Figure 5, and flashover of the clearances set to occur at $6 \mathrm{kV}$

\begin{tabular}{cccccc}
\hline Peak/Length & $2 \mathrm{kA}$ & $3 \mathrm{kA}$ & $5 \mathrm{kA}$ & $7 \mathrm{kA}$ & $10 \mathrm{kA}$ \\
\hline $10 \mathrm{~m}$ & $17 \mathrm{~J}$ & $27 \mathrm{~J}$ & $51 \mathrm{~J}$ & $670 \mathrm{~mJ}$ & $218 \mathrm{~mJ}$ \\
$30 \mathrm{~m}$ & $17 \mathrm{~J}$ & $128 \mathrm{~mJ}$ & $30 \mathrm{~mJ}$ & $23 \mathrm{~mJ}$ & $18 \mathrm{~mJ}$ \\
$50 \mathrm{~m}$ & $69 \mathrm{~mJ}$ & $34 \mathrm{~mJ}$ & $17 \mathrm{~mJ}$ & $11 \mathrm{~mJ}$ & $10 \mathrm{~mJ}$ \\
\hline
\end{tabular}

The results shown in Table 3 merit close examination as they reveal some counter-intuitive trends: we might have expected that for higher impinging current values, the resulting energy deposited in the downstream varistor would be higher. Likewise, we might also have expected that for a longer branch circuit, the greater inductance would store more energy, ultimately to be deposited in the varistor. In fact, the opposite occurs. The table also reveals the interesting finding that the first three -lowercurrent, short-line cases (bold face type in the table) produce larger energy deposition, compared to the other cases. Actually, the explanation that follows is simple and might be anticipated (especially with hindsight, illustrating that intuition is a hazardous process when dealing with nonlinear circuit components).

Starting with the second observation (more joules at lower threat levels), we have a beautiful illustration of the blind spot effect -- not limiting tests and designs to the maximum stress of a worst-case scenario -- [13]: for 10 meters of circuit and at the lower current levels, the resulting voltage at the clearance is not sufficient to cause flashover, and all the energy has to go to the downstream varistor. At the higher threat level of $7 \mathrm{kA}$, the voltage produced in the inductance of 10 meters of line, added to the varistor voltage, is sufficient to sparkover the $6 \mathrm{kV}$ gap, relieving the varistor from further involvement beyond that of discharging the energy stored in the line. In the case of the 30-m long line, this transition occurs between $2 \mathrm{kA}$ and $3 \mathrm{kA}$.

Turning now to the first observation, that higher current or greater inductance result in less stress, this apparent paradox is caused by the fact that with the higher values of $d i / d t$ and $L$, the voltage at the clearance rises more quickly to the flashover point. Consequently, the build-up of energy in the line inductance is shut-off earlier so that the current level in the line reached at that point is lower and, in spite of the greater inductance, the stored energy $1 / 2 L i^{2}$ is lower for higher applied current peaks and longer branch circuits. 


\section{CONCLUSIONS}

The development of a validated EMTP model using existing computational tools allows us to look into all scenarios of surge propagation and surge mitigation schemes. The reality check proposed by the measurements and modeling reported in this paper should be useful in the process of selecting stress levels to be specified in the application of SPDs downstream from the service entrance, from the point of view of successful cascade coordination as well as integrity of electromagnetic compatibility. Specific conclusions can be drawn:

1. Realistic surge current amplitudes and rise times can be defined for SPDs installed at the end of branch circuits, with upper limits set by the laws of physics applied to real-world conditions.

2. The general practice for describing surge waveforms is to cite "rise time" or "front time", followed by duration, as in 8/20. However, when the effects of circuit inductance are assessed, in particular by numerical modeling, the maximum rate of rise must be considered, not an average over the rise time. It is especially important to define the conditions at the origin of the waveform, such as inclusion of a gentle toe.

3. The importance of looking for blind spots is, once again, demonstrated by the parametric computations, a much simpler task than exhaustive equipment-exhausting tests.

4. Reliable computational tools make it possible to obtain a wide range of parametric assessments, and thus avoid recourse to intuition when dealing with nonlinear circuits, where blind reliance on common-sense may lead to flawed conclusions.

5. The parametric computations offered in the paper point out the need to consider a balance or trade-off among several critical factors in the design of branch circuit protection, in particular the uncontrollable length of branch circuits in actual installations.

\section{ACKNOWLEDGMENTS}

The measurements reported in this paper were conducted by Kermit Phipps at the EPRI Power Electronics Applications Center. Support for the modeling was provided by the Electric Power Research Institute. Support for the development of this reality check, motivated by the discussions and contributions of IEEE and IEC colleagues, was provided by Delmarva Power \& Light and by Pacific Gas \& Electric.

\section{REFERENCES}

[1] IEEE/ANSI C62.41-1991, "Recommended Practice on Surge Voltages in Low.Voltage AC Power Circuits."

[2] Martzloff, F.D., "Coordination of Surge Protectors in Low-Voltage AC Power Circuits," IEEE Transactions PAS-99, No.1, January/ February 1980, pp 129-133.

[3] Goedde, G.L., Marz, M.B., and Henry, D.C., "Coordinating Lightning Stroke Protection From the Utility System to Load Devices."
In Proceedings, Second International Power Quality ASD Conference, October 1990, Philadelphia.

[4] Lai, J.S. and Martzloff, F.D., "Coordinating Cascaded Surge Protection Devices: High-Low versus Low-High," In Conference Record, IEEE-LAS 1991 Annual Meeting, pp 1812-1819. Also in IEEE Transactions, IAS-29 No.4, July/August 1993, pp 680-687.

[5] Standler, R.B., "Coordination of Surge Arresters and Suppressors for Use on Low-Voltage Mains." In Proceedings, 1991 Zürich EMC Symposium, pp 517-524.

[6] Hostfet, O.T., Hervland, T., Nansen, B. and Huse, J., "Coordination of of surge-protective devices in power supply systems: Needs for secondary protection," In Proceedings, 20th International Conference on Lightning Protection, 1992.

[7] Hasse, P., Wiesinger, J., Zahlmann, P. and Zischank, W., "Principle for an advanced coordination of surge protective devices in low voltage systems," In Proceedings, 22nd Inter-national Conference on Lightning Protection, 1994.

[8] Rousseau, A. and Perche, T., "Coordination of Surge Arresters in the Low-Voltage Field," In Proceedings, Seventeenth International Telecommunications Conference (INTELEC 95), 95CH35824, pp 119. 125.

[9] Martzloff, F.D., "Coupling, Propagation, and Side Effects of Surges in an Industrial Building Wiring System," IEEE Trans-actions IA-26, No.2, March/April 1990, pp 193-203.

[10] EPRI, "Electromagnetic Transients Program (EMTP), Version 2.0; Volume 1; Main Program; Volume 2: Auxiliary Routines" EPRI Report EL-6421-L, July 1989.

[11] Standler, R.B., "Transmission Line Models for Coordination of Surge-Protective Devices," In Proceedings, IEEE Inter-national Symposium on Electromagnetic Compatibility, 1993, pp 358-362.

[12] Martzloff, F.D., Mansoor, A., Phipps, K.O. and Grady, M. "Surging the Upside-Down House: Measurements and Modeling Results," In Proceedings, PQA '95 Conference, EPRI, 1995.

[13] IEEE/ANSI C62.45-1992 “Guide on Surge Testing for Equipment Connected to Low-Voltage AC Power Circuits."

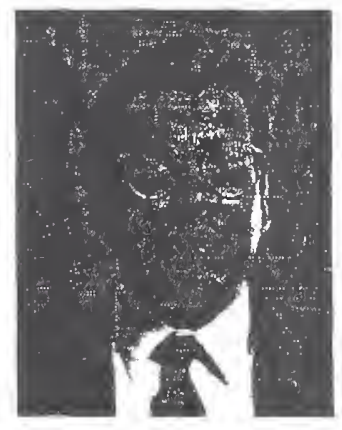

Arshad Mansoor (M’1995) Is Electrical Systems Engineer at the EPRI Power Electronics Applications Center (PEAC). He received his MS and $\mathrm{Ph} . \mathrm{D}$. in electrical engineering from the University of Texas, Austin, in 1992 and 1994 respectively. His areas of interest include power quality, power systems transients, harmonics, surge protection, and EMTP model development.

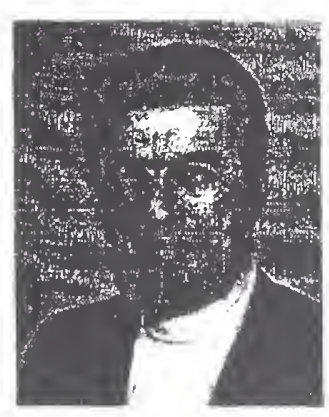

François Martzloff (M'1956, F'1983) Born and educated in France, with additional MS degrees from Georgia Tech and from Union College, worked at General Electric for 29 years and now ten years at the National Institute of Standards and Technology. He is contributing to several committees for development of standards on EMC and surge protection in the IEEE and the IEC. 


\section{Discussion}

\section{Darveniza (University of Queensland, Australia 4072):}

The $a z^{*}+\mathrm{frs}_{\mathrm{s}}$ are to be congratulated for drawing attention to an important feature in surge proter. Namely, the magnitude of the voltage up-line from a surge protective device will distancis and on waveshape of the incident surge. Because of this, flashover at an upstrean device (for example, another SPD) will limit the severity of the surge stressing the downstream SPD.

Two examples are ofiered which support the author's statement "more begets less" and which can be rephrased by saying that in some cases, a less onerous surge may impose more severe overstress than a more onerous incident surge. The two examples are:

1. A cable-entry substation protected by an upstream SPD connected at the overhead line-to-cable junction. The most severe stress at the substation occurs when the surge incident from the line onto the cable is just not large enough for operation of the SPD at the line-cable junction.

2. A hybrid surge protection system for low-voltage and electronic equipment involving two SPD's coordinated by an intervening series impedance. The series impedance is selected to ensure that the downstream SPD is not overstressed, by virtue of operation of the upstream SPD caused by the voltage drop in the impedance (which adds to the clamp voltage of the downstream SPD). However, if the voltage drop is not large enough to "turn-on" the upstream SPD, either because the magnitude or the steepness of the incident surge current is not sufficiently large, then the downstream SPD may still be overstressed if the duration of the surge current is too long. Paradoxically, a more severe incident surge will "turn-on" the upstream SPD, thus protecting the downstream SPD from excessive overstress.

Manuscript received October 4, 1996.

\section{François Martzloff :}

We are glad that the message we were presenting has found a favorable echo with Professor Darveniza, and appreciate his kind words. The two examples he cites are indeed good illustrations of the "more begets less" theme which we have expressed in the manner of a paradox/epigram to make it easy to remember. This reality check on the likelihood of a stress-limiting flashover should be applied whenever a scenario is proposed that involves the propagation of surge currents. We hope that our colleagues involved in standards development will remember this well and assess some of the proposals now under consideration for SPD requirements in the light of that epigram.

Manuscript received November 13, 1996. 


\section{The Effect of Neutral Earthing Practices on Lightning Current Dispersion in a Low-Voltage Installation}

Arshad Mansoor, Member, IEEE Power Electronics Applications Center Knoxville TN 37932 USA Amansoor@epri-peac.com
François Martzloff, Life Fellow, IEEE National Institute of Standards and Technology Gaithersburg MD 20899 USA f.martzloff@ieee.org

(C) 1996 IEEE

Reprinted, with permission, from IEEE Transactions on Power Delivery, Vol.12, No.3, July 1997

\section{Significance:}

Part 2 Development of standards - Reality checks

Part 4 Propagation and coupling of surges

In the case of a direct lightning stroke to a building, the earth-seeking current is dispersed among all available paths to earthing electrodes, including intentional made electrodes and opportunistic electrodes. A substantial part of that current will exit the building via its connection to the power distribution system.

The configuration of this power distribution system (daisy chain from the transformer or radial from the transformer) influences the sharing of the current among these possible paths.

From simulations performed with a 10/350 waveform, the paper provides quantitative information on these effects. 
$\varnothing$ 


\section{The Effect of Neutral Earthing Practices on Lightning Current Dispersion in a Low-Voltage Installation}

\author{
Arshad Mansoor, Member, IEEE \\ Power Electronics Applications Center \\ Knoxville TN 37932 USA
}

\author{
François Martzloff, Life Fellow, IEEE \\ National Institute of Standards and Technology* \\ Gaithersburg MD 20899 USA
}

Abstract - Computer modeling with the EMTP code has been applied to several configurations and earthing practices in use in various countries to show the effect of any differences in the dispersion (sharing) of a lightning stroke current among the available paths for the earth-seeking lightning current. Simplifying assumptions have been made to some details of the configurations to focus on the main difference .- earthing practices. Identifying such differences provides the necessary perspective on their significance and the strong need to take them into consideration when developing international standards on surge-protective device applications.

\section{INTRODUCTION}

When designing a lightning protection scheme for a lowvoltage power system within a building, several scenarios must be considered for the point of termination of the lightning stroke. Common wisdom classifies these by decreasing order of severity: directly to the building, directly to overhead lowvoltage distribution lines (or other utilities) outside of the building, to other objects near the building, distant cloud-toearth strokes, and finally perhaps cloud-to-cloud discharges. Several standards-writing projects are underway, at the IEEE and at the IEC, based on present knowledge of the lightning flash characteristics and on assumptions about the way the lightning current divides among the many paths available for distributing (dispersing) this current to the ill-defined "earth" which is the termination of the cloud-to-earth strike.

The purpose of our paper is to show the effect that different practices for neutral earthing in the low-voltage distribution system can have on the relative dispersion of the lightning current which is seeking the path of least impedance to earth.

* Electricity Division, Electronics and Electrical Engineering Laboratory, Technology Administration, U.S. Department of Commerce.

PE-968-PWRD-0-05-1997 A paper recommended and approved by the IEEE Surge Protective Devices Committee of the IEEE Power Engineering Society for publication in the IEEE Transactions on Power Delivery. Manuscript submitted January 2, 1997; made available for printing May 23, 1997.
To accomplish this purpose in an eight-page paper, and to concentrate on the essential difference, the models we present are simplified from the detailed reality, so that one of our first tasks will be to explain and justify the simplification. To avoid confusion in the meaning of the word "distribution" which can relate to the distribution of electric power by the utility or to the distribution of the lightning current among the available paths, we will use the term "dispersion" for the second meaning, lighting current dispersion. Another term used by some authors to convey the concept is "sharing" (among available paths). Note that the actual return stroke actually goes from earth to cloud in the majority of cases, but the scenario is generally described as if the stroke "terminated" on earthbound objects.

In the case of a low-voltage power distribution system, different countries have adopted different practices on earthing the neutral conductor, and writing a history of why that is so would give an interesting insight into the development of power systems. The fact is that today, two approaches are well entrenched in their respective territories, the so-called TN system and TT system where the difference lies in the mode of earthing the neutral. We will give a brief overview of the differences in a following section. Our purpose is to show how the difference in these practices affect the sharing, or dispersion, of the lightning current among the available paths to earth, and consequently affect the rating of surge-protective devices which may be included in these paths. We used the EMTP simulation code [1] to model several scenarios in each of the TN and TT systems, with small but possibly significant differences in the configuration. By postulating a direct stroke to one building, and requesting EMTP to compute currents in the (simplified) complete power system, we obtained results for the two most severe cases of lightning termination: the case of a direct stroke to one building, and the case of a nearby stroke which propagates and impinges at the service entrance of many buildings on that part of the low-voltage distribution system.

The literature and draft standards contain many examples of such scenarios, but it seems that each is confined to a specific approach or power system configuration with fairly detailed arrangements of load connections. The result is that from this plurality of examples, it is difficult to extract a clear perception of the significant parameters in the dispersion of the lightning current resulting from different earthing practices. In this paper, we will simplify the scenarios to concentrate on the fundamental difference between the neutral earthing practices. 


\section{THE TT AND THE TN SYSTEMS}

The IEC has promulgated a letter code system describing the arrangement of the neutral earthing in single-phase and poiyphase power systems [2]. For the purposes of our paper, we can summarize the TT system as being a distribution system where the neutral is earthed only at the distribution transformer secondary, and the protective earth in a building is obtained from a local earth electrode. This system is used in some countries. The TN system has its neutral earthed at any available opportunity outside of a building, including the distribution transformer secondary, some or all poles, and the service entrance. In the United States, an "Equipment Grounding Conductor" (EGC) is created at the service entrance, bonded to the incoming power system neutral and to the common local earthing point, after which the neutral concuctor and the EGC are carefully (and by mandate from the National Electrical Code [3]) kept separate from one another.

\section{NECESSARY SIMPLIFICATIONS}

Another difficulty in making a detailed comparison of results from different authors is that different models are often used. When apparently different results are reported, a lingering question is that of differences attributable to the simplifying assumptions and possible modeling artifacts. We have used the well-known EMTP code [1] for which our previous experience in cross-validation between the computer model and full-scale experimental measurements [4], [5] gave us great confidence in the validity of the results.

The literature offers many contributions on the system simulation but our purpose is not literature review -- again, our purpose is only to focus on the neutral practices considerations. However, to support some of our postulates, we will cite some papers to show that in the maze of assumptions, simplifications, and simulations, we are not alone.

\section{A. Down-conductor representation}

Some authors have included in their modeling a downconductor feeding the stroke current to the common bonding point of the building [6]. In our model, since we postulate that the current is delivered from a current source, the impedance of the down-conductor has no effect on the current being injected at the common bonding point which is the point at which dispersion (sharing) begins. Therefore, we did not include a down-conductor in our models.

\section{B. Earthing impedance as a function of time ared current}

Some authors consider the fact that the exact value of the earthing impedance is variable as a function of time and current level. For instance, [6] initially proposes a model involving resistance, capacitance, and inductance, with some dependency on time or current, or both. But after studying the problem closer, the authors of [6] conclude that a reasonable approximation is merely a fixed $10-\Omega$ resistance. We have used this value in our models of the building earthing, and postulated an improved, lower $5-\Omega$ resistance at the earthing electrode of the distribution transformer.

\section{Other available current paths}

Some standard proposals include telephone, water and gas connections as possible paths for the earth-seeking lightning current. Considering that the telephone service is a balanced system normally isolated from earth (until a network interface device becomes involved), that some water and gas services can include a cathodic-protection isolation or be implemented with plastic pipes, we chose a conservative approach of not including these as additional paths to earth.

\section{Actual Circuit Configuration for Service Entrances}

Figure 1 shows a schematic of a single-phase 3-wire TN $120 / 240-\mathrm{V}$ service to a building. One surge-protective device (SPD) is connected between each of the two lines and the common earth at the service entrance, ignoring any SPDs within the building under the assumption that in a well-coordinated cascade [7] the majority of the current is carried by the service entrance SPD which has the lowest limiting voltage in the installation. The stroke current, postulated to have terminated on a point of the earthing system of the building, can seek a path to earth in two ways: directly through the earth electrode of the building, and by means of the three conductors back toward the power system.

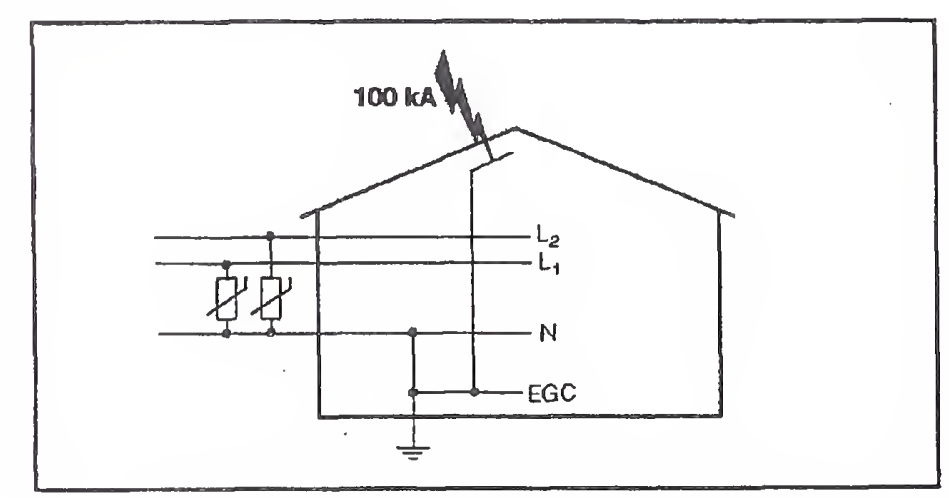

Figure 1. Service connections in a 3-wire TN system

Figure 2 shows a schematic of a three-phase 4-wire TT $230 / 400-V$ service to a building. A dedicated protective earth is created and connected to a local earth electrode, while the incoming neutral of the power distribution system is not bonded to this protective earth. At the service entrance, SPDs are connected between the local earth and each of the incoming lines and the neutral.

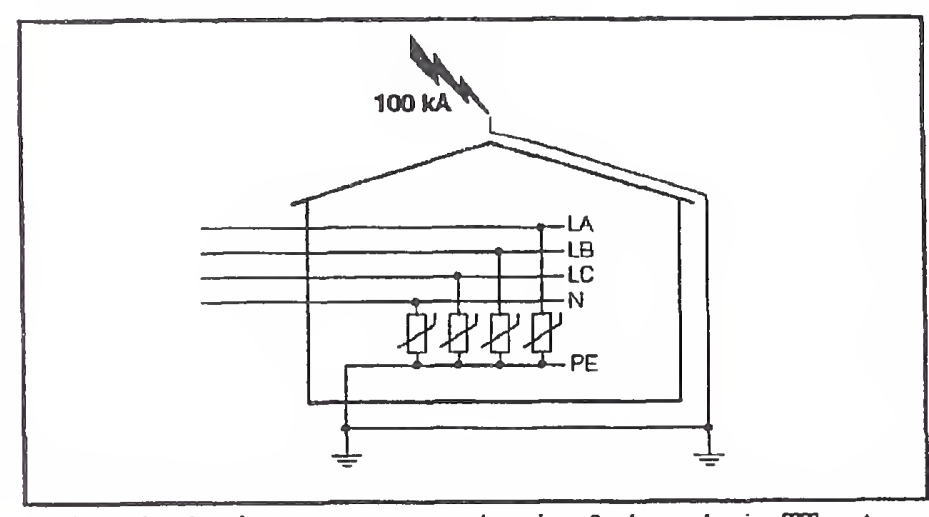

Figure 2 - Service entrance connections in a 3-phase, 4-wire TT system 


\section{E. Postulated lightning stroke current}

While some authors propose a $200 \mathrm{kA}, 10 / 350 \mu$ s surge [8], [9], others suggest that even a $100 \mathrm{kA}$ peak might already be too high a value [6], [10], [11]. In agreement with the latter three references, we postulated a $100 \mathrm{kA}$ peak, $10 / 350 \mu$ surge current. This selection also offers the convenience that when we report current levels in kiloamperes in the various circuits, the numbers also represent the percentage of the sharing, making it easier to follow the process. Since many standards for surges impinging on SPDs (at the service entrance) are still based on an $8 / 20 \mu$ s current waveform, we will also show one example of the energy deposition in the SPDs when such an $8 / 20 \mu$ s surge is postulated.

The surge currents are modeled using the EMTP Type 60 Slave Source. Using the "Freeform FORTRAN" expression, any surge current waveform that can be expressed as a closedform equation can be used as signal source in the main EMTP program. The equations for the $10 / 350 \mu$ s and $8 / 20 \mu$ s waveforms with a $100 \mathrm{kA}$ peak are respectively (1) and (2) below:

$10 / 350 \mu s: \quad I(t)=\left[I_{p} / \eta\right]\left[\exp \left(-t / \tau_{\nu}\right)-\exp \left(-t / \tau_{2}\right)\right]$

$$
\text { where } \begin{aligned}
I_{p} & =100 \mathrm{kA} \\
\eta & =0.9542 \\
\tau_{1} & =480 \\
\tau_{2} & =4
\end{aligned}
$$

$8 / 20 \mu s: \quad I(t)=A I_{p} t^{3} \exp (-t / \tau)$

$$
\text { where } \begin{aligned}
I_{p} & =100 \mathrm{kA} \\
A & =0.01243 \\
\tau & =3.911
\end{aligned}
$$

(In both equations, $t$ and $\tau^{3} \mathrm{~s}$ are in $\mu \mathrm{s} ; 1(t)$ is in same units as $I_{p}$ )

\section{F. Influence of Distribution Transformer Simplification}

The presence of distribution transformers has been included in many models in the literature, but their characteristics are not the same among authors. Some authors have used a coupled inductor with parasitic capacitor to represent the inter-winding capacitor in the transformer model [12].

While these models are more accurate in studying transformer failure modes due to low-side surges, for our main focus which is current dispersion among available paths, we have chosen the simple model postulated in [8] of a simple inductor to represent the winding. As results show, the presence of a transformer at the far end of a daisy-chain lowvoltage distribution system does not have considerable effect on the results. Therefore, we felt justified in adopting the same transformer model as described in [8] for all of our circuit configurations.

\section{G. Simplifying the Circuit for Modeling}

The circuit impedances have been modeled in EMTP using discrete components. The wiring between buildings and from building to transformer is modeled as a series inductance with the following parameters: $\mathrm{R}=1 \mathrm{~m} \Omega / \mathrm{m}$ and $\mathrm{L}=1 \mu \mathrm{H} / \mathrm{m}$, typical values for aluminum conductors of $34 \mathrm{~mm}^{2}$ cross section (\#2 AWG) [13]. The SPDs are modeled using the EMTP Type 92 Nonlinear Element model. Because of the simplified nature of the model, we performed parametric variations on factors such as line impedance and transformer inductance, and found that their influence on current dispersion is not large enough to warrant concern on the somewhat arbitrary values we have postulated in the baseline scenario.

\section{MODELING RESULTS}

In this section, we present selected results of EMTP runs for each of three TN or TT system configurations with points of lightning termination next to the distribution transformer ("first" case) or at the opposite end of the transformer ("last" case), for a total of seven scenarios. We postulated a separation of $100 \mathrm{~m}$ between buildings and $20 \mathrm{~m}$ from the transformer.

For each scenario, a pair of figures is given. The first figure of each pair is a schematic showing the configuration and point of stroke, together with indications of the peak current values in the circuit branches. The second figure of each pair shows selected current waveforms, generally currents leaving the house by way of the earthing electrode and the service conductors. Note that the peaks can occur at different times so that the sum of peak branch currents shown on the figures, Kirkhoff notwithstanding, is not always exactly zero.

\section{A. TN-Radial, strike on one of the buildings}

A distribution transformer supplies three buildings in a radial arrangement where all the service drops originate at the pole where the transformer is installed (Figure 3). This configuration is a typical U.S. residential configuration. The lightning stroke is postulated to terminate on the earthing system of one of the three buildings. Figure 4 shows the current waveforms.

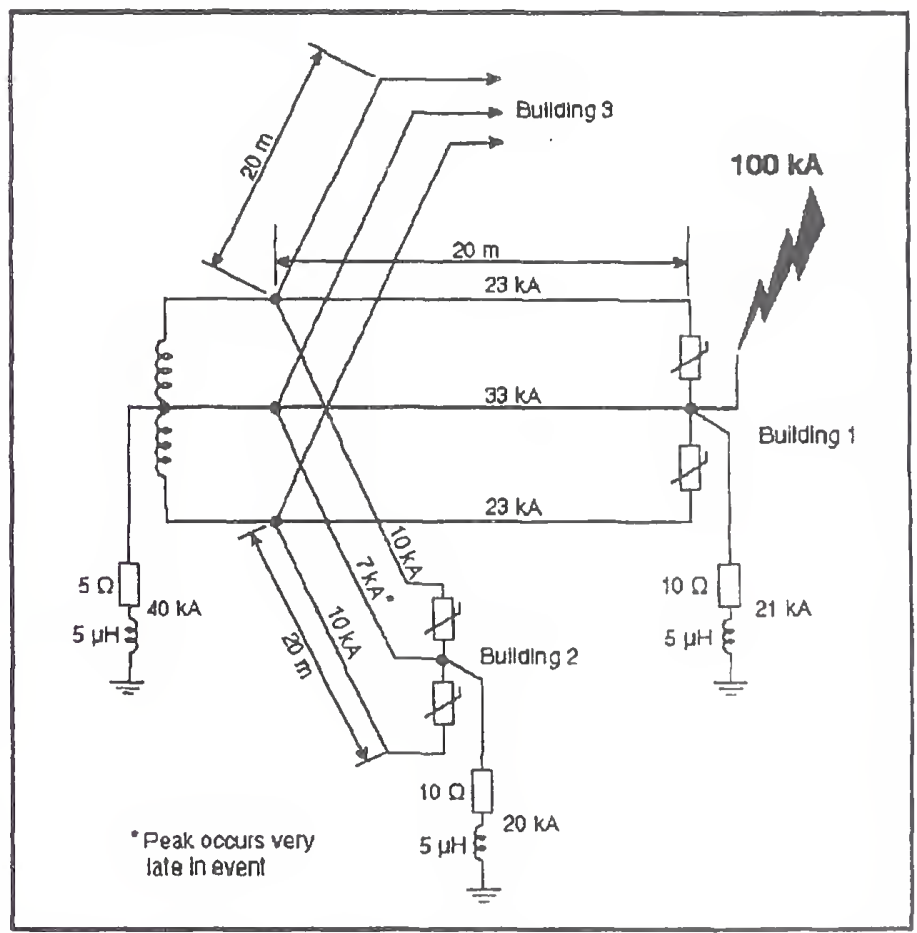

Figure 3 - Radial TN configuration with three buildings supplied by one distribution transformer, one building struck by a 10/350 $\mu \mathrm{s}, 100 \mathrm{kA}$ surge, showing peak values of currents shared among available paths. 


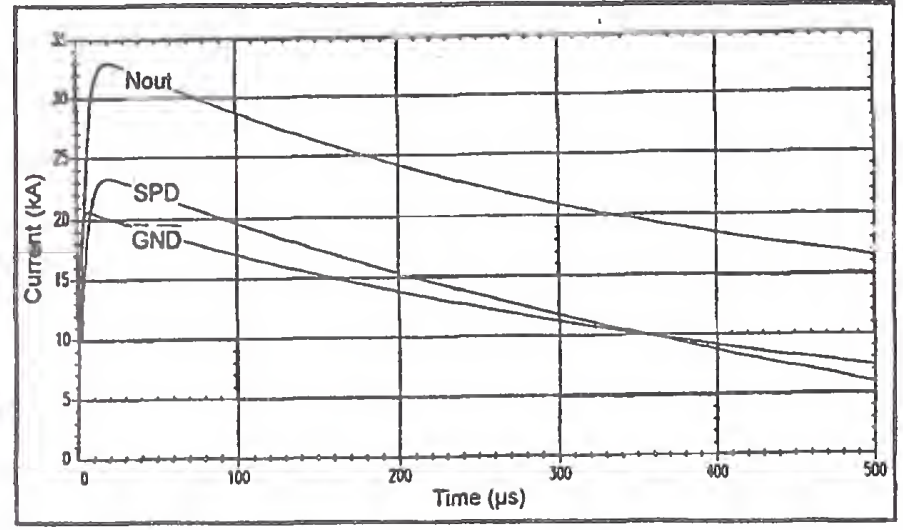

SPD - Current into each line of service drop, through SPDs

GND - Current into local bullding earth electrode

Nout - Current into neutral conductor of service drop

Figure 4 - Waveforms of currents leaving Building 1, as defined in Figure 3 , for a $100 \mathrm{kA}, 10 / 350 \mu$ s surge terminating on the building earthing system

\section{B. TN-Daisy chain, strike on first building}

Another typical arrangement uses a distribution transformer which supplies several buildings along a street, with short service drops from the polles to each building. The lightning stroke is postulated to occur upon the first building, next to the transformer. Figure 5 shows the circuit configuration and the peak currents in the branches; Figure 6 shows the waveforms of the currents leaving the building. Note the early peak of the current in the neutral -- directly connected to earth at the pole, thus a lower inductance compared with the inductance of the line conductors that include the transformer winding.

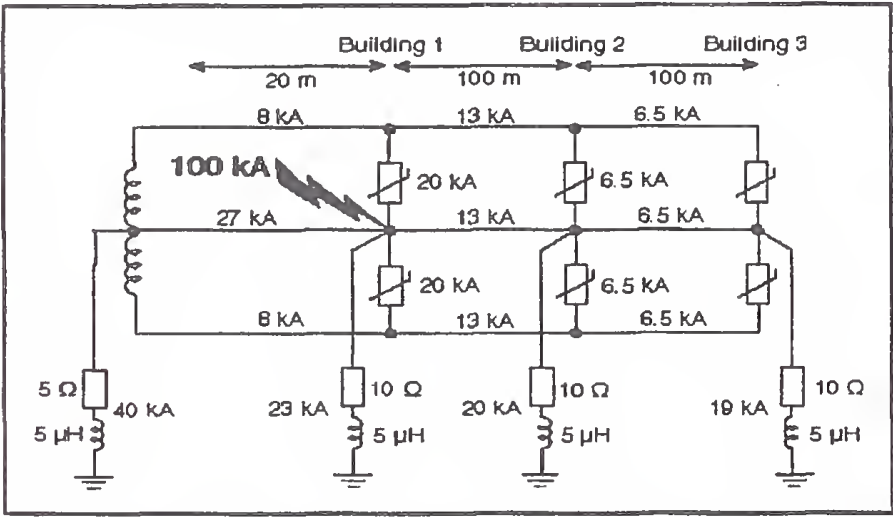

Figure 5 - Daisy chain TN configuration with building next to transformer struck by a $10 / 350 \mu \mathrm{s}, 100 \mathrm{kA}$ surge, showing peak values of currents

\section{TN-Daisy chain, strike on last building}

This is the same configuration as $\mathrm{B}$, but the building being struck is at the opposite end (Figure 7). The difference, if any, would give insight on the relative importance of modeling the presence of a specific transformer. In fact, the difference in the SPD stress for a strike on the first building $(20 \mathrm{kA})$ compared with a strike on the last building ( $26 \mathrm{kA})$ is small, showing the small effect of transformer position. In the building earthing, where there are no SPDs, a strike on the last building produces $42 \mathrm{kA}$ compared with $23 \mathrm{kA}$ for a strike on the first building.

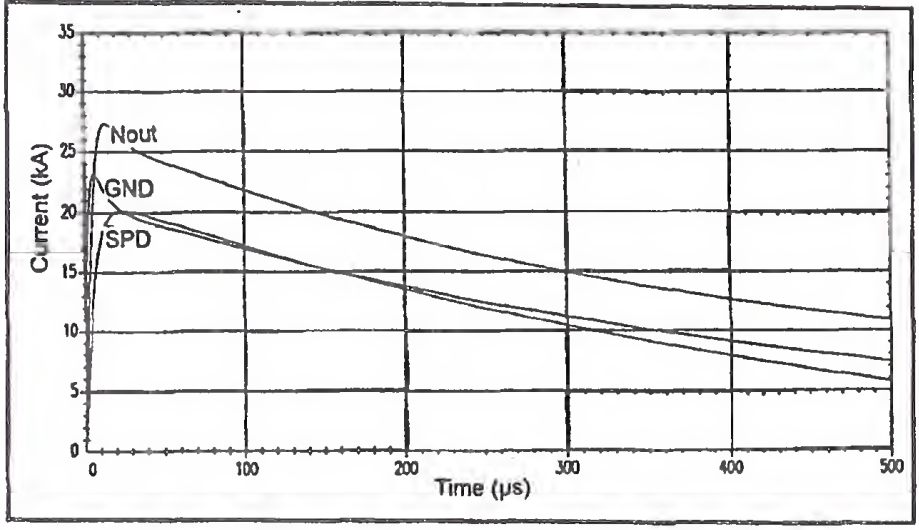

SPD - Current into each line of service drop, through SPDs GND - Current into local building earth electrode

Nout - Current into neutral conductor toward the transformer earth

Figure 6 - Waveforms of currents leaving Building 1, as defined in Figure 5, for a $100 \mathrm{kA}, 10 / 350 \mu$ s surge terminating on the building earthing system

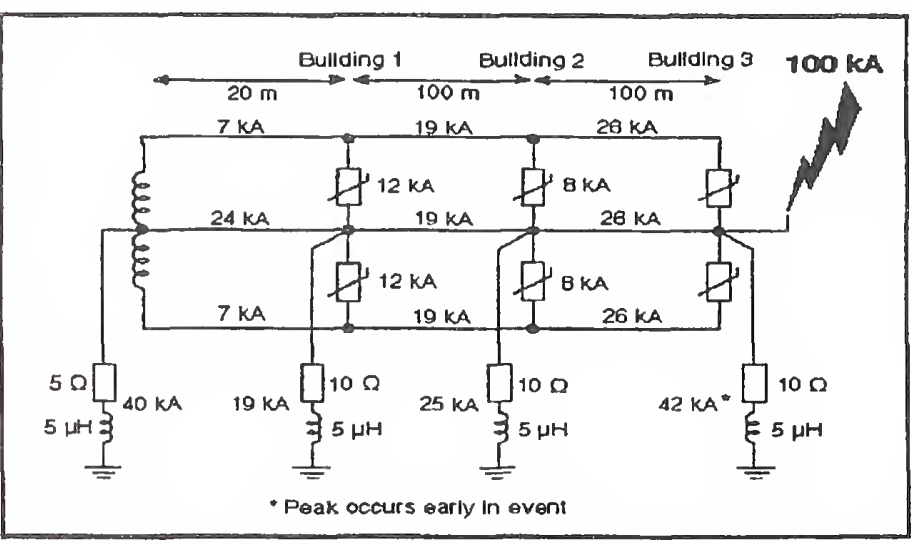

Figure 7 - Daisy chain TN configuration with building at opposite end of transformer struck by a $10 / 350 \mu \mathrm{s}, 100 \mathrm{kA}$ surge, showing peak currents

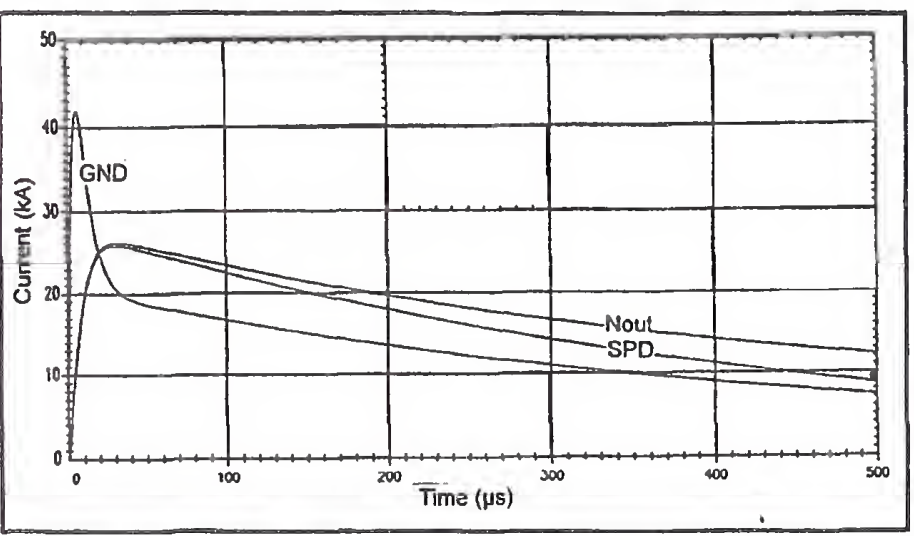

SPD - Current into each line of service drop, through SPDs

GND - Current into local building earth electrode

Nout - Current into neutral conductor toward the transformer earth

Figure 8 - Waveforms of currents leaving Building 3, as defined in Figure 7 , for a $100 \mathrm{kA}, 10 / 350 \mu \mathrm{s}$ surge terminating on the building earthing system

For Figures 7-8, the greater distance (inductance) from the transformer earth electrode forces initially more current flow in the building earth than in Figures 5-6 for a closer transformer. 
TABLE 1

SUMMARY OF CURRENT SHARING AMONG CONDUCTORS FOR THREE CONFIGURATIONS IN SEVEN SCENARIOS FOR I00 KA STROKE

\begin{tabular}{|c|c|c|c|c|c|c|c|c|}
\hline \multirow{2}{*}{$\begin{array}{l}\text { Configuration: } \\
\text { Distribution } \\
\text { system }\end{array}$} & \multirow[t]{2}{*}{$\begin{array}{l}\text { Scenario: } \\
\text { Building } \\
\text { being } \\
\text { struck }\end{array}$} & \multirow[t]{2}{*}{$\begin{array}{c}\text { See } \\
\text { figures }\end{array}$} & \multicolumn{4}{|c|}{$\begin{array}{l}\text { Most severe but rare - Building being directly struck } \\
\text { Currents leaving building via building earthing } \\
\text { and service conductors (peak kA or \%) * }\end{array}$} & \multicolumn{2}{|c|}{$\begin{array}{l}\text { Less severe but more frequent } \\
\text { Currents impinging onto } \\
\text { adjacent buildings (peak kA or \%) }\end{array}$} \\
\hline & & & $\begin{array}{l}\text { Building } \\
\text { earthing }\end{array}$ & $\begin{array}{l}\text { Service } \\
\text { neutral }\end{array}$ & $\begin{array}{l}\text { SPD in } \\
\text { the neutral }\end{array}$ & $\begin{array}{l}\text { SPD in } \\
\text { the lines }\end{array}$ & $\begin{array}{l}\text { SPD in } \\
\text { the neutral }\end{array}$ & $\begin{array}{l}\text { SPD in } \\
\text { the lines }\end{array}$ \\
\hline TN Radial & Any & $3-4$ & 21 & 33 & $\mathrm{~N} / \mathrm{A}$ & $23 \times 2$ & N/A & $10 \times 2$ \\
\hline $\begin{array}{l}\text { TN Daisy } \\
\text { TN Daisy }\end{array}$ & $\begin{array}{l}\text { First } \\
\text { Last }\end{array}$ & $\begin{array}{l}5-6 \\
7-8\end{array}$ & $\begin{array}{l}23 \\
42\end{array}$ & $\begin{array}{l}27 \\
26\end{array}$ & $\begin{array}{l}\text { N/A } \\
\text { N/A }\end{array}$ & $\begin{array}{l}20 \times 2 \\
26 \times 2\end{array}$ & $\begin{array}{l}\text { N/A } \\
\text { N/A }\end{array}$ & $\begin{array}{l}7 \times 2 \\
8 \times 2\end{array}$ \\
\hline $\begin{array}{l}\text { TT 2-wire } \\
\text { TT 2-wire }\end{array}$ & $\begin{array}{l}\text { First } \\
\text { Last }\end{array}$ & $\begin{array}{r}9-10 \\
11-12\end{array}$ & $\begin{array}{l}26 \\
48\end{array}$ & $\begin{array}{l}\text { N/A } \\
\text { N/A }\end{array}$ & $\begin{array}{l}51 \\
38\end{array}$ & $\begin{array}{l}28 \times 1 \\
38 \times 1\end{array}$ & $\begin{array}{l}10 \\
13\end{array}$ & $\begin{array}{l}10 \times 1 \\
13 \times 1\end{array}$ \\
\hline $\begin{array}{l}\text { TT 4-wire } \\
\text { TT 4-wire }\end{array}$ & $\begin{array}{l}\text { First } \\
\text { Last }\end{array}$ & -- & $\begin{array}{l}22 \\
38\end{array}$ & $\begin{array}{l}\text { N/A } \\
\text { N/A }\end{array}$ & $\begin{array}{l}32 \\
20\end{array}$ & $\begin{array}{l}16 \times 3 \\
20 \times 3\end{array}$ & $\begin{array}{l}5 \\
6\end{array}$ & $\begin{array}{l}5 \times 3 \\
5 \times 3\end{array}$ \\
\hline
\end{tabular}

* Peak values do not occur at the same time in the different paths so that totals of numbers shown may be more than the impinging $100 \mathrm{kA}$ peak.

\section{ENERGY CONSIDERATIONS}

In the model parameters, to start the iterative process, we have postulated that the SPD consists of a metal-oxide varistor (MOV) with relatively large cross-section that might be capable of absorbing the energy involved in diverting the $10 / 350 \mu \mathrm{s}$ surge. For the TN configurations, we selected a $150 \mathrm{~V}$ rms rating, and a $300 \mathrm{~V}$ rms rating for the TT configurations. For the cross section, we postulated an area equal to ten $20-\mathrm{mm}$ discs in parallel because available manufacturer's data [14] readily gives the $20-\mathrm{mm}$ disc characteristic. Such a combination would have a total one-shot joule rating of 800 joules for a $10 / 1000 \mu$ s surge in the $150 \mathrm{~V}$ rating.

Because we suspect that even this array of ten discs might not be capable of dissipating the energy involved in a $10 / 350 \mu \mathrm{s}$ surge, the next step in this iterative process is then to compute the energy that would be deposited in the SPDs, under the current distribution patterns computed in the seven scenarios.

As one example, Table 2 shows the energy deposited in the MOVs, computed for the case of the TN Radial configuration where one SPD is connected between each of the two lines and the earth point of the installation (Figure 3). Two waveforms are shown in the table, the $10 / 350 \mu$ s and the $8 / 20 \mu$ s surges.

TABLE 2

ENERGY DEPOSITION IN SERVICE ENTRANCE MOVS FOR THE TN RADIAL CONFIGURATION AND TWO WAVEFORMS

\begin{tabular}{cccc}
\hline \multirow{2}{*}{ Waveform } & $\begin{array}{c}\text { Rating for ten } \\
20-\mathrm{mm} \text { discs }\end{array}$ & \multicolumn{2}{c}{ Energy deposition } \\
\cline { 3 - 4 } & $800 \mathrm{~J}$ & Direct strike & Nearby strike \\
\hline $10 / 350 \mu \mathrm{s}$ & $800 \mathrm{~J}$ & $200 \mathrm{~J}$ & $840 \mathrm{~J}$ \\
\hline $8 / 20 \mu \mathrm{s}$ & $200 \mathrm{~J}$ & $80 \mathrm{~J}$ \\
\hline
\end{tabular}

For the $10 / 350 \mu$ s waveform, the rare scenario of a direct strike (energy deposited is $3500 \mathrm{~J}$ ) would require a very large varistor at the service entrance -- four times the ten discs we postulated, while this ten-disc array would be sufficient in the less rare scenario of a nearby strike $(840 \mathrm{~J})$.

On the other hand, if we were to stay with the $8 / 20 \mu$ s as a postulated waveform, even the large $100 \mathrm{kA}$ peak would be handled with comfortable margin by the ten-disc array. These results provide quantitative data which we will discuss further under the Cost/Risk heading.

\section{PARAMETRIC VARIATIONS}

We performed several parametric variations for the purpose of exploring the typical "what if" questions, and also to show whether or not our postulated values might be viewed as too arbitrary because of their influence on the results.

\section{A. Line impedance and building separation}

The value of $1 \mu \mathrm{H} / \mathrm{m}$ for conductors has long been used by many researchers as a typical value. To investigate the significance of that postulated $1 \mu \mathrm{H} / \mathrm{m}$ combined with the 100 . $\mathrm{m}$ separation, we ran two cases, one with half the value and one with double the value. The first case corresponds to either half the separation for the same unit impedance or half the unit impedance with the same separation. For the second case, one of the parameters is doubled while the other is held constant. Table 3 shows a comparison of the baseline case with these two parametric variations.

TABLE 3

EFFECT OF LINE IMPEDANCE ON SHARING - TN DAISY LAST

\begin{tabular}{lccc}
\hline Percent of $100 \mathrm{kA}$ peak & $\begin{array}{c}\text { Baseline } \\
100 \mathrm{~m}, 1 \mu \mathrm{H} / \mathrm{m}\end{array}$ & $\begin{array}{c}\text { Half } \\
\text { baseline }\end{array}$ & $\begin{array}{c}\text { Double } \\
\text { baseline }\end{array}$ \\
\hline Current into building earthing & 42 & 32 & 53 \\
\hline Current in service neutral & 26 & 27 & 25 \\
\hline Current in SPDs & 26 & 26 & 25 \\
\hline
\end{tabular}

This comparison shows no significant differences in the current sharing for each of the three available conductors (there are two line conductors, each with an SPD) when the postulated unit impedance or building separation is varied over a 1:4 range, so that our selection for these two parameters should not be a matter of concern.

\section{B. Transformer pole earthing resistance and building earthing system resistance}

By their relationship, these parameters can be expected to have an influence on the outcome. In the baseline case, we postulated a $5-\Omega$ pole earthing resistance and a $10-\Omega$ building earthing resistance. Table 4 shows the comparison of the baseline case with the reversed relationship between the pole earthing resistance and the building earthing resistance. 
TABLE 4

EFFECT OF POLE EARTHING/BUILDING EARTHING - TN RADIAL

\begin{tabular}{lcc}
\hline Percent of $100 \mathrm{kA}$ peak & $\begin{array}{c}\text { Baseline } \\
5-\Omega \text { pole, } 10-\Omega \text { bldg. }\end{array}$ & $\begin{array}{c}\text { Reverse baseline } \\
10-\Omega \text { pole, } 5-\Omega \text { bldg. }\end{array}$ \\
\hline Current in building earth & $2 \mathrm{I}$ & 31 \\
\hline Current in service earth & 33 & 14 \\
\hline Current in SPD & 23 & 22 \\
\hline
\end{tabular}

Indeed, the relationship of pole versus building earthing resistance has a significant effect on the current carried by the neutral, but not on the current carried by the SPDs. This is particularly true, although not obvious in the table (where only the peak values are shown, reflecting the inductive effect on initial current dispersion), for the tail of the 10/350 $\mu \mathrm{s}$ waveform where the subsequent sharing is determined by the resistance ratios [6], [12].

\section{Length of circuit (more buildings along a street)}

Postulating a greater number of buildings along the daisy chain, while keeping the resistance of the building earthing constant, can be expected to offer a path of lesser impedance to the currents exiting the building, because of the greater number of available earth electrodes. Table 5 shows the effect of going from 3 buildings (baseline) to 9 buildings, still with the last building being struck.

TABLE 5

EFFECT OF NUMBER OF BUILDINGS IN TN CIRCUIT ON SHARING, DISTANT HOUSE STRUCK

\begin{tabular}{lcc}
\hline Percent of $100 \mathrm{kA}$ peak & Baseline 3 buildings & 9 buildings \\
\hline Current in building earth & 42 & 42 \\
\hline Current in service earth & 39 & 14 \\
\hline Current in SPD & 26 & 27 \\
\hline
\end{tabular}

Again in this case, a difference is noticeable in the neutral conductor current, but not in the SPD current. Thus, this parametric variation shows that the number of buildings between the building being struck and the distribution transformer, while affecting the neutral current, does not affect the stress imposed on the SPDs in this TN configuration.

\section{DISCUSSION}

\section{A. Effect of postulated waveform}

While we have adopted for our baseline the $10 / 350 \mu$ s waveform, many SPD standards cite an $8 / 20 \mu \mathrm{s}$ or a $4 / 10 \mu \mathrm{s}$ surge waveform as an SPD capability requirement [15], [16] or as a surge environment description [17]. To explore the effect on sharing of the stroke current with different waveforms, in particular during the initial part of the $10 / 350 \mu$ s surge where inductive effects dominate for the circuit parameters selected, we made one run with a $8 / 20 \mu$ s surge instead of the $10 / 350 \mu \mathrm{s}$ used in the baseline case of the TN Radial. Predictably, given the small difference between a $10 \mu$ s and an $8 \mu$ sise time, little effect was noted in the sharing during the first $20 \mu \mathrm{s}$. Of course, the energy involved for the total surge duration is another matter, already discussed in Section V.

\section{B. Selection of SPDs}

If the design objective is to provide protection for a direct stroke to the building (a topic which will be the subject of the cost/risk analysis mentioned below), the SPDs must be selected with sufficient current-handling capability to survive the surges resulting from the postulated surge.

Alternate proposals have been made to use a spark gap as service entrance SPD. Such a gap must then be capable of clearing the resulting follow current, which may be an issue for systems having a large available fault current, such as the $10 \mathrm{kA}$ rms specified for U.S. installations [3], [18].

We have made one run with a spark gap model instead of a varistor model. From the sharing point of view, the difference is small, which can be readily explained by the fact that inserting in the lightning current paths a varistor with a limiting voltage of $1 \mathrm{kV}$ or so, or a gap with an arc voltage of $100 \mathrm{~V}$ or so, should have a very small effect on the sharing because of the many kilovolts developed by the lightning current flowing in the inductances and resistances of the line conductors and earthing connections.

\section{Cosi/Risk Analysis}

An essential aspect of designing an effective surge protection system is to perform a cost/risk analysis involving the probability of a building being struck by a large surge, such as $100 \mathrm{kA}$, versus the cost of ensuring survival of the service entrance SPDs to be installed. This analysis introduces factors such as the flash density in the locale, the randomness of the distribution of the flashes over the area of attraction of the building which depends in part on the height of the building, and the distribution of peak amplitudes of lightning strokes. For instance, [11] reports statistics [19] whereby an $80 \mathrm{kA}$ amplitude is exceeded for less than $5 \%$ of the strokes. Such an analysis is beyond the scope of our paper, but it must be mentioned here to keep the situation in perspective and remind developers of SPD application guides or standards to include it in their recommendations.

\section{Applying field experience to standards}

The ultimate test of the usefulness of a standard is that equipment manufactured according to that standard has satisfactory field experience, while being produced at a cost that users are willing to accept. Very low field failure rates can be seen as overdesign, high failure rates obviously as underdesign. It is the dream of one of the authors to establish a clearinghouse where field experience of manufacturers could be collected and applied to optimize the definition of the environmental stress [20]. Given the competitive nature of the industry, this is likely to remain only a dream. However, many U.S. utilities are now offering to their customers the installation of a meter-base adapter SPD. The field experience for these SPDs might be collected from utilities -- with safeguards on proprietary information -- and become an input to the process of moderating some proposals for high-stress requirements, on the basis of the successful field experience of SPDs with capabilities below those implied in proposed standards. 


\section{CONCLUSIONS}

Modeling several typical TN and TT configurations of neutral earthing practices and scenarios of lightning strike point provides insights on significant effects, which should lead to more effective application of surge-protective devices (SPDs).

1. A direct lightning stroke to a building can produce high stresses on the service entrance SPDs as the earth-seeking current will exit in part by way of the utility service drop. SPDs in that building will be strongly affected, while nearby buildings will be impacted by much lower surge currents.

2. The major difference among the scenarios we have modeled appears in the current carried away from the building by the neutral conductor.

- In a TN system where the neutral is bonded to earth at the service entrance, there is no SPD in that path, and thus no concern about neutral SPD integrity. In typical residential single-phase U.S. systems, the line SPDs can carry about $25 \%$ of the stroke current.

- In a TT system where there is an SPD in the neutral path, a single-phase two-wire configuration can have $50 \%$ of the stroke current being carried by the neutral SPD. In a three-phase TT system where there are four conductors to carry away the stroke current, the neutral SPD can carry up to $30 \%$ of the stroke current.

3. For line conductors, the difference reflects primarily the total number of conductors in the system, which can be two, three or four. The earth-seeking lightning current will divide (but not always equally) among these conductors. While the initial dispersion (during the first $20 \mu \mathrm{s}$ ) is controlled by the inductances, the later dispersion is controlled by the relative values of the earthing resistances.

4. If the postulated stroke is as high as some of the proposed standards suggest, modeling the behavior of service entrance SPDs of the type installed in increasing numbers by U.S. utilities shows that some failures could be expected. As field experience seems to indicate an acceptable failure (if any) rate, one can question the need for imposing such severe requirements, unless the mission of the facility is such that even a rare failure would be unacceptable.

\section{ACKNOWLEDGMENTS}

Support and encouragement for this work was provided by the parent organization of each author. Additional support was received from Delmarva Power Company, from Pacific Gas \& Electric Company, and from PECO Energy Company. Gerald FitzPatrick and Roger Witt contributed comments on the draft.

\section{REFERENCES}

[1] EPRI, "Electromagnetic Transient Program (EMTP), Version 2.0; Volume 1: Main Program: Volume 2: Auxiliary Routines, EPRI Report EL-642I-L, July 1989.

[2] IEC International Standard 364-1, Electrical Installations of Buildings Part 1: Scope, Object and Fundamental Principles, 1992.

[3] NFPA 70, National Electrical Code, 1996.
[4] Martzloff, F.D., Mansoor, A., Phipps, K.O., and Grady, W.M., "Surging the Upside-Down House: Measurements and Modeling Results," Proceedings, EPRI PQA'95 Conference, 1995.

[5] Mansoor, A. and Martzloff, F.D., "Driving High Surge Currents into Long Cables: More Begets Less," Paper 96 SM399-6 PWRD, 1EEE PES Summer Meeting, Denver CO, 1996.

[6] Rakotomalala, A., Auriol, Ph., and Rousseau, A., "Lightning Distribution Through Earthing System." Symposium Record, IEEE International Symposium on EMC, Chicago IL, USA, August 1994, pp 419-423.

[7] Lai, J.S. and Martzloff, F.D., "Coordinating Cascaded Surge Protection Devices: High-Low versus Low-High," IEEE Transactions IA-29 No.4, July/August 1993, pp 680-687.

[8] Birkl, J., Hasse, P., and Zahlmann, P., "Systemgerechter Einsatz von Ableitern in Niederspannungsnetzen," Elektrotechnische Zeitschrift No.17, 1994, pp 964-971

[9] Flisowski, Z., and Mazzetti, C., "Efficiency of Lightning Protection System as Screening Measure Against LEMP," Proceedings, EMC'96 ROMA, September 1996.

[10] Darveniza, M., Sargent, Limbourn, Liew, Caldwell, Currie, Holcombe, Stillman \& Frowd, "Modelling for Lightning Performance Calculations" IEEE Transactions $P A S-98$, No.6, Nov/Dec 1979, pp 1900-1908.

[11] Kirder, E.P. and Uman, M.A., "Cloud-to-Ground Lightning Mechanisms of Damage and Methods of Protection," Seminars in Neurology, Vol.15, No.3, September 1995.

[12] Dugan, R.C. and Smith, S.D., "Low-Voltage-Side Current-Surge Phenomena in a Single-Phase Distribution Transformer System," IEEE Transactions PWRD-13, No. 2, April 1988.

[13] Steigerwald, R.L., Ferraro, A., and Tompkins, R.E, "Investigation of a Family of Power Conditioners Integrated into the Utility Grid," Sandia Report SAND81-7031, 1981, page 20.

[14] Transient Voltage Suppression Devices, Harris Corp., 1991.

[15] ANSI/IEEE C62.11-1991, IEEE Standard for Metal-Oxide Surge Arresters for $A C$ Power Circuits.

[16] ANSI/AEEE C62.34-1996, IEEE Standard for Performance of LowVoltage Surge-Protective Devices (Secondary Arresters).

[17] ANSI/nEEE C62.41-1991, IEEE Recommended Practice on Surge Voltages in Low-Voltage AC Power Circuits.

[18] UL Std. 1449, Transient Voltage Surge Suppressors, 1996.

[19] Berger, K., Anderson, R.B., and Kroninger, H., "Parameters of Lightning Flashes," Electra, 1975-80, pp 1548-1565

[20] Martzloff, F.D., "Keeping up with the Reality of Today's Surge Environment," Power Quality Solutions, September 1995 Proceedings, pp 243-249.

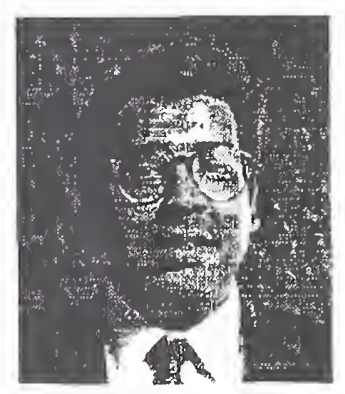

Arshad Mansoor (M' 1995) is an Electrical Systems Engineer at the EPRI Power Electronics Applications Center (PEAC). He received his MS and Ph.D. in electrical engineering from the University of Texas, Austin in 1992 and 1994 respectively. His areas of interest include Power Quality, power systems transients analysis, harmonics, surge propagation and protection, and EMTP model development.

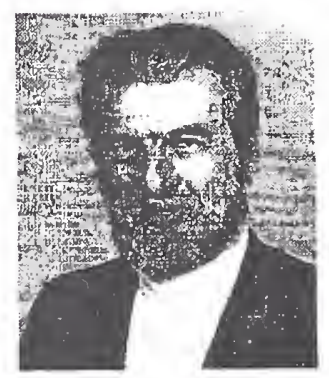

François Martzloff (M'1956, F'1983) Born and educated in France, with additional MS degrees from Georgia Tech and Union College, worked at General Electric for 29 years and now 12 years at the National Institute of Standards and Technology. He is contributing to severa committees for the development of standards on EMC, surge protection and Power Quality in the IEEE and the IEC. 


\section{Discussion}

P. Hasse and J. Birkl (Dehn + Sơhne, 92318 Neumarkt, Germany): The problem of lightning current distribution depending on the different kinds of current distribution systems and under the influence of possible variables has been very clearly represented with this contribution.

The curve development gained by the EMTP program matches very well with the simulation calculations conducted in Germany with the PSPICE program.

In respect to the described results, however, a few additions are necessary from our point of view:

\section{Section III. G. and VI. A.:}

The induction of a conductor system always results out of the geometric system of the slip-knot consisting of coming and going conductor. A separation in coming conductor impedance and going conductor impedance is not realistic.

In particular, in case of multiple conductor cables it is to be observed that in case of the same flow direction of the lightning current, the inductivity of the total system differentiates to a single conductor system.

\section{Section VI. Schedules 3 - 5:}

In particular, in case of longer connecting cables between buildings and between building and transformer a change in waveform of the surge flowing through these cables. Only the observance of the amplitude factor of the flowing lightning currents is not sufficient. In this situation, it would be more meaningful to consider also the energy distribution.

\section{Section VII. B.:}

For decades now, in Europe, spark gap arresters, with a mains follow current quenching capability, are being installed successfully as lightning current arresters at the building entrance. In particular, the high down-lead ability and impulse-time shortening of the rest impulse make a favourable co-ordination with connecting MOV's possible.

\section{Section VII. 4:}

The lightning protection necessity for a system, as well as the deduced lightning protection class resulting from this, is described in IEC 1662. At the same time the lightning protection class is determined, the layout of the lightning protection system necessary lightning parameters are defined (IEC 1312-1). A deviating layout of protection measures on the basis of test currents $8 / 20 \mu \mathrm{s}$ is therefore not permissible.

Manuscript received November 3, 1997.
François D. Martzloff (National Institute of Standards and Technology, Gaithersburg MD) :

We thank the two authors of the discussion for taking the time to review our paper and provide comments aimed at broadening the consensus on the subject. In particular, we are delighted to hear that our computations based on EMTP matches very well with the simulation calculations conducted in Germany with the PSPICE program. With respect to their specific four comments, we offer the following responses, preceded by the general remark that the purpose of our computations was to reveal the differences among various postulates for the circuit configurations, as influenced by the grounding practices for the neutral in effect in different countries, rather than the precise values for a particular set of parameters. We emphasize the concept of postulate, lest we fall into the trap of taking electromagnetic environment standards as an exact duplication of reality, while they are in fact only the documentation of an industry consensus on how reality might be represented ${ }^{1}$.

\section{Section II G and IV A}

Indeed, the concept of inductance is based on a conductive loop that carries the current in a closed circuit. However, in the circuits we postulated for our computations, the conductors in question - phase and neutral - may be considered as one part of the closed circuit and might be called "coming," according to the terminology used by our colleagues, while the path consisting of the earth, the distant return to the cloud, the lightning channel, and even the down-conductor (see Section III A) may be considered as the other part of the loop and might be called "going" conductors.

For this reason, we represented in our figures the phase and neutral as if they were separate, while in reality they can be at some finite distance from each other (the so-called "open wiring" used in overhead lines) or in close vicinity, as in the case of an underground cable or an overhead "triplex." Aware of the differences, we started our computations for a given, postulated configuration - always the same for the variations in the neutral grounding - but performed a parametric variation in the line inductance (taking twice or half the value used in the baseline), as stated in the subject paragraph, to convince ourselves that the influence on dispersion is not large enough to cause concern. Space limitations for the paper prevented us from providing detailed numerical results - as they also do here - and we were hoping that our simple statement that we did consider the issue and found little effect on the differences among neutral grounding scenarios might be acceptable.

\section{Section VI 3 to 5}

One of the results of our computations based on a postulated $10 / 350 \mu$ s waveform was to show that, for the distances we selected, the impedance of the cable between buildings - and therefore their length - has only a small influence on the longterm current waveform and dispersion among conductors, which is primarily influenced by the postulated values for respective earthing resistances. With the values selected for inductances, 
the current dispersion is substantially affected by the respective inductances only for the first 20 or $30 \mu \mathrm{s}$.

We agree that additional information might be conveyed by reporting the energy distribution along the complex path of the lightning current, but here again space limitations intervene. We can offer the response, however, that in view of the large values of the earthing resistance compared to the other resistances in the circuit - cable resistances and dynamic "resistances" of the varistor or gap SPDs - the latter are not a priority in reporting results. The EMTP model of course has the capability of reporting any set of parameters if "asked" to do so.

For specific applications of one type or another of SPD technology, the EMTP model can provide detailed information on the energy that will be deposited in these SPDs for the various scenarios to be considered.

\section{Section VII B}

We are aware that in some countries, the installation of a service-entrance arrester is a common practice, and that gapped arresters may be used for that purpose. The issue is one of cost vs. benefits for an arrester designed for the large lightning currents associated with a rare direct strike to the building. We have observed, during our interactions with several international or IEEE technical committees, that consensus has not been reached on what current waveform and peak amplitudes should be considered when making the cost vs. benefits analysis. Depending on the nature of the installation, the cost vs. benefits equations are different. Several proposals for "risk analysis" are currently under consideration in several standards-developing bodies, and consensus is clearly not achieved at this point. This lingering question is addressed in our response to the fourth and last comment after the present one.

Our intention in making the remark on available fault current in the second paragraph of this section was not to contest the successful European experience cited by our colleagues, but to alert our readers at large to the importance of considering that requirement. The point that mains follow-current quenching capability is not trivial was confirmed in a comment by one of the reviewers of our forthcoming paper, "Gapped Arresters
Revisited" (scheduled for presentation at the IEEE-PES Winter 1998 Meeting and later publication in IEEE Transactions).

\section{Section VII 4}

We are aware of the work conducted in the IEC Technical Committee 81, the responsible body for development of the IEC 61662 and JEC 61312 publications. We are also aware of some discomfort among other parties concerning the stipulations from that body which might result in less than fully cost-effective solutions to the question of real necessity for protection against worst-case scenarios. The footnote offered in support of our introductory remark applies here also. There is a long and successful history of application of surge-protective devices based on a postulated $8 / 20 \mu$ s surge current waveform, using the appropriate values of amplitudes. For that reason, we included in our paper as alternate postulate the $8 / 20 \mu \mathrm{s}$.waveform. From the point of view of $\mathbb{E C}$ TC 81 , their recommendations might be considered normative and thus non-negotiable, but protection measures in the various countries are typically determined - if at all - by bodies that promulgate codes based on a consensus drawn from experience based not exclusively on TC 81 recommendations. Therefore, the use of the term "not permissible" appears somewhat strong in the context of voluntary or even regulatory practices.

In conclusion, we appreciate the opportunity to present more detailed background information on our computations and underlying postulates, thanks to the discussion contributed by our colleagues.

1. Long ago, my mentor, Frank Fisher, taught me this concept which I recite in the following terms, well worth repeating in the present context: "The criterion of validity of an environment standard is not so much how closely it duplicates reality but rather how well equipment designed in accordance with this standard perform in the field. If equipment designed in accordance with the standard perform well in the field, while equipment ignoring the standard do not perform well, the chances that the standard be a good standard are pretty good."

Manuscript received January 7, 1998. 


\section{The Dilemma of Surge Protection vs. Overvoltage Scenarios: Implications for Low-Voltage Surge-Protective Devices}

\author{
Arshad Mansoor, Member, IEEE \\ Power Electronics Applications Center \\ Knoxville TN 37932 USA \\ Amansoor@epri-peac.com
}

\author{
François Martzloff, Life Fellow, IEEE \\ National Institute of Standards and Technology \\ Gaithersburg MD 20899 USA \\ f.martzloff@ieee.org
}

(c) 1998 IEEE

Reprinted, with permission, from

Proceedings, $8^{\text {th }}$ Annual Conference on Harmonics and Quality of Power, Athens, October 1998

Significance:

Part 2 Development of standards

Part 7 Mitigation techniques

The application of surge-protective devices (SPDs) in low-voltage AC power circuits, in particular metal-oxide varistors (MOVs) has been influenced by the perception that low-limiting voltage is a desirable characteristic. Unfortunately, this low limiting voltage - intended for surge protection - makes the devices more susceptible to fail under conditions of extended temporary overvoltage (TOV).

Like any electronic component, SPDs will fail if overstressed beyond reasonable limits, and this is not a cause for rejecting their application, but a cause for concern on ensuring that the failure mode - rare as it might be - will be acceptable.

This acceptability must also take into consideration the effect of the available fault current that the power system can deliver at the point of connection of the SPD. This point needs to be more clearly and specifically stated in emerging standards on SPD applications. 
$\varnothing$ 


\section{The Dilemma of Surge Protection vs. Overvoltage Scenarios: Implications for Low-Voltage Surge-Protective Devices}

\author{
Arshad Mansoor, Member, IEEE \\ Power Electronics Applications Center \\ Knoxville TN 37932 USA
}

\author{
François Martzloff, Fellow, IEEE \\ National Institute of Standards and Technology* \\ Gaithersburg MD 20899 USA
}

\begin{abstract}
The application of surge-protective devices in lowvoltage systems faces the dilemma of providing effective limiting against surges while not artempting to limit the temporary overvoltages that do occur in a power system. The paper illustrates this dilemma with specific scenarios and presents recommendations for reconciling these two conditions through adequate design and more explicit standands.
\end{abstract}

\section{INTRODUCTION}

The concept of "Whole-House Surge Protection" has become a popular subject of discussion and has in fact been implemented by several utilities in North America. In this approach, the utility will install a surge-protective device (SPD) at the service entrance of the customer and provide additional plug-in SPDs. These additional SPDs are presumed to be well-coordinated with the service-entrance SPD, and are installed within the customer premises, presumably at the point of connection of so-called "sensitive appliances" such as home entertainment, computers, and sophisticated kitchen appliances.

The main purpose of these SPDs is to protect sensitive equipment against surges, a mission that they can accomplish quite well. However, the failure mode of these devices under temporary overvoltages (TOVs) that might be expected under abnormal but possible conditions of the power system has become cause of some concern for utilities and their customers.

An SPD should not be expected to protect downstream equipment in the case of a TOV and then return to normal operation, as it does by definition for surge protection. The dilemma for SPD designers is whether to select a maximum continuous operating voltage ( $\mathrm{MCOV}$ ) high enough to survive common TOVs - but at the price of diminished surge protection - or to select surge protection with a lower MCOV - and then accept failure of the SPD for infrequent but possible TOVs. In any case, one should expoct that if a TOV at any level would cause the SPD to fail, that failure mode should be acceptable.

\footnotetext{
- Electriciry Division, Electronics and Electrical Engineering Laborabory. Technology Administration, U.S. Department of Commerce.
}

Contributions from the Nutionel Instrituse of Standands and Technology are not subject to U.S. copyright.

Paper accepted for presentation at the $\delta^{\text {s Intemational }}$ Conference on Harmonics and Quality of Power ICHQP 98, jointly organized by IEEE/PES and NTUA, Athers, Greece, Otwober 1416, 1998

0-7803-5105-3/98/\$10.00 1998 IEEE
This dilentma of surge protection versus overvoltage scenarios has been created by the industry's obsession with providing very low clamping voltages for surge mitigation (Martzloff \& Leedy, 1989[1]). And now, the need to ensure coordination of the "cascade" of the service-entrance SPD and the plug-in SPDs has exacerbated this situation. The issue of cascade coordination has already been debated at length in the literature (Martzloff \& Lai, 1991 [2]); (Stonely \& Stringfellow, 1991 [3]); (Hostfet et al., 1992 [4]); (Rousseau \& Perche, 1995 [5]). Further debate or exhaustive references to the many papers on that subject is not our purpose. It is mentioned here only as a contributing factor to the dilemma, but a factor that cannot be ignored in a complete assessment.

\section{SURGE PROTECTTVE DEVICES FOR LOW-VOLTAGE SYSTEMS}

The introduction of metal-oxide varistors (MOVs) in the seventies was a timely innovation, concurrent with the increasing use of semiconductors in consumer products. While these semiconductors opened new opportunities, their relatively low tolerance for surges created a strong demand for better surge-protective devices. Unfortunately, market competition encouraged a downward "auction" that led to attributing high value to low clamping voltages, a situation unwittingly encouraged by the listing of "transient suppression levels" stipulated in UL Standard 1449 [6]. The list begins at $330 \mathrm{~V}$ for SPDs intended for $120 \mathrm{~V}$ circuits, although there is good evidence that most consumer loads do not need such a low level of protection (Anderson \& Bowes, 1990 [7]); (Smich \& Standler, 1992 [8]).

The generic structure of typical low-voltage residential power systems is shown in Figure 1 for the case of a detached home. Underground service has similar characteristics. This system extends from the outdoor line-side of the service drop all the way through the premises wiring, including plug-in type SPDs. Figure 1 also shows the various locations where an SPD can be installed.

Typically, there ane six locations. The first three: (1) at the outdoor weather-head, at the service entrance, and (3) on the line side of the main disconnect are within the scope of IEEE Std C62.34 [9]. The next three are within the scope of ongoing IEEE project P62.62 [10]: (4) at the load side of the panel disconnect, (5) at a permanently wired receptacle, and (6) as a plug-in device. Locations (3) through (5) are within the premises wiring and therefore under the control of the end-user, while locations (1) and (2) are under the control of the utility. 


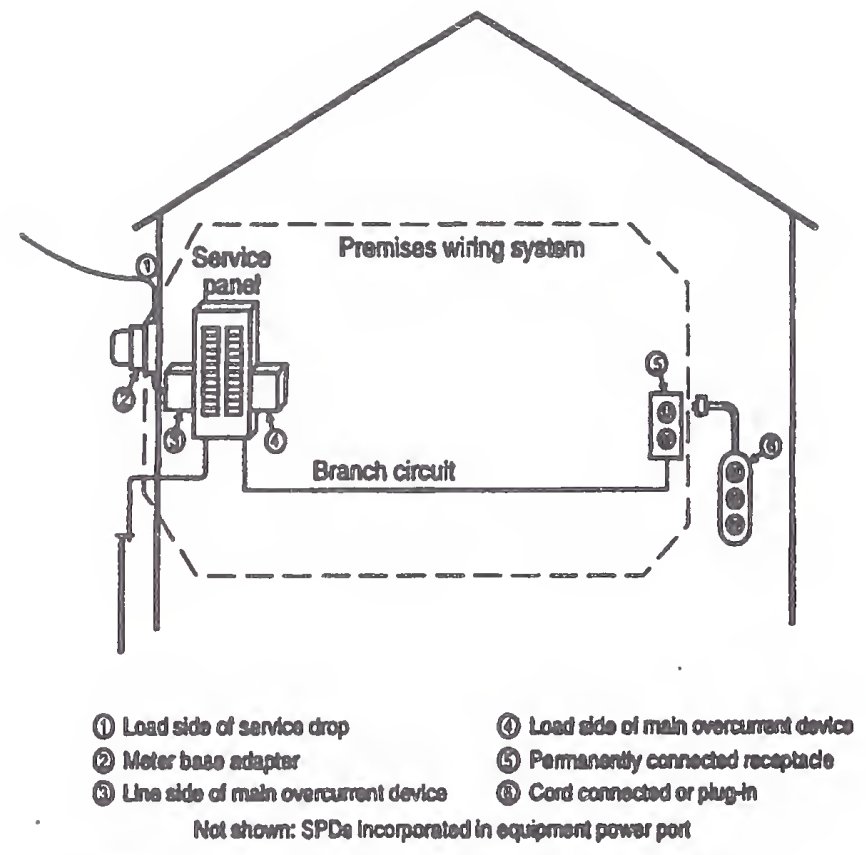

Figure $\mathbb{1}$ - Possible SPD locations for a residential building

An emerging requirement in standards for application of the low-voltage SPDs under development at the International Electrotechnical Commission (IEC 61643-1 [11]) as well as at the IIEEE (P62.62 [10]) is the provision of a "disconnector" intended to disconnect a failing SPD. Failure under conditions exceeding the SPD capability is recognized as unavoidable, but the consequences of such failure are made acceptable thanks to the action of the disconnector.

Unfortunately, some ambiguity has crept in the interpretation of this requirement. In some cases is bas been interpreted as only disconnecting the failed SPD component from the power systern, but leaving the load energized — and without further surge protection (Martzloff, 1998 [12]). If the disconnector is of this latter type, the SPDs components of an SPD package will fail under TOV conditions, presumably in a safe manner, but then allow the TOV to be applied to the downstrearn load. This is undesirable for the typical user who values equipment protection above continuity of operation. Finally, there is the worst case, as reported in many anecdotal instances, where the failure mode of SPDs under TOV conditions has not been graceful, to say the least. These instances, while not very frequent, have led to new testing requirements for failure modes from the Underwriters Laboratories in the updated Second Edition of their UL 1449 [6] Standard for low-voltage surge-protective devices ("TVSS" in the industry jargon).

Given this unsettled situation, it will be useful to review the scenarios that can lead to failure of an SPD component in an SPD package, in particular under TOV conditions. For the sake of completeness, we will describe first some failure scenarios under surge conditions, as they have some bearing on the disconnector design.

\section{FAILURIS MODES UNDER SURGE CONDIIIONS}

For a correctly applied SPD, failure under surge conditions should be a very rare occurrence. Nevertheless, one can enumerate the following failure scenarios in a field application - including misapplications:

1. A single, large, and not anticipated impinging surge exceeds the capability of the SPD. An example of this situation can be the presence of switched capacitor banks;

2. A succession of surges, such as multiple lightming strokes, exceeds the capability of the SPD. This situation has been identified for distribution amresters (Darveniza, 1997 [13]) and might also occur for low-voltage SPDs;

3. A thermal runaway is launched in an SPD exposed to high ambient temperatures at the time when a surge (within specifications for normal ambient) occurs:

4. In the questionable scenario of an alleged "degraded" SPD (Stringfellow, 1992 [14]), a thermal runaway is launched by the heat generated during a within-specifications surge.

For all these scenarios, the ultimate failure mode depends on the fault current that the power system can deliver at the point of connection of the SPD. For moderate fault currents, such as on branch circuits, the disconnector can generally provide protection. The fuse design can still be a challenge: carry the load current, carry the specified surge current, but melt in case of a power-frequency fault current resulting from failure of the SPD component. For very high available fault currents, such as that prevailing at some service entrances close to a large distribution transformer, successful clearing may be a greater challenge. Furthermore, coordination of overcurrent protection is more diffinculth compared to branch circuits inside the building where the wiring impedance and the rating of circuit breakers in the panel can ensure proper coordination.

\section{FAILURE MODES UNDER TOV CONDITIONS}

Three major types of TOV-induced failures can be identified for low-voltage SPDs:

Moderate TOVs associated with power system faults, such as a line-to-earth fault in a three-phase system, creating a 1.73 times normal line voltage in the other phases. Ferroresonance can also produce moderate but significant overvoltages.

Extreme TOVs associated with the commingling scenario (accidental fall of conductors of a higher voltage upon conductors of a lesser voltage). No conventional, varistor-only SPD can be expected to survive such a scenario.

Double voltage TOVs associated with the loss of neutral in a single-phase, three-conductor, earthed center-tap system such as the $120 / 240 \mathrm{~V}$ service typical of North American systems.

Depending on the philosophy of the system designer, in particular the utility for the case of a service-entrance SPD, survival or expected but acceptable failure can be stipulated for the loss-of-neutral scenario. 
a) Moderate TOVs: System Faults

Among abnormal conditions that can produce temporary overvoltages, we give two examples of incidents resulting in overvoltages not exceeding twice the normal voltage. Sorne SPDs based on the misconception that a very low clamping voltage is desirable might not survive such moderate TOVs.

Single-phase faults to earth on a three-phase system produce a shift in the unfaulted phases. The severity of the voltage rise depends on the fault location, the system impedance, and the earthing practices. For a TT power system in steady-state, the neutral will by symmetry be at the same potential as earth, as in Figure 2 (a). However, if an earth fault occurs on one phase, it will cause a shift of potential as the system aittempts to maintain balance. The neutral will be elevated and a corresponding shift will be experienced by the other two phases. In the worst case of a completely isolated system with a bolted fault to earth on one of the phases, we could have the situation depicted in Figure 2 (b). This shows a neutral which has been elevated to one per unit, causing the unfaulted phases to drift up to 1.73 per unit with respect to earth.

For three-phase systems with an artificial neutral through an earthing transformer or a finite resistance, the earth impedance is high. This arrangement limits the fault current during a single-line-to-earth fault, but allows enough for fault detection using overcurrent relays. It also inserts some impedance between the system neutral and the actual earth so that the voltage on the unfaulted phases will shift toward somewhat less than line-line value as shown in Figure 2 (c).

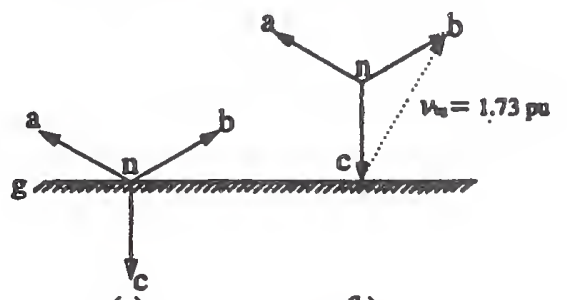

(a)

(b)

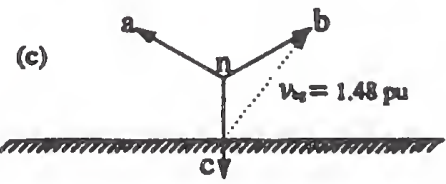

Figure 2 - Effect of a single phase-to-earth fault

Series resonances occur in a power system when a series circuit consisting of an inductance and a capacitance is excited at its natural frequency. As an example of this condition, Figure 3 shows a portion of a temporary overvoltage resulting from a power system switching incident (restoring power phase by phase after interruption (15]), which produced a sustained rms voltage exceeding $150 \%$ and lasting four seconds.

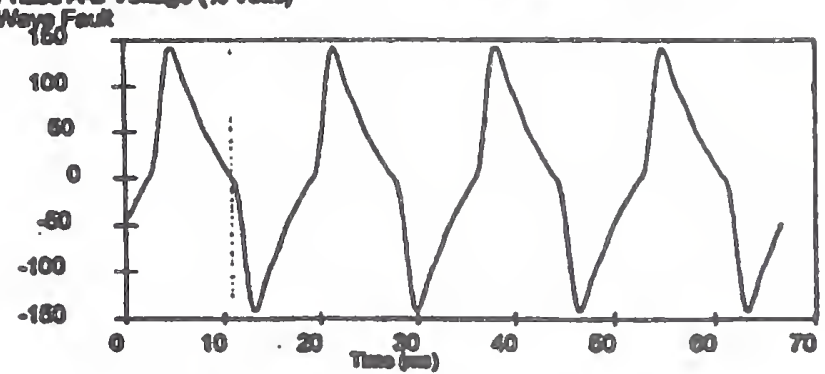

Source: EPAI Report [15]

Figure 3 - Temporary overvoltage caused by ferroresonance

\section{b) Extreme TOVs: Commingling}

In this real-life scenario, the low-voltage SPD connected on the secondary side of the distribution transformer, and normally energized at its rated voltage, is first brought to failure by the large overvoltage resulting from commingling conductors. In an overbuilt system, a collision of a vehicle with a pole, or breaks caused by icing, the conductors of the higher voltage distribution system or sub-transmission system can fall on the lower voltage distribution system. Such accidental contact injects an intruding voltage for a few cycles, until the higher voltage breaker clears the fault.

Figure 4 shows a simplified one-line diagram of the two medium-voltage systems (the intruding $M V I$ and the victim MV2) being accidentally commingled. In this figure, the bond between the two systems earth connections is shown in dotted line to present the generic case of comuningling. In an overbuilt system with common neutrals, a solid bond exists where the dotted line is shown in the diagram. In the scenario of a simple crossing of two systems (not overbuilt along the right of way), or delta systems, a solid bond might not be present, and the fault current from MVI will involve the earthing impedances shown in the diagram In that case, the intruding voltage $V_{1}$ might be less than the system voltage MV1 but still enough to precipitate failure of an SPD on the secondary.

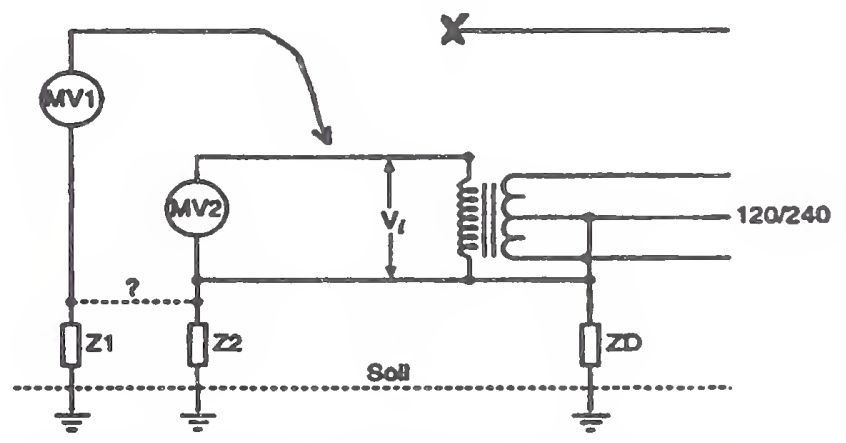

Figure 4 - Commingling overvoltage applied to the distribution transformer primary and reflected on the LV side 
c) Double-voltage TOV (Loss of meutral)

There are many situations where loss of neutral can occur. Some can be of a transient nature, such as a loose connection, while some might be permanent until repaired such as a mechanical break or corrosion of the neutral conductor. While the latter might not linguistically fall under the label of "teraporary', the consequences are the same. In a three-wire, single-phase system typical of North American practice, this condition has been observed many times.

Figure 5 shows a system where one side of the supply (LI) is lightly loaded, while the other side (L2) is heavily loaded, Under normal conditions, the two sides remain at normal voltage. Should the neutral connection be lost, then the voltage at mid-point is determined by the ratio of impedances on the two sides: the $L 1$ side experiences an overvoltage that can approach twice normal. Any SPD connected to this side will then be exposed to the twice-normal voltage, with an available current determined by the impedance 22 . This current, by the very design of the circuit, will not be interrupted by the overcurrent protection and is available to generate substantial heat in the SPD that has failed as the result of the overvoltage. A disconnector designed to clear larger fault currents, such as those occurring if the SPD fails while the neutral is connected, might not be capable of clearing the limited current. Other schemes are then necessary to ensure an acceptable failure mode, such as a thermally-activated disconnect.

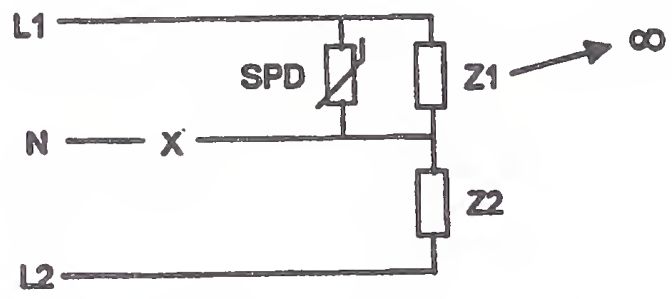

Figure 5 - Three-wire, single-phase system where a broken or intermittent neutral connection creates a voltage imbalance

\section{AVAILABLE FAULT CURRENT}

As described in the preceding paragraphs, several scenarios can produce failure of the SPD, ultimately offering a very low (bur not zero) impedance to the flow of the fault current that the power system can deliver. For each scenario, the available fault current at the point of connection of the SPD will have a very significant effect on the failure mode.

The significance of available fault current is recognized in standards. but the value that should be considered is generally left undefined. The following statements can be found in published standards.
1996 National Electrical Cade, 230.65, Available Short-Cireuit Current

"Service equapment shall be suitable for the short-circuit current available at the supply terminals."

IEEE C62.341996, Slandard for Performance of Low.Voltage Swrge-Protective Devices (Secondary Arresters), Article 7.6

"If the manufacturer claims a fault current withstand rating. then that rating shall be verified."

IEC 61643-1 (FDIS November 1997) Surge prosective devices consected to low-voliage power distribution systems - Part 1: Performance reguairements and testirg methods, Article 6.2.11

"The SPD shall be able to carry the power short-circuit current until it is interrupted either by the SPD itself, by an insernal or extemal overcurrent disconnector, or by the backup overcurrent protection."

It is noteworthy that none of these documents specify a value for the available short circuit, but rather leave it to the discretion of the manufacturer, while imposing criteria of acceptability after the failure. The NEC tersely requires the device to be "suitable," without elaboration. The two standards applicable to a service-entrance SPD - where the available fault current can be quite high - acknowledge the possibility of failure and significance of the available fault current, but do not stipulate specific values.

In an attempt to obtain information on what levels of fault currents should be considered, an informal survey was conducted among a few utility engineers. It turns out that very few utilities limit the available fault current at the service point of residential customers but many people are under the misconception, as cited below, that all residential service load centers and breakers are limited to an available fault current of $10 \mathrm{kA}$ and therefore they assume that actual available fault current must be less than $10 \mathrm{kA}$.

Interestingly, none of the individuals consulted on this issue could cite a standard or even a document with the status of a consensus guide that does stipulate a current value. Two perceptions seem to prevail among the individuals consulted, as quoted below:

1. Based on the observation that breakers for typical residential service panels (up 80200 A) generally have an insterrupting capacity of $10 \mathrm{kA}$, is would be logical that the available fauls current at the service entrance would be in the same order of magnitude.

2. Based on the reality that a service entrance connected clo. 210 a large distribution transformer (such as a garden apartomens or high-rise) will hove available fauls currents in excess of $10 \mathrm{kA}$, it would be prudent to review the specifics of the situation.

Furthermore, these standards do not require that the SPD application data state a limit of acceptable fault current. 


\section{EMERGING STANDARDS}

a) SPDs installed downstream from the service entrance

In recognition of the issues raised by failure modes of the SPDs within the scope of UL Standard 1449 - downstream of the main disconnect - the second edition of this standard [6] now requires demonstration of an acceptable behavior in the failure mode of SPDs exposed to various overvoltage scenarios. Specifically, among the many tests required by UL, three tests address the issue:

Temporary overvoltage with high available current - This test is stipulated under article 37.2 of UL 1449, calling for extended exposure to $125 \%$ of normal line voltage with either an acceptable temperature equilibrium being attained or until an internal disconnect device operates. This test will demonstrate capability of sustaining moderate overvoltages, primarily providing a margin against high system voltage, but not the higher levels of temporary overvoltages covered in the next test. The available fault current specified for this test is defined as a function of the ampere rating of the service over a range of $200 \mathrm{~A}$ to $25000 \mathrm{~A}$.

Full phase vollage with high available fault current - This test is stipulated under article 37.3 of UL 1449, calling for exposure to the "full phase voltage" as shown on Figure 2(b) of this paper. The same criteria as above apply, namely acceptable temperature equilibrium or operation of an internal disconnect.

The available fault current specified for this test is defined as a function of the ampere rating of the service over a range of $200 \mathrm{~A}$ to $25000 \mathrm{~A}$.

Overvoltage with limised current - This test is stipulated under article 37.4 of UL 1449, with overvoltage values presumably comresponding to a loss of neutral scenario, and the associated low values of current supplied by the connected load, as in Figure 5.

It is noteworthy that in the stipulations of these three tests, the emotionally charged word "failure" is not used. Instead, a list of unacceptable conditions is given, including emission of flame, molten metal, flaming particles, charring of adjacent material, ignition of enclosure, or creation of openings leaving live parts accessible.

\section{b) SPDs installed upstream from the service entrance}

For SPDs connected upstream from the service panel, the recently published IEEE Standard C62.34 does describes a loss-of-neutral scenario with limited current, similar to the UL 37.4 test. However, a demonstration test is not mandated, as the consensus development process settled for a weaker statement: "if the manufacturer claims a loss of neutral withstand capability ... then that capability shall be verified ..." Thus, the inference might be made that if no claim for loss-ofmeutral withstand capability is made, no demonstration test is required. However, an additional paragraph in the standard does mention "...must fail in an acceptable manner."
From this brief overview of emerging standards, it appears that on the low side of available fault current, both the UL and the IEEE standards have recognized the issues of acceptable failure modes associated with temporary (or quasi-permanent) overvoltages. On the other hand, at the high side of available fault currents, it seems that insufficient recognition of the issue still prevails, as discussed in the preceding section on the significance of the level of available fault currents.

Nevertheless, Figure 6, offered as background information in a tutorial addressing considerations on the revenue meter environment (Ward, 1980 [16]), shows typical values of fault current as a function of distribution transformer size and length of service drop. That figure clearly shows values in excess of $10 \mathrm{kA}$, but somehow this information has not been fully recognized by the SPD community.

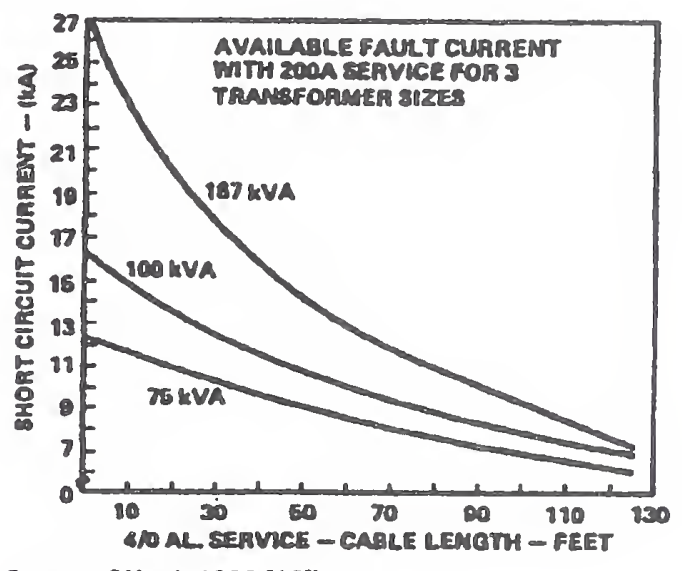

Source: (Ward, 1980 [16])

\begin{abstract}
Figune 6 - Poult carrent amplitude as a function of. transformer rating and length and size of service drop
\end{abstract}

\section{POSSIBLE SOLUTIONS}

Among possible solutions, two approaches may be considered: making the SPD less sensitive to TOVs, and, in any case, ensure that if failure is unavoidable under extreme stress, it will be in an acceptable mode.

The obvious way to desensitize SPDs to TOVs is to design them with a higher MCOV. However, as the higher MCOV in a varistor-only SPD means a higher surge-limiting voltage, there is a limit beyond which such an SPD becomes useless (op cit., [2-5]).

A posi.ble solution may be in reviving the concept of a gapped arrester for the upstream SPD of a "whole house" scheme (Mansoor et al., 1998 [17]). There, the initial let-through associated with the gap volt-time response can easily be mitigated by the downstream SPD, while the gap prevents the SPD from becoming involved with moderate TOVs. 
Of course, for the (rare) commingling scenario, little can be done but to ensure a graceful failure. This condition should be an implicit requirement, but, as discussed in the section on available fault current, the implications of such a requirement apparently have not been recognized by all interested parties. Even among the community of SPD engineers, there has been some reluctance to accept the concept that temporary overvoltages should be addressed in documents discussing the surge environment.

\section{CONCLUSIONS}

1. The dilemma of providing a suitable surge protection of load equjpment by means of surge-protective devices, while ensuring acceptable response of these surgeprotective devices to unavoidable temporary overvoltages raises several application issues that demand attention.

2. "Acceptable response" can be interpreted either as survival of the SPD (a challenge to the coordination of cascades) or as accepting failure, but within well-defined conditions of the failure mode (a challenge for applications where high available fault currents prevail).

3. Coordinating a cascade of surge-protective devices can be solved by providing a gapped arrester at the service entrance, which will coordinate with the de facto situation of low limiting voltage SPDs inside the building.

4. The need for a service-entrance arrester to withstand the scenario of lost neutral can be satisfied by a gapped arrester having sufficient maximum continuous operating voltage capability.

5. Emerging standards for low-voltage SPDS have given mew recognition to the importance of taking into consideration temporary overvoltages in the design of SPDs.

6. Notwithstanding conclusion (5), SPD application standards as well as performance and test standards should be more explicit in defining how to deal with the issues raised by available fault current in case of unavoidable SPD failure.

\section{REFERENCES}

1. Marzloff, F.D. and Leedy. T.F., "Selecting Varistor Clamping Voltage: Lower Is Not Better!" Proceedings, 1989 Zurich International EMC Symposium.

2. Marzloff. P.D. and Lai, I.S., "Cascading Surge-Protective Devices: Coordination versus the IEC 664 Staircase," Proceedings, PQA 9] Conference.

3. Stringfellow, M.F. and Stonely, B.T. "Coordination of Surge Suppressors in Low-Voltage AC Power Circuits," Proceedings. Forum on Surge Protection Application, NISTIR-4657. August 1991.

4. Hostfet, O.T. Hervland, T., Nansen, B. and Huse, J., "Coordination of surge-protective devices in power supply systems: Needs for secondary protection," Proceedings. Insemational Conference on Lightning Protection. Berlin, September 1992.
5. Rousseau, A. and Perche, T., "Coordination of Surge Arresters in the Low-Voltage Field," Proceedings, 7th International Telecommunications Conference (INTELEC), 95CH35824.

6. UL 1449 Standard for Safety for Transient Vollage Surge Suppressors, Second Edition, August 1996.

7. Anderson, L.M. and Bowes, K.B., 'The Effects of Power-Line Disturbances on Consumer Electronic Equipment," IEEE Transactions PWRD-5, No.2, April 1990.

8. Smith, S.B. and Standler, R.B., "The Effects of Surges on Electronic Appliances," IEEE Transactions PWRD.7, No.3. July 1992

9. IEEE Std C62.34, IEEE Standard for Performance of Low. Voltage Surge Protective Devices (Secondary Arresters), 1996.

10. JEAE Project P62.62 - Application Guide - Low-Voltage SurgeProtective Devices (ongoing).

11. IEC Document 37A/63/FDIS -Draft IEC 61643-1: Surgeprotective devices connected to low-voltage distribution systems Part 1: Performance requirements and testing methods, November 1997.

12. Martaloff, F.D. "Interpretation and Misinterpretation of TVSS Disconnector Indications," Scheduled for publication in Power Quality Magazine, July/ August 1998.

13. Darveniza, M., Tumma, L.R., Richter, B., and Roby, D.A., "Multiple Lightning Currents and Metal-Oxide Arresters," IEEE Transactions PWRD-12, No.3, July 1997.

14. Stringfellow, M.F." "Fire Hazard of Surge Suppressors," Proceedings, Fifth Annual Power Quality Conference. Irvine CA, 1992.

15. EPRI Report An Assessment of Distribution System Power Quality, Electric Power Research Institute, Palo Alto CA, 1996.

16. Ward, D.J. "Secondary Fault Currents at the Service Entrance." Proceedings, 55 th Annual Electric Meter School and Conference, University of Floridla, Gainesville FL, 1980.

17. Mansoor, A., Martzloff, F.D., and Phipps, K.O.. "Gapped Arresters Revisited: A Solution to Cascade Coordination" Paper PE-114-PWRD-0-12-1997, IEEE Winter Power Meeting, 1998.

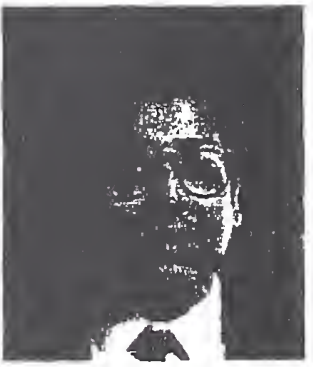

Arshad Mansoor ( $M^{\circ}$ 1995) is an Electrical Systems Engineer at the EPRI Power Electronics Applications Center (PEAC). He received his MS and Ph.D. in electrical engineering from the University of Texas, Austin in 1992 and 1994 respectively. His areas of interest include Power Quality, power systems transients analysis, harmonics, surge propagation and protection, and EMTP model development.

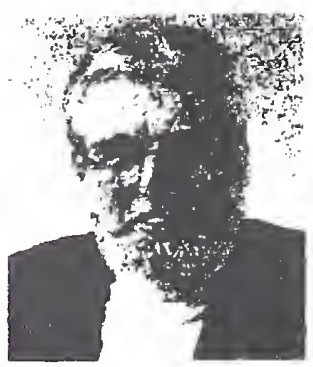

Francois Martajofi (M'1956, F'1983) Born and educated in France, with additional MS degrees from Georgia Tech and Union College, worked at General Electric for 29 years and now 13 years at the National Institute of Standards and Technology. He is contributing to several technical committees for the development of standards on EMC, surge protection and Power Quality in the IEEE and the IEC. 


\section{The Fallacy of Monitoring Surge Voltages: SPDs and PCs Galore!}

\author{
Arshad Mansoor \\ EPRI PEAC Corp \\ Knoxville TN 37932 \\ Amansoor@epripeac.com
}

\author{
François Martzloff \\ National Ins titute of Standards and Technology \\ Gaithersburg MD 20899 \\ f.martzloff@ieee.org
}

Kermit Phipps

EPRI PEAC Corp

Knoxville TN 37932

Kphipps@epri-peac.com

Reprinted from Proceedings. PQA '99 Conference

\section{Significance:}

Part 2 Development of standards

Part 5 Monitoring instruments

Recent projects of monitoring Power Quality in AC systems have focused on voltage surges rather than current surges. The predictable results of such monitoring - low apparent surge voltages - which in fact only monitors whatever limiting voltage is allowed by the proliferating SPDs and PCs, do not reflect the surge activity, now confined to surge currents flowing into the "attractive" paths of the SPDs and the capacitors included in the switch-mode power supplies of PCs (and other electronic appliances).

At standard-writing times, questions have emerged as to why mention "large" surges when monitoring shows only low voltages. With proper perspective, it becomes apparent that the proliferation of these voltage-limiting, surgeabsorbing SPDs and PCs are the explanation. While voltage surges might now no longer be a threat, the possibility of substantial current surges is indeed a threat to equipment. 


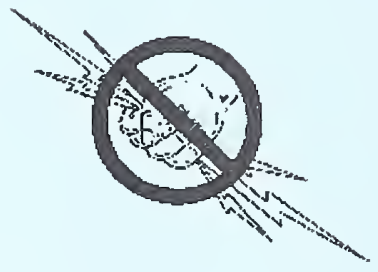




\title{
The Fallacy of Monitoring Surge Voltages: SPDs and PCs Galore!
}

\author{
Arshad Mansoor and Kermit Phipps \\ EPRI-PEAC \\ 10521 Research Dr. \\ Knoxville, TN 37932
}

\author{
François Martzloff \\ National Institute of Standards \\ and Technology' \\ Gaithersburg MD 208998113
}

\begin{abstract}
To support the recommendation of shifting transient monituring from vollage surges to current surges, the paper presents experimental results as well as numerical modeling results demonstrating two mechanisms causing an apparent decrease of surge activity in low-voltage ac power circuits. The first mechanism is the proliferation of surge-protective devices, a situation which is by now well recognized. The second, which should also have been recognized, apparently escaped scrutiny so far: the proliferation of electronic appliances containing a switch-mode power supply that effectively places large surge-absorbing capacitors across the ac power systems.
\end{abstract}

\section{Introduction}

This paper is unabashedly tutorial, and some of the themes presented here might be quite familiar to some of our readers. However, we have observed that these concepts, which could almost be characterized as obvious when given the benefit of hindsight, are still not widely recognized. 'Therefore, we will present them to this forum, and illustrate their validity by experimental measurements and numerical modeling. The three major themes of this presentation are:

1. There is a logical explanation for the apparent decrease in the level of voltage surges reported in recent power quality surveys: the proliferation of surge-mitigating devices.

2. The present practice of recording voltage surges can lead to erroneous concepts on surge protection, which in turn can lead to equipunem failutes.

3. There is an unfulfilled need to develop and deploy power quality monitors that can characterize the energy-delivery capability of a surge event.

The first theme will be introduced by a historical perspective showing how voltage surges became the focal point of monitoring surges, even before the term "power quality" was coined. Experimental measurements and numerical modeling will be described to illustrate the effect of the proliferation of surge-protective devices (SPDs) and of new electronic appliances that serve respectively as intended and unintended surge-mitigating devices. The next two themes will be only briefly discussed because, once the first is accepted, these two follow quite logically.

I Electricity Division. Electronics and Electrical Engineering Laboratory. Technology Administratim. U.S. Department of Commerce.

Contributons from the National Instituse of Standards and Te'chnology' are not subject ro U.S. Copyright. 


\section{Historical Perspective}

The proliferation of SPDs in low-voltage ac power circuits has been recognized as one of the root causes of the apparent decrease of the surge levels recorded in recent power quality surveys. The change in the occurrence of surges began to be recognized [Dorr, 1995] ' and explanations were offered attributing the phenomenon to the emerging proliferation of SPDs in low-voltage ac power circuits [Martzloff, 1996]. It is noteworthy that for many people, the term "surge" is equivalent to "transient overvoltage" to the point that the phenomenon has generally been recorded by instruments acting as voltmetcrs, and the term was without much scrutiny accepted in general as meaning a voltage surge.

For instance, in the bi-lingual publications of the International Electrotechnical Commission (IEC), the French text which parallels the English text uses the term "surtension" (meaning overvoltage), because there is a mind set, reinforced by the lack of a neutral term in French that could be applied to either or both voltage surges and current surges. In the United States, the Underwriters Laboratories perpetuates this narrow perspective by calling SPDs "Transient Voltage Surge Suppressors" (italics ours) [UL Std 1449, 1996], although both recent IEC and IEEE definitions of SPDs introduce and emphasize the concept of current surges as well as voltage surges.

Now less recognized but significant, a similar cause for the apparent decrease of voltage surge levels is becoming important as more and more electronic appliances depend on a switch-mode power supply' with a rectifier-capacitor DC link. Through the rectifier, the DC link capacitor which is typically in the order of $200 \mu \mathrm{F}$ to $500 \mu \mathrm{F}$, offers a low-impedance path to current surges impinging on the power port of these appliances. With many such appliances connected in an cnduser installation, the effect is that of quite a large capacitor being connected across the ac mains. Small wonder then that even large surge currents (for instance, with the capability of delivering currents of $3 \mathrm{kA}, 8 / 20 \mu \mathrm{s}$ ) [ANSI/IEEE C62.41-1995] can no longer raise the voltage across the mains to the high values sometimes reported in earlier surveys of surge voltage occurrences.

Another historical mind-set has been to recognize the origin of surges only as a voltage event while in fact it can be either a true induced-voltage event, or the end-result of the injection of a surge current somewhere in the power system. Typical induced-voltage surges are associated with the electromagnetic coupling into the power circuits of the field created by a ncarby (but not direct) lightning flash. Such voltage surges, which can develop substantial voltages in highimpedance circuit loops [Martzloff et al., 1995] can easily be mitigated with relatively small SPDs because their energy-delivery capability is relatively small [IEC document 64/1034/CD, 1998]. In contrast, current surges are produced either by the dispersion of the current associated with a lightning flash when a direct strike injects current at some point of the power system, in close vicinity or at a more remote point of the power distribution system [Mansoor ct al., 1998]. Another source of current surges is switching surges involving the injection of residual encrgy into parts of the power system. The energy-delivery capability of these current surges can bc substantial, and be a threat to the survival of improperly sized SPDs. Note in passing the use of the term "cncrgy-delivery capability" and not "cnergy in the surge." Some of our readers arc by now familiar with that theme [Lindes et al., 1997] — perhaps even tired of seeing it repeated but the sad truth is that usage of the term "surge energy" is still rampant.

1 Citations appearing in the text as (Author, date/ are listed in alphabetical order in Section 7, Bibliograph): 
The significance of making the distinction between recording current surges versus recording voltage surges is very important for equipment designers. A decision to provide only modest surge withstand capability for an SPD incorporated at the power port of the cquipment might be made because the contemporary surveys reveal few and moderate (volage) surges. When combined with the misconception that "the lower the clamping voltage, the better" [Martzloff et al., 1989], the result can be disastrous. We have in our laboratory 'morgue' two examples of such massproduced devices incorporating an inappropriate SPD that led to early mortality of the product. Without identifying the culprit - perhaps a harsh word for a designer who was lulled into this position by referring to misleading reports on surge activity - but to illustrate the situation, we can name the two products: a compact fluorescent bulb, and a remotely-controlled ceiling fan. To recite a recurrent theme in our tutorial presentations ("Transients Are Here to Stay"), voltage surges might appear to have faded away, but current surges are still here, ready to destroy a small SPD incorporated in a design based on the misperception of fading voltage surges, fostered by recording only voltage surges.

\section{Experimental Measurements}

To illustrate the effect of nonlinear SPDs as well as linear capacitors connected across the main: the Power Electronics Applications Center (PEAC) "Upside-Down House" [Key et al., 1994] was used to inject surges into the service entrance of the Upside Down House with various combinations of SPDs and/or personal computer (PC) power supplies connected at the end of l wo branch circuits, one 9-m long, the other 36-m long. In Figure 1, currents in the branches and voltages at the nodes are identified respectively as $I_{s}, I_{9}, I_{36}$, and $V_{0}, V_{9}, V_{36}$. The charging voltage setting of the Combination Wave surge generator was kept constant to provide a $2 \mathrm{kV}, 1.2 / 50 \mu$ s open-circuit voltage (OCV). In a second series of experiments, the setting was increased to $4 \mathrm{kV}$. This second series, not reported here in detail because of limited space, confirmed the expected nonlinear response of varistors and the linear response for capacitors only.

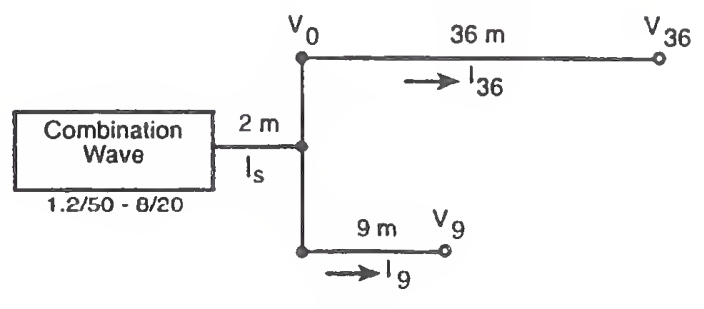

Figure 1 - Upside-Down House branch circuits

\subsection{Metal-oxide varistors only}

Given the known and predictable behavior of multiple SPDs - often reported in the literature to the point that bibliographic citations would take several lines to list all of them - this part of the experiment was performed only to provide a baseline. Metal-oxide varistors (MOVs) rated $150 \mathrm{~V}, 20 \mathrm{~mm}$ diameter, were used for this experiment. To record all interesting currents and voltages, two shots are necessary when using the 4-channel digital signal analyzer; therefore each oscillogram in the figures contains the trace of $V_{0}$ to serve as a common reference (Figure 2 ). 

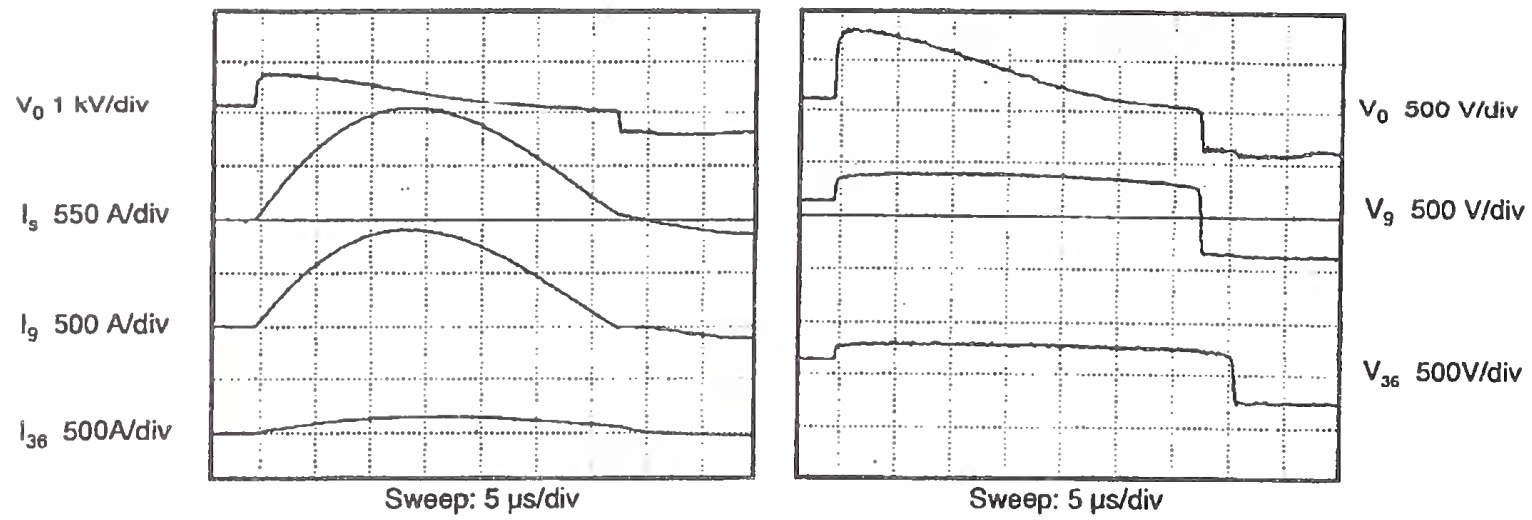

Currents in branches

\begin{tabular}{|c|c|c|c|}
\hline $\begin{array}{c}V_{0} \\
\text { (peak V) }\end{array}$ & $\begin{array}{c}I_{s} \\
\text { (peak A) }\end{array}$ & $\begin{array}{c}I_{9} \\
\text { (peak A) }\end{array}$ & $\begin{array}{c}I_{36} \\
\text { (peak A) }\end{array}$ \\
\hline 790 & 1000 & 900 & 150 \\
\hline
\end{tabular}

Voltages at nodes

\begin{tabular}{|c|c|c|}
\hline $\begin{array}{c}V_{0} \\
\text { (peak V) }\end{array}$ & $\begin{array}{c}V_{9} \\
\text { (peak V) }\end{array}$ & $\begin{array}{c}V_{36} \\
\text { (peak V) }\end{array}$ \\
\hline 790 & 410 & 330 \\
\hline
\end{tabular}

Figure 2 - Typical recordings ${ }^{1}$ made during the first experiment - SPDs only.

In Figure 2, the current traces (left oscillogram) show the unequal sharing between the two MOVs, reflecting the diffcrence in the inductance of the two branch circuits. Because the peaks of llie I wo biallich-circuit currents are not simultaneous (the current in the longer branch circuit takes longer to build up) their sum seems to exceed the peak of the injected current, $I_{s}$.

The voltage traces (right oscillogram) show how the voltage at the service entrance, $v_{0}$, is mitigated from the $2 \mathrm{kV}$ open-circuit voltage supplied by the generator that would propagate without attenuation in the absence of a surge-mitigating device [Martzloff et al., 1986]. This voltage $V_{0}$ is the sum of the clamping performed by the varistor at the node $V_{9}$, and the inductive voltage drop in the $9-\mathrm{m}$ long connection. Note that this inductive voltage is additive during the rise of the current $I_{9}$, and subtractive during the fall, hence the apparent "overshoot" in the trace of $V_{0}$, compared to the flat-top trace of the varistor at $V_{9}$. The voltages at $V_{9}$ and $V_{36}$ are the typical clamping voltages of the MOVs corresponding to the current they carry.

In a subsequent experiment with a $4 \mathrm{kV}$ open-circuit voltage setting of the generator (twice the value of Figure 2, but not reported here in detail because of limited space), the voltages across the varistors, predictably, were not substantially increased. However, the substantially increased current in the 9-m long branch circuit (from $1000 \mathrm{~A}$ to $2800 \mathrm{~A}$, resulting from the nonlinear response of the varistor) produced an increased inductive effect to the point that the voltage at the service entrance was raised to $1300 \mathrm{~V}$ from the $790 \mathrm{~V}$ recorded for the case of Figure 2. Table 1, at the end of this section, presents a summary of the peak values recorded in the various combinations of components, branch circuits, and amplitudes of the injected surge.

\footnotetext{
'The experimental values shown in Figures 2, 3, and 1, and in Table / were recorded with a digital signal analyzer. They have been rounded off to the nearest ten to convey a simpler set of numbers, uncluttered by a precise last digit. Uncertainty in these measurements is not an issue here as it does not affect the general conclusions.
} 


\subsection{Capacitors only}

In a second set of experiments, less easily predictable would be the bchavior of the still all-linear circuit involving the capacitors of a PC power supply $(440 \mu \mathrm{F}$ each in this experiment) when receiving a surge originating from the complex RLC wave-shaping network of a Combination Wave surge generator (Figure 3).

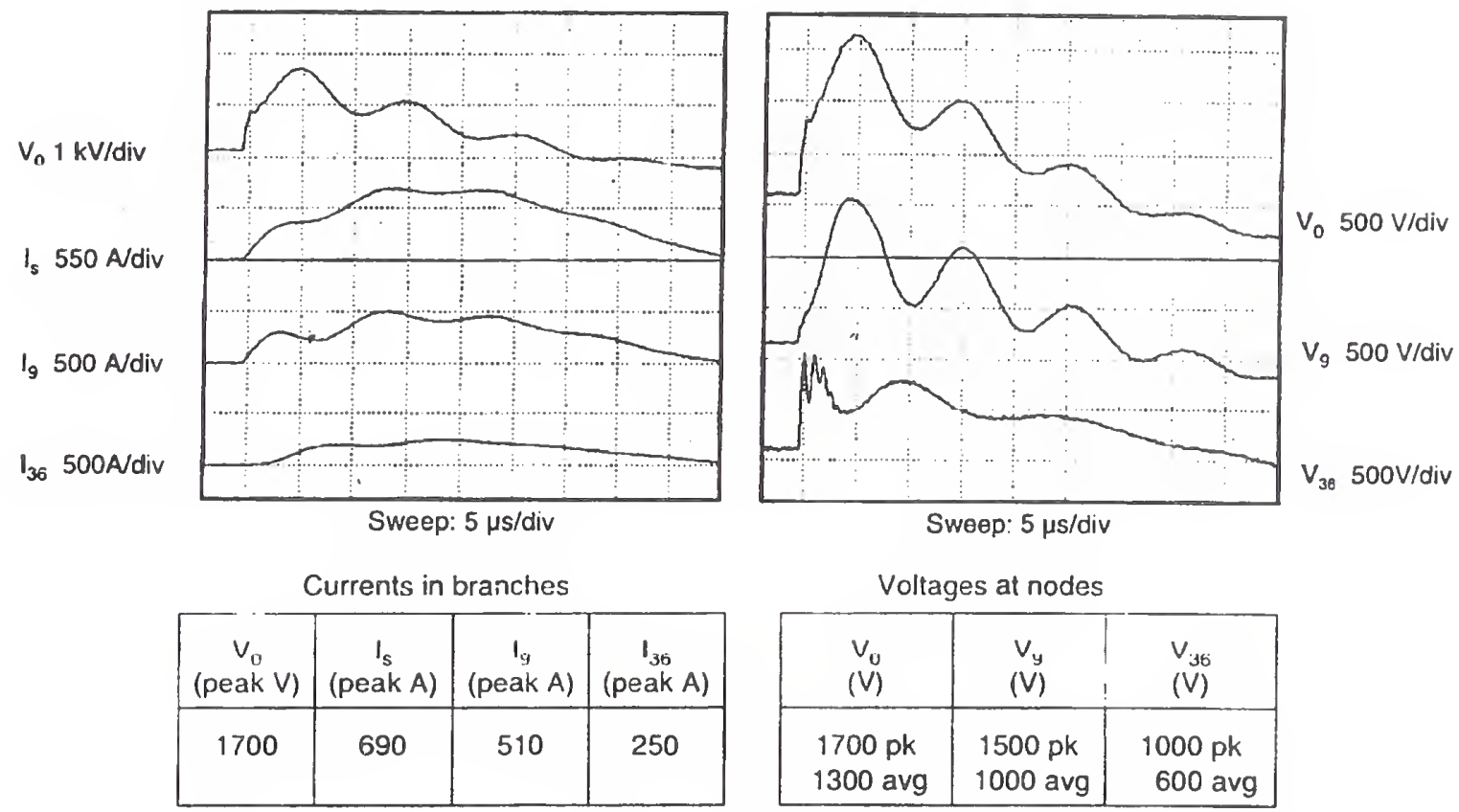

Figure 3 - Typical recordings made during the second experiment - Capacitors only

In Figure 3, the voltage at the service entrance, $v_{0}$, is mitigated from the $2 \mathrm{kV}$ open-circuit voltage supplied by the generator. However, because of the interaction between the RLC components in the wave-shaping network of the Combination Wave generator on the one hand, and the capacitances of the PC power supplies and inductances of the branch circuits on the other hand, this voltage rings around an average voltage level of $1300 \mathrm{~V}$, reaching a peak of $1700 \mathrm{~V}$ To reflect this situation, the tabulation of the voltages in the figure shows two lines, peak and average. Thus, the mitigation effect is degraded by the ringing. Nevertheless, one can expect that as more PCs would he added, the ringing frequency wonld hecome. lower and the voltage peaks lower.

\subsection{Capacitor and MOV}

In a third set of experiments, a capacitor was connected at the end of the $9-\mathrm{m}$ branch circuit and an MOV was connected at the end of the $36-\mathrm{m}$ branch circuit. Interest in this particular configuration was motivated by the desire to show how an MOV would mitigate the ringing that was observed in the preceding experiment at the end of the 36- $\mathrm{m}$ line ( $\mathrm{V}_{36}$ in Figure 3 ). 

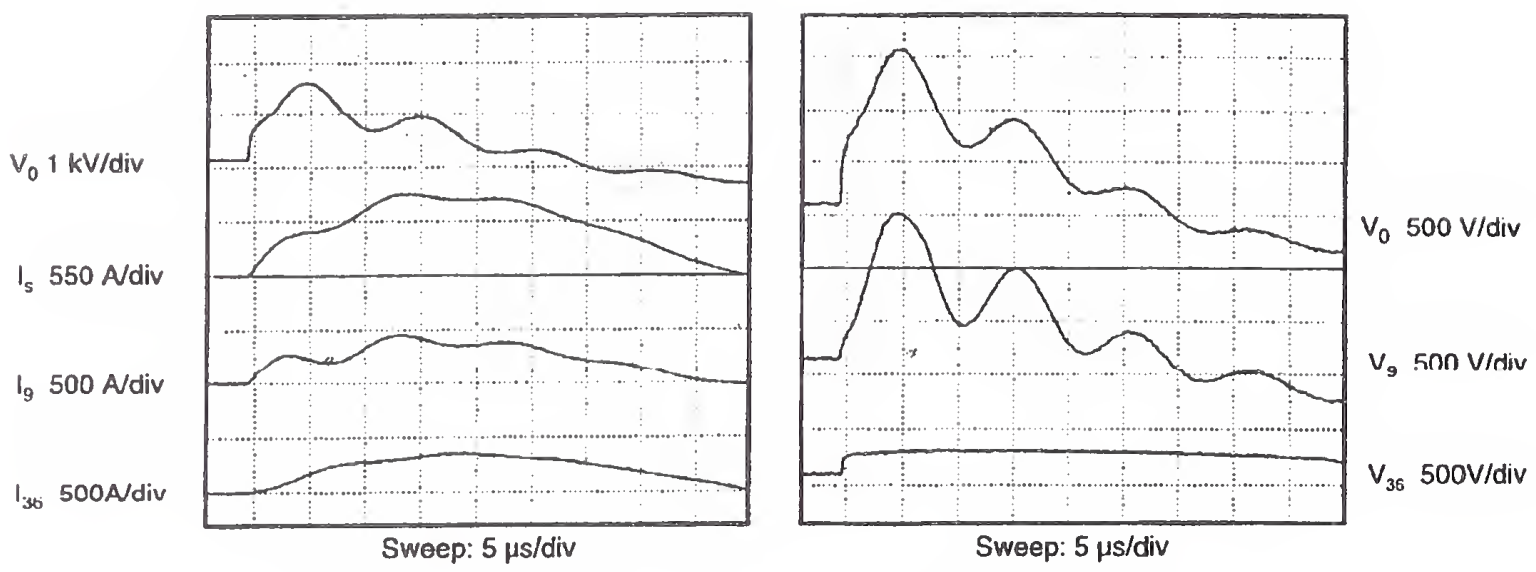

Sweep: 5 us/div

Currents in branches

\begin{tabular}{|c|c|c|c|}
\hline $\begin{array}{c}V_{0} \\
\text { (peak V) }\end{array}$ & $\begin{array}{c}\mathrm{I}_{s} \\
\text { (peak A) }\end{array}$ & $\begin{array}{c}\mathrm{I}_{9} \\
\text { (peak A) }\end{array}$ & $\begin{array}{c}\mathrm{I}_{36} \\
\text { (peak A) }\end{array}$ \\
\hline 1600 & 769 & 470 & 360 \\
\hline
\end{tabular}

Voltages at nodes

\begin{tabular}{|c|c|c|}
\hline $\begin{array}{c}V_{0} \\
(V)\end{array}$ & $\begin{array}{c}V_{9} \\
(V)\end{array}$ & $\begin{array}{c}V_{36} \\
\text { (peak V) }\end{array}$ \\
\hline $\begin{array}{c}1600 \mathrm{pk} \\
1000 \mathrm{avg}\end{array}$ & $\begin{array}{c}1500 \mathrm{pk} \\
800 \mathrm{avg}\end{array}$ & 330 \\
\hline
\end{tabular}

Figure 4 - Typical recordings made during the third experiment - capacitor and MOV.

Experiments 2 and 3 (Figures 3 and 4 ) do show decreasing levels of voltage surges at various points of the Upside Down House, compared to the open-circuit conditions. However, the interactions between the capacitors of the generator RLC wave-shaping network on the one hand, and the PC capacitors on the other hand, make detailed interpretation of the waveforms tedious and beyond the scope of our illustrative examples. Numerical modeling with a current source, as reported in the following section, avoids this interaction and provides further evidence on the "PCs Galure" effect. For readers interested in the details, Table l documents the results concerning peak voltages noted from the oscillograms kept on file but not reproduced here. Readers interested primarily in the big picture may skip a close examination of this table.

Table 1 - Summary of node voltages for component combinations

\begin{tabular}{|c|c|c|c|c|c|c|c|c|}
\hline \multirow[t]{2}{*}{$\begin{array}{l}\text { Dctailcd expcriment } \\
\text { description number }\end{array}$} & \multicolumn{2}{|c|}{$\begin{array}{l}\text { Dovico } \\
\text { Combination }\end{array}$} & \multicolumn{3}{|c|}{$\begin{array}{c}\text { Voltages for } 2 \mathrm{kV} \text { OCV } \\
\text { (peak V) }\end{array}$} & \multicolumn{3}{|c|}{$\begin{array}{c}\text { Voltages for } 1 \mathrm{kV} \text { OCV } \\
\text { (peak V) }\end{array}$} \\
\hline & $9 \mathrm{~m}$ & $36 \mathrm{~m}$ & $V_{0}$ & $V_{9}$ & $V_{36}$ & $V_{0}$ & $V_{9}$ & $v_{36}$ \\
\hline & \multirow{3}{*}{ Open } & Open & 2500 & $2600^{\circ}$ & $3300^{\circ}$ & \multicolumn{3}{|c|}{ Not done (linear) } \\
\hline & & MOV & 1700 & 330 & $1900^{*}$ & 1300 & 400 & 370 \\
\hline & & Capacitor & 1800 & $1900^{*}$ & 1300 & \multicolumn{3}{|c|}{ Not done (linear) } \\
\hline & \multirow{3}{*}{ MOV } & Open & 860 & 400 & $1300^{\circ}$ & 1400 & 400 & $2000^{\circ}$ \\
\hline \multirow[t]{3}{*}{ 3.1-MOVs only } & & MOV & 790 & 410 & 330 & 1300 & 390 & 400 \\
\hline & & Capacitor & 720 & 420 & 700 & 1300 & 390 & 990 \\
\hline & \multirow{3}{*}{ Capaviluı } & Open & 2000 & 1600 & $2100^{*}$ & \multicolumn{3}{|c|}{ Not done(linear) } \\
\hline 3.3- Capacitor and MOV & & MOV & 1600 & 1500 & 370 & \multicolumn{3}{|c|}{ Capacitor failed, end test } \\
\hline 3.2 - Capacitors only & & Capacitor & 1700 & 1550 & 1100 & \multicolumn{3}{|c|}{ Not done (linear) } \\
\hline
\end{tabular}

- Ringing at the open-ended line is the cause of this voltage being greater than $V_{0}$. 


\section{Numerical Modeling}

Our previous experience with modeling cascaded SPDs [Lai et al., 1993] and the behavior of the Upside Down House with installed SPDs [Martzloff et al., 1995] can be readily applied to the prediction of the behavior of the three circuits subjected to the experimental measurements, with an imposed current source, free from the unavoidable interactions that occurred in the preceding experimental measurements. This approach yields the best of the two methods: a computation that has been well demonstrated as suitable for modeling nonlinear SPDs, and the freedom to impose any fixed wavetorm - what reality imposes on a residence is not the surge from an impedance-limited surge generator - combined with the possibility to model many branch circuits and many combinations of SPDs and/or capacitors.

\subsection{Modeling combinations of loads and branch circuit lengths}

In a series of modeling runs similar to the combinations of the experimental measurements, the model used the circuit of Figure 5. $\Lambda$ current source feeds a fixed current surge via a common service drop to the panel bus of the service entrance, where three branch circuits made of $2-\mathrm{mm}$ diameter conductors (\#12 AWG) take off, with length of respectively $5 \mathrm{~m}, 10 \mathrm{~m}$, and $20 \mathrm{~m}$. The choice of these lengths was based on curiosity about the effect of the long distancc connection (and thus an effect that might be delayed or (icgraded) to the immediatc occurrence of an overvoltage at the end of shorter branch circuits. The currents in the circuit are identified $m$ Figure 5 respectively as $I_{5}, I_{0}, I_{5}, I_{10}$, and $I_{20}$, with the node voltages at the service bus and branch circuit ends respectively as $V_{0}, V_{5}, V_{10}$, and $V_{20}$.

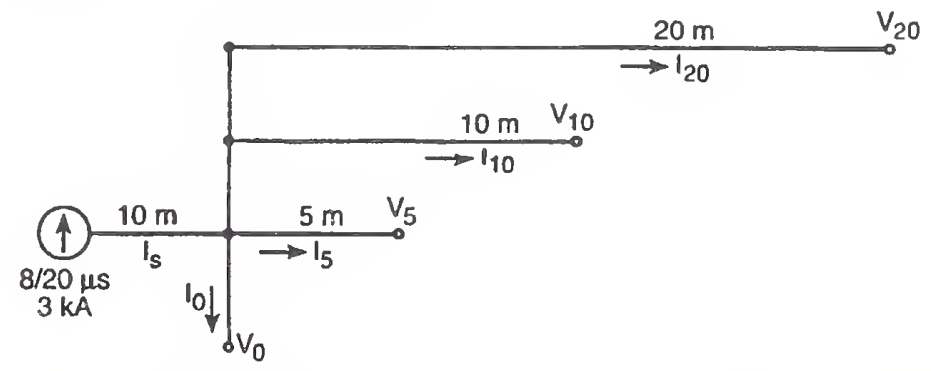

Figure 5 - Service drop and branch circuits for modeling combinations

As in our previous modeling applications, the EMTP program [EPRI, 1989] was used. To avoid computational artifacts, a finite $10 \mathrm{k} \Omega$ resistance was always postulated at the ends of all branch circuits, whether these were left in "open" or "loaded" condition. The loads that were modeled included combinations of SPDs, capacitors, and $100 \Omega$ resistors. The SPDs were all $20-\mathrm{mm}$ diameter, 130-V rated MOVs. The capacitors included a capacitance of $440 \mu \mathrm{F}$ and a series resistance ("ESR") of $0.25 \Omega$ to represent an electrolytic capacitor. Initial conditions for the models stipulated an initial charge on the capacitor to represent the normal condition of the DC link. The $100 \Omega$ resistor was selected as a typical value for a $150-\mathrm{W}$ power-consuming appliance connected at the end of the branch circuit. 
Just to illustrate the point of a readily predictable behavior of a purely linear circuit, Figure 6 shows the voltages and currents for the case of $100 \Omega$ loads confronted with a current source. Compared with the $100 \Omega$ load at the end of the branch circuits, the series impedancc has a vcry small effect and the impinging surge current $I_{\mathrm{s}}$ divides almost equally $(3000 \mathrm{~A} / 4=750 \mathrm{~A})$ in the nearly identical four branches $I_{0}, I_{5}, I_{10}$, and $I_{20}\left(I_{0}\right.$ being the current in the service entrance 'branch', with a length of 0 ). Thus, the voltage developed by this $750 \mathrm{~A}$ current across $100 \Omega$ would simply be expected to be $75000 \mathrm{~V}$ (seventy five thousand volts). We say "would be expected" because, of course, the insulation level of a real-world low-voltage insulation cannot withstand such a voltage. The result of this theoretical case is another illustration of the theme "More Begets Less," according to which a high-amplitude, steep-front surge cannot propagate in branch circuits because a flashover will occur at the origin [Mansoor et al., 1998].

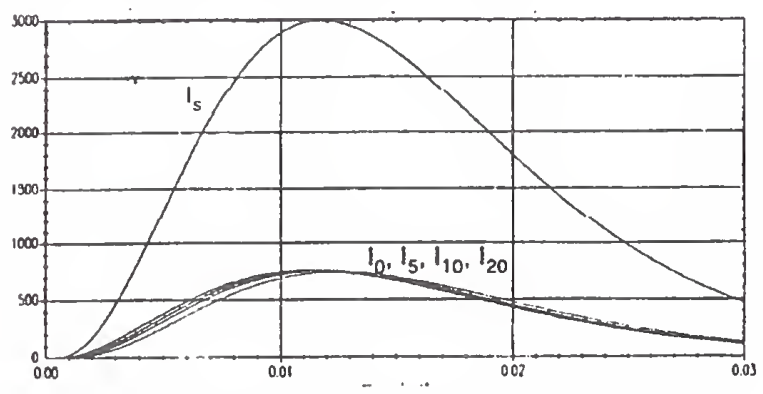

Currents in branches: Time in milliseconds, peaks in amperes

\begin{tabular}{|c|c|c|c|c|}
\hline$I_{s}$ & $I_{0}$ & $I_{5}$ & $I_{10}$ & $I_{20}$ \\
\hline 3000 & 757 & 755 & 752 & 742 \\
\hline
\end{tabular}

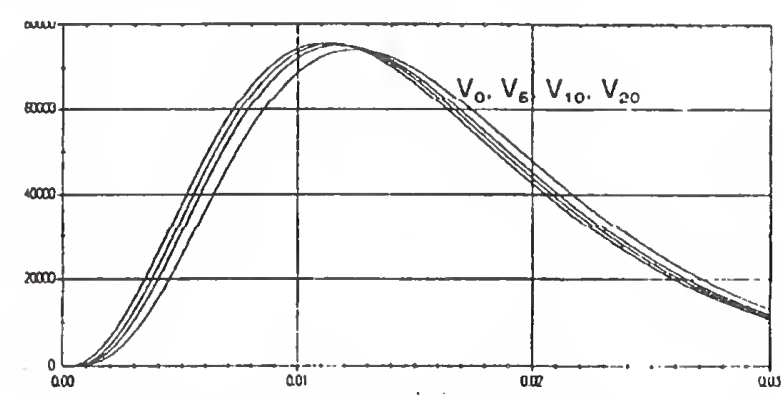

Voltages at nodes: Time in milliseconds, peaks in volts

\begin{tabular}{|c|c|c|c|}
\hline$v_{0}$ & $v_{5}$ & $V_{10}$ & $v_{20}$ \\
\hline 75700 & 75500 & 75300 & 74200 \\
\hline
\end{tabular}

Figure 6 - Currents and voltages for the baseline case of $100 \Omega$ loads without SPDs

Figure 7 shows the examplc of two PCs, onc at the cnd of the 5-m branch circuit, the other at the end of the $10-\mathrm{m}$ branch circuit: the surge current is shared (unequally) between the two capacitors, with a corresponding decrease of the voltage level at each DC link, and also a reduction of the voltage at the open end (unprotected) of the $20-\mathrm{m}$ branch circuit. This example shows the beginning of the "PCs Galore !" effect. Several intermediate and further steps were modeled by adding combinations of surge-mitigating devices to build our case file and confirm the expected effects, but we will spare the reader from a tedious recitation.

The results shown in Figure 6 call for several comments:

- The unequal division of the currents $I_{5}$ and $I_{10}$ reflects the effect of the larger impedance of thc $10-\mathrm{m}$ branch circuit, compared to the 5 - $\mathrm{m}$ branch circuit.

- Substantial mitigation is obtained at the nodes $V_{5}$ and $V_{10}$, as a result of the filter-like action of the line inductance and the capacitance of the PC power supply.

- The voltage surge developed at the node $V_{0}$ propagates, unabated, to the end of the opencircuited $20-\mathrm{m}$ branch circuit, a reminder that the notion of voltage surges being attenuated as they propagate in building wiring [IEC Report 664, 1980] was incorrect. 


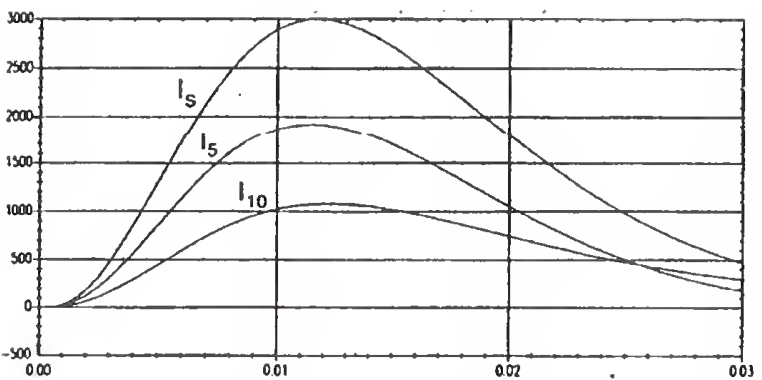

Currents in branches: Time in milliseconds, peaks in amperes

\begin{tabular}{|c|c|c|c|c|}
\hline$I_{s}$ & $I_{0}$ & $I_{5}$ & $I_{10}$ & $I_{20}$ \\
\hline 3000 & 0 & 1920 & 1080 & 0 \\
\hline
\end{tabular}

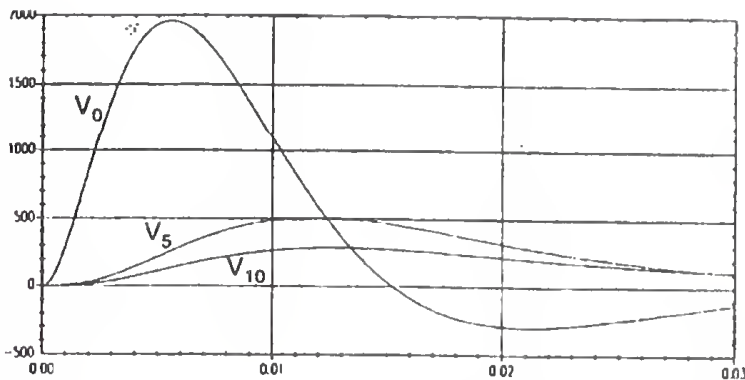

Voltages at nodes: Time in milliseconds, peaks in volts

\begin{tabular}{|c|c|c|c|}
\hline$V_{0}$ & $V_{5}$ & $V_{10}$ & $V_{20}$ \\
\hline 1960 & 507 & 290 & 1960 \\
\hline
\end{tabular}

Figure 7 - Currents and voltages for the case of two PCs without SPDs

The voltage results are especially worth noting, in the context of what a power quality monitor would report in such an installation, depending upon its point of connection.

- From the (impossible) high voltages of the $100 \Omega$ baseline (no SPDs), the voltage that would be recorded by a monitor installed at the service entrance is now reduced to "only" $1960 \mathrm{~V}$.

- A voltage-only monitor installed at the point of use of the power (typical sclection of point of installation in many surveys), namely the two receptacles at $5 \mathrm{~m}$ and $10 \mathrm{~m}$ fecding the I'Cs, would report respectively $510 \mathrm{~V}$ and $290 \mathrm{~V}$, creating the illusion (fallacy) that there is no significant surge activity at these points.

- In reality a current surge $\mathrm{I}_{5}$ of nearly $2000 \mathrm{~A}$ is carried by the PC rectifier into the capacitor, via a line fuse. Such a high current - undetected by a voltage-only monitor - could very well be fatal for the rectificr or the input fusc, or for the capacitor of the PC power port. Such failures were found in post-mortems of equipment recently performed at PEAC. That scenario is also what occurred in the experimental test of Section 3 for a $4 \mathrm{kV}$ open-circuit voltage and capacitor-MOV combination (shown in next-to-last row of Table 1).

\subsection{Modeling PCs Galore}

As a grand finale for illustrating our major theme, the case of an increasing number of PCs was modeled, with each of the PCs connected at the end of a dedicated branch circuit, with all branch circuits having the same length of $20 \mathrm{~m}$, still with the $10-\mathrm{m}$ long service drop driving a $3 \mathrm{kA}$ current surge into the installation.

Table 2 shows the resulting voltages at the service entrance and at the point of connection of the PCs, as well as the inposed inpinging cunent and the resulting currents in the individual power ports of the PCs. Indeed. the effect is linear with increasing numbers of PCs, and the resulting decrease in the voltages expected to be reported by a power quality monitor installed at the point of use is quite apparent. 
Table 2 - Effect of an increasing number of connected PCs

\begin{tabular}{|c|c|c|c|c|}
\hline $\begin{array}{c}\text { Number } \\
\text { of }\end{array}$ & $\begin{array}{c}\text { Impinging current } \\
(\mathrm{A})\end{array}$ & $\begin{array}{c}\text { Current at PC port } \\
(\mathrm{A})\end{array}$ & $\begin{array}{c}\text { Voltage at sarvice entrance } \\
(\mathrm{V})\end{array}$ & $\begin{array}{c}\text { Voltage at PC point of use } \\
\text { (V) }\end{array}$ \\
\hline 1 & 3000 & 3000 & 5600 & 790 \\
\hline 2 & 3000 & 1500 & 2800 & 400 \\
\hline 5 & 3000 & 600 & 1200 & 160 \\
\hline 10 & 3000 & 300 & 570 & 79 \\
\hline
\end{tabular}

Inspection of the table shows that the effect is practically proportional to the number of PCs in use in the installation. While we have used the short acronym of PC in the title and preceding discussions, the proliferation that we observe is not limited to PCs, but includes many electronic appliances, such as home entertainment, heating and air conditioning with adjustable speed drive, that use a DC link with large energy-storage capacitor.

\section{Action ltems}

The customary closure of a paper is to list conclusions. However, in this case we suggest action items for industry, rather than aciudcmic conclusions:

- The cxamples given here clearly show that the fallacy of little surge activity can be creatcd by limiting power quality measurements to voltage surges. With undetected current surge activity, users of electronic appliances will be puzzled by unexplained failures in the face of reports of little voltage surge activity.

- We offer the explanation that these unexplained failures are likely to be associated with the (heretofore not characterized) surge current delivery capability of the environment. Such failures could have been avoided, had designers been better informed.

- With our leading theme now solidly established, questions arise about what to do about it. This matter requires the dedicated attention of both manufacturers and users of power quality monitoring instruments.

- Unfortunately, more than three years after beginning the crusade to overcome the fallacy of limiting surge measurements to voltage surges [Martzloff, 1995], there is no commercially available power quality monitor capable of characterizing the energy-delivery capability of a surge event.

- Worse yet, among the international delegates to an IEC working group chartered to develop a standard on measurement of power quality parameters (which is likely to dominate the design of future monitoring instruments), there are some claims being made that "a current surge is not a power quality parameter" and therefore it should not be included in the emerging standard prescribing measurements methods. This misconception needs to be corrected.

- Therefore, the crusade must be pursued with perseverance, and it is the goal and hope of the auchors that sufficient recugnitiun of ilne fallacy will eventually create a market demand for appropriate instruments, which forward-looking manufacturers may have developed or may be in the process of developing in anticipation of such recognition. 


\section{Bibliography}

ANSIILEEE C62.41-1945, IEEE Kecommended Practice on Surge Voltages in Low-Voltage AC Power Circuits.

Dorr, D., "Point of Utilization Power Quality Results," IEEE Transactions /A-3I, No.4, July/August 1995.

EPRI, "Electromagnetic Transient Program (EMTP)," Version 2.0; Volume 1: Main Program: Volume 2: Auxiliary Routines, EPRI Report EL-642I-L, Jully 1989.

IEC Report 664-1980 (sic) Insulation coordination within low-voltage systems including clearances and creepage distances for equipment, 1980.

IEC 64/1034/CD, General basic information regarding surge overvoltages and surge protection in lowvoltage a.c. power circuits, Committee Draft, 1998.

Key, T.S. and Martzloff, F.D., "Surging the Upside-Down House: Looking into Upsetting Reference Voltages," Proceedings, PQA'94 Conference, 1994.

Lai, J.S. and Martzloff, F.D., "Coordinating Cascaded Surge Protection Devices: High-Low versus LowHigh,"IEEE Transactions, IAS-29 No.4, July/August 1993.

Lindes, G., Mansoor, A., Martzloff, F.D., and Vannoy, D., "Surge Recordings that Make Sense - Joule Deposition: Yes ! - 'Joule Content': Never !' Proceedings, PQA '97 Conference, 1997

Mansoor, A., Martzloff, F.D., and Nastasi, D, “Applying Reality Checks to Standards on the Surge Environment," Proceedings, 23rd International Conference on Lightning Protection, 1\%lorence, Septemher 1996.

Mansoor, A. and Martzloff, F.D., "Driving High Surge Currents into Long Cables: More Begets Less," IEEE Transactions PWRD.12, July 1997.

Mansoor, A. and Martzloff, F.D., "The Effect of Neutral Earthing Practices on Lightning Current Dispersion," IEEE Transactions PWRD-13, July 1998.

Martzloff, F.D. and Gauper. H.A.. "Surge and High-Frequency Propagation in Industrial Power I.ine,," IEEE Transactions IA-22, July/August 1986.

Martzloff, F.D. and Leedy. T.F., "Selecting Varistor Clamping Voltage: Lower Is Not Better!" Proceedings, 1989 Zurich International EMC Symposium, 1989.

Martzloff, F.D. and Lai, J.S., "Cascading Surge-Protective Devices: Coordination versus the IEC 664 Staircase," Proceedings, PQA 91 Conference, 1991.

Martzloff, F.D., "Keeping up with the Reality of Today's Surge Environment," Conference Proceedings, Power Quality Solutions, Intertech Pub., Ventura CA, USA, September 1995.

Martzloff, F.D., Mansoor, A., Phipps, K., and Grady, W.M., "Surging the Upside-Down Ilouse: Measurements and Modeling Results," Proceedings, PQA '95 Conference, EPRI, 1995.

Martzloff, F.D., "Surge Recordings that Make Sense: Shifting Focus from Voltage to Current Measurements," Proceedings EMC'96 ROMA Symposium, Rome, September 1996.

UL Std. 1449, Transient Voltage Surge Suppressors, Second Edition, 1996. 


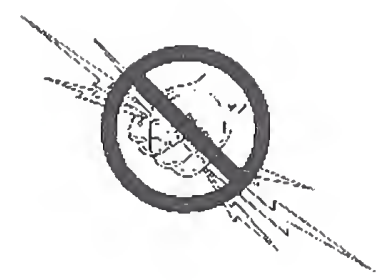




\title{
On the Dispersion of Lightning Current After a Direct Flash to a Building
}

\author{
François Martzloff \\ National Institute of Standards and Technology \\ Gaithersburg MD 20899 USA \\ f.martzloff@ieee.org
}

Reprinted with permission from Proceedings, $25^{\text {th }}$ International Conference on Lightning Protection, Rhodes, 2000

\section{Significance:}

Part 2 Development of Standards - Reality checks

Part 4 Propagation and coupling of surges

Comparison between two simplified modeling studies of the dispersion and a documented case of the complexity of a direct flash to a residence.

Reservations on the justification of very high stress requirements for SPDs are expressed in a discussion, followed by a proposal to encourage more information sharing on the subject 
$\varnothing$ 


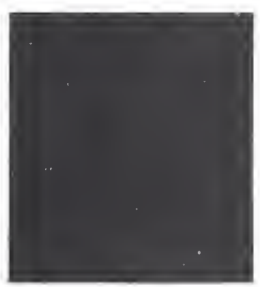

\title{
ON THE DISPERSION OF LIGHTNING CURRENT AFTER A DIRECT FLASH TO A BUILDING
}

\author{
François Martzloft \\ f.martzloff@ieec.org \\ National Institute of Standards and Technology* \\ U.S.A.
}

\begin{abstract}
Simplifications often made when simulating the dispersion of lightning current can yield results that depart too much from the complex reality of a direct lightning flash to a building. The unpredictable occurrence of side-lashes increases even more the complexity. Such simulations, if taken at face value, might lead to unrealistic specifications for serviceentrance surge-protective devices (SPDs). A real-world anecdote illustrates both the complexity and a case where an SPD with only modest ratings, compared with some present proposals, provided satisfactory protection on the power-port appliances of a residence.
\end{abstract}

Key Words: Lightning current dispersion, sideflashes, surge-protective devices

\section{INTRODUCTION}

Recent discussions among participants in the development of surge-protection standards have shown a lack of consensus on the possible scenarios concerning the dispersion of the lightning current when a direct flash to a building is involved. Skepticism has been expressed both on the simulation of available paths for the dispersion, and on the magnitudes and waveforms postulated for the resulting currents flowing in the conductive elements of the installation - especially the service entrance surgeprotective devices (SPDs). Note that the skepticism does not aim at the parameters of the lightning flash itself, which have been accepted now for many years [1], but at the simulation conclusions concerning requirements for service-entrance SPDs with very high current-handling capability.

Another objection has been that the distinction between a building equipped with a lightning protection system (air terminals, down-conductors and earthing system), on the one hand, and a building without such a system, on the other hand, might be misleading.
Every building that contains electrical circuits (power or communications), electrically-conducting mechanical elements, metallic structures, etc., has a de facto lightning 'protection' system of intended or unintended air terminals and down-conductors - except that their connection to the earthing system might have unpredictable and unwanted side effects.

As an input toward developing consensus, this paper reviews in a first part two examples of simulations that have been performed by others, and in a second part relates a real-world anecdote of a corroborated case of a direct flash to a residence.

\section{SIMULATING DISPERSION}

\subsection{Examples of simulations}

A Joint Working Group of the International Electrotechnical Commission (IEC) has recently developed a Technical Report on surge protection [2]. This four-year effort involved the participation of five IEC Technical Committees interested in the subject. The data base considered by the group included, among many sources, two published papers, identified in the Bibliography of the report, authored independently by members of the group.

In both studies, a 10/350 $\mu$ s waveform was postulated, and a time-invariant earthing resistance and inductance were postulated. Currents in the available paths to earth and voltages at selected points of the systems were computed. For the purpose of this paper, three figures only are reproduced here for a qualicative glimpse on the results.

Figure 1, simplified from Ref [2], shows the nature of circuit components and configuration: two buildings and the distribution transformer linked by a cable in a linear arrangement. The point of strike is Building 1. The detailed numerical values, which are given in the referenced paper. are not significant for this comparison of the two studies. 


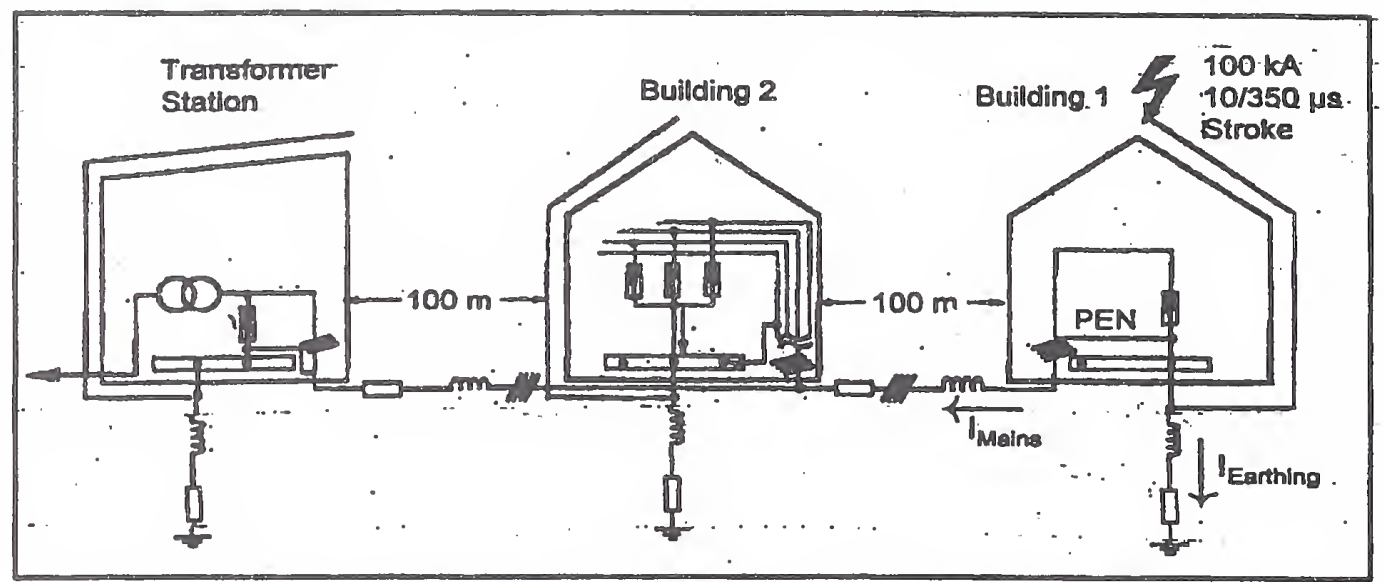

Figure 1-Circuit components and configuration used in the Hasse simulation (Ref [2])

Figure 2 shows examples of the computed waveforms for currents at selected points of the Figure 1 circuit, from top to bottom : the postulated stroke current, the current exiting Building 1 via the power supply cable, the current in the earthing impedance of the building, and the current in the service-entrance SPDs of Building 2 resulting from the surge that is now, for Building 2, an impinging surge.

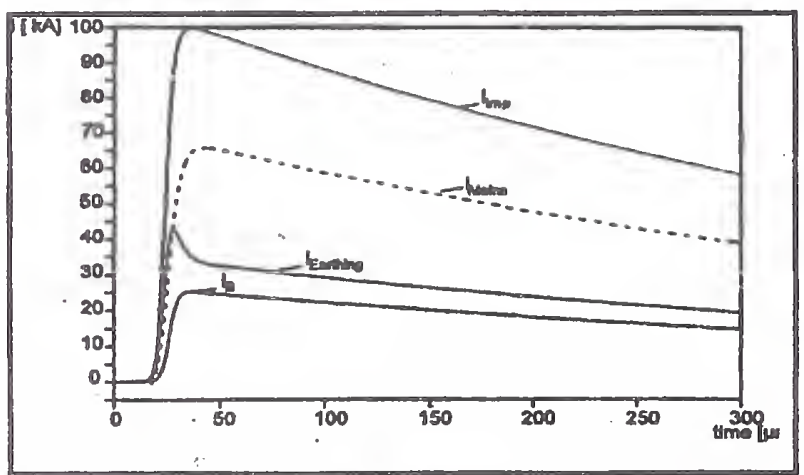

Figure 2 - Current dispersion for Figure 1

The numerical values are not significant, but the waveforms are. The current exiting the building $\left(I_{\text {Mains }}\right)$ has the same waveform as that of the stroke. The earthing current ( $\left(l_{\text {earthing }}\right)$ has an initial peak, due to the additional inductance of the power supply cable; in the long term, the inductive effect disappears, and the current division simply reflects relative values of the available earthing resistances.

In contrast with Figure 1 where the buildings are strung along a power supply cable, Figure 3, from Ref [3], shows a radial configuration of three buildings, each supplied by its own service drop, with all three connected directly to the terminals of the common distribution transformer. Varistor-type service-entrance SPDs are provided for each building. The transformer and each building have their own earthing electrode connection, represented by a fixed resistance and an inductance.
The radial service drops also consist of a resistance and an inductance, not drawn in the figure, but modeled in the computation according to the $20-\mathrm{m}$ length of each radial drop. The point of strike of the flash is the earthing system of Building 1 (to which the neutral is bonded).

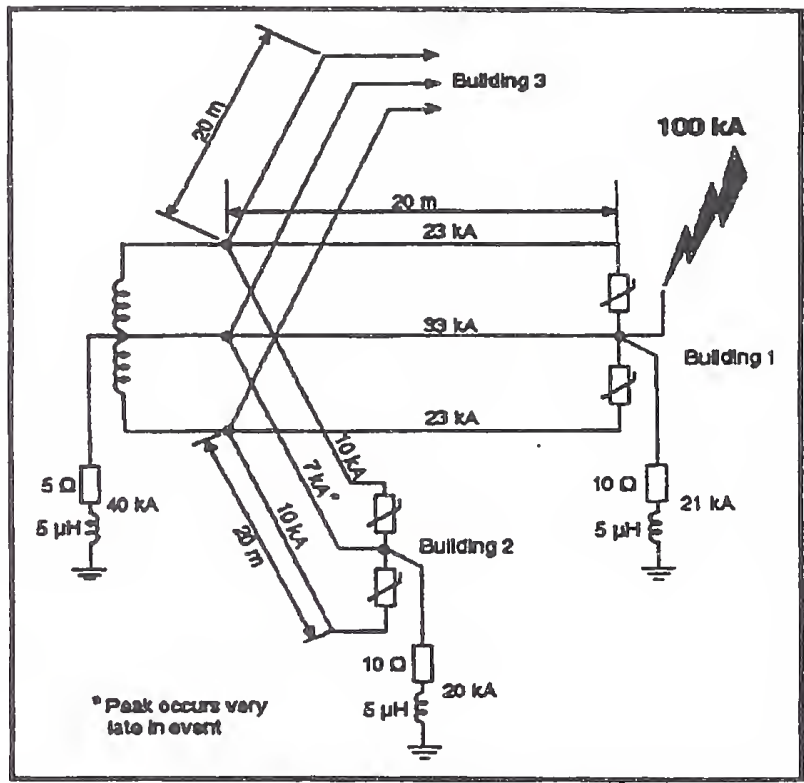

Figure 3 - Buildings configuration and resulting currents, according to Mansoor (Ref [3])

The significance of citing these two independent studies, separated by an ocean, by two different languages used by the authors, and by two different simulation programs, is that quite compatible conclusions were reached sfter exchanging information, first across the cable during IEC working group meetings, then later on, via intensive e-mail messages, as a working relationship blossomed in spite of logistics barriers. This important point will be elaborated further in Section 7 of this paper.

\section{0 - ICLP 2000}


With hindsight, it appears predictable that the initial current dispersion (the first ten microseconds) should be strongly influenced by the relative values of the postulated inductances, and the later dispersion by the relative values of the postulated (time-invariant) earthing resistances.

\subsection{Involvement of service-entrance SPDs}

The results of these simulations show that the stresses imposed on the service-entrance SPDs that become involved in dispersing the part of the lightning current toward remote earthing electrodes of the power distribution system will reflect the relative values of the earthing impedances. These stresses also vary with the postulated current waveform, ranging from the short $8 / 20 \mu$ s long-used for designing SPDs, to the more recent proposed 10/350 $\mu \mathrm{s}$ and finally to the seldom-considered continuing current within a multiple-stroke flash.

Performing these simulations was not a futile exercise but provided insight on the influence of significant parameters. However, among end-users, this complexity of postulates decreases the credibility of defining SPD requirements on the basis of simulations, giving a greater credibility to field experience of widely-used SPDs that have demonstrated satisfactory performance over many years.

\section{SIDE FLASH}

One event that contributes to the complexity and uncertainty of lightning current dispersion is the possible occurrence of a side-flash. A side-flash can establish unexpected paths to earth, with two consequences that extend beyond the consideration of service-entrance SPD stresses - the motivating concern for this paper.

- The side-flash itself can have hazardous consequences by acting as an igniter, as will be told in the anecdote of Section 4.

- The side-flash can cause currents to flow along conductive paths within the installation, thereby coupling transient overvoltages in the circuits of the installation, by common path or by induction.

Of course, the latter has the same end-result as what the bonding applied to avoid the side flash will produce, except for its unpredictability.

\section{FROM SIMULATIONS TO REALITY}

\subsection{Setting the stage}

To illustrate the credibility gap that separates reality from simplified representations, the following story should be narrated:

.... Once upon a time, in a far-away land (Upstate New York, U.S.A.) there lived an engineer who was recording surges, writing papers and presenting tutorials on surge protection, including the need for good bonding practices.
This engineer had bought a house from the previous owner who had lived many happy years there without any problem, so that our engineer made the (unwarranted) assumption that the house and its electrical wiring were in good order. The house was surrounded by several tall, mature trees so he thought that the cone of protection from the trees would benefit the house. Alas ! All-knowing Zeus recognized that this engineer needed to be taught a lesson on reality and thus sent a downward stepped leader toward the general area of the engineer's house ...

By now, dear readers, you have guessed that our mythical engineer is none but the author of this paper... who will now offer this irue story for your edification. First, the "where" : Figure 4 shows a simplified (here we go again ...) topology of the house, a two-story wood frame with basement and atric. Utilities (power, telephone, and cable TV), all entered, via overhead service drops, at the rear of the house, while water and sewer underground pipes were at the front of the house. The telephone system was not involved in the incident and the refore is not shown in the figure. The power installation included the usual revenue-meter (outside) and service panel (inside) with circuit breakers controlling a multitude of branch circuits. Only three are shown in the figure: lighting fixture in the attic, TV on the second floor, and a counter-top receptacle (via ground-foult interrupter) for the kettle (2) in Figure 4) sitting on the enamelled cast-iron kitchen sink. (The significance of this detail will surface shortly.)

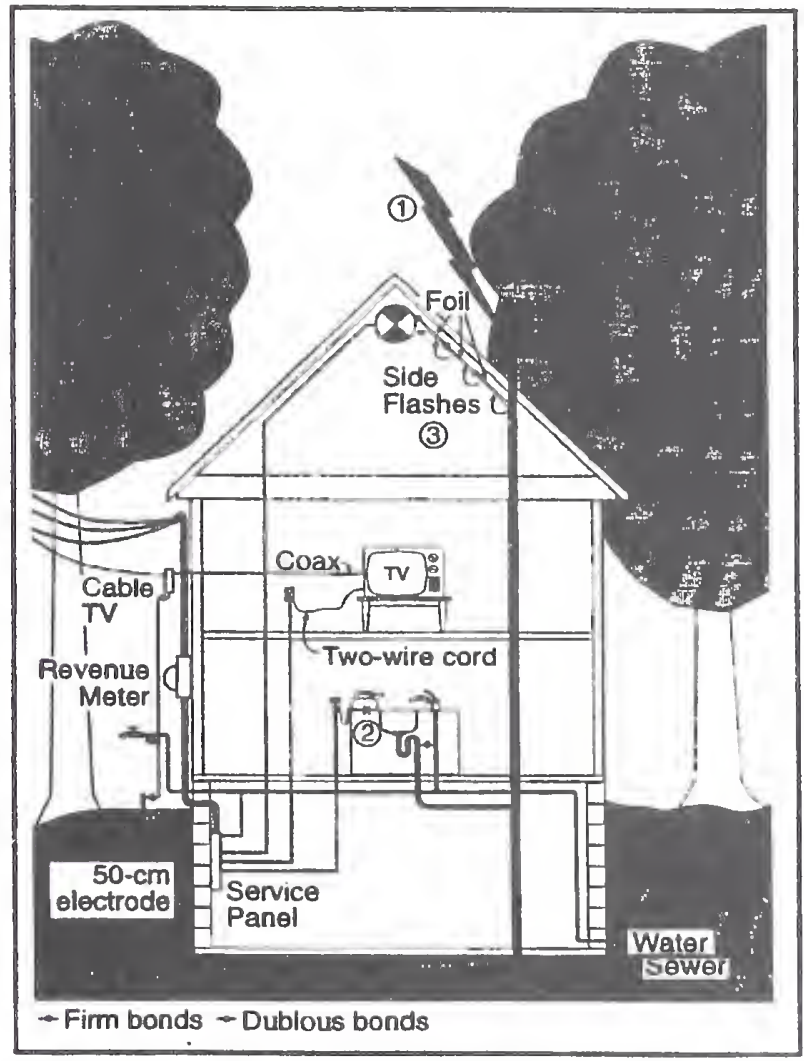

Figure 4 - Simplified configuration of anecdotal story 
Water service and indoor piping were all copper, with a bond between the ground bus of the service panel and the nearest cold-water pipe. There was no. visible grounding conductor to a (non-existent) made-electrode, but the perception existed that, given the vintage of the house (circa 1920), the water piping was sufficient, in addition to the multiple-grounded neutral of the power company.

Upon moving in the house, I had installed in the service panel a surge arrester (circa 1965 vintage) consisting of a silicon-carbide disk in series with a stamped-metal air gap. The cable IV service, as originally installed by the utility, only had a $50-\mathrm{cm}$ long picket allegedly serving as "ground". Having been exposed to the concept of bonding. I had installed a bond between the picket and the nearby outdoor water faucet. A very passive - but soon to become active - part of the installation was the typical sewer system made of lead-bonded cast-iron pipe extending a to vent through the roof and connected to the street sewer, still with cast-iron pipes and thus offering the topology of a well-grounded air terminal, albeit below the peak of the roof. But I am getting ahead of myself, as I had never considered this vent as a lightning air terminal, since the house was surrounded by taller trees and thus "obviously" within their cone of protection.

\subsection{Zeus' wrath}

Now for the "When" and "How": On the day when the tale unfolded, my wife (the corroborating eye-wimess) and I were standing in the kitchen, listening to the approaching thunder and watching the big drops of rain just beginning to splash on the window. Then, a bright flash outside, with an immediate, deafening thunderclap, and also we both saw a small flash under the ketrle. "That was a close one" we both said, whereupon I proceeded to check all appliances in the house. Several were inoperative, but a check of their branch circuit breakers revealed that they had tripped, and resetting them restored order. The only one that did not work was the old TV set, although there was no evidence of severe damage or burned smell, and we considered ourselves lucky - until a smell from the attic attracted my attention: the ceiling of the attic (which was covered by cellulose-base panels) was smoldering!

Fortunately - and not by accident - a handy fire extinguisher allowed me to quench the smoldering, while my wife called the fire department. To their credit, they were in front of the house within minutes. I told them that I believed that the fire exinguisher had done the job; nevertheless, one fireman proceeded to climb on a ladder to the artic window and hacked it away to let the smoke out, while another entered the house, pushing me aside, with a high power water hose in tow - which fortunately he did not turn on. After ripping several of the ceiling panels to verify that the fire indeed was out, the firemen left, with our emotional thanks and the applause of the neighbours gathered in front of the house.

\subsection{The homeowner's epilogue}

- One obsolescent TV receiver, which was not repaired, but catalysed the purchase of a new and upgraded set (missing the opportunity to do an extensive postmortem as in the "Case of the Cozy Cabin" [4]):

- Several hundred dollars expended to repair the window destroyed by the firemen, install a splice on one attic rafter weakened by charring, and replacing the ripped. panels.

- After recovering from the shock, a realization of how lucky to have been in the house at the time of the incident, and glad for the foresight of having a fire extinguisher on every floor of the house !

\subsection{The engineer's epilogue}

Such a traumatic experience called for an investigation of the incident. The first observation was that the previous owner had installed insulation between the attic rafters, stapling the aluminum foil of the bats to the rafters, but not overlapping them across the edges of the rafters. This arrangement, concealed by the panels, created several gaps allong the 5-m distance separating the sewer vent pipe from the light fixture at the apex of the attic, but reducing the total gap to a few centimetres - an easy side-flash scenario, resulting in the ignition of the dust and surface fuzz of the rough-from-sawmill rafters.

The second observation, a few days after the incident, was to notice a small rust spot on the kitchen sink where the kettle usually sat: there was a small hole in the otherwise good-condition glaze, exposing the underlying cast iron: The flash seen under the kettle (2) was the cause of the enamel puncture; several kilovolts must have been required to break down the series-connected insulation of the heating element inside the kettle, and the porcelain glaze of the sink. The electronic ground-fault circuit breaker controlling the receptacle had to be reset, but it was not damaged, and subsequent use of the kettle did not cause it to trip, so we concluded that the brief breakdown of the insulation of the heating element was not a massive event.

The immediate action was to install a bond between the sewer vent pipe and all extraneous metal in the attic. The long-term effect on the engineer was a consciousnessraising on the issue of surge protection of multiple-port appliances, even though a bond had been provided between the incoming cable TV service and the power system [5]. At that time, the concept of the surge-reference equalizer [6] had not yet surfaced, and no commercial device was available to provide that function. In fact, the proliferation of plug-in surge-protective devices launched by the introduction of metal-oxide varistors had not yet occurred.

A rasual inspection of the frat-sized surge arrestcr at the service panel showed no distress, an indication of adequate design for the rare scenario of a direct strike to a building [7].

\section{2 - ICLP 2000}


This arrester used only a 30-mm diameter silicon carbide disk as varistor, which most likely would be destroyed by the high-energy lightning surges presently considered or recommended by some IEC committees. (Sorry, the house has changed owners and an exhaustive test on that particular surge arrester, desirable as it would be in retrospective, is not possible.)

The attic side-flash (3) in Figure 4) clearly indicated that the sewer vent pipe was the point of strike (D), raising the question of why the tall trees failed in their expected mission of establishing an effective cone of protection. Perhaps one explanation might be that during the initial part of the rainfall, the still-dry trees could not emit a successful competing upward streamer, compared to the wellgrounded cast-iron pipe. Comments from lightning physics experts on this speculation would be welcome.

Thus, our engineer had learned his lesson, and lived happily without further incident for fifteen more years in the far-away land. However one cannot say 'lived happily ever after' : After moving to a new home further South, one night a nearby lightning flash triggered a burglar alarm (which had to be pried open to silence the horn turned on by a failed semiconductor, at 02:00 am no less) and damaged a remote-control garage door opener: Zeus had still kept track of the battle-hardened surge-protection engineer, but that is another story ...

\section{FROM REALITY TO SIMULATION}

Among several investigations based on rockettriggered lightning, the ongoing effort at Camp Blanding in Florida, U.S.A. is aimed at injecting a lightning current at specific points of the replica of a residential power system. Initial results (1997) were inconclusive because of instrumentation problems, but as these are progressively overcome, more definitive information becomes available. Actually, the most recent report [8] provides so many raw measurement results that an effort of synthesis will be necessary to gain a better understanding of the issues.

The major advantage of such systematic projects over a random recitation of anecdotes could be the possibility of going from a real-world configuration to a sufficiently detailed numerical representation of the circuit parameters. A cross-validation of the measurement results and of the simulation results would then significantly increase the credibility of both, and lead to realistic designs and ratings for SPDs.

The challenge, of course, will be to represent enough of the many, many parameters involved in the real world but not so many as to make the simulation model unmanageable. For instance, the real-world situation of the anecdote already sumplitied in Figure 4 - with the ill-defined bonds and side-flashes - would be difficult to turn into a manageable and credible simulation.

\section{DISCUSSION}

The simplified assumptions on lightning current dispersion illustrated in Section 2 have met with some skepticism among the North-American surge-protection community and perhaps others. Part of this skepticism is also based on the relatively rare occurrence of massive failures for secondary arresters (distribution transformer secondary terminals and residential service entrance) designed to withstand the "classical" $8 / 20 \mu s$ or $4 / 10 \mu \mathrm{s}$ surges, at crest levels of a few to a few tens of kiloamperes. Furthermore, the two simulations cited in Section 2 were based on the assumption that earthing electrodes have a constant resistance during the flow of the lightning current, an assumption that is questioned on the basis of preliminary resuits of measurements made in Florida in connection with triggered lightning experiments [8].

In contrast with these simplified scenarios, the realword anecdote would be a challenge for any numerical modelling but demonstrates evidence of substantial overvoltages developed in the installation (insulation puncture at the kettle) during the flow of this undetermined lightning current dispersion among the complex available paths to earth. The anecdote also offers an example of a surge arrester with modest current-handling capability surviving the scenario of a direct strike to a building.

A symptom of the incomplete consensus is the noticeable lack of a discussion of risk analysis in the report developed by the IEC Joint Working Group [2]. This topic was initially included in the document outline, raising high expectations, but, confronted with incompatible proposals, the group gave up on that initiative. The proposed methodologies ranged from elaborate and detailed mathematical formulae - which turned out to be using somewhat arbitrary postulates - to common-sense, almost intuitive considerations.

\section{A PROPOSAL FOR THE DISPERSION OF LIGHTNING INFORMATION}

In a 1963 freedom-seeking speech that still resonates today, the mantra "I have a dream" was coined. On a much more modest scale, the author has a dream of unfettered information-sharing on lightning. Having cited the preceding examples of developing, but still incomplete. consensus on the dispersion of lightning current, here is the proposal (or is it a challenge ?): Hopefully helpful timely participation, on a world-wide basis via electronic mail could supplement - not compete with - the established routes for information sharing, at a much accelerated pace. We are still mostly in a mode of developing standards a notoriously slow process - by volunteers or delegates often hampered by travel budgets, or of publishing peerreviewed papers - unquestionably a wise process, but entailing long delays between generation and ultimate publication of the information. 
This process of information dispersion might take one of the many forms by which the Internet has revolutionised information sharing. Should this paper be accepted for oral presentation at the Conference, the author would propose to make only a very brief summary of the paper itself available to all in print - and make use of the scheduled presentation time for a cross-pollination of idess among the attendees (much superior to the one-on-one poster process) on how to implement the proposal, bringing reality to the dream. Pessimists will point out hurdles such as the requirement of "previously unpublished information" for later acceptance of an archival paper reporting research on the subject, or the understandable modesty of researchers who want to be sure that the work is complete before publishing even preliminary results, and so forth. Optimists will find ways to by-pass these hurdles and broaden an early consensus.

\section{CONCLUSIONS}

- While there is no disagreement, or at least very little skepticism, on the specific parameters of the lightning discharge, consensus on the implications of lightning current dispersion for the rating of surge-protective devices has not yet been reached.

- Anecdotal information offered in many countries on their experience with service entrance surge-protective devices having moderate handling capability suggests that the proposed ratings for very high duty levels might be unnecessary and not cost-effective, unless a convincing risk analysis demonstrates otherwise.

- Information dispersion on these issues could be greatly enhanced by establishing an informal and timesensitive world-wide site (in parallel, not in conflict with more formal procedures), which the author is prepared to undertake if encouraged and supported by colleagues in the lightning-protection community.

\section{REFERENCES}

\subsection{General}

Many publishing organizations, in their instructions for the peer-review process, raise the question "Are references adequate to show knowledge of work by others?" or words to that effect. While undoubtedly a valid question, the result is sometimes a lengthy recitation of up to several hundred citations, which seems an overkill.

Standard-writing organizations have evolved the concept of differentiating between, on the one hand "References" - a listing of documents that are made an integral part of the standard by a ritual introductory statement, and, on the other hand, citations - in the form of a "Bibliography" with or without annotations.
For this paper, "References"- are limited to the strict minimum necessary to support a particular point being made. To illustrate where extensive listing of "references" might lead, a literature search was conducted with "lightning" as a leading key word, and next with one additional word. The results are listed below, showing the number of "hits" found for the period of just 1969-1999 the accessible on-line data base did not include Benjamin Franklin's seminal letters to the Royal Society on lightning protection of houses and the Purfleet munitions storage [9].

$\begin{array}{lr}\text { Lightning } & 15791 \\ \text { Lightning + surge } & 2348 \\ \text { Lightning + current } & 3306 \\ \text { Lightning + damage } & 1130 \\ \text { Lightning + protection } & 6349 \\ \text { Lightning + arrester } & 1816 \\ \text { Lightning + earth + electrode } & 139\end{array}$

These numbers show that it would be unrealistic for a single researcher to examine in detail the contents of fifteen thousand papers. Injecting the concerted filtering and sharing action of today's active researchers into a readily accessible data base - the author's dream - would be a great improvement.

\subsection{Specific references}

[1] Anderson, R.B. and Eriksson, A.J., "Lightning parameters for engineering applications," ELECTRA, No.69, March 1980.

[2] IEC 62066: 2000, General basic information regarding surge overvoltages and surge protection in low-voltage a.c. power cincuits.

[3] Mansoor, A. and Martzloff, F.D., "The Effect of Neutral' Earthing Practices on Lightning Current Dispersion in a Low-Voltage Installation, "IEEE Transactions PWRD:13; July 1998.

[4] Key, T.S., Nastasi, D., Phipps, K.O., and Martzloff, F.D., "Some enlightening care histories on lightning damage," Submitted for presentation at ICLP 2000, September 2000.

[5] Key, T.S., and Martzloff, F.D., "Surging the Upside-Down House: Looking into Upsetting Reference Voltages," Proceedings, PQA 94 Conference, Amsterdam, October 1995.

[6] IEEE Std 1100-1999 ("Emerald Book") IEEE Recommended Practice for Powering and Grounding Electronic Equipment, IEEE, 1999.

[7] IEEE PC62.41.1-2000-Drafi IEEE Guide on the Surge Environment in Low-Voltage (1000 V and less) AC Power Circuits.

[8] EPRI "Investigation of lightning entry into a secondary service using rocket-triggered lightning," EPRI Report TR-110418, April 1998.

[9] Cavendish, Watson, Franklin and Robertson, "A report of the Committee appointed by the Rnyal Snciety to confider a Method for Jecuring the Powder Magazines at Purfleet," Philosophical Transactions of the Royal Society, London, 1772.

\section{4 - IELP 2000}


Annex A

Citations Part 2

Development of standards - Reality checks 


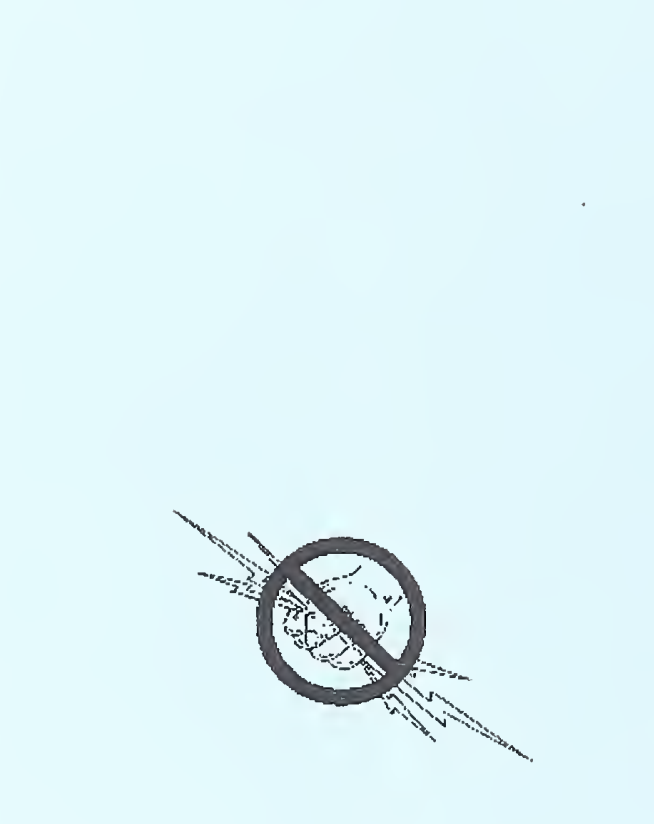

66

(20)

$$
\text { . }
$$




\title{
Annex A
}

\author{
Citations Part 2 - Development of standards - Reality checks \\ Alphabetical order by first author -- See Part 1 for a listing of all the citations of the SPD Anthology, \\ including Part 1 through Part 8
}

\begin{abstract}
ANDERSON, L.M. and BOWES, K.B., "The Effects of Power-line Disturbances on Consumer Electronic Equipment," IEEE Transactions PWRD-5, No.2, April 1990.

- Experimental study of the immunity of typical electronic equipment to sags and surges.

- Surges applied were not the ANSI C62.41, but a 100 or $300 \mu$ s pulse, presumably open-circuit voltage.

- Surges of $1000 \mathrm{~V}$ (open-circuit voltage of generator) did not cause any failure of PCs.

BACHL, H., MARTZLOFF, F.D. and NASTASI, D., "Using Incandescent Lamp Failure Levels for Assessment of the Surge Environment," Proceedings, 12 $2^{\text {th }}$ International Zürich Symposium on Electromagnetic Compatibility, 1997.

- Shows failure mechanisms and levels by electrical measurements and with high-speed video recording.

- $120-\mathrm{V}$ lamps can fail in the range of $800 \mathrm{~V}$ to $1200 \mathrm{~V}$, depending on waveshape and phase angle.

- Makes the point that surges are unlikely to occur frequently at levels above the failure level of lamps.

- 5 references
\end{abstract}

BARTKOWIK, M., COMBER, M.G., and MAHAN, G.D., "Failure Modes and Energy Absorption Capability of ZnO Varistors," IEEE Transactions PWRD-14, January 1999.

- Simulation of varistor behavior under current pulses of various magnitudes and duration.

- Comparison with experimental results.

- Demonstrates that energy-handling capability is not a constant, but depends on intensity and duration.

- 14 references, 1 discussion

FENIMORE, C. and MARTZLOFF, F.D., "Incompatibility Between the 100/1300 Surge Test and Varistor Failure Rates." Proceedings, $9^{\text {th }}$ International Zürich Symposium on Electromagnetic Compatibility, 1991

- Numerical computations of the energy deposition associated with a proposed IEC standard indicate that massive failure of ubiquitous metal-oxide varistors should occur - but they do not.

- The proposed test was eventually removed from the menu of IEC EMC test methods.

- 10 references

FENIMORE, C. and MARTZLOFF, F.D., "Validating Surge Test Standards by Field Experience: High-Energy Tests and Varistor Performance," IEEE Transactions IA-28 No.6, December 1992. (First publication in Conference Record, IEEE/IAS Annual Meeting, Oct. 1990).

- Computer modeling of the resulting current and energy deposition into typical varistors subjected to the C62.41 $10 / 1000 \mu$ s waveform and proposed IEC 100/1300 $\mu$ s waveform.

- Yields a prediction of failure for the small varistors and survival for the larger varistors.

- Because small varistors do not fail in the field at the rate that is predicted by the model of the IEC waveform, the conclusion is that stresses associated with this proposed waveform make it unrealistic.

- 15 references

FISHER, F.A. and MARTZLOFF, F.D., "Transient Control Levels: A Proposal for Insulation Coordination in LowVoltage Systems," IEEE Transactions PAS-95, No. 1, Jan/Feb 1976.

- Proposes an approach parallel to that of the BIL concept for high-voltage system.

- First published version of a test circuit for $100 \mathrm{kHz}$ Ring Wave.

- 12 references, 3 discussions

GOEDDE, G.L., KOJOVIC, Lj.A., and WOODWORTH, J.J., "Surge Arrester Characteristics that Provide Reliable Overvoltage Protection in Distribution and Low-Voltage Systems," Proceedings, IEEE-PSE Summer Meeting, Seattle WA, July 2000

- Describes field experience of arresters designed in accordance with IEEE Std C62.11-1999.

- Concludes that tests with a 10/350 $\mu$ s waveform are not necessary.

- 11 references

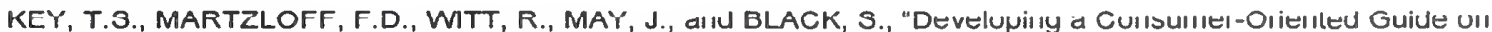
Surge Protection," Proceedings, PQA'97 North America, 1997.

- Progress report on the development of a tutorial on surge protection.

- Presents the need for "intersystem bonding" at the entrance of power and communications utilities.

- Brief discussion of the need for surge reference equalizers.

- 6 references 
MACIELA, F., "Energetic Design and EDF Distribution Network Experience of MV Metal Oxide Surge Arresters," CIGRE SC33.95 (1995 Colloquium).

- Field experience of EDF on 700000 arresters.

- Failure rate lower (1/4) than calculated in Rousseau, 1989 (CIRED).

MANSOOR, A., MARTZLOFF, F.D., and NASTASI, D., "Applying Reality Checks to Standards on the Surge

Environment," Proceedings, $23^{\text {rd }}$ International Conference on Lightning Protection, Florence, 1996.

- Shrinking surge recording occurrences explained by proliferation of SPDs.

- $\quad$ Applying equipment failure rates to assess the surge environment.

- Limits to pushing surges into branch circuits.

- 19 references

MANSOOR, A. and MARTZLOFF, F.D., "Driving High Surge Currents into Long Cables: More Begets Less," IEEE Transactions PWRD-12, No.3, July 1997.

- Measurements and modeling, validating each other, show the physical impossibility for large surge currents to propagate very far into the branch circuits of a building, because flashover will occur at the service entrance.

- Demonstrates the importance of considering the maximum rate of rise (early in the surge) rather than an average derived from the peak value and overall rise time.

- 13 references

MANSOOR, A. and MARTZLOFF, F.D., "The Effect of Neutral Earthing Practices on Lightning Current Dispersion in a Low-Voltage Installation," IEEE Transactions PWRD-13, July 1998.

- Compares the TN and TT for dispersion of lightning current in several scenarios.

- Shows the need for careful review of grounding practices in effect at service entrances.

- Questions the applicability of high amplitude, long duration requirement for service entrance SPDs.

- 20 references

MANSOOR, A. and MARTZLOFF, F.D., "The Dilemma of Surge Protection vs. Overvoltage Scenarios: Implications for Low-Voltage Surge-Protective Devices," Proceedings, 8th International Conference on Harmonics and Power Quality, Oct 14-16, 1998, Athens, Greece.

- Three examples of temporary overvoltage conditions that can produce failure of SPDs.

- The significance of available fault current and the need for more explicit standards.

- 17 references

MANSOOR, A., MARTZLOFF, F.D., and PHIPPS, K., "The Fallacy of Monitoring Surge Voltages: SPDs and PCs Galore!" Proceedings, EPRI PQA'99 Conference, May 1999

- Experimental measurements of effective mitigation by multiple SPDs.

- Numerical simulation of the effect of proliferating SPDs and PCs.

- Calls for an industry-wide reassessment of surge monitoring parameters.

- 20 references

MARTZLOFF, F.D. and FISHER, F.A., "Transient Control Level Philosophy and Implementation," Part 1: The Reasoning Behind the Philosophy," Proceedings, $2^{\text {nd }}$ Symposium on Electromagnetic Compatibility, Montreux, 1977.

- Presents the concept of testing low-voltage equipment patterned on the high-voltage BIL concept.

- Techniques and equipment for making TCL tests.

- 10 references

MARTZLOFF, F.D., "Varistor Versus Environment: Winning the Rematch," IEEE Transactions PWRD-1, No. 2, April 1986.

- Staged test of capacitor switching on remote MV side produces ring waves on low-voltage load.

- Coordination between $3 \mathrm{kV}$ and $480 \mathrm{~V}$ varistor-based SPDs.

- 5 references, 1 discussion

MARTZLOFF, F.D., "Testing Varistors Against the VDE 0160 Standard," Proceedings, Open Forum on Surge Protection Application, NISTIR-4654, August 1991.

- Reports tests performed with a prototype 100/1300 surge generator, resulting in failure of the ubiquitous

- $20-\mathrm{mm}$ diameter varistors, hence demonstrating that the proposed standard is unrealistic.

- 9 references

MARTZLOFF, F.D. and PELLEGRINI, G., "Real, Realistic Ring Waves for Surge Testing," Proceedings, $9^{\text {th }}$ International Zürich Symposium on Electromagnetic Compatibility, 1991.

- Reports measurements on the propagation of oscillatory waves in typical low-voltage circuits, as opposed to the unidirectional waves initially defines for high-voltage power systems.

- Shows how impinging unidirectional surges can produce oscillatory waves responses.

- 17 references 
MARTZLOFF, F. D., "On the Dispersion of Lightning Current after a Direct Flash to a Building, " Proceedings, $25^{\text {th }}$ International Conference on Lightning Protection, Rhodes, 2000.

- Computer modeling of the current dispersion among available paths to ground.

- Comparison between proposed SPD ratings based on computer modeling and field experience.

- 9 references

MEISSEN, W., "Überspannungen in Niederspannungsnetzen" [Overvoltages in low-voltage networks], ETZ Bd. 104, 1983.

- The seminal paper proposing a long waveform with extremely high energy-deposition capability, leading to the development of German Standard DIN 0160.

RICHMAN, P., "New Fast-Transient Test Standards Inadvertently Permit Overstressing by as much as 600 Percent," EMC Test and Design, Vol.2, No.5, Sept/Oct 1991.

- Points out ambiguities in the test procedures described in IEC EFT standard.

ROUSSEAU, A., "Requirements for Rating of MV Zinc Oxide Surge Arresters on EDF Distribution Networks," CIRED 1989.

- Design of ZnO MV arresters based on statistics of lightning current magnitude and tail.

- Sharing of current between many arresters as well as the number of lightning strike per year and per km of overhead line are used in calculations.

- Design based on an energy requirement converted in lab into a 4/10 standard waveshape.

- 13 references

SMITH, S.B. and STANDLER, R.B., "The Effects of Surges on Electronic Appliances," IEEE Transactions PWRD-7, No.3, July 1992.

- Clocks, TV receivers, and switching power supplies were subjected to surges from $0.5 \mathrm{kV}$ to $6 \mathrm{kV}$.

- The switching power supplies and television receivers were damaged with surges from $4 \mathrm{kV}$ to $6 \mathrm{kV}$.

- Three of five models of digital clocks were upset with surges from $1.6 \mathrm{kV}$ to $6 \mathrm{kV}$.

- The conventional wisdom that electronic appliances are easily damaged by surges with a peak voltage of a few kilovolts greatly exaggerates the effect of surges on modern consumer appliances.

- 15 references

STANDLER, R.B., "Development of a Performance Standard for Surge Arresters and Suppressors," Proceedings, IEEE 1991 International Symposium on Electromagnetic Compatibility.

- Some critical issues in the development of a performance standard for surge arresters and suppressors for use on low-voltage mains are discussed.

- Describes a series of electrical tests to determine the safety and adequacy of surge protective devices.

- 4 references

STANDLER, R.B., "Calculation of Energy in Transient Overvoltages," Proceedings, IEEE EMC Symposium, 1989

- Shows that using the integral of $V^{2} / 50$ sdt to compute energy in a surge is invalid.

- A quantitative error analysis is presented that uses an artificial AC line network to simulate a long branch circuit and to give the impedance of the $A C$ line as a function of frequency.

- A method for measuring energy dissipated in a varistor is advocated for use in future experiments.

- 18 references

STANDLER, R.B., "Standards for Surge-protective Devices for Connection to the Low-voltage Ac Supply Mains in the USA," Proceedings, Lightning Protection 92 - Buildings, Structures and Electronic Equipment Conference and

Exhibition, 1992.

- Review of major standards in the USA for low-voltage AC power surge-protective devices prepared for presentation at a Europea-based forum.

- Since it is clear that international standards are greatly preferable for both manufacturers and users, the US position [in 1992] on the IEC SC37A drafts is also briefly reviewed.

- 9 references

VANCE, E.F., NANEVICZ, J.E., and GRAF, W., "Unification of Electromagnetic Specifications and Standards," Defense Nuclear Agency Report DNA 5433F-1, Washington DC, 1980.

- Describes the need for dual capability of a test generator to adapt inherently to the impedance of the EUT, even during the surge event 


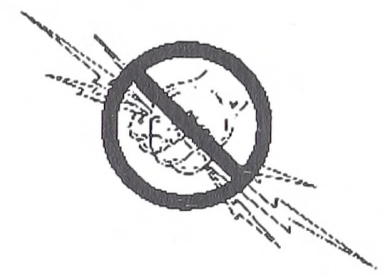



